Portland State University

PDXScholar

\title{
Factors Influencing Middle School Teachers to Change Classroom Practice in Response to Standards-Based Reform
}

Gayle Yvonne Thieman

Portland State University

Follow this and additional works at: https://pdxscholar.library.pdx.edu/open_access_etds

Part of the Educational Leadership Commons, Educational Methods Commons, and the Elementary and Middle and Secondary Education Administration Commons Let us know how access to this document benefits you.

\section{Recommended Citation}

Thieman, Gayle Yvonne, "Factors Influencing Middle School Teachers to Change Classroom Practice in Response to Standards-Based Reform" (2000). Dissertations and Theses. Paper 1461.

https://doi.org/10.15760/etd.1460

This Dissertation is brought to you for free and open access. It has been accepted for inclusion in Dissertations and Theses by an authorized administrator of PDXScholar. Please contact us if we can make this document more accessible: pdxscholar@pdx.edu. 
FACTORS INFLUENCING MIDDLE SCHOOL TEACHERS TO CHANGE CLASSROOM PRACTICE IN RESPONSE TO STANDARDS-BASED REFORM

\author{
by \\ GAYLE YVONNE THIEMAN
}

A dissertation submitted in partial fulfillment of the requirements for the degree of

\author{
DOCTOR OF EDUCATION \\ in \\ EDUCATIONAL LEADERSHIP: \\ ADMINISTRATION
}

Portland State University

(C)2000 


\section{DISSERTATION APPROVAL}

The abstract and dissertation of Gayle Yvonne Thieman for the Doctor of Education in Educational Leadership: Administration were presented May 1, 2000, and accepted by the dissertation committee and the doctoral program.

COMMITTEE APPROVALS:

Robert B. Everhart, Chair

Thomas Chenoweth

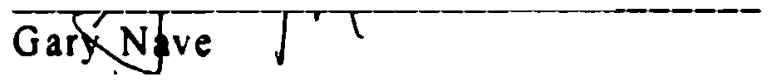

Kareh Noordhdff ,

Barry Ánderson

Representative of the Office of Graduate Studies

DOCTORAL PROGRAM APPROVAL:

PhyllidJ. Etamundson, Dean Graduate School of Education 


\section{ABSTRACT}

An abstract of the dissertation of Gayle Yvonne Thieman for the Doctor of Education in Educational Leadership: Administration presented on May 1, 2000.

Title: $\quad$ Factors Influencing Middle School Teachers to Change Classroom Practice in Response to Standards-based Reform

In an environment of systemic educational reform, which emphasizes the alignment of curriculum standards, instructional practices. and assessments. an important question arises: What are the factors which influence teachers to change their classroom practice in response to standards-based reforms? My study examined the initial legislative model, Washington Education Reform Act HB1209 (1993). and tested other factors that led to changes in classroom practice in three middle schools which are currently implementing HB 1209.

The case studies included multiple sources of evidence (administrator and teacher interviews, surveys, classroom observations, focus groups, and documents). The data were analyzed for each school 
individually and across all three schools to clarify the connection between standards-based reform policy, teachers' learning, and changes in classroom practice.

The study examined the influence of six teacher factors and four school level factors on familiarity with the reform policy, involvement in educational reform, and changes in classroom. Teacher factors were: (a) present teaching experience; (b) previous teaching experience; (c) pedagogical knowledge needed to implement the reform; (d) involvement in educational reform; (e) sense of empowerment; and (f) self-efficacy. School level factors were: (a) previous educational policies; (b) participation in a collaborative learning group; (c) building level and district administrative expectations and support; and (d) organizational feat ures that enhance time for teachers to learn and collaborate.

Both teacher and school level factors were related to familiarity with the policy, involvement in reform, and changes in classroom practice. Teacher factors (involvement in reform, empowerment) predicted more of the variance in familiarity with HB 1209 than did school level factors (collegial teams, school reform plan). Contrary to my uriginal hypothesis, knowledge of the reform policy itself was the largest single predictor of involvement in educational reform and of 
changes in classroom practice. However, while knowledge of the policy was necessary, it was not a sufficient predictor. Teacher factors (staff empowerment, pedagogical knowledge) predicted more of the involvement in reform than did school level factors (time for planning and curriculum development, school reform plan). Teacher factors (involvement in reform) and school level factors (workshops, conversations about practice) were equally predictive of changes in classroom practice. 


\section{DEDICATION}

This dissertation is dedicated to my family, whose love and support have sustained me for fifty years. By her example, my mother, Lorraine Degener Rothenberger taught me to !ove learning and to complete whatever I started, no matter what. My father, Jay Rothenberger, shared his love for adventure and always asked me if I could do better. My husband, Don, has been my steadfast partner, always encouraging me to seek new challenges and believing I could achieve my goals. Our children, Cynthia and Robert, and my mother-inlaw. Odella Thieman Savage, have taught me to seek a balance in life, have some fun, and take time to smell the flowers. 


\section{ACKNOWLEDGEMENTS}

This dissertation is the result of my life long interest in teaching and learning, first as a student, then as a classroom teacher, and most recently as a high school administrator and instructor in educational administration at Portland State University. Throughout my educational career, I have been very interested in educational reform and change.

As a doctoral student $I$ have been mentored by outstanding professors who unstintingly offered their time and expertise as members of my committee. I am deeply grateful for the inspiring leadership of my advisor, Dr. Robert Everhart, who first encouraged me to choose the doctoral program at Portland State University. His wise counsel and critical review of endless drafts of this dissertation were invaluable to me. The quantitative research in this study was greatly enhanced by the teaching and encouragement of Dr. Gary Nave who patiently elucidated the mysteries of statistical analysis. Dr. Thomas Chenoweth welcomed me as a teaching colleague, freely sharing his research and knowledge of educational reform . Dr. Karen Noordhoff has been my friend and mentor since our years together in Fairbanks, Alaska. She helped me focus my research on teachers' professional 
learning. I also appreciate the insights of Dr. Barry Anderson, who drew my attention to the psychological dimensions of organizational change. This dissertation was also shaped by my first advisor, Dr. Elizabeth Donohoe, who guided me through my first comprehensive exam and taught me to analyze the policy dimensions of educational reform.

I am deeply grateful to the district and building administrators of the three Washington middle schools who allowed me to conduct my research in their schools. These busy administrators and their staff unreservedly shared their challenges and successes in educational reform and change. Without their support this dissertation would not have been possible.

I would also like to thank Dr. Bobbi Kerlin for her timely support and consultation on qualitative research methods. I am grateful to the staff of the Metropolitan Instructional Support Lab and Instruction and Research Services who so graciously provided technical support.

Finally, I wish to express my appreciation to Dean Phyllis Edmundson and the entire faculty of the Graduate School of Education who have encouraged and supported me as a colleague. 


\section{TABLE OF CONTENTS}

\section{PAGE}

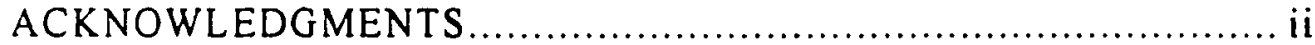

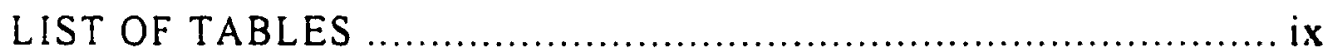

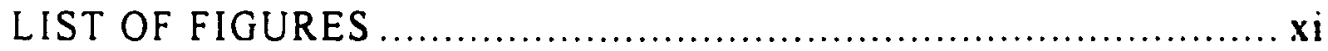

CHAPTER

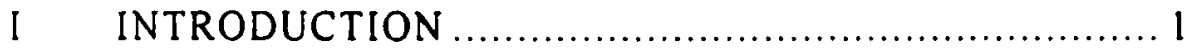

Historical Context of the Washington Education

Reform Act ................................................. 2

Definitions ................................................ 7

Theoretical Framework for the Study ...................... 10

Systemic Reform

Organizational Learning Theory

Constructivism and Standards-Based Reform

Problem to be Studied ........................................... 18

Methodology ................................................ 20

II REVIEW OF THE LITERATURE ......................... 25

Systemic Reform Policy and Standards-Based 
Theoretical Concepts of Systemic Reform and Organizational Learning

Systemic Reform through Innovation and Change Systemic Reform through Policy Implementation Systemic Reform through Professional and Organizational Learning

Theoretical Concepts of Constructivism

Principles and Theory-Based Practices of Constructivism

Elements of Constructivism in Standards-Based Reform

Constructivist Theory Applied to Organizational Learning

Factors Which Influence Changes in Classroom

Practice.

Teacher Influences on Changes in Classroom Practice

School Level Influences on Changes in Classroom Practice

Conceptual Framework. 79

Summary of Literature Review and Rationale for Study

III METHODOLOGY AND PROCEDURES 87

Research Questions and Research Design. 88

Context of the Study and Selection of Sites 92

Case Study Sites. 93

Laurel Middle School

Lighthouse Middle School

Ponderosa Middle School 
Case Study Data Collection Procedures 104

Research Steps

Data Collection Instruments

Research Timeline

Data Analysis Procedures

Units of Analysis

Quantitative Data Analysis

Qualitative Analytical Tools

Strengths and Limitations of the Study

IV FINDINGS

Introduction

Characteristics of the Survey Respondents

Characteristics of the Interviewees

Research Question One

Research Question Two

Analysis of Involvement in Educational Reform by School

Research Question Three 143

Analysis of Changes in Classroom Practice by School

Analysis of Top Five Instructional Practices by School

Summary of Changes in Classroom Practice by School

Research Question Four 169

Relation of Teacher Factors and Familiarity with HB 1209

Summary of the Relation of Teacher Factors and Familiarity with HB1209 
Relation of Teacher Factors and Involvement in Educational Reform

Summary of the Relation of Teacher Factors and Involvement in Educational Reform

Relation of Teacher Factors and Changes in Classroom Practice

Summary of the Relation of Teacher Factors and Changes in Classroom Practice

Research Question Five.

Relation of School Level Factors and Familiarity with HB 1209

Summary of the Relation of School Level Factors and Familiarity with HB 1209

Relation of School Level Factors and Involvement in Educational Reform

Summary of the Relation of School Level Factors and Involvement in Educational Reform

Relation of School Level Factors and Changes in Classroom Practice

Summary of the Relation of School Level Factors and Changes in Practice

Relationship of Familiarity with the Reform Policy, Involvement in Educational Reform, and Changes in Practice

Summary of the Relation of Familiarity with HB 1209, Teacher Factors, School Level Factors, and Changes in Practice

V. CONCLUSIONS 288

Review of the Study 288

Purpose of the Study

Theoretical Framework of the Study

Research Design

Major Findings 302

Research Question One 


\begin{abstract}
Research Question Two
Research Question Three

Research Question Four

Research Question Five
\end{abstract}

Research Model

Implications and Recommendations of the Study 318

Implications for Legislators and Policy-makers

Implications for District Level Administrators

Implications for Building Administrators

Implications for Instructional Staff

Implications for University Educational Preparation Programs

Recommendations of the Study

Directions for Further Research

REFERENCES

APPENDICES

A ADMINISTRATIVE INTERVIEW PROTOCOL 352

B MIDDLE SCHOOL INSTRUCTIONAL STAFF SURVEY

C TEACHER INTER VIEW PROTOCOL 365

D CLASSROOM OBSERVATION PROTOCOL 368

E INTERIM REPORTS AND FOCUS GROUP PROTOCOL 372

F QUALITATIVE DATA CODING SCHEME 375

G SUPPLEMENTAL CHARTS 380

H DOCUMENT CHECKLIST 390 


\section{LIST OF TABLES}

1. Comparison of Demographic Data for Three Middle Schools .. 94

2. Data Collection Instruments

3. Comparison of Survey Return Rates and Demographic Characteristics of Respondents

4. Number and Percentage of Staff Reporting Somewhat or Very Familiar with HB1209

5. Comparison of Mean Scores of Familiarity with HB 1209 by School

6. Comparison of Mean Scores for Level of Involvement in Educational Reform.

7. Comparison of Mean Scores for Changes in Classroom Practice.

8. Top Five Instructional Practices Reported by Staff at each School

9. Mean Level of Familiarity with HB1209 by Academic Area ... 172

10. Mean Level of Familiarity with HB 1209 by Grade Level ...... 173

11. Mean Level of Familiarity with HB1209 by Position........... 176

12. Multiple Regression of Teacher Factors and Familiarity with HB1209

13. Multiple Regression of Teacher Factors and Involvement in Educational Reform. 
14. Relation of Teacher Factors and Changes in Classroom Practice.

15. Multiple Regression of Teacher Factors and Changes in Classroom Practice.

16. Correlation of Collaborative Learning Group and Familiarity with HB 1209

17. Multiple Regression Analysis of School Factors and Familiarity with HB1209

18. Correlation of Collaborative Learning Group and Involvement in Educational Reform

19. Multiple Regression Analysis of School Factors and Involvement in Reform

20. Correlation of Collaborative Learning Group and Changes in Classroom Practice.

21. Multiple Regression Analysis of School Factors and Changes in Practice

22. Correlation of Familiarity with HB1209 and Changes in Classroom Practice. 276

23. Multiple Regression Analysis of Familiarity with HB1209, Teacher Factors, School Level Factors, and Involvement in Educational Reform

24. Multiple Regression Analysis of Familiarity with HB1209, Involvement in Educational Reform, Teacher Factors, School Level Factors, and Changes in Practice 283

25. Multiple Regression Analysis of Familiarity with HB1209, Involvement in Reform, Teacher and School Level Factors, and Changes in Practice for each Individual School 


\section{LIST OF FIGURES}

FIGURE

PAGE

1. Interaction of Professional and Organizational Learning in a School-Based Learning Community....

2. Model of the Connection between Policy, School-Based

Learning Community, and Changes in Classroom

Practice. 80

3. Case Study Units of Analysis ..................................... 115

4. Mean Level of Involvement by School in the Three Educational Reform Activities with Most Variation

5. Mean Level of Familiarity with HB1209 by Level of Involvement in Educational Reform.

6. Mean Level of Familiarity with HB1209 and Total Sense of Empowerment.

7. Mean Level of Staff Involvement in Educational Reform by Academic Area

8. Mean Level of Overall Involvement in Educational Reform by Grade

9. Mean Level of Staff Involvement in Educational Reform by Position

10. Comparison of Sense of Empowerment and Involvement in Educational Reform

11. Mean Change in Classroom Practice by School .................. 200

12. Mean Change in Classroom Practice by Grade ................... 203

13. Mean Change in Classroom Practice by Level of Involvement in Reform. 
14. Research Model of the Connection between Standards-Based Reform Policy, School-Based Learning Community, and Changes in Classroom Practice.

15. Multiple Regression of Teacher and School Level Factors with Familiarity with HB 1209

16. Multiple Regression of Teacher and School Level Factors and Familiarity with HB 1209 with Involvement in Educational Reform

17. Multiple Regression of Teacher and School Level Factors and Familiarity with HB 1209 with Changes in Classroom Practice.

18. Multiple Regression of Reform Policy, Teacher and School Level Factors with Involvement in Educational Reform And Changes in Classroom Practice. 


\section{CHAPTER I}

\section{INTRODUCTION}

In the current environment of systemic educational reform, which emphasizes the alignment of curriculum standards, instructional practices, and assessments, an important question arises: What are the factors which influence teachers to change their classroom practice in response to the mandated standards-based reforms? My study addressed this question by focusing on three Washington middle schools which are currently responding to the Washington Education Reform Act HB1209 (1993), herein referred to as HBL 209.

Passed in 1993, HB1209 mandated an increased focus on the improvement of teaching and learning through systemic changes rather than the piecemeal initiatives of earlier eras. HB1209 established a set of content and performance standards known as Essential Academic Learning Requirements (EALRs); mandated state assessments for all fourth, seventh, and tenth grade students; and funded professional development to support the expected changes in classroom practice and student learning. 
Research indicates that systemic standards-based reform (such as HB1209 envisions) requires complex changes in epistemology, curriculum, and pedagogy. Such reform calls into question traditional ideas of how learning takes place, what content should be taught, and how students should be taught and assessed. These changes will not occur simply because of legislative policy. The literature indicates that teachers must be active participants in a community of learners in order to change their understanding of teaching (Fullan, 1993). According to Knapp (1997), organizational learning, which focuses on the learning of teachers at both the individual and organizational level, is needed to change classroom practice and implement standards-based reforms. My study of three middle schools focused on the connection between standards-based reform policy, teachers' learning, and changes in classroom practice to improve student learning.

\section{Historical Context of the Washington Education Reform Act}

Educational researchers divide the series of educational reforms which have swept the nation since World War II into three waves (Darling-Hammond, 1997; Firestone, Fuhrman \& Kirst, 1991; Vinovskis, 1996). The Washington Education Reform Act (1993) can be viewed within the context of the Third Wave of educational reform. The First Wave focused on piecemeal changes through the curriculum 
reform initiatives in the 1960 's, followed by the instructional reform initiatives of the 1970's. The current standards movement can be traced to publication of A Nation At Risk in 1983. This report identified the primary cause of poor student performance as low standards for student achievement and teacher preparation. The report had three consequences: (a) increased high school graduation standards and testing, (b) increased college entrance requirements, and (c) an emphasis on teacher professionalization and teacher testing.

Beginning in the late 1980's and early 1990's a Second Wave of educational reform developed. Also known as the "restructuring movement," this second wave emphasized: (a) reorganizing instruction to improve teaching and learning for understanding, and (b) giving teachers and parents a greater role in decision-making. Challenging academic content standards were developed at both state and national levels, such as the California curriculum frameworks, the National Council for Teachers of Mathematics (NCTM) standards, and the

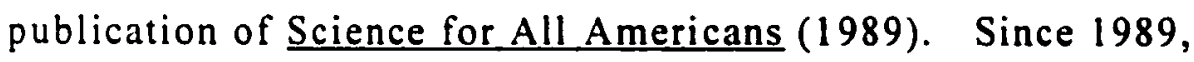
professional organizations have developed national content standards for almost all subject areas.

In 1989, President Bush's Education Summit with the nation's governors led to the development of six national educational goals. Goal Three has had particular influence on the standards movement. 
American students will leave grades 4,8 , and 12 having demonstrated competence in challenging subject matter including English, mathematics, science, history, and geography; and every school in America will ensure that all students learn to use their minds well so they may be prepared for responsible citizenship, further learning, and productive employment in our modern economy. [U.S. Department of Education (DOE), 1990, p. 5]

Under the Clinton administration there has been a continued emphasis on national standards. Clinton's Goals 2000: Educate America Act (1994) codified eight national education goals, supported certification of voluntary national education standards, and appropriated funds to support the development of content and performance standards. This legislation represents a Third Wave of systemic reform by emphasizing alignment of standards, curriculum, texts, instructional practices, assessment, and teacher preparation. As of 1998, most states had developed educational reform plans which incorporate elements of this systemic reform. Moving beyond content standards, the Third Wave focuses on student learning and assessment as the critical outcomes.

The patterns of alignment characterized by the Third Wave are reflected in the development of Washington's education reform plan. Washington's Governor Booth Gardner was a key player in the Governors' Education Task Force which met in February, 1990, after the Education Summit meeting with President Bush the previous year. 
In 1991 Gardner created the state-level Governor's Council on Education Reform and Funding (GCERF), composed of 21 legislative, education, and business leaders in Washington. The Governor's Council developed a series of recommendations, reported in Putting Children First (1992), which were incorporated in the Washington Education Reform Act (1993). In Putting Children First (1992) the Governor's Council articulated the need for citizens who "think critically and creatively, integrate experience and knowledge to form reasoned judgments and solve problems" (p. 28) and argued: "All students can learn at significantly higher levels" (p. 28). These assumptions about what students can and should learn are embedded in HB 1209 , which was passed by the legislature in 1993.

In addition to the political context of Washington's education reform, the economic context also illuminates the assumptions of the reform. As United States society has shifted from an industrial to an information age, which requires the ability to access, interpret, analyze, and use information for decision-making, the competencies needed to succeed in the workplace have changed as well. The key policy statement that connects societal changes to educational changes is found in Sec 1. of HB1209: 
The legislature finds that student achievement in Washington must be improved to keep pace with societal changes, changes in the workplace, and an increasingly competitive international economy. To increase student achievement.... Washington needs to develop a public school system that focuses more on the educational performance of students, that includes high expectations for all students, and that provides more flexibility for school boards and educators in how instruction is provided.

HB1209 established four broad learning goals to anchor 1 common content standards and state assessments. The legislation also established a Commission on Student Learning (CSL), which identified expected student knowledge and skills based on the four broad learning goals and developed a student assessment and school accountability system. The Commission created subject area task forces of educators, community and business leaders, and parents. These task forces developed Essential Academic Learning Requirements (EALRs) in language arts, math, science, social studies, physical education/health, and the arts. The EALRs combine content standards and benchmarks

1 The four state learning goals are: Goal 1: Read with comprehension; write with skill, and communicate effectively and responsibly in a variety of ways and settings; Goal 2: Know and apply the core concepts and principles of mathematics; social, physical, and life sciences; civics and history; geography; arts; and health and fitness; Goal 3: Think analytically, logically, and creatively, and to integrate experience and knowledge to form reasoned judgments and solve problems; and Goal 4: Understand the importance of work and how performance, effort, and decisions directly affect career and educational opportunities. (Washington State Commission on Student Learning, 1997, p. 2) 
and identify the knowledge, skills, and behaviors needed for students to achieve at high levels.

Student assessment has become the centerpiece of HB 1209. Assessment reform is viewed as a means of setting appropriate targets for students, focusing staff development efforts, encouraging curriculum reform, and improving instruction. The Washington Assessments of Student Learning (WASL) represent performance standards. They are based on the Essential Academic Learning Requirements and include a variety of tasks: answering multiple choice questions, writing open-ended responses, reading and interpreting complex text, listening to and interpreting oral communication, and demonstrating problem solving skills. These mandatory standardized, criterion-referenced, performance-based tests for all fourth, seventh, and tenth grade students in public schools are being phased-in, beginning in 1998 (fourth grade language arts and math) through 2001 (tenth grade language arts, math, and science).

\section{Definitions}

When addressing the Washington Education Reform Act (1993), it is helpful to clarify some of the standards-based terminology. Linn and Baker (1995) and Burger (1995) help to clarify definitions of standards. 
Content standards define subject specific knowledge and skills that schools are expected to teach and students are expected to learn. They answer the question: What should students know, understand, and be able to do? For example, one of the four content standards for the Essential Academic Learning Requirements in writing is:

The student writes clearly and effectively. To meet this standard, the student will develop concept and design; use style appropriate to the audience and purpose; and apply writing conventions. (Washington State Commission on Student Learning, 1997, p. 29)

Benchmarks describe the application of content standards at various grade levels. They address the question: What should the student at grade know, understand, and be able to do? For example, the seventh grade benchmark for the previously cited content standard includes:

Demonstrate consistent focus; construct a logical argument; write in a number of genres and forms; discriminate between essential, intriguing, or useful information and trivia; use effective organizational structures; construct sequenced paragraphs using effective transitions.(p. 31)

Performance standards define acceptable (and unacceptable) levels of student achievement. They answer the question: How well must students perform on the assessment? For example, the scoring criteria for content, style, and organization of the written essays on the seventh grade Washington Assessment of Student Learning (WASL) include: 
4 points (exceeds the standard): maintains consistent focus on the topic and has ample supporting details; has a logical organizational pattern and conveys a sense of completeness and wholeness; provides transitions which clearly serve to connect ideas; uses language effectively by exhibiting word choices that are engaging and appropriate for intended audience and purpose; includes sentences of . varied length and structure; allows the reader to sense the person behind the words.

2 points: (betow the standard): demonstrates an awareness of the topic and includes some (or few) supporting details, but may include extraneous or loosely related material; shows an attempt at an organizational pattern, but exhibits little sense of wholeness and completeness; provides transitions which are weak or inconsistent; has a limited and predictable vocabulary which may not be appropriate for the intended audience and purpose; shows limited variety in sentence length and structure; attempts somewhat to give the reader a sense of the person behind the words. (WASL Example Test Grade 7, p. 107)

Opportunity to learn standards define criteria for assessing the adequacy of learning opportunities provided for students. They answer the question: What resources do students need in order to meet the content standards, including instructional materials, a safe learning environment, and well-trained teachers? The Washington Education Reform Act (1993) does not outline specific opportunity to learn standards for Washington students. However, it does specify: "Time and resources for educators to collaboratively develop and implement strategies for improved student learning" (Sec. 1). The legislature funded Student Learning Improvement Grants (SLIGs) from 1994 to 
1999 to support professional development and planning to improve student learning.

\section{Theoretical Framework for the Study}

The theoretical framework for this study drew from three areas of research. These three areas are systemic reform, organizational learning theory, and constructivism.

\section{Systemic Reform}

The concept of systemic reform policy has developed over the last twenty-five years. Historically, the antecedent of the term systemic reform is the concept of restructuring (Thompson, 1993). The National Association of Secondary School Principals (1992) defined restructuring as "...reforming school organizational interrelationships and processes to increase student learning and performance" (p.3). However, I will argue that restructuring is not synonymous with systemic reform. Systemic reform goes beyond restructuring of the individual components of the school organization and considers the dynamic complexity of schools and the change process. Sarason (1996) and Hoy and Miskel (1996) view the school as an open, dynamic system with internal and external feedback loops which provide information about the system and potentially allow it to self-correct and change. 
Both Sarason and Hoy and Miskel emphasize the importance of the system's external environment (e.g., state legislatures, community attitudes, socio-economic factors). Senge (1990) and Fullan (1993) stress the importance of the system's internal environment (e.g., the culture, relationships, and communication within the organization). Thus, systemic (educational) reform involves changing classroom practice within the opportunities and constraints of a dynamic, complex, open system.

In the last decade standards have been incorporated into systemic reform. Standards-based systemic reform refers to the alignment of standards, curriculum, texts, instructional practices, assessment, and teacher preparation. Smith and O'Day (1991), Darling-Hammond (1997), and Knapp (1997) apply the concept of "systemic reform" to those educational policies which combine state curriculum frameworks with site-based reforms. This model of systemic reform underlies the premises of HB1209.

Knapp (1997) outlines three perspectives of systemic reform which provide different explanations of the interaction of reform policy and classroom practice. Systemic reform through innovation and change focuses on how new practices are diffused and replicated in a variety of educational settings. Systemic reform through policy implementation emphasizes the way policy intentions interact with 
implementing agencies at multiple levels such as districts and schools. Both systemic reform through innovation and change and through policy implementation contribute to our understanding of the interaction of policy and practice. However, I believe Knapp's third perspective, systemic reform through professional and organizational learning. provides the clearest picture of the factors which influence teachers to change classroom practice in response to standards-based reform. Knapp uses the term, "professional and organizational learning" to explain learning by individual professional teachers and by the school organization as a whole. Both the learning of individual teachers as professionals and the learning that takes place at the organizational level are necessary.

\section{Organizational Learning Theory}

The concept of learning organizations was popularized by Senge (1990). His five disciplines provide a starting point for understanding how the capacity or will to change develops in an educational organization. Personal mastery, mental models, shared vision, team learning, and systems thinking are interrelated, essential elements of all learning organizations. Senge argues that the goal of the learning organization is "metanoia" or the shift of mind that enables people to discover how they create their reality and how they can change it. 
Fullan (1993, pp. 15-17) applies Senge's ideas at the individual level and describes four capacities which are necessary for teachers to change. The four capacities are mastery, personal vision building, inquiry, and collaboration. He contends that individual and organizational change occur simultaneously. According to Fullan, both individual (professional) and organizational change is more likely to occur when individuals work in collaboration with others in a "community of learners."

This study focused on the factors which influence middle school teachers to change classroom practice in response to standards-based reform. Specifically, my research considers the factors which affect the professional learning of individual teachers and the organizational learning of the school as a whole. Based on the work of Senge, Fullan, and Knapp cited above, a school-based learning community is one in which learning of an intentional nature is taking place, simultaneously and interactively, at both the individual professional and organizational level.

Organizational learning theory provides a framework for understanding the research into the conditions which influence teachers to change classroom practice in response to standards-based reform. Over forty studies, conducted since the 1980 's, provide insight into the barriers and supports for the organizational learning needed to 
implement state educational reforms similar to HB1209. Many of the studies focus on those factors which influence teachers to change their classroom practices. A simple framework, which I developed, for organizing these factors is to view them as teacher (professional) and school level (organizational) influences on classroom practice. Within a school-based learning community both sets of factors interact and influence teachers' will and capacity to change. Figure 1 below summarizes the theoretical framework for my study.

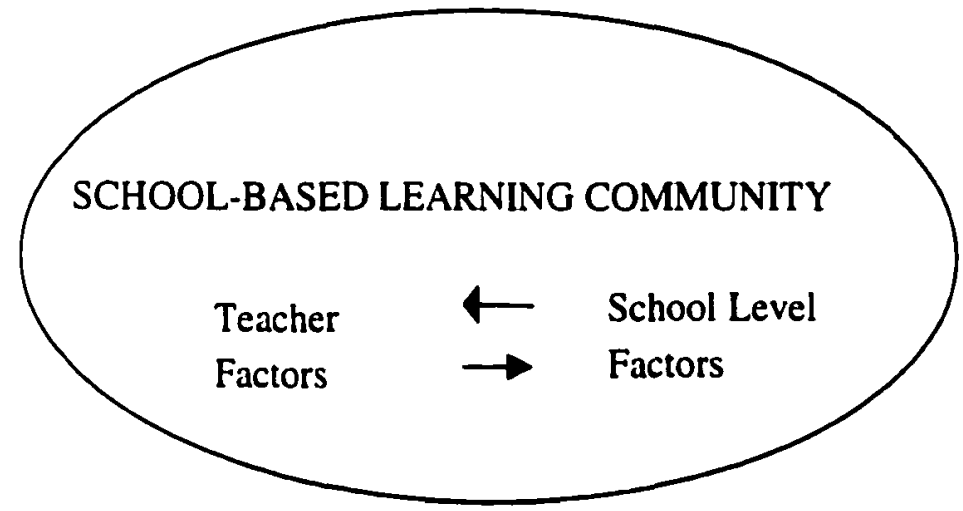

Figure 1. Interaction of professional and organizational learning in a school-based learning community.

Teacher (professional) factors are those influences which are internal to the teacher as a learner. They include: (a) present teaching experience (academic area, grade, position); (b) previous teaching experience; (c) pedagogical knowledge needed to implement the reform; (d) involvement in educational reform; (e) sense of empowerment; and (f) self-efficacy. Teachers' previous learning, beliefs, and attitudes are 
an essential ingredient in the process of change (Darling-Hammond, 1990; Gearhart, Wolf, Burkey \& Whittaker, 1994). These ideas develop through teachers' experiences as students themselves and as teachers. Also, researchers argue that standards-based reforms require teachers to shed established modes of understanding and adopt constructivist visions of knowledge (Cohen \& Spillane, 1992; Knapp, 1997). This requires changes in teachers' pedagogical knowledge, e.g., instructional and assessment strategies. Furthermore, the standards also require changes in teachers' content knowledge. Many research studies (see Chapter II) have documented the critical importance of a third factor, active teacher involvement in educational reform. And finally teacher empowerment and self-efficacy have been documented as important factors influencing teachers' capacity and will to change (Marks \& Louis, 1997; Sarason, 1996).

School level factors are those influences which are external to the teacher but affect the school's culture as a learning organization. They include: (a) previous educational policies; (b) participation in a collaborative learning group; (c) building level and district administrative expectations and support; and (d) organizational features which enhance time for teachers to learn and collaborate. Previous educational policy is an important factor influencing teachers' response to standards-based reform (Cohen \& Ball, 1990b; Darling- 
Hammond, 1990). In addition, the important influence of a teacher's colleagues and professional community has been well documented (Louis, Marks \& Kruse, 1996; Peterson, McCarthey \& Elmore, 1996). Third, researchers (Aschbacher, 1993; Berman \& McLaughlin, 1978; Sarason, 1996; Spillane, 1998) have concluded that administrative leadership and support for reform is a necessary condition for local implementation. And finally, an obvious, but often underestimated influence on teachers' ability to change classroom practice is time for learning, planning, practicing, and revising as well as collaborating with colleagues (Prestine \& McGreal, 1997).

Constructivism and StandardsBased Reform

While the primary focus of this research was the factors which influence teachers to change their classroom practice in response to standards-based reform, a secondary issue was the types of changes which result. Based on my understanding of the standards movement in general and HBI209 in particular, I contend that constructivist ideas of teaching and learning are embedded in the Washington Education Reform Act (1993).

Fosnot (1996) defines constructivism as a theory about knowledge and learning which describes what knowing is and how one comes to know. While constructivism is not a theory of teaching, it 
does suggest ways of teaching. Major elements of constructivist epistemology (Caine \& Caine, 1991, 1997; Chaille \& Britain, 1997;

Lambert et al., 1995) are: (a) Knowledge exists within the learner. (b) The learner constructs meaning from personal values, beliefs, and experiences. (c) Learning is a social activity enhanced by shared inquiry. (d) Reflection and metacognition are essential aspects of constructing knowledge and meaning. (e) Learners play a central role in assessing their own learning.

The connection between constructivist pedagogy and standardsbased reform is articulated by Wolf, Bixby, Glenn \& Gardner, H. (1991, pp. 47-48) as they define the "epistemology of mind" that underlines standards-based teaching and assessment. By this phrase they mean all learners construct rather than merely absorb knowledge, through inference, observation, rule generation, and theory building. Learning is understanding how to apply what one knows, not just the amount of information one can absorb.

Constructivist pedagogy is not specifically referenced in the legislation or documentation of the Washington Education Reform Act (1993). However, several elements of constructivist pedagogy, active student learning and performance assessment, are key features. Furthermore, A Framework for Excellence [Office of the Superintendent of Public Instruction (OSPI), 1996] refers to 
metacognition, an important aspect of constructivist pedagogy, in the description of performance assessments. The Washington Assessment of Student Learning (WASL) is designed to elicit students' understanding of core processes and concepts and give them the opportunity to demonstrate their reasoning in problem solving. In addition to an emphasis on reflection and metacognition, the Washington state assessments also reflect the principle that learners construct meaning from personal values, beliefs, and experiences.

\section{Problem To Be Studied}

My thesis was designed to examine the fundamental assumption underlying the Washington Education Reform Act (1993): If the state raises standards and requires standards-based assessments, teachers will change classroom practice, and students will demonstrate improved academic achievement. Despite the assumptions of HB1209, the premise of a causal link between (a) reform policy, (b) changing classroom practice, and (c) improving student learning has not been well documented. Because implementation of HB1209 is still in its early stages, my research focused on factors which influence changes in classroom practice in response to standards-based reform.

The purpose of my study was to examine the connection between standards-based reform policy, teachers' learning, and changes in 
classroom practice to improve student learning. An additional purpose was to provide useful information to teachers and administrators who are implementing HB1209. Five questions framed the research for this study.

- What is the school faculties' understanding of the purpose of HB1209 and their familiarity with the Essential Academic Learning Requirements and the Washington Assessment of Student Learning in language arts and mathematics?

- What is the school faculties' overall level of involvement in educational reform and in what types of educational reform are they involved?

- To what degree and in what ways do teachers change classroom practice in response to $\mathrm{HB} 1209$ ?

- How are the following teacher factors related to staff members' familiarity with HB1209, their involvement in educational reform, and changes in classroom practice: (a) present teaching experience (academic area, grade, position); (b) previous teaching experience; (c) pedagogical knowledge; (d) involvement in educational reform; (e) sense of empowerment and (f) self-efficacy?

- How are the following school level factors related to staff members' familiarity with HB1209, their involvement in educational reform, and changes in classroom practice: (a) previous educational policies; (b) 
participation in a collaborative learning group; (c) building level and district administrative expectations and support; and (d ) organizational features that enhance time for teachers to learn and collaborate?

Research reveals that changing classroom practice and improving student learning are complex, multidimensional phenomena. Systemic standards-based reform, such as HB1209 envisions, requires complex changes in epistemology, curriculum, and pedagogy. Such reform calls into question traditional ideas of how learning takes place, what content should be taught, and how students should be taught and assessed. These changes will not occur simply because of legislative policy. The literature indicates that teachers must be active participants in a community of learners in order to change their understanding of teaching (Fullan, 1993). According to Knapp (1997), professional and organizational learning which focuses on the learning of teachers at both the individual and organizational level, is needed to change classroom practice and implement standards-based reforms.

\section{Methodology}

This research involved case studies of three middle schools, which are responding to the requirements of $\mathrm{HB} 1209$, and included the following research activities:

- interviews with district (central office) and building administrators 
- surveys completed by instructional staff at each middle school

- interviews with three language arts teachers at each middle school who volunteered to participate in interviews/classroom observations

- five classroom observations of each interviewed teacher

- review of district/ building documentation regarding response to HB 1209

- observation of faculty meetings, site council and team meetings as appropriate at each school.

- focus group interviews with each grade level team at each middle school

Decisions about site selection and research methodology were informed by the case study methodology of leading researchers in the field of systemic reform and organizational learning (Elmore, Peterson \& McCarthey, 1996; Newmann, Secada \& Wehlage, 1995; Peterson et al., 1996). Criteria for choosing the three exemplary middle schools included involvement in some of the following activities:

- creating a vision of expected classroom practices and student learning

- creating professional development/collaborative learning groups

- involving instructional staff in site-based decision-making.

- aligning curriculum to match state EALRs /assessments

- developing/articulating student performance standards 
- changing classroom practice to a more constructivist approach

- using classroom and state assessments to inform instructional practice

The first stage of this multi-stage research project was to interview a district (central office) administrator and the middle school principal in each of the three participating schools. In the second stage, an instructional staff survey was developed to assess the influence of the factors which may influence changes in classroom practice at each site. In the third stage of the research, three language arts teachers at each middle school were selected based on administrator recommendation and the teachers' willingness to participate in follow-up interviews and classroom observations. Based on the results of the instructional staff survey, follow-up interviews were designed to develop further insights into the connection between HB1209, organizational learning at the middle school, and changes in classroom practice to improve student learning. After the interviews with the language arts teachers, classroom observations were conducted with the consent of the interviewed teachers to clarify and verify the self-reported changes in classroom practice. Faculty meetings, site council, and team meetings were also observed. In the final stage, an interim report of the survey findings was presented in grade level focus groups at each school. 
Both quantitative and qualitative analytical tools were used to analyze the data from the administrator and teacher interviews, surveys, and classroom observations. The data were analyzed for each school individually and across all three schools to clarify the connection between standards-based reform policy (HB1209), teachers' learning, and changes in classroom practice to improve student learning.

This study is valuable because very few studies have looked specifically at the connection between standards-based reform policy, organizational learning, and changes in classroom practice at the secondary level. As the pressure for teacher and principal accountability increases and the assessment stakes get higher, research which explores these connections will be vital. This study will help to clarify how professional and organizational learning and individual teacher will and capacity to change develop and how the two are related. It also will examine the ways in which middle school teachers' learning is transferred into consistent, sustained classroom practice.

My research is intended to assist administrators and teachers as they work together to develop a learning community and create opportunities for professional and organizational learning. It is also intended for those who make and implement policy at the state and district level and who seek to understand the factors which mediate between educational reform policy and changes in classroom practice. 
Finally, my research may inform university educators who teach in educational administration and teacher preparation programs. 


\section{CHAPTER II}

\section{REVIEW OF THE LITERATURE}

This study was designed to examine the assumption underlying the Washington Education Reform Act (1993): If the state raises standards and requires standards-based assessments, teachers will change classroom practice, and students will demonstrate improved academic achievement. The research examined the initial legislative model and tested other factors which, in combination with standards and assessments. led to changes in classroom practice in three middle schools which are currently implementing HB1209.

Despite the assumptions of $\mathrm{HB} 1209$, the premise of a causal link between reform policy, (b) changing classroom practice, and (c) improving student learning has not been well documented. On the contrary, research extending from the RAND study of federally funded educational programs of the 1960 's to the analysis of implementation of the California Curriculum frameworks in the 1990's reveals that changing classroom practice and improving student learning are complex, multidimensional phenomena. My research was designed to 
examine some of the dynamic relationships in the assumptive framework of the Washington Education Reform Act (1993).

The purpose of this literature review is to address the following questions:

1. How has the present environment of standards-based systemic reform developed?

2. What insights come from three research perspectives of systemic reform: a) innovation and change, b) policy implementation, and c) professional and organizational learning?

3. What theory of learning is embedded in HB 1209 ?

4. What does research show about factors which influence changes in classroom practice in response to standards-based education reform?

5. How does the study's conceptual framework integrate organizational learning theory, constructivism, and the research-based factors which influence changes in classroom practice?

6. What areas need further study and thus provide the rationale for this dissertation? 


\title{
Systemic Reform Policy and \\ Standards-Based Learning
}

\begin{abstract}
Research Question 1: How has the present environment of standards-based systemic reform developed?
\end{abstract}

The concept of standards-based systemic reform policy consists of three separate terms: standards-based, systemic reform, and policy. Knapp (1997) defines policy as a "purposeful course of action by individuals at higher levels in the system designed to guide, direct, or support action at lower levels of the system across settings and across time“ (p. 233).

The concept of systemic standards-based reform has developed over the last twenty-five years. Historically, the antecedent of the term systemic reform is the concept of "restructuring." Thompson (1993) defines systemic reform as a call for reconceptualization of schools from the ground up, including teaching and learning, educational relationships, and school-community relationships. Systemic reform is viewed as an alternative to the tinkering with various inputs that describes previous educational reform efforts, many of which were disjointed and sometimes contradictory. Thompson applies the term educational "restructuring" to systemic reform and includes the following elements: learner outcomes, curriculum, instruction, 
assessment, technology, school-community relations, governance, teacher leadership, and working relationships. The National Association of Secondary School Principals (1992) defines restructuring in similar ways: "Restructuring is defined as the reforming of school organizational interrelationships and processes to increase student learning and performance" (p. 3). However, I contend that restructuring is not synonymous with systemic reform.

Both Thompson and the NASSP formulated their definitions of restructuring during the early 1990's and can be viewed as Second Wave theorists. Newmann et al. (1995) cautions that while structural change may be a necessary condition for changes in teaching, it is probably not a sufficient condition. Fullan (1993, p. 50) cites numerous research studies of restructuring efforts, which did not change the cultural core of teaching and learning. The restructuring movement was succeeded by the Third Wave of educational reform emphasizing systemic reform through alignment of more challenging standards for learning with curriculum, texts, instructional practices, assessment, and teacher preparation (Darling-Hammond, 1997, p. 5; Vinovskis, 1996).

Systemic reform goes beyond restructuring of the individual components of the school organization and considers the dynamic complexity of schools and the change process. Sarason (1996) and Hoy 
and Miskel (1996) view schools as open, dynamic systems. It is not enough to manipulate the inputs (e.g., students and teaching materials) hoping to affect the outputs (e.g., student achievement). An open system also includes transformation processes (e.g., classroom practices) and internal and external feedback loops which provide information about the system and potentially allow it to self-correct and change. Both Sarason and Hoy and Miskel emphasize the importance of the system's external environment (e.g., state legislatures, community attitudes, socio-economic factors). Senge (1990) and Fullan (1993) stress the importance of the system's internal environment (e.g., the culture, relationships, and communication within the organization). Thus, systemic (educational) reform involves changing classroom practice within the opportunities and constraints of a dynamic, complex, open system.

The third term, standards-based, refers to the alignment of standards, curriculum, texts, instructional practices, assessment, and teacher preparation. Smith and O'Day (1991) are credited by Vinovskis (1996) with applying the concept of "systemic reform" to those educational policies which combine state curriculum frameworks with site-based reforms. According to Smith and O'Day, by establishing what students should know and be able to do, curriculum frameworks provide direction for upgrading content and instruction. Aligning state 
education policies provides a coherent structure to support the schools. Restructuring the governance system gives schools the resources, flexibility, and responsibility they need to improve student learning. Smith and O'Day (199l) and Darling-Hammond (1994, 1997) also support opportunity to learn standards to ensure that all students have access to high quality education. The Smith and O'Day model of systemic reform underlies the premises of HB 1209.

Knapp (1997, p. 228) also defines systemic reform as "standards-based reform" and reviews large-scale systemic reform initiatives aimed at mathematics and science education. His summary of the reform initiatives' premises illuminates the policy assumptions of HBI 209.

1) A major constraint on teaching quality is the lack of alignment among key elements of the system.

2) Better teaching and learning will result when all the elements that influence the classroom (curriculum, pedagogy, assessment, teacher preparation, and accountability) are aligned with the standards.

3) Teachers and students will improve their performance only if the standards are higher and clearly stated. Teachers are most likely to align their practice with the standards if their training, curriculum, and assessments are integrated. If the high standards apply to all students, equity will be enhanced. 
4) Systemic reform is compatible with appropriate local professional development and discretion.

Vinovskis (1996) cites other views of systemic reform ranging from a call for national curriculum (Chester Finn), to a rejection of mandatory national or state instruction guidance (William Clune), to the provision of extra-educational services such as early childhood education, health care facilities, and family resource and youth centers (Kentucky Education Reform Act). But for purposes of this literature review, I will use the Smith and O'Day (1991) and Knapp (1997) models of standards-based systemic reform.

Fullan (1993) cites the failure of the restructuring initiatives to fundamentally change classroom practice and educational relationships. How then, will standards-based systemic reform, as defined by Smith and O'Day (1991) and Knapp (1997), meet the challenge and improve student learning? The research into systemic reform and organizational learning provides some insights. 
Theoretical Concepts of Systemic Reform and Organizational Learning

Research Question 2: What insights come from three research perspectives of systemic reform: a) innovation and change, b) policy implementation, and c) professional and organizational learning?

Knapp (1997) outlines three perspectives of systemic reform which provide different explanations of the interaction of reform policy and classroom practice. (a) Systemic reform through innovation and change focuses on how new practices are diffused and replicated in a variety of educational settings. (b) Systemic reform through policy implementation emphasizes the way policy intentions interact with implementing agencies at multiple levels such as districts and schools. Both systemic reform as innovation and change and as policy implementation contribute to our understanding of the influence of educational reform policy on classroom practice. However, I believe (c) systemic reform through professional and organizational learning provides the clearest picture of the factors which influence teachers to change classroom practice in response to standards-based reform. This section of the literature review describes all three perspectives with a 
major emphasis on the contribution of professional and organizational learning to changes in classroom practice.

\section{Svstemic Reform through Innovation} and Change

The role of change agents and the difficulties of implementing educational change.were analyzed in-depth by Berman and McLaughlin (1978) in the landmark RAND study of federally funded educational programs. Subsequently Bridges (1991), Fullan (1993), Odden (1995) and Sarason (1996) have continued research into the role of change agents and the ways in which innovations are diffused or disseminated to users throughout a system. Knapp (1997) describes a typical sequence. "Change agents promote awareness of the new practice and encourage its use through a dissemination strategy that combines various incentives and supports" (p. 249). These innovations encounter resistance because of (a) the nature of the innovations themselves, (b) their degree of compatibility with the adopting organization, and (c) the sophistication of the change strategy.

Viewed from this perspective, the Washington state legislature has created a policy, HB1209, which encompasses a product (essential learnings/EALRs and assessments/WASL), implied classroom practices, and a process for aligning curriculum and classroom practices with the standards to improve student learning. The change agents include the 
state legislature, the Commission on Student Learning, school district administrators, and classroom teachers. Resistance to HB1209 could develop for several reasons: (a) opposition to the imposition of state content and performance standards and assessments on local districts; (b) frustration with the complexity of the reform plan; (c) contradiction of HB1209 and previous state and local policies; (d) lack of congruence between the classroom practices implied by HB1209 and teachers' pedagogical knowledge or beliefs; and (e) different levels of readiness to change across districts.

I agree with Knapp (1997) who suggests that this perspective treats educational reform as a dissemination of innovative ideas and practices, which is too simplistic for understanding the complex processes of pedagogical reform such as HB 1209 proposes. The innovation perspective is more useful for understanding change related to single innovations than the multiple changes in curriculum, instruction, and assessment which HB1209 requires.

\section{Systemic Reform through}

Policy Implementation

Viewing reform from the perspective of policy implementation has its roots in political science. According to Knapp (1997), this perspective focuses on the interaction of policy with its context and the dynamics of change as the policy travels through the intergovernmental 
process and is reinterpreted in the process. Berman and McLaughlin (1978) found evidence of the mutual adaptation of policy and its setting to each other. McLaughlin (1987) also studied the capacity of implementing agencies and their will to put policy into practice.

Adaptation is the process by which a policy is redefined to fit the local scene and vice versa. Local attitudes, material resources, and time also influence the adaptation process. Because interpreting policy involves constructing ideas about the policy based on previous beliefs and knowledge, different individuals within the implementing agency may interpret the policy differently (Spillane, 1998).

One example of the many studies of standards-based educational reform illustrates the policy implementation perspective. Cohen and Ball (1990a) studied the interaction of policy and practice in their case study of elementary teachers who were implementing California's math curriculum frameworks. "Teachers are at once the targets and agents of change... Instructional policies are filtered through teachers' knowledge and beliefs about academic subjects, and through their established practices" (pp. 237-238).

Viewed from this perspective HB 1209 may be implemented differently depending on the attitudes, resources, and knowledge within districts and schools across Washington. Districts in which the parents, educators, and the community actively support the changes in teaching 
and learning implied by HB 1209 will differ from districts whose stakeholders are indifferent to or oppose the changes. Districts which have the resources to invest in the requisite professional development needed to implement the changes in curriculum and classroom practice will have different results than districts who lack such support.

While this perspective helps us understand the impact of the state or local educational environment on policy implementation and the role of teachers as change agents, it doesn't explain how the capacity or will to change develops at the school level. Nor does this concept explain how educational reform policy influences changes in classroom practice. For a detailed understanding of those factors which influence the changes in classroom practice required by HB1209, it is necessary to review the literature on professional and organizational learning.

\section{Systemic Reform through Professional} and Organizational Learning

Knapp (1997) uses the term, "professional and organizational learning," to explain learning by individual professional teachers and by the school organization as a whole. The concept of learning organizations was popularized by Senge (1990). His five disciplines provide a starting point for understanding how the capacity or will to change develops in an educational organization. Personal mastery involves continually clarifying and deepening one's personal vision, 
i.e., seeing the future one would like to create. Senge considers personal vision the cornerstone of the learning organization. Mental models are the deeply ingrained assumptions and generalizations that influence how we understand the world and how we take action. Senge (1990) cites Argyris: "Although people do not [always] behave congruently with their espoused theories [what they say], they do behave congruently with their theories-in-use [their mental models]" (p. 175). If teachers' mental model of teaching is the transmission of knowledge, they will teach that way, even if they talk about student construction of knowledge. Shared vision provides the focus and energy for learning and a commitment to long term change and growth within the organization. Team learning starts with "dialogue in which team members suspend assumptions and develop free-flowing meaning" (p. 140) which enables the group to discover insights not attainable individually. Dialogue is different from discussion in which people tell each other what they think; dialogue involves listening to others and being willing to change one's thinking. Systems thinking integrates the other four disciplines and enables the individual and the organization to see interrelationships rather than disparate events. In other words, all elements of the system interact with and influence all other elements of the system. 
Senge argues that the goal of the learning organization is "metanoia" or the shift of mind that enables people to discover how they create their reality and how they can change it. Comparing Senge's five disciplines to the faculty meetings and inservices which most public school educators have experienced explains why most school organizations do not have the will or capacity to change! Rather than facilitating dialogue in which teacher share deeply held beliefs about teaching and learning, most faculty meetings and inservices are designed to discuss upcoming events or transmit information.

Fullan applies Senge's ideas at the individual level and describes four capacities which are necessary for teachers to change. He argues that individual and organizational change occur simultaneously. Fullan (1993) explains mastery as "the capacity to suspend belief, take risks, and experience the unknown" (p. 17). He suggests that "people must behave their way into new ideas and skills, not just think their way into them" (p. 15). Fullan believes personal vision building precedes shared vision, because one must have something to share. While Fullan does not use Senge's (1990) term, "mental models," he believes that teachers must examine their beliefs about teaching and their purpose as educators. Inquiry is also necessary to internalize habits for continuous learning through reflective practice, personal journals, action research, working in innovative mentoring and peer 
settings. Fullan's idea of collaboration is similar to Senge's team learning in that there is a limit to how much we can learn as

individuals. Both individual and organizational changes are more likely to occur when individuals work in collaboration with others in a "community of learners."

Applying Senge's and Fullan's ideas to organizational learning in schools represents a significant shift of mind from the typical faculty meeting or one-shot in-service training program. Organizational learning requires a commitment to developing trust and mutual respect, open communication, inquiry, experimentation, and collaboration. It requires much more time and greater resources than are normally allocated to staff development in most schools. Fullan (1993) cites three major studies of educational reform in Maine, New York, and the United Kingdom. All three studies identified the importance of professional learning. Fullan concludes that in the process of working together, teachers changed their beliefs and practices over time.

Sagor's (1997) work in collaborative action research adds another component to the characteristics of a learning organization: data-based decision-making. In addition to an atmosphere of openness and professional discourse in which teachers are encouraged and supported to try innovations and make program changes, Sagor argues that teachers must share their research findings and results from the data 
they have collected. He emphasizes collegiality and experimentation as two of the most critical components of effective schooling. Sagor (1997) cautions that it is not just conducting research that makes the difference. "It is the transformational experience of working in an environment that is steeped in professional discourse that moves these educators in a continuously upward spiral in both their understandings and their practices" (pp. 187-188).

The literature on systemic reform as professional and organizational learning indicates that teachers need to be active participants in a community of learners in order to change their understanding of teaching. According to Knapp, organizational learning focuses on the learning of teachers which is needed to change classroom practice and the learning that takes place at the organizational level in the school or district as standards-based reforms are implemented. Knapp (1997) emphasizes that, "Teachers must engage in a long-term process of learning like the constructivist processes that underly the reforms for students. Those who support teachers (administrators, state agency officials, community members) must also understand what these reforms mean" (pp. 252-253).

Organizational learning theory provides a framework for understanding the research into the conditions which influence changes in classroom practice in response to standards-based reform. However, 
investigating the impact of HB1209 also raises a question concerning the theory of learning and the changes in classroom practice which the reform implies.

Theoretical Concepts of Constructivism

Research Question: What theory of learning is embedded in HBI 209?

While the primary focus of this research was the factors which influence teachers to change their classroom practice in response to standards-based reform, a secondary issue was the nature of the resulting changes. Based on my understanding of the standards movement in general and HB1209 in particular, I contend that constructivist ideas of learning and teaching are embedded in the Washington educational reform plan. In the following section I will examine (a) the principles and theory-based practices of constructivism, (b) the elements of constructivism reflected in standards-based reform in general and HB1209 in particular and (c) the connection between constructivism and professional and organizational learning. 


\section{Principles and Theory-Based Practices}

of Constructivism

Fosnot (1996, p. ix.) defines constructivism as a theory about knowledge and learning which describes what knowing is and how one comes to know. She describes knowledge as temporary, developmental, internally constructed, and socially and culturally mediated. Learning involves struggling with the conflict between the learner's existing model of the world and discrepant new insights. Learning involves constructing a new representation of reality with culturally developed tools and symbols, such as language, and negotiating meaning through cooperative social activity.

Constructivism is a theory of learning (epistemology) that suggests ways of teaching (pedagogy). Major assumptions of constructivist pedagogy (Caine \& Caine, 1991, 1997; Chaille \& Britain, 1997; Lambert et al.,1995) are: (a) Knowledge exists within the learner. (b) The learner constructs meaning from personal values, beliefs, and experiences. (c) Learning is a social activity enhanced by shared inquiry. (d) Reflection and metacognition are essential aspects of constructing knowledge and meaning. (e) Learners play a central role in assessing their own learning.

Fosnot (1996, pp. 29-33) applies the following constructivist principles to these classroom practices: (a) Learning is developmental: 
Teachers need to let learners raise their own questions, generate hypotheses, and test them for validity. (b) Disequilibrium facilitates learning: Teachers should offer challenging, open-ended questions. (c) Reflective abstraction (see definition below) is the driving force of learning: Teachers should encourage student reflection through journal writing and discussion of connections across experiences. (d) Dialogue engenders further thinking: Classrooms should be "communities of discourse" engaged in activity, reflection, and conversation. (e) Learning proceeds toward development of cognitive structures:

Classroom experiences should focus on central, organizing principles that can be generalized across experiences.

While constructivism is a relatively recent theory of learning supported by cognitive research, educational theorists from Dewey, to Piaget. Bruner, and Vygotsky have contributed to its development (Brooks \& Brooks, 1993; Fosnot, 1996; Lambert et al., 1995). Dewey espoused the social construction of knowledge and the centrality of student experiences for learning. Piaget pioneered studies of the stages of children's cognitive development and originated the principles of assimilation and accommodation to explain learning. His view of learning as constructing and reorganizing knowledge based on experiences, rather than as memorizing information presented by teachers or texts, is the key idea that sets constructivism apart from 
other theories of cognition (Fosnot, 1996, p. 7). Piaget elaborated the concept of "reflective abstraction" which is the process by which the human brain generates new possibilities. Piaget hypothesized that when cognitive structures are disturbed by discrepant information, subsequent reflection leads to structural change or accommodation that transforms the original cognitive structure and assimilates the new information.

Bruner expanded on Piaget's theories, explaining the role of language and prior experience in the development of cognitive growth (Fosnot, 1996). Vygotsky focused on the effect of social interaction, language, and culture on learning. He theorized that individuals negotiate and create meaning in the "zone of proximal development" which is the gap between the student's level of actual development and the level of potential development the student can achieve with the support of the teacher or peers. Vygotsky's idea, cited in Fosnot, "that the most effective learning occurs when an adult draws the child out to a jointly constructed potential level of performance" (p. 20), supports the concept of scaffolding in which the teacher provides sufficient support to help the student achieve the learning goal.

The work of Dewey, Piaget, Bruner, and Vygotsky rejected the associationist/behaviorist principles of learning that have dominated American education for much of the twentieth century. Behaviorism 
views learning as a system of behavioral response to physical stimuli. Teachers break content into parts and teach from the simple to the complex. Learning results from observing, listening to explanations, and memorizing information. In contrast to the constructivist who views learners as actively searching for patterns, questioning, and constructing deep understanding through concrete, meaningful experiences, the behaviorist views learners as essentially passive, needing external motivation and reinforcement (Darling-Hammond, 1997; Fosnot, 1996). Critics contend that most teaching practices continue to reflect the idea that learning is an accumulation of pieces of knowledge and bits of skill (Resnick \& Klopfer, 1989). Most classrooms are dominated by teacher talk and textbook assignments, with most students working in relative isolation on low skilled tasks to produce the one right answer (Brooks \& Brooks, 1993; DarlingHammond. 1997; Goodlad, 1984).

Despite the continuing influence of behaviorism on American classrooms, constructivism has continued to evolve through the recent contributions of cognitive psychology and brain research. According to cognitive researchers, knowledge cannot be "transmitted" to students. Building on Piaget's theory, Resnick and Klopfer (1989) argue that learning requires students to elaborate and question what they are told, examine new information in relation to previous understanding, and 
build new cognitive structures before knowledge becomes "generative" (used to interpret new situations, solve problems, think, and reason).

Reflecting Dewey's emphasis on experience, Bransford and Vye (1989) believe students must have the opportunity to use information to solve problems connected to the real world and experience its effect on their own understanding. Otherwise, students acquire information that remains isolated and can not be applied in new situations. Furthermore, Bransford and Vye argue that students need the experience of "coached practice" in which their attempts at problem solving are supported by their teacher or peers in a cooperative group. This idea of supported learning is an application of Vygotsky's "zone of proximal development."

A number of researchers have developed constructivist principles of learning based on brain research (Caine \& Caine, 1991, 1997; Fosnot, 1996: Sylwester, 1995). One of Sylwester's (1995) most interesting premises is that "emotion drives attention, which drives learning and memory" (p. 86). After an extensive discussion of this premise, Sylwester suggests the following active learning strategies which take advantage of emotion and attention in enhancing learning: student projects, portfolio assessments, debates, storytelling, cooperative learning, simulations, role-playing, and metacognitive 
discussions. All involve the students in actively constructing meaning, based on concrete experiences.

Caine and Caine $(1991,1997)$ reiterate that the brain is a social organism, shaped by interactions with the environment and interpersonal relationships. Since learning involves conscious and unconscious processes, learners need opportunities for reflection and metacognition. Caine and Caine believe that integrated curriculum, thematic instruction, cooperative learning, and student self assessment are brain-based classroom practices that will improve student learning. Fosnot (1996) incorporates these ideas in her conception of the classroom as "a community of learners engaged in activity, discourse, and reflection" (p. ix).

Dewey, Piaget, Bruner, and Vygotsky altered our conceptions of learning and set the stage for constructivist pedagogy (Lambert et al., 1995). Cognitive researchers continued to refine these ideas and apply them to classroom practice. The next stage was the incorporation of constructivist ideas into standards-based reform policy.

Elements of Constructivism in Standards-Based Reform

The development of the standards movement also contributed to the application of constructivist principles. National Education Goal 3 (U. S. DOE. 1990) states in part "every school in America will ensure 
that all students learn to use their minds well..." (p. 5). The connection between constructivist pedagogy and standards-based reform is articulated by Wolf et al., (1991, pp. 47-48) as they define the "epistemology of mind" that underlies standards-based teaching and assessment. All learners construct rather than merely absorb knowledge, through inference, observation, rule generation, and theory building. Learning is understanding how to apply what one knows, not just the amount of information one can absorb.

Zemelman, Daniels and Hyde (1998) summarize the constructivist practices which underly the recommendations for practice of national curriculum standards reports, including: experiential learning, active student engagement, emphasis on higher order thinking, student metacognition, performance-based assessments, scoring rubrics/guides, reading of whole books and primary sources, student portfolios and cooperative learning.

Knapp (1997) explains that standards-based teaching and learning emphasize the learners' understanding of central processes and ideas, the students' ability to reason and apply ideas to non-routine complex problems, and an in-depth immersion in themes and topics rather than superficial coverage of curriculum. The Washington state assessments are designed to elicit students' understanding of core processes and concepts and give them the opportunity to demonstrate their reasoning 
in problem solving. For example, a question on the seventh grade assessment requires students to read a poem and an article about an octopus and use both pieces of writing to support the student's opinion about whether an octopus is a dangerous creature. This question requires students to demonstrate their ability to comprehend and interpret what they read, develop an opinion and support it with information, and communicate their ideas clearly through writing.

Porter (1994), Taylor (1994), and Burger (1995) also summarize the underlying assumptions about teaching and learning which permeate standards-based reform such as that found in Washington HB1209. The standards model is based on the be!ief that most students can achieve the educational standards set for them. The model assumes that different student performances may occur under the same standards. Approximately twenty-five percent of the questions on the Washington Assessment of Student Learning (WASL) require extended responses in which students write or draw illustrations or graphs to support their reasoning. Each student's response is individually evaluated based on specific scoring criteria.

The standards model also views performance as contextual and not simply a function of the individual's ability. Students need varying amounts of time and differing instructional methods to achieve the same standards. Standards-based, criterion-referenced assessments are 
central to the instructional process and provide feedback to students and teachers. Teachers are encouraged to use the sample WASL tests and their students' scores on the WASL to make decisions about instructional practice to improve students' learning.

According to the standards model, students are examined when they are ready, and students may accumulate products or performances over time in a portfolio. Assessments require teachers to be knowledgeable of the structure and content of the discipline in order to make professional judgments about student performance. Furthermore the standards apply to all students and hold schools as well as students accountable. A potential conflict between the standards model and the WASL is the requirement that all students are required to take the test in fourth, seventh, and tenth grade, whether they are ready or not, and schools are accountable for the scores of all students. Scores of zero are assigned to students who do not take the WASL, even if their IEP exempts them from the state assessment; and these zero scores count against the school's overall percentage of students performing at or above the standard.

HB 1209 calls for classroom assessments which are performance based, and the state assessments require written presentations and problem solving. According to Baker and O'Neil (1995) performance assessment is characterized by constructed responses and long-term 
engagement in project-like tasks which may be completed individually or by groups of students. Performances may involve hands-on behavior (experiments, oral or written presentations, problem-solving tasks) or products developed over time (works of art or portfolios). Bạker and O'Neil elaborate (1995). "Emerging from a constructivist approach to learning, performance assessment is thought to model ideal processes for students to engage in complex thinking and multi-stepped tasks" ( $p$. 4).

While constructivist pedagogy is not specifically referenced in the legislation or documentation of the Washington Education Reform Act (1993), active student learning and performance assessment are discussed. A Framework for Excellence (OSPI, 1996) articulates the state's educational reform plan. Included in the factors which create equitable learning environments are:

teaching practices that focus on individual student needs and lifelong learning, learning opportunities that include students in the life of the community in an educational and social context, flexibility for each and every student to achieve his or her potential, and strategies that support active student learning, such as participatory learning environments. (p. 27)

While these factors are not necessarily indicative of constructivist pedagogy, they are consistent with constructivist theory. 
A more direct linkage between constructivism and Washington policy is found in the Governor's Council's (1992) articulation of the need for citizens who "think critically and creatively, integrate experience and knowledge to form reasoned judgments and solve problems" (p. 28). Furthermore, A Framework for Excellence (OSPI, 1996) refers to metacognition, an important aspect of constructivist pedagogy, in its description of performance assessments. School-based performance assessments include report writing, laboratory experiments, artistic performances, public presentations, and organizing community projects. "A performance-based assessment is, above all, a space for self-expression and a service which schools provide for students to reflect on their learning" (p. 17).

In addition to an emphasis on reflection and metacognition, the Washington state assessments also reflect the principle: the learner constructs meaning from personal valuss, beliefs, and experiences. The language arts section requires students to read and analyze several texts and interpret them in extended written responses, incorporating the students' understanding of the author's viewpoints and their own experiences. The mathematics section emphasizes students' application of knowledge and creative problem solving abilities. For some questions there is no one "right answer"; instead, multiple solutions are possible. 
HB 1209 resulted in the development of content standards, benchmarks, and performance standards which are consistent with constructivist principles. However, the dismal failure of federal legislation in the 1960's and 1970's to reform public education (Sarason, 1996) calls into question the assumption that current state educational reform policies will necessarily result in changes in classroom practice and improved student learning. Having analyzed the changes in student learning implied by HB 1209 from a constructivist perspective, it is important to apply constructivist theory to the principles of professional and organizational learning.

\section{Constructivist Theory Applied to}

\section{Organizational Learning}

Just as constructivist theory helps inform the changes in teaching and learning for students, it also sheds light on adult learning within schools. Lambert et al. (1995) explain that all people bring their

personal schema, that have been formed by their previous experiences, beliefs, values, sociocultural histories, and perceptions to the process of learning. When new experiences are encountered and mediated by reflection and social interaction, meaning and knowledge are constructed. When learners are actively engaged in reflective dialogue (Senge's team learning), they become more complex in their thinking, more tolerant of diverse perspectives, more flexible and open to new 
experiences. If adults are to engage with each other in a process of growth and development, they need an interactive professional culture.

Lambert et al. (1995, pp. 29, 38) call for constructivist leadership which involves reciprocal processes that enable participants in an educational community to construct meanings that lead toward a common purpose about schooling. Most teachers have few opportunities at school to engage with each other in ways that call forth ideas and experiences and help them make sense of their world. Nor do they experience the supported encounters with discrepant information about teaching and learning that are essential for significant change. Applying these ideas to the school as learning organization implies that leadership is an important factor in supporting teachers' will and capacity to change.

Senge (1990) describes three capacities of leadership that are constructivist by implication. The first task of the leader is to design the learning process, whereby people can deal productively with the critical issues they face and develop their mastery in the learning disciplines. The second task is to be a steward, listening carefully to other people's visions. The third task is to be a teacher, fostering learning for everyone through mentoring and coaching.

Sagor (1997) advocates an approach that also reflects constructivist principles of leadership. 
1. Pose questions that teachers cannot answer with their current level of knowledge [suggesting discrepant ideas]. 2. Support teachers in carrying out their investigations [using information to construct new knowledge or understanding]. 3. Celebrate learning whether it is the outgrowth of success or failure. 4. Model high expectations and communicate the belief that everyone can learn [students and teachers]. (pp. 189-190)

Organizational learning theory, enhanced by a constructivist perspective, offers important insights into the supportive environment necessary for educators to change their understanding of teaching and their classroom practice. Systemic standards-based reform requires complex changes in epistemology, curriculum, and pedagogy. Such reform calls into question traditional ideas of how learning takes place, what content should be taught, and how students should be taught and assessed. Organizational learning theory provides a framework for understanding the research into the conditions, which influence teachers to change classroom practice in response to standards-based reform. 
Factors Which Influence Changes in Classroom Practice

Research Question t: What does research show about factors which influence changes in classroom practice in response to standards-based education reform?

Since the 1980's, over forty studies have provided insight into the barriers and supports for the organizational learning needed to implement state educational reforms similar to HB1209. Many of the studies (discussed below) focus on those factors which influence teachers to change their classroom practices. A simple framework, which I developed, for organizing these factors is to view them as teacher and school level influences on classroom practice. Teacher factors are those influences which are internal to the teacher as a learner. They include: (a) present teaching experience (academic area, grade, position); (b) previous teaching experience; (c) pedagogical knowledge; (d) involvement in educational reform; (e) sense of empowerment and (f) self-efficacy, School level factors are those influences, which are external to the teacher but affect the school's culture as a learning organization. They include: (a) previous educational policies; (b) participation in a collaborative learning group; (c) building level and district administrative expectations and support; 
and (d) organizational features which enhance time for teachers to learn and collaborate.

\section{Teacher Influences on Changes in}

\section{Classroom Practice}

Previous experience. Previous experience as a student and as a teacher creates a mental model of teaching and learning. While most teachers do not use the term epiștemology, they do have a theory in use (Senge, 1990) of learning and how students should be taught. Teachers' prior learning, beliefs, and attitudes are an essential ingredient in the process of change. In a study of the effect of student performance assessments on elementary teachers' knowledge and practice of reading and writing, Gearhart et al. (1994) suggested that the slow pace of change may reflect beliefs developed during teachers' "apprenticeships of observation" (Lortie, cited in Gearhart et al.) as students themselves, compounded by their own "apprenticeships of participation" in teaching. Darling-Hammond (1990, pp. 342-343) pointed out that transformation of beliefs, knowledge, and actions requires more "experiential confrontation and exploration" than most current programs envision for students or provide time for teachers. Shepard (1995) also found that fundamental and conceptual change occurs slowly. "Changes in student understandings must necessarily 
come last, after changes in teacher thinking and changes in instruction" (p. 26).

Flexer, Cumbo, Borko, Mayfield and Marion (1995) reported similar results in a study of changes in elementary teachers' math instruction. They found that changes in practice that fit the teachers' knowledge and beliefs were assimilated, while changes that didn't fit were modified to accommodate the teachers' beliefs. In a more extensive study of the relationship between state curriculum policy and classroom practice in three states, Grant, Peterson and ShojgreenDowner (1996) confirmed the importance of teachers' prior knowledge and experience. In his review of the extensive research into classroom effects of implementing the California Frameworks, Knapp (1997) found that "teachers' capacity to change their ways of teaching was shaped by their limited grasp of and prior experience with the kind of teaching the frameworks required" (p. 241).

Teachers' pedagogical and content knowledge. Closely associated with teachers' previous experience is their knowledge of standards-based curriculum and teaching strategies, i.e. content and pedagogical knowledge. Cohen and Spillane (1992) argue that standards-based reforms require teachers to shed established modes of understanding and adopt constructivist visions of knowledge. Such reforms propose that students become active, engaged, collaborative 
learners and thus, teachers must learn to become facilitators of student learning. Peterson (1990) reported that a significant barrier for elementary teachers was their lack of knowledge of and confidence in their ability to teach math as the California math frameworks proposed.

Baron (1991) and Stiggins (1991) believe that in order for students to learn in different ways, teachers must learn to teach in different ways. Darling-Hammond (1997) contends that in order to learn to teach differently, teacher participation in developing assessments is essential, and assessments should be used to help teachers understand student learning.

Peterson, McCarthey, and Elmore (1996) analyzed cases of restructuring in three elementary schools and found that "changing practice is primarily a problem of learning for teachers, not a problem of school-based organization" (p. 148). The researchers described one teacher as having a great deal of subject matter and pedagogical knowledge and knowledge of learners. The teacher saw herself as a learner who was continuing to develop her own knowledge in the same way the students were developing their knowledge. They concluded,

Teaching and learning occur mainly as a function of teachers' beliefs, understandings, and behaviors in the context of specific problems in the classroom. Teachers who see themselves as learners worked continuously to develop new understandings and improve their practices. (p. 147) 
Aschbacher (1993) also found that a significant issue was the need for ongoing support and training in basic cognitive learning theory and the need for time to learn about and practice new assessments in social studies and math. Watson (cited in Aschbacher, 1993)) reported that middle school math teachers needed to return to the student role in order to understand and construct for themselves a new philosophy of teaching and learning math and to learn new instructional strategies. Grant et al. (1996) also confirmed the importance of ongoing professional development with time to reflect on the new pedagogy and the need to consider oneself as a learner, as opposed to one shot inservice programs that merely demonstrate new curriculum and instructional strategies.

Some researchers have documented an interactive process between teacher knowledge, change in classroom practice, and student learning. In their study of first grade math teachers, Fennema, Franke, Carpenter and Carey (1993) found that teachers who understood childrens' thinking and held beliefs congruent with a cognitive perspective taught math differently (and had students who learned more math) than teachers with less knowledge and different beliefs.

"Research based knowledge about children's thinking enabled teachers to structure instruction so children could learn more" (p. 579). The 
process of teacher change and improved student outcomes was interactive. When children began to show increased learning, teachers continued to implement new methods that resulted in improved learning. Flexer, Cumbo, et al. (1995) also found that changes in elementary math teachers' practice came first, and after students learned more math as a result of the changed practice, then teachers changed their beliefs about how to teach math. Positive feedback from students encouraged teachers to make more changes.

The influence of teachers' prior knowledge on their ability to change classroom practice may be explained by cognitive/constructivist principles. According to Weick (1979), schema represent internally organized knowledge which people use to understand their environment and achieve their goals. According to Hoy and Miskel (1996), schema "reflect the active construction of reality" (p. 93) through learning and integrating new information with prior knowledge. Experienced teachers have a large store of task-relevant knowledge and a wellorganized long-term memory (schema) which can be an efficient and effective guide for perceiving, interpreting, and responding to familiar situations. However, schema are also powerful perceptual screens which can cause problems in new situations requiring creative, flexible thinking. In the context of educational reform that calls for changes in 
teaching and learning, the schema of veteran teachers and administrators can be barriers to change.

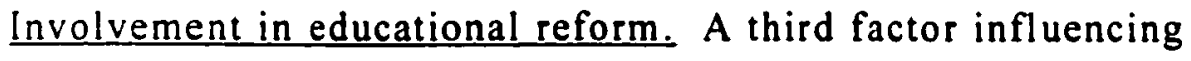
teachers to change classroom practice is their active involvement in educational reform, such as designing and evaluating standards-based curriculum and assessments. Cohen $(1990$, p. 326) states that teachers are the chief agents for changing educational practices and implementing policies. The new standards and assessment policies seek great changes in knowledge, learning, and teaching which will not occur unless teachers take an active part and have the resources to change. In their study of 1750 math teachers at grades 4,8 , and 10 , Wiley and Yoon (1996) found a positive relationship between participation in the California math frameworks, teacher implementation of the practices, and higher student scores on the CLAS math test.

Hasseler and Collins (1993) found engaging teachers in structured collaborative reflection is a powerful change strategy. Specifically, teacher involvement in professional standards development (e.g., authoring standards, serving as field test subjects, designing curriculum, translating content standards into classroom lessons, initiating standards-setting projects, monitoring and assessing 
standards-setting efforts) resulted in changes in practice (Abdal-Haqq, 1995; Almasi, Afflerbach, Guthrie \& Schafer, 1995).

Chrispeels (1997) also documented the impact of teacher involvement in reform on long-term change in instructional strategies. She found that even after the California governor vetoed the California Learning Assessment System (CLAS), many districts continued to implement performance assessment. Chrispeels offered three explanations: (a) teacher involvement in school improvement programs prior to veto of CLAS; (b) teacher participation in subject-matter projects as participants and trainers; (c) teacher efforts in piloting and scoring CLAS instruments, "which many teachers regarded as the best professional development they had ever experienced" (p. 463). As administrators and teachers worked to implement the policies they were engaged in joint construction of the policies through their own interpretations and sense-making. This interactive process supported continued implementation of performance assessments even after the state officially withdrew its support.

Sense of empowerment. A fourth factor is teachers' involvement in decision-making connected to instruction and student learning and teachers' sense of empowerment (Taylor \& Bogotch, 1994). Empowerment is the degree to which teachers believe they can influence instructional policies and practices. In many cases 
empowerment is a result of teachers' participative decision-making within the school and/or district. In their longitudinal study of instructional outcomes of participative decision-making in a K-8 district, Smylie, Lazarus and Brownlee-Conyers (1996) found: (a) teachers perceived an increase in accountability and learning opportunities and improvements in instruction and student learning, and (b) in some schools students' test scores increased or remained the same. The researchers concluded that accountability and organizational learning opportunities may be the most important factors in the relationships between participative decision-making and instructional outcomes.

Participative decision-making may lead to a sense of empowerment which also influences changes in classroom practice. Marks and Louis (1997) regard empowerment of teachers as an essential condition for building a school culture focused on teaching and learning--not just a participatory governance structure which may focus on trivial matters or create conflict. "While teacher empowerment is not a sufficient condition for improving student academic performance we believe it is a necessary one" (p. 248). For teachers to be able to function in a professional community, they must be able to influence policies and practices pertaining to the instructional mission. Marks and Louis found that teacher empowerment results in greater school- 
wide attention to instruction and student learning. They found that teacher empowerment, teacher acknowledgment of their collective responsibility for student learning, and "authentic pedagogy"

(Newmann et al., 1995) all indirectly contributed to achievement for all students. Marks and Louis (1997, p. 266) concluded that empowerment works to the academic advantage of students only when it supports teachers in changing instruction to be more involving and demanding of students.

My study of the Camas, WA school district's educational reform efforts (Thieman, 1997) supports the importance of participation and empowerment. I found significant correlations between the level of secondary teachers' involvement in educational reform and selfreported changes in classroom practice and between secondary teachers' involvement in decision-making (school governance/ empowerment) and self-reported changes in classroom practice and student learning.

Personal efficacy. A fifth internal factor influencing teachers' will and capacity to change classroom practice is self-efficacy (i.e., the teachers' belief they can influence student learning). Metacognition is a powerful tool humans use to understand and control their own thinking (Gardner, 1987). This reflective self-consciousness (Bandura, 1986) enables people to analyze their experiences and think about their 
own thinking. Bandura defines self-efficacy as an individual's judgment about future ability to carry out an action needed to achieve a certain level of performance. The stronger the self efficacy, the greater the individual's efforts.

Hoy and Miskel (1996) cite research that positively correlates self-efficacy with teacher adoption of innovations and higher levels of student academic achievement. Because self-efficacy is based on experiences, it is dynamic and can change over time. This theory is useful for administrators who wish to facilitate positive growth for teachers. For example, by modeling higher expectations, using persuasion. and providing staff opportunities to master new ways of teaching as well as reducing their anxiety and stress, administrators can support changes in teaching and learning.

In his review of Berman and McLaughlin's 1978 study of federally funded education reform for the RAND Corporation, Sarason (1996) supports self-efficacy theory.

Teachers' sense of efficacy--a belief that the teacher can help even the most difficult or unmotivated students.. showed strong positive effects on all outcomes [including implementation of innovations and gains in student achievement]. (p.77)

Vitali (1994) found significant correlations between positive teacher efficacy and use of performance-based assessments in a study of 117 teachers implementing the Kentucky Educational Reform Act (KERA). 
He concludes, "A positive sense of teacher efficacy is correlated with the likelihood that teachers will adopt and teach toward innovations" (p. 17) especially in elementary grades where teachers instruct smaller numbers of students, know them better, and have a higher sense of efficacy and also tend to use more performance assessments. Kelley and Protsik (1997) reached a similar conclusion in their study of six exemplary elementary and middle schools who were implementing KERA. They found, teachers in the schools that had made the largest changes [in classroom practice] believed that their behaviors could positively and sufficiently influence student performance on KIRIS [Kentucky Instructional Results Information System] (p. 499).

The research cited above documents the importance of teacher factors which are powerful influences on teachers' capacity and will to change their classroom practice. These influences (previous experience, pedagogical and content knowledge, involvement, empowerment, and self-efficacy) are internal to the teacher as a professional and learner. Fullan (1993) stresses the importance of the school's culture in helping teachers view themselves as learners. Trust, mutual respect, open communication, inquiry, experimentation, and collaboration are essential for teacher learning. 
School Level Influences on Changes

in Classroom Practice

Fullan (1993) argues that individual and organizational change occur simultaneously. Thus, there are also important school level factors which are external to the teacher and which influence the school culture in which teachers operate. These school level factors also influence the teachers' will and capacity to change classroom practice. The following influences will be reviewed below: (a) previous educational policies, (b) participation in a collaborative learning group, (c) building level and district administrative expectations and support, and (d) organizational features that enhance time for teachers to learn and collaborate.

Previous educational policies. Previous educational policy is an important factor influencing teachers' responses to standards-based reform. Previous policies may include mandated curriculum, required teaching strategies, and statewide testing. Darling-Hammond (1990) asserts that new policies do not exist in a vacuum; rather, they are embedded in the context of previous educational policies that continue to impact implementation of new policies. Aschbacher (1993) concurs. Many teachers are reluctant to change and implement new assessment policies because they recognize an implied paradigm shift. 
Organizational practices in many schools currently work against teaching and evaluating students' conceptual understanding.

Elmore et al. (1996) explain that teachers may adopt materials and technology initiated by a new policy without any real understanding of the changes in beliefs that the policy intends. Research by Cohen and Ball (1990b) illustrate the confusion that results when teachers attempt to implement two contradictory policies. The California math frameworks were introduced into a policy environment, which had emphasized direct instruction, mastery learning, and convergent thinking. Yet the California teachers in Cohen and Ball's study did not see the contradiction between direct instruction and the constructivist emphasis of the new math frameworks. They implemented the new frameworks in the context of the old policy. "They poured new wine into old bottles, resulting in a blend of direct instruction and teaching for understanding" (p. 334).

A similar juxtaposition of two contradictory testing policies is also evident in Washington where teachers are expected to prepare students for two very different testing modalities. Students at the third, fifth, and eighth grade level take the norm-referenced, multiple-choice objective Iowa Test of Basic Skills, and students at the fourth, seventh, and tenth grade level take the WASL which is a criterion-referenced, 
standards-based test of students' conceptual knowledge and problemsolving abilities.

\section{Participation in a collaborative learning group.. Knapp (1997)}

emphasized the importance of another external influence: the teacher's professional corimmunity/colleagues.

The content and extent of each teacher's learning and capacity to introduce it in the classroom were dependent on the immediate circumstances of the professional assignment, collegial peer group, and opportunities for learning. (pp. 242-243)

Flexer and Gerstner (1995) reported that teachers experienced conflicts and difficulty in reconciling the implementation of the California frameworks with other teachers' expectations, parent demands, school goals, and their own beliefs.

In a study of "high capacity" schools implementing the California frameworks, O'Day (1995) cited the collegial nature of such schools which influenced changes in classroom practice. The schools were actively engaged in restructuring. The teachers valued collaboration within school communities of learning. A critical mass of teachers and the school culture were committed to change.

In a synthesis of the research into conditions fostering organizational learning in fourteen elementary and secondary Canadian schools, Leithwood, Leonard and Sharrott (1998) confirm the importance of collegiality. "Norms of mutual support among teachers, 
respect for colleagues' ideas, and a willingness to take risks in attempting new practices were associated by the teachers with their own learning" (p. 262).

Peterson et al. (1996) studied the effects of restructuring on changes in elementary teachers' classroom practice and found that collegiality and organizational learning were more important for changes in classroom practice than any "restructuring" by itself.

Teachers who see themselves as learners work continuously to develop new understandings and improve their practices.... Successful relations occur among school structure, teaching practice, and student learning in schools where...teachers share a common point of view about their purpose and principles of good practice. (pp. 148-149)

Inspired and supported by colleagues, the teachers tried out new ideas and practices within the context of their own classrooms.

Peterson et al. (1996) also noted the importance of supported encounters with discrepant information. They described the critical role of a colleague who gave one teacher substantive feedback about her teaching of writing skills. The colleague served as a facilitator of the teacher's learning and helped her examine her practice in light of research from the disciplinary community, i.e., National Writing Project.

The question remains how to build a professional community. Louis et al. (1996) studied the factors which led to professional 
community in 24 restructuring schools. They defined professional community as movement toward five elements of practice: shared values, focus on student learning, collaboration, deprivatized practice, and reflective dialogue. These five elements are very similar to Senge's and Fullan's principles. Louis also emphasized the importance of collaborative decision-making.

...formally scheduled time is necessary to implement significant change agendas and to maintain innovation.... Professional communities are more likely to thrive in schools with flexible governance arrangements, such as site-based management and school-based decision-making, rather than bureaucratic centralization. (760-762)

Louis et al (1996) described professional development which creates opportunities to support individual growth and develop collective knowledge, e.g., collaborative peer coaching and coordinated school-focused in-service opportunities. Overall they found that certain structural conditions (but not school size) and human and social resources also facilitated professional community.

Active involvement in governance may be more important in the traditional comprehensive high school. Governance meetings provide a vehicle for raising key issues but they do not provide the opportunity for reflective dialogue.... Overall the evidence points to a reasonable assumption that teachers' increased sense of mastery and control over student learning is likely to be either a cause or consequence of improvements in student performance. (pp. 784-786) 
Peterson et al. (1996) describe the various ways teachers supported their own learning at one of the elementary schools they studied. Teachers learned by talking with colleagues, participating in study groups and literature groups, attending professional development workshops and retreats, reflecting on their own practices, and from their writing (personal journals and formal articles), and from their students.

In contrast to the studies which emphasize the importance of collegiality in influencing changes in classroom practice, Prestine and McGreal (1997) found that a significant barrier to collegiality is teachers' reluctance to infringe on other educators' classrooms and practices. "While changes in core technology may be decided on by a collaborative agreement at the school level, they must still be implemented at the individual teacher level" (p. 380). The researchers found that at one school, the desire to maintain social relationships, established work norms and traditional organizational arrangements sabotaged efforts to influence individual teachers' classroom practice. Barth (1990) describes such staff behavior as congeniality, not collegiality. Prestine and McGreal cite Little's (1990) warning that "Teachers may show little inclination to engage with peers around matters of curriculum and instruction if doing so jeopardizes selfesteem and professional standing" (p. 516). One counterweight to the 
"inherited traditions of non-interference and equal status" (Little, 1990, p. 512) may be a proactive stance by school administrators.

\section{Building level and district administrative leadership and support.}

A third external factor which influences teachers to change classroom practice is building level and district administrative leadership and support. Senge (1990) articulates the leader's task as designing the learning process, listening carefully to others, and fostering learning through mentoring and coaching. Researchers (Aschbacher, 1993; Berman \& McLaughlin, 1978; Spillane, 1998) have concluded that district administrative support for reform is a necessary condition for local implementation. Knapp (1997) cited the Educational Policy and Practice Study (EPPS) of implementation of the California frameworks. Depth and range of policy impacts on teachers were dependent on the way the policy influenced and was influenced by those who lie between the policy and classroom practice, e.g., district personnel. Knapp cited Peterson, Prawatt and Grant (1994) who found that in one district the central office staff responded to educational reform as an opportunity to learn and "strove to make sense of and enact the pedagogical reforms in their own policies and practices" (p. 33). The district administrator in charge of staff development recognized that teachers needed opportunities for more individual exploration and problem solving, just as their students did, and changed in-service workshops accordingly. 
Knapp (1997) goes on to say, "Where policy makers or other

intermediaries became or remained open to new learning implied by the reform, the reform was likely to make progress" (pp. 243-244).

Teachers in the Leithwood et al. (1998) study identified aspects of supportive districts which facilitated organizational learning: (a) a district vision that acknowledges the need for continuous professional growth; (b) a collaborative district culture that supports a sense of community among schools and between the district and schools; (c) a district support structure that promotes staff participation in district and school-level decisions; (d) district policies and resources that provide for common planning and professional development; and (e) access to technical assistance from consultants. lead teachers, and classroom visitations.

Within the district, the role of the principal in supporting changes in classroom practice is vitally important. Sarason's review (1996) of Berman and McLaughlin supports the administrator's role in effecting change.

The quality of working relationships among teachers, the active support of principals, and the effectiveness of project directors powerfully affected continued implementation of the education reforms...The principal is the 'gatekeeper of change (p. 77).

Reitzug (1994) defines empowering principal behavior as support, facilitation, and possibility, i.e. making it possible to actualize 
teachers' ideas. In their study of the impact of the Maryland School Performance Assessment Program, Almasi et al. (1995) found that "Principals who were actively involved with instructional changes created environments in which common goals were established and creativity and risk-taking were encouraged" (p. 37). Smylie (1992) also cited the importance of the principal-teacher working relationship in influencing teacher willingness to participate in decision-making.

Teachers in the Leithwood et al. (1998) study identified "transformational leadership" practices that facilitated organizational learning such as: providing individualized support and intellectual stimulation; conveying high performance expectations and encouraging teachers to be creative and try new strategies; and fostering a collaborative culture with participative decision-making.

Organizational features that enhance time for teachers to learn and collaborate. An obvious, but often underestimated, influence on teachers' ability to change classroom practice is time for learning, planning, practicing, and revising as well as collaborating with colleagues. Prestine and McGreal (1997) assert:

The issue of time may be the most significant obstacle confronting attempts at implementing changes in core technology. Learning new teaching techniques, pulling together new materials, trying out new approaches--all take a heavy toll on teachers' time, energies, and enthusiasm. (p. 384) 
Studies of the restructuring movement and shared decision-making in the earlier 90 's attest to the critical importance of the lack of time for collaboration and professional development (Donahoe, 1993; Waters \& Castle, 1993).

Standards-based reform implies complex epistemological and pedagogical changes. A significant barrier is the lack of time to reflect on personal teaching style, to deeply analyze the assumptions underlying the constructivist instructional practices of the reforms, and the time to practice new instructional strategies and assessments. (Aschbacher. 1993; Baker \& Linn, 1994; Gearhart et al.,1994).

School staff have sought to restructure the school day in order to gain time for teacher planning and collaboration. At the elementary level, some schools have a weekly early release day which gives teachers additional planning time without students present. Other schools have alternate, community-based programs for students one afternoon a week, staffed by parents and community volunteers so that teachers can meet for professional development. At the secondary level, some schools have moved to block scheduling with periods extending from 80 to 120 minutes or longer which results in longer preparation/planning time for teachers. However, restructuring the school day by itself does not necessarily result in more staff collaboration, unless that expectation is articulated and shared by staff. 
A more common approach is to pay teachers for after school or evening meetings or to hire substitutes so that teachers can meet during their teaching day. However, since teachers already have a full-time job, paying them to meet after school extends their work day and often conflicts with other professional or family responsibilities. On the other hand, many teachers find that preparing for a substitute is an additional burden, and they are reluctant to be away from their students for any extended period of time. Thus even if the school has the money to buy time for collaboration, professional development, or planning, time remains problematic.

The research cited above documents the importance of school level factors which are powerful influences on teachers' capacity and will to change their classroom practice. These influences (previous educational policies, participation in a collaborative learning group, building level and district administrative expectations and support, and organizational features which enhance time) are external to the teacher but affect the school's culture as a learning organization. The studies in this literature review suggest an interactive process between the teacher factors and the school level factors. Both sets of factors are needed in a school-based learning community, which is responding to standards-based reform with the goals of changing classroom practice and improving student learning. 


\title{
Conceptual Framework
}

\author{
Research Question 5: How does the study's conceptual \\ framework integrate organizational learning theory, \\ constructivism, and the research-based factors which influence \\ changes in classroom practice?)
}

This research study was designed to examine the fundamental assumption underlying the Washington Education Reform Act (1993): If the state raises standards and requires standards-based assessments, teachers will change classroom practice, and students will demonstrate academic achievement. The legislative model assumes that both raising standards and requiring assessments are necessary for teachers to change classroom practice. A major premise of HBI209 is that standards are needed to provide a common understanding of what students should know and being able to do; assessments are necessary to provide accountability for teachers and students. However, the research cited in this literature review indicates that changes in classroom practice and student learning will not occur simply because of legislative policy. The literature indicates that professional and organizational learning is needed to change classroom practice. The conceptual framework, Figure 2 below, shows the connection between 
standards-based reform policy, teachers' learning, and changes in classroom practice.

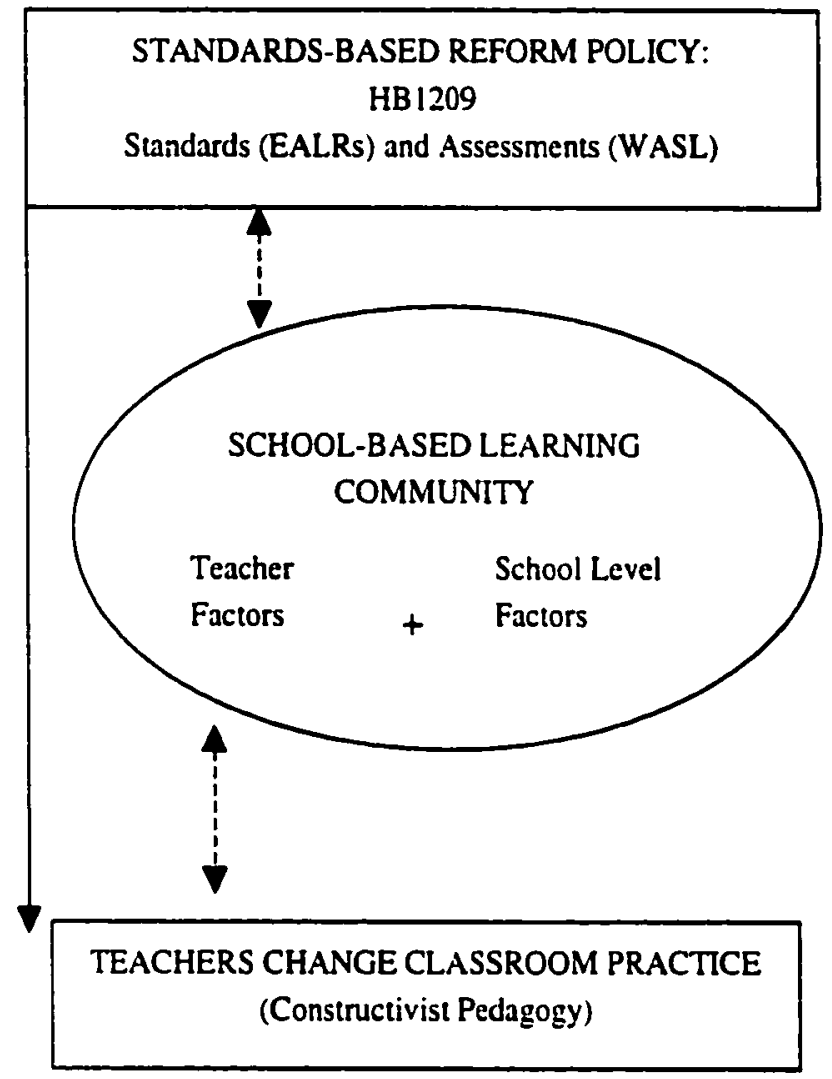

Figure 2. Model of the connection between policy, school-based learning community, and changes in classroom practice.

In the conceptual framework above, the initial legislative model is indicated by rectangular boxes and solid arrows. $\square \rightarrow \rightarrow$ It is assumed that the legislative policy (HB 1209) will result in changes in classroom practice which will in turn lead to improved student performance on the state assessments (WASL). The model in Figure 2 
shows that a school-based learning community, is needed to mediate between policy and practice. This learning community is indicated by an oval and dotted arrows. $\bigcirc \rightarrow$ Within the school-based learning community are both teacher factors and school level factors which influence changes in classroom practice.

Teacher factors are those influences which are internal to the teacher as a learner. They include: (a) present teaching experience (academic area, grade, position); (b) previous teaching experience; (c) pedagogical knowledge needed to implement the reform. (d) involvement in educational reform; (e) sense of empowerment, and (f) self-efficacy. School level factors are those influences which are external to the teacher but affect the school's culture as a learning organization. They include: (a) previous educational policies, (b) participation in a collaborative learning group, (c) building level and district administrative expectations support, and (d) organizational features that enhance time for teachers to learn and collaborate.

The research model also indicates that changes in classroom practice may include a constructivist approach to learning. The dotted two-way arrows indicate the interaction between the standards-based reform policy and a school-based learning community and between the learning community and changes in classroom practice. 
This model deliberately focuses on the connection between policy, professional and organizational learning, and classroom practice. It does not include the myriad of other factors which influence changes in practice and learning such as student, parent, and community characteristics and values. Nor does it include other influences on the teachers' will and capacity to change such as professional educational associations or the district negotiated agreement. Hoy and Miskel (1996) and Sarason (1996) view the school as an open, dynamic system and emphasize the importance of the system's external environment, e.g., state legislature, community and parent attitudes, and socio-economic factors). Senge (1990) and Fullan (1993) stress the importance of the system's internal environment, represented by the school as a learning community. Systemic educational reform involves changing classroom practice within the constraints of both the external and internal environments. However, the focus of this dissertation was on the internal environment of the teachers within the school. 
Summary of Literature Review and Rationale for Study

Research Question 6: What areas need further study and thus form the rationale for this dissertation?

Common themes emerge from the research studies cited in this literature review. Systemic standards-based reform requires complex changes which will not occur simply because of legislative policy. In order for teachers to develop the will and capacity to change their classroom practice they must reflect on their own epistemological understanding of what knowledge is and how students learn. They must have the opportunity to develop and experience the new curricula and teaching practices embedded in HB1209 and make sense of the reforms. Their previous educational experiences, pedagogical and content knowledge will influence how they respond to the challenges of standards-based reform. Teachers' involvement in educational reform activities, their sense of empowerment and self-efficacy will contribute to their ability and willingness to change. Furthermore, previous educational policies, the opportunity and time to collaborate with colleagues, and administrative leadership and support will also influence their ability to change. The principles of organizational learning and constructivism provide a framework for understanding how 
these factors work together to support systemic standards-based reform.

Darling-Hammond (1997) argues that prior reform efforts have not been supported by the ongoing professional development needed to prepare teachers to teach in the complex ways that learner-centered practice demands. At present, we lack a clear understanding of the contextual influences on educational change and the need to document how professional and organizational learning and individual teacher will and capacity to change develop and how the two are related (Everson, 1995; Knapp, 1997). The assumption that teachers will learn new ways of teaching by being exposed to them and by working in schools that promote collegial interaction is too simplistic because it fails to consider that teacher acquisition of new knowledge and skills is very complex (Peterson et al., 1996). It is not just a new way of teaching, but a new way of thinking about knowledge. As Fullan (1993) suggests, to restructure is to reculture.

In the present environment of standards-based reform we need to consider the structures which support such learning. What are the contextual influences on educational change and improvements in classroom practice? How is teachers' learning transferred into consistent, sustained classroom practice? What is the nature of the changes in classroom practice in response to standards-based reform? Both theory and research cited in this literature review support my 
hypothesis that teacher involvement in a supportive community of learning is essential to changing classroom practice.

Much of the research to date on the influence of standards-based educational reform on changes in classroom practice has occurred in California and Kentucky, with some research on the influence of standards-based assessments on classroom practice in Colorado, Michigan, Maryland, and Vermont. The majority of the research has focused on three subject areas: mathematics, language arts (reading and writing), and science. Furthermore, the majority of case studies of change in classroom practice have focused on elementary teachers with fewer studies of middle school or high school.

This research examined the Washington education reform policy and the factors which led to changes in classroom practice in three middle schools currently implementing HB1209. My focus on secondary, rather than elementary, schools was based on the paucity of research at this level. Furthermore, I chose to focus on middle schools, rather than high schools, due to the status of HB1209's implementation. State assessment data on changes in student learning in math and language arts became available for seventh grade performance during the summer of 1999. While the schools varied in their response to the Washington Education Reform Act (1993), each of them had received 
their spring, 1998 baseline test scores and were working towards improving those scores on the spring, 1999 state assessment.

Very few studies have looked at the connection between standards-based reform policy, professional and organizational learning, and changes in classroom practice. As the pressure for teacher and principal accountability increases and the assessment stakes get higher, research which explores these connections will be vital. My study helped clarify how organizational learning and individual teacher will and capacity to change develop and how the two are related. The study also examined the ways in which middle school teachers' learning is transferred into consistent, sustained classroom practice. 


\section{CHAPTER III}

\section{METHODOLOGY AND PROCEDURES}

This chapter describes the research design and instrumentation used in this study. The purpose of the study was to examine the fundamental assumption underlying the Washington Education Reform Act (HB 1209): If the state raises standards and requires performance assessments, teachers will change classroom practice, and students will demonstrate improved academic achievement. Despite the assumptions of HB 1209, the premise of a causal link between (a) reform policy, (b) changing classroom practice, and (c) improving student learning has not been well documented. Because implementation of HB1209 is still in its early stages, the research focused on factors which influence changes in classroom practice in response to standards-based reform.

The first section of this chapter centers on research design and research questions. The next section on the context of the study explains the selection of the case study sites. The third section describes the setting, demographic characteristics, and organizational features of each middle school. The fourth section focuses on case 
study data collection and includes the research steps, data collection instruments, and research timeline. The fifth section specifies data analy sis procedures, including embedded units of analy sis and analy tical tools. The chapter concludes with the strengths and limitations of the study.

\section{Research Questions and Research Design}

Five questions framed the research for this study.

1. What is the school faculties' understanding of the purpose of HB1209 and their familiarity with the Essential Academic Learning Requirements and the Washington Assessment of Student Learning in language arts and mathematics?

2. What is the school faculties' overall level of involvement in educational reform and in what types of educational reform are they involved?

3. To what degree and in what ways do teachers change classroom practice in response to HB 1209 ?

4. How are the following teacher factors related to staff members' familiarity with HB1209, their involvement in educational reform, and changes in classroom practice: (a) present teaching experience 
(academic area, grade, position); (b) previous teaching experience; (c) pedagogical knowledge; (d) involvement in educational reform; (e) sense of empowerment and (f) self-efficacy?

5. How are the following schoolevel factors related to staff members' familiarity with HB1209, their involvement in educational reform, and changes in classroom practice: (a) previous educational policies; (b) participation in a collaborative learning group; (c) building level and district administrative expectations and support; and (d) organizational features that enhance time for teachers to learn and collaborate?

The research explored whether and how factors associated with a school-based learning community influence middle school teachers to change classroom practice. It involved explanatory case studies of three middle schools, which were identified as actively responding to the requirements of HB1209, based on certain selection criteria (below).

Yin (1994) defines a case study as an empirical inquiry that investigates a contemporary phenomenon within its real life context; when the boundaries between phenomenon and context are not clearly evident; and in which multiple sources of evidence are used. This study focused on a contemporary issue, implementation of standards-based 
reform policy in Washington, within the context of three middle schools which are responding to HB 1209

The decision to seek nominations of middle schools which were actively responding to HB1209 (rather than choosing schools which represented a diversity of response to HB1209) was based on the case study methodology of leading researchers in the field of systemic reform and organizational learning (Elmore et al., 1996; Newmann et al., 1995; Peterson et al., 1996). For example, in their analysis of the relationship between school restructuring and the development of constructivist teaching practices, Elmore et al. (1996) chose the best cases to maximize the likelihood they would find significant structural changes and shanges in teaching practice.

Decisions about research methodology were also informed by previous case studies of the relationship between organizational learning and classroom practice (Elmore et al., 1996; Louis et al., 1996, 1998; Peterson et al., 1996, ) as well as case study protocol (Yin, 1994). Both the Elmore and Louis studies included multiple sources of evidence: interviews with administrators and staff, surveys, classroom observations, documentary evidence, and observation of school-wide 
and department meetings. My study included the following research activities between January, 1999 and February, 2000.

- interviews with district and building administrators $(\mathrm{N}=8)$

- surveys completed by instructional staff at each middle school $(N=157)$

- interviews with three language arts teachers at each middle school who volunteered to participate in interviews/classroom observations after completing the survey $(\mathrm{N}=9)$

- five classroom observations of the interviewed teachers at each school $(N=45)$

- review of district/building documentation regarding response to $\mathrm{HB} 1209$

- observation of faculty meetings, site council, team meetings, and inservices as appropriate at each middle school $(N=36)$

- focus group interviews with grade level teams at each middle school $(\mathrm{N}=12)$

A separate case study database was maintained for each school with careful attention to maintaining a clear chain of evidence. 
Context of the Study and Selection of Sites

Three Washington middle schools were selected for this study. The sites were selected based on recommendations from knowledgeable educators in Washington, including representatives of the Commission on Student Learning, the Office of the Superintendent of Public Instruction, the Association of Washingt on School Principals, the Northwest Regional Educational Lab, and Washington superintendents. Criteria for choosing the three middle schools included involvement in at least feur of the seven activities:

- creating a vision of expected classroom practices and student learning

- creating professional development/collaborative learning groups

- involving instructional staff in site-based decision-making.

- aligning curriculum to match state EALRs /assessments

- developing/articulating student performance standards

- changing classroom practice to a more constructivist approach

- using classroom and state assessments to inform instructional practice 
Based on the recommendations of the initial informants noted above, a letter was sent to the district superintendent, requesting approval to conduct the research and asking for assistance in contacting the building principal. After the building principal expressed willingness to consider participation in the study, I contacted the administrator by telephone and letter, sent a copy of the dissertation abstract and prospectus, and requested an appointment. The characteristics of each of the case study sites are detailed next.

\section{Case Study Sites}

Three Washingt on middle schools were selected for this study. While each school and district was actively responding to HBI209, each school differed in the degree of staff familiarity with HB1209, staff involvement in educational reform, and changes in classroom practice. All three schools differed in community size and location and the socioeconomic background of their students.

Laurel Middle School is located in a small district within a large urban area of the state with a highly diverse student population.

Lighthouse Middle School is located in a medium sized suburban district with a less diverse student population. Ponderosa Middle School is 
located in a small rural district with a highly diverse student

population. Table 1 below summarizes the key features of each school.

\section{Table 1}

Comparison of Demographic Data for Three Middle Schools

\begin{tabular}{|l|l|l|l|}
\hline & Laurel Middle & Lighthouse Middle & Ponderosa Middle \\
\hline $\begin{array}{l}\text { Enrollment Data } \\
\text { Student } \\
\text { Population }\end{array}$ & Urban & Suburban & Rural \\
\hline Ethnic Minority & $52 \%$ & 1040 & 704 \\
\hline $\begin{array}{l}\text { Free \& reduced } \\
\text { lunch }\end{array}$ & $58 \%$ & $15 \%$ & $88 \%$ \\
\hline $\begin{array}{l}\text { E.S.O.L. } \\
\text { Program }\end{array}$ & $17 \%$ & $30 \%$ & $85 \%$ \\
\hline $\begin{array}{l}\text { Special } \\
\text { Education IEP }\end{array}$ & $10 \%$ & 0 & $26 \%$ \\
\hline Chapter I & $\begin{array}{l}\text { School-wide } \\
\text { program }\end{array}$ & $11 \%$ & $10 \%$ \\
\hline $\begin{array}{l}\text { School Reform } \\
\text { Plan }\end{array}$ & $\begin{array}{l}\text { Accclerated } \\
\text { Schools Project }\end{array}$ & $\begin{array}{l}\text { Personalized } \\
\text { Education } \\
\text { (District) }\end{array}$ & $\begin{array}{l}\text { Expeditionary } \\
\text { Learning Outward } \\
\text { Bound }\end{array}$ \\
\hline
\end{tabular}

* Statistics are for the 1998-1999 school year from district documents

\section{Laurel Middle School}

The school is located in a small district of approximately 2500 students within a large metropolitan area. While the district's tax base is supported by manufacturing, retail, and wholesale/utilities businesses, low family income and a high level of student transition are challenges. Fifty-eight percent of the middle school students qualify for free and reduced breakfast/lunch, and consequently the school is 
designated as a school-wide Chapter I program. Laurel Middle School has a majority minority student population with over $52 \%$ of its students from ethnic minority populations with approximately equal numbers of Black (113), A sian (102), and Hispanic (90) students. Moreover, $17 \%$ of its students are enrolled in English for Speakers of Other Languages (ESOL), speaking over thirty different home languages. Many students are newly arrived immigrants from war-torn countries. The dramatic increases in student diversity have occurred within the last decade; in 1990 the district student population was $27 \%$ ethnic minorities; ten years later the district student enrollment is $56 \%$ ethnic minorities.

Laurel Middle School staff members are organized into three grade-level teams (sixth, seventh, and eighth) and an electives team. During the 1998-1999 school year, students attended eight, 40 minute periods each day. Each teacher taught six periods and had one period for individual planning and one period for team planning each day. The principal changed the master schedule for the $1999-2000$ school year to increase the focus on core academic subjects, provide time for schoolwide reading and writing activities each week, and allow time for department as well as grade level team planning. Students now attend 
four 80-minute blocks each day for language arts/social studies; math; health/fitness/science (alternating days); and electives (alternating days). They also participate in a twenty-minute reading/writing skill building activity in their first period class three days a week.

The 1998-1999 school year was the Laurel Middle School principal's first year in the district, having taught in schools ranging from kindergarten to post-secondary $(K-14)$ and served as a middle and high school administrator for thirty years. Two of her goals were to provide instructional leadership and change the school structure and schedule to focus on core academic skills, and support implementation of the Accelerated Schools Project (ASP).

What we have here is a junior high curriculum with a middle school philosophy.... [In terms of staff development, the teachers] are tabla rasa, and they are very willing to admit that. So in the core curricular areas teachers are saying, I want help, I want to know teaching strategies. ... I want to transform the culture from "This too shall pass. What do you expect me to do with these kids?" to everybody can learn and at high standards. (U: interview, 1/14/99)

In the 1997-1998 school year the Laurel superintendent directed his administrative team to investigate and choose a comprehensive school design model. Last year the middle school was awarded a threey ear state Comprehensive School Reform Demonstration (CSRD) grant 
for a whole school educational reform plan, Accelerated Learning Project. According to the school's application for the state grant, ASP was chosen because:

The goals of this model are to hold high expectations for every student and provide each student with powerful learning experiences that stress complex and engaging activities, relevant content and active discovery of curriculum objectives. The goal of Accelerated Schools is to improve student achievement by providing powerful learning opportunities to all students. Powerful learning is based on five student learning components: continuous, inclusive, learner-centered, interactive, and authentic (Comprehensive School Reform Demonstration Program application for Laurel Middle School).

The Accelerated Schools Project provides a training and coaching model to facilitate implementation of school-wide change. The initial training was provided during the summer of 1998 by the Northwest Satellite Center for the Accelerated Schools Project for the middle school principal, coach, and internal facilitators. The coach was a middle school teacher who was released half-time for the 1998-1999 school year, and the internal facilitators were full-time teachers who received a stipend for their leadership role with ASP. All Laurel staff members received two days of ASP training at the beginning of the 1998-1999 school year and then participated in further ASP training on seven early release days during the school year. The Northwest 
Satellite Center staff continued to provide support and training for the principal, coach, and internal facilitators who assumed responsibility for direct support to the rest of the staff.

\section{Lighthouse Middle School}

The school is located in a large suburban district of approximately 20,872 students. The district's tax base is supported by wholesale and retail businesses, utilities, manufacturing, and it is a major transportation hub. Only thirty percent of the students qualify for free and reduced breakfast/lunch programs, and only nine percent of the students receive Chapter I remedial education services. Lighthouse Middle School has a small ethnic minority population (15\%) with a small number of A sian (47), Black (44), Hispanic (37), and Indian (25) students. None of the Lighthouse students are enrolled in English for Speakers of Other Languages (ESOL) classes.

Lighthouse Middle School staff members are organized into four houses, two sixth grade houses and two seventh-eighth grade houses. During the 1998.1999 school year, students attended a short advisory period and seven 42 minute classes each day. Each teacher taught six periods and had one period for individual and team planning each day. 
Sixth grade students were assigned to two teachers for core academic classes and rotated through a series of electives. During the 1999-2000 school year the principal changed the master schedule to allow for optional team teaching at the seventh and eighth grade level.

The 1998-1999 school year was the Lighthouse Middle School principal's fourth year as the building administrator, having taught at the middle school level and served as an elementary and middle school administrator for over twenty years. Her major goal was to support the professional development of her teachers and encourage them to develop "a more holistic approach, [looking at] who that child is as a learner" (S:interview, 2/2/99). She saw a big connection between the district's focus on personalized education and the state EALRs because ... if you don't know where that child is at, if you don't know where their gaps are and you're not putting the pieces in place for them to be successful on any kind of assessment, you're not moving that child. If you're teaching language arts class, and you're try ing to have them do some writing and you see the kids having some real difficult time with grammar and you need to go back and readdress it. But if you're not assessing that and you're not getting some data to drive your instruction, then what are you basing your information on and how are you developing the curriculum if you're not pulling that kind of information out? (S: interview, 2/2/99) 
The Lighthouse district's educational reform plan focuses on personalized education and matching students' strengths and needs with appropriate instruction to increase their achievement. Continuous improvement, multiple and ongoing assessments, continuous feedback and reinforcement are emphasized in the district's plan. The main idea of personalized education was summarized by a district administrator who said: "We need to screen kids, we need to diagnose, we need to prescribe and certify" (S: interview, 1/28/99).

Professional development is provided through multiple sources at the district and state level. A district reading specialist was assigned to Lighthouse Middle School, and she facilitated bi-monthly discussions of reading strategies with teachers who volunteered to attend the meetings. The district also provided up to six day s for professional development, some of it through district-mandated training and other time for building-initiated workshops to support personalized education.

\section{Renderosa Middle School}

The school is located in a small district of approximately 3361 students within a rural area. While the district's tax base is supported by farming and food processing, low family income and a high level of 
student transition are challenges. Eighty-five percent of the middle school students qualify for free and reduced breakfast/lunch programs, and thus Ponderosa Middle School is classified as a school-wide Chapter I program. Ponderosa Middle School has a majority minority student population with $\mathbf{8 8 \%}$ of its students from ethnic minority populations. The largest group is Hispanic students (410), followed by A merican Indian students (189). Twenty-six percent of the students are enrolled in English for Speakers of Other Languages (ESOL); their home languages are primarily Spanish and Asian.

Ponderosa Middle School staff were organized into three grade level teams (sixth, seventh, and eighth) and an electives team. At each grade level two core academic teachers teamed with an instructional assistant to provide language arts, reading, math, science, social studies, and learning support to approximately sixty students. Students attended a short advisory period and seven 47 minute periods each day for instruction in the five core academic subjects plus physical education and an elective or learning support class. Each teacher taught advisory and five periods a day and had a double block of 94 minutes for individual and team planning. The principal structured the double 
block planning time each week to facilitate meetings by grade level, department, and teacher/instructional assistant teams.

The 1998-1999 school year was the Ponderosa Middle School principal's twenty-fourth year in the district, having taught sixth grade at the elementary school and later at the middle school, and served as the middle school principal for 12 years. His goals for the school were to :

[Help teachers develop] a lot more concrete ways to facilitate learning and kids being engaged in the learning process and doing things on a daily bas is as opposed to having things done to them.... [through] team planning and curriculum development and expeditionary learning and giving staff time to think about the goals and how they're going to get there. ( $R$ : interview, 1/26/99)

Approximately ten years ago the principal and middle school staff established a continuing relationship with a language arts consultant from the University of Montana who ... many of those years spent as many as eighteen to twenty days in the school with us, doing workshops, writing process, literature based reading workshops and then developing curriculum and units with the staff. ( $R$ : principal interview, 1/26/99)

In the 1997-1998 school y ear the superintendent directed his administrative team to investigate and choose a comprehensive school design model. Last year the school was awarded a three-y ear state 
Comprehensive School Reform Demonstration (CSRD) grant for a whole school educational reform plan, Expeditionary Learning Outward Bound. The major focus of the grant was incorporation of reading strategies across the curriculum as well as interdisciplinary, experiential, "expeditionary learning" activities. According to the school's application for the state grant, Expeditionary Learning was chosen because:

... of the strong match between this design and our needs. In order to implement the Title 1 school-wide plan and the school action plan, we must make education meaningful and relevant to our students, and broaden their background and experience. Expeditionary Learning is a comprehensive design for school improvement that enables all students to meet rigorous academic standards and character goals. (Ponderosa CSRD grant application, p. 7)

The initial training was provided during the summer of 1998 by the Expeditionary Learning (EL) consultant for all the teachers and instructional assistants in the EL design principles. During the fall of 1998, the consultant worked with the Learning Improvement Team (site council) to integrate the school's strategic plan for improving student literacy with a series of workshops that were held during early release half days. In addition, the consultant conducted training at grade 
level/electives team meetings and with the instructional assistants and modeled literacy strategies in classrooms.

\section{Case Study Data Collection Procedures}

The research design involved a four-stage study: (a) initial administrative interviews, gathering of documentary evidence, and observation of meetings; (b) instructional staff survey; (c) interviews with and observation of language arts teachers and continued observation of meetings; and (d) focus group interviews with grade level teams. All four stages involved investigation of the professional and organizational learning taking place at the school and the teacher and school level factors affecting teachers' ability and willingness to change classroom practice in response to standards-based reform.

\section{Research Steps}

Stage One (January-February 1999). The first stage of this multistage research project was to interview a district administrator and the middle school principal in each of the three districts which had previously agreed to participate in the study. The interviews included the same questions for each school site, with opportunity to probe for 
information specific to each school and district. Interviews were taperecorded and transcribed verbatim.

The interview protocol (see Appendix A) was designed to probe for administrators' understanding of the teacher and school-level factors which influence changes in classroom practice. The information from the administrator interviews was used to refine the instructional staff survey (see Appendix B).

The interviews with a district administrator and the middle school principal in each of the three districts were designed to provide information in five areas. First, the administrative interviews provided an initial impression of the responses to HB 1209 that were occurring in the larger district context and at the specific middle school. Second, research indicates the importance of district and building administrative leadership and support for changes in classroom practice. These interviews provided an opportunity to clarify the administrators' understanding of the supports needed to implement HBI209. Third, the principals were asked about their schools' involvement in the activities, which were used as selection criteria for the study. Fourth, district and building administrators were asked to describe the impact of previous educational policies on implementation of HB1209. Finally, the 
principals were asked about their perception of changes in classroom practice that were taking place in their schools.

In addition to the administrator interviews, I gathered background data regarding the school's demographics, organization, structure, and calendar. I also gathered documentary evidence such as: site council minutes, summaries of staff development workshops and general faculty meetings, planning documents, school report card/ end of year evaluations, relevant school board or district administrative team meetings, school improvement plans, district or building newsletters, and other reports which illustrated the school's response to HB1209. The purpose of the documentary evidence was to corroborate and augment the data from the other sources. Inferences drawn from the documents were then investigated through the surveys and interviews.

Stage Two (March-May 1999). In the second stage, an instructional staff survey was developed and administered (see Appendix B). The survey was based on the interviews and documents in each district. The purpose of the survey was to indicate the prevalence of factors associated with a school-based learning community at each site and also to determine the nature and extent of 
changes in classroom practice. Selection of classroom practices for the survey and subsequent observations was based on practices implied by implementation of the EALRs and WASL and constructivist pedagogy. The survey was administered at a faculty meeting with the stipulation that participants would remain anony mous. The survey included the following areas of inquiry:

- teacher characteristics (position, subject area, grade level, years of previous teaching experience, gender, and previous level of teaching experience)

- understanding of HB1209, Essential Academic Learning Requirements (EALRs), and state assessments (WASL)

- involvement in educational reform activities

- factors that act as barriers to changing classroom practice

- factors that act as supports for changing classroom practice

- changes in the teacher's classroom practice to improve student learning in response to $\mathrm{HB} 1209$

- sense of empowerment and self-efficacy as a teacher at the middle school

Preliminary survey data analysis indicated that the directions were unclear for survey question seven. Therefore, I resurveyed the entire 
instructional staff on this one question at all three schools in late April and $M$ ay. I then used the demographic data accompanying the original surveys and the resurveyed section to merge the data on the two sets of survey data for each middle school.

Stage Three (April-August 1999). In the third stage of the research, three language arts teachers at each middle school were selected based on: (a) administrator recommendation of teachers who were changing their classroom practice, (b) the recommended teachers' willingness to participate in follow-up interviews and classroom observations, and (c) the desire to balance gender, ethnicity and teaching experience. The decision to interview and observe language arts teachers was based on the emphasis of the WASL on reading, writing, and communication skills. The language arts teacher interview protocol (see Appendix $C$ ) included the following areas of inquiry:

- professional background and teaching experience

- involvement in educational reform activities

- interpretation of HB1209

- understanding of changes needed to implement HB1209

- impact of previous/current educational policies

- sense of empowerment and self-efficacy 
- reflection on changes in their own learning and on changes in classroom practice in response to HB 1209.

In addition, I observed department and grade level team meetings as appropriate, spent time in the faculty room, and observed school activities as they occurred during my site visits. I also attended inservices, district committee meetings, and professional development with the teachers I observed.

After the interviews with the language arts teachers, classroom observations were conducted with the consent of the interviewed teachers to clarify and verify the self-reported changes in classroom practice. The observation protocol (see Appendix D), which was based on classroom practices implied by the EALRs and WASL and constructivist pedagogy, included the following areas of inquiry:

- Reading strategies

- Writing strategies

- Integration of technology

- Active student engagement

- Student metacognition

- Assessment practices 
- Interdisciplinary curriculum

- Influence of EALRs and WASL

- Math problem solving strategies

- Interventions with students

Based on the results of the instructional staff survey and the classroom observations, I conducted follow-up interviews with the teachers, whom I observed, to develop further insights into the connection between HB1209, organizational learning at the middle school, and changes in classroom practice in response to HB 1209.

Stage Four (October 1999 to February 2000). In the final stage I presented an interim report (Appendix E) based on the survey and observational data to the building administrator and staff at each school and conducted focus group interviews with grade level teams.

\section{Data Collection Instruments}

Table 2 below summarizes the areas of inquiry and the data collection methods used to investigate each area. Multiple sources of evidence for the areas of inquiry were designed to facilitate triangulation of data. Both the administrative interview data and the documentary evidence helped refine the surveys. The teacher 
Table 2

\section{Data Collection Instruments}

\begin{tabular}{|c|c|c|c|c|c|}
\hline A rea of Inquiry & \begin{tabular}{|l|} 
Admin. \\
Interview \\
App. A
\end{tabular} & \begin{tabular}{|l|} 
Staff \\
S urvey \\
App.B \\
\end{tabular} & \begin{tabular}{|l|} 
Teacher \\
Interview \\
App.C
\end{tabular} & $\begin{array}{l}\text { Class } \\
\text { Observe } \\
\text { App.D } \\
\end{array}$ & \begin{tabular}{|l} 
Focus \\
Group \\
App. E
\end{tabular} \\
\hline $\begin{array}{l}\text { Understanding HBI209, EALRs, } \\
\text { and WASL }\end{array}$ & $\mathrm{x}$ & $\mathrm{x}$ & $\mathrm{X}$ & & $\mathrm{X}$ \\
\hline $\begin{array}{l}\text { Understanding of level of support } \\
\text { for change by district. state }\end{array}$ & $\mathrm{x}$ & $\mathrm{X}$ & $\mathrm{x}$ & & $\mathrm{x}$ \\
\hline $\begin{array}{l}\text { Level \& type of involvement in } \\
\text { educational reform activities }\end{array}$ & $\mathrm{x}$ & $\mathrm{X}$ & $\mathrm{x}$ & & $\mathrm{x}$ \\
\hline $\begin{array}{l}\text { Development of school-based } \\
\text { learning community/professional } \\
\text { development }\end{array}$ & $\mathrm{x}$ & $\mathrm{X}$ & $\mathrm{X}$ & & $\mathrm{x}$ \\
\hline $\begin{array}{l}\text { Changes in classroom practice in } \\
\text { response to HB1209 }\end{array}$ & $\mathbf{x}$ & $\mathbf{X}$ & $\mathrm{X}$ & $\mathbf{X}$ & $\mathbf{x}$ \\
\hline \multicolumn{6}{|l|}{ Teacher Factors: } \\
\hline Present experience & $\mathrm{x}$ & $\mathrm{x}$ & $\mathrm{X}$ & & \\
\hline Previous teaching experience & $\mathrm{X}$ & $\mathrm{X}$ & $\mathrm{X}$ & & \\
\hline Pedagogical knowledge & $\mathrm{x}$ & & $\mathrm{X}$ & $\mathrm{X}$ & $x$ \\
\hline $\begin{array}{l}\text { Involvement in educational } \\
\text { reform }\end{array}$ & $\mathrm{x}$ & $\mathrm{x}$ & $\mathrm{X}$ & & $x$ \\
\hline Sense of empowerment & $\mathrm{X}$ & $\mathrm{X}$ & $\mathrm{x}$ & & $x$ \\
\hline Sense of self-efficacy & $\mathrm{X}$ & $\mathrm{X}$ & $\mathrm{X}$ & & $x$ \\
\hline \multicolumn{6}{|l|}{ School Level Factors: } \\
\hline Previous educational policies & $\mathbf{x}$ & & $\mathrm{X}$ & & $x$ \\
\hline $\begin{array}{l}\text { Participation in collaborative } \\
\text { learning }\end{array}$ & $\mathrm{x}$ & $\mathrm{X}$ & $\mathrm{x}$ & & $\mathrm{x}$ \\
\hline $\begin{array}{l}\text { Building level /district } \\
\text { support }\end{array}$ & $\mathrm{x}$ & $\mathrm{X}$ & $x$ & & $\mathbf{x}$ \\
\hline $\begin{array}{l}\text { Organizational features that } \\
\text { enhance time }\end{array}$ & $\mathrm{X}$ & $\mathrm{X}$ & $\mathrm{x}$ & & $x$ \\
\hline
\end{tabular}

interviews were designed to clarify and amplify the data from the staff surveys. In turn the initial teacher interviews helped focus the classroom observations. Finally, the post-observation interviews with the teachers provided reflection on the changes in classroom practice in 
response to HB1209. The focus group interviews with grade level teams provided an opportunity to corroborate the findings of the survey and note any significant changes during the following school year.

Research Timeline

November-December 1998

1. Chose three middle schools for case study

January 1999

2. Secured permission of three district superintendents and middle school principals

February 1999

3. Initial site visits to each school

- Interviewed district and building administrator

- Toured the school; gathered background data re: demographics, school organization, structure; calendar, etc.

- Gathered documentary evidence: agendas, summaries of staff development workshops and general faculty meetings; planning documents; school report card/ end of y ear 
evaluations; relevant school board or district administrative team meetings; school improvement plans; newsletters

4. Used information from interviews and documentary evidence to refine instructional staff survey and classroom observation protocol

5. Field tested instructional staff survey and classroom observation protocol

March-April 1999.

6. Site visits to each school

1. Conducted survey at staff meeting

2. Interviewed teachers who agreed to be observed

3. Observed classrooms

4. Attended staff meetings, department and grade level meetings, and professional development inservices with the teachers.

7. Preliminary data analysis from surveys and initial observations May-June 1999

8. Site visits to each school

- Observed classrooms

- Interviewed teachers who were observed re:interaction with colleagues; involvement in a school-based learning community; 
reflection on changes in own learning and in classroom practice in response to $\mathrm{HB} 1209$

- Attended staff meetings, site council meetings, grade level and department meetings and professional development opportunities with teachers

\section{June-September 1999}

9. Final interviews with teachers.

10. Data analy sis

October 1999-February 2000.

11. Data analysis

12.Presented interim reports of survey data to each building and conducted focus groups with grade level teams at each school

\section{Data Analy sis Procedures}

Both quantitative and qualitative analytical tools were used to analyze the data from the administrator and teacher interviews, surveys, classroom observations, and documentary evidence. The data were analyzed for each school individually and across all three schools to clarify the connection between standards-based reform policy (HB1209), teachers' learning, and changes in classroom practice in 
response to HB1209. Following Yin's (1994) recommendation, I triangulated the data by using multiple sources of information to develop converging lines of inquiry as indicated in Table 2 above.

\section{Units of Analysis}

Each school represented a unit of analysis, and within each school the instructional staff as a whole and building administrators and three language arts teachers represented additional units of analysis. Figure 3 below illustrates the different units of analysis.

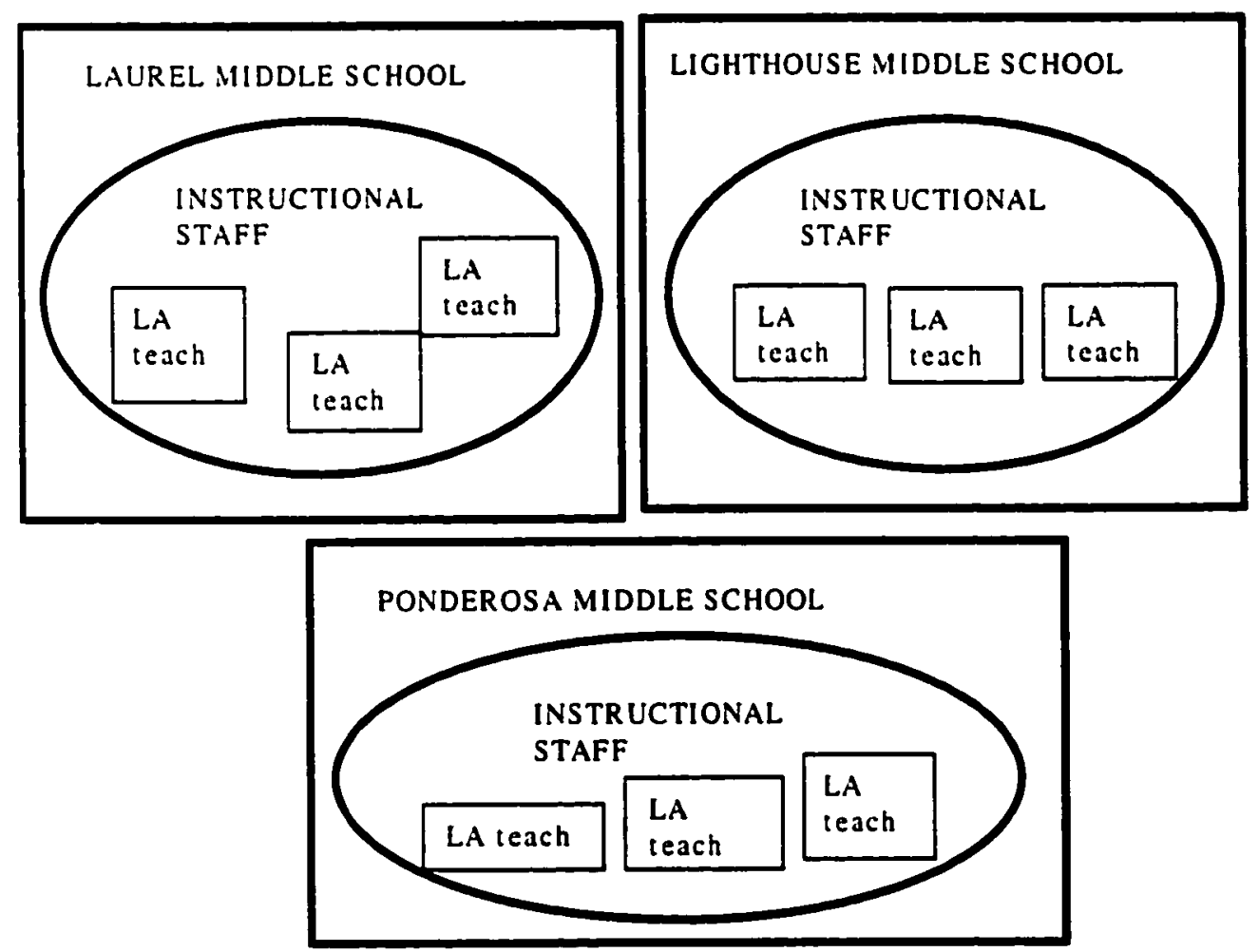

Figure 3. Case study units of analysis. 
Laurel, Lighthouse, and Ponderosa represent three individual cases indicated by three large boxes. Within each case are two levels of embedded units of analysis, the instructional staff as a whole, indicated by the oval $\bigcirc$ and the three language arts teachers who will be interviewed and observed, shown in the boxes. $\begin{aligned} & \text { LA } \\ & \text { teacher }\end{aligned}$

Yin (1994) recommends a three step approach. First, I analyzed the units within each case and interpreted the results at the single case level. Second, I used the patterns established for each case to compare results across cases, following the replication model for a multiple case study. Third, the conclusions drawn from the cross-case analysis became the conclusions for the overall study. Each individual case (school) was analyzed using triangulated dat a from the administrator and teacher interviews, staff surveys, classroom observations, focus group interviews, and documentary evidence. The data were also analyzed across all three cases.

\section{Quant it ative Dat a Analysis}

The survey results yielded extensive quantitative data. The following analytical tools, using SPSS (Statistical Package for the Social Sciences), were employed. Frequency statistics were created for the 
following areas of inquiry: (a) demographic data including school, current academic area, grade level, position, previous teaching experience; (b)familiarity with HB1209, (c) involvement in educational reform activities, (d) school level factors which act as barriers to changing classroom practice, (e) school level factors which act as supports for changing classroom practice, $(f)$ changes in classroom practice, (g) sense of empowerment and self-efficacy. The frequency statistics enabled me to analyze descriptive similarities and differences within each case and across the three cases.

In addition, I conducted chi square and ANOVA tests to determine significant differences among participants by various teacher factors and school level factors. Correlational analysis was used to test for relationships between teacher factors and familiarity with HB1209, involvement in educational reform, and changes in practice.

Correlational analysis was also used to test for relationships between school level factors and familiarity with HB1209, involvement in educational reform, and changes in practice. Finally, multiple regression analysis was used to determine which of the teacher and school level factors were most predictive of familiarity with HB1209, involvement in educational reform, and changes in practice. 


\section{Qualitative Analytical Tools}

In addition to the surveys, the interviews and observations provided rich qualitative data. Miles and Huberman (1984) state that qualitative data analysis involves an interactive, cyclical process which integrates ongoing analysis with data collection. As data are collected, they are displayed through charts, tables, or graphs. This preliminary data display may result in initial conclusions which can be refined through further data collection. My research design timeline specified using the information from the initial administrative interviews and document analysis to refine the instructional staff survey. Also the preliminary review of the survey results were used to refine the teacher interview and classroom observation protocols.

First I transcribed the interviews and typed the observations into word documents which were merged into a qualitative software program, N.U.D.I.S.T. (Non-numerical, Unstructured Data Indexing, Searching, and Theory Building). To help organize the data from the documents, interviews, and observations, I followed these steps recommended by Miles and Huberman (1984). 
1. Developed a coding scheme for the interviews and observations based on the theoretical framework (see Appendix F).

2. Applied the coding scheme to the interview and observation dat a and refined the codes.

3. Conducted over 200 searches of the qualitative data using the codes to analyze the data by individual schools and across cases.

4. Developed propositions or explanations for each case. After the initial administrator interviews and staff survey data were collected and preliminarily analyzed, similarities and differences among the three schools became apparent. As a picture emerged of the teacher and school level factors influencing changes in practice at each school, explanations were developed.

5. Wrote an interim site report that synthesized what I knew about the site from the quantitative and qualitative data. This initial site report was shared with the staff at each school in grade level focus group interviews. 
6. Summarized the information and wrote the final report integrating the qualitative and quantitative data.

\section{Strengths and Limitations of the Study}

Yin (1994) cites four tests for validity and reliability in judging the quality of case studies: construct validity, internal validity, external validity, and reliability. Construct validity involves the establishment of correct operational measures for the concepts being studied. The ten factors, which influence changes in practice in my study, were based on an extensive review of the literature, my earlier pilot study in Washington, and the theoretical framework of systemic reform through professional and organizational learning. (Fullan, 1993; Knapp, 1997; Senge, 1990). The types of changes in classroom practice which I observed were based on my analy sis of HBI209 and the theoretical framework of constructivism (Brooks \& Brooks, 1993; Caine \& Caine, 1997; Darling-Hammond, 1997; Fosnot, 1996;). Yin suggests using multiple sources of evidence, establishing a clear chain of evidence, and having key informants review drafts of the case study report to insure construct validity. All three suggestions were incorporated in my research. 
Internal validity is important in an explanatory case study, which is attempting to establish causal relationships. My research studied the factors which influence teachers to change classroom practice and focused on the connection between reform policy, teachers' learning, and changes in practice. Using the technique of pattern matching, (Yin, 1994) I compared the empirically based data pattern from the interviews, surveys, observations, and document analysis with the predicted or theoretical pattern of data. According to Yin, pattern matching enables the researcher to make causal inferences when the predicted outcomes are found, and alternative or contradictory outcomes are not found. In my study, I considered rival hypotheses as explanations of the causal relationship between reform policy, teachers' learning, and changes in practice. For example, did the interviews and surveys suggest the establishment of a collaborative learning team led to changes in classroom practice in response to HB 1209 (predicted outcome) or was it the influence of the policy and mandated state test (rival hy pothesis)?

External validity establishes the domain to which the study's findings can be generalized. Using a multiple case study approach can result in more compelling evidence if each of the three cases predicts 
similar results (literal replication) or produces contrasting results for predictable reasons (theoretical replication). I hoped that the findings would be theoretically generalizeable to other middle schools in Washingt on. However, the findings were not statistically generalizeable to the larger population of middle schools due to the selection method (recommendations, not random sample) and the limited size of the sample.

Reliability is important in establishing that errors and bias are minimized (internal) and that the study could be replicated with similar results (external). While the individual nature of case study research does not lend itself to establishing external reliability, using the same case study protocol for all three sites and maintaining a case study database helped insure internal reliability.

The time frame for data collection at the three middle schools, including initial interviews, surveys, classroom observations and follow-up interviews, was limited to eight months between January and August 1999. There was some follow-up with the three schools between October 1999 and February 2000. Thus, my case study research represented several snapshots rather than an in-depth portrait of the connection between reform policy (HB1209), teachers' learning, 
and changes in classroom practice. Furthermore, the principal data source about changes in classroom practice was participants' perceptions and self-reports and limited classroom observations. Another limitation was the focus on language arts teachers for followup interviews and observations. Knapp (1997) contends that there may be significant differences in policy interpretation, implementation. and associated changes in classroom practice by subject area. Thus, generalizability of this study is limited. However, the findings from this case study research may contribute to clarifying the connection between policy, organizational learning, and classroom practice. 


\section{CHAPTER IV}

\section{FINDINGS}

\section{Introduction}

The case study research presented in this chapter includes data from an instructional staff survey as well as interviews with district and building administrators and classroom teachers, observations of classroom practice, observations of meetings and inservices, and focus group interviews. The introduction to this chapter summarizes the characteristics of the survey respondents and the interviewees. Following the introduction are five major sections corresponding to the five research questions. The first section (research question one) focuses on the school faculties' understanding of the purpose of the policy and their familiarity with it. The second section (research question two) considers the school faculties' involvement in educational reform. The third section (research question three) analyzes the changes in classroom practice which have occurred in response to HB1209. The fourth section (research question four) examines the relationship between the six teacher factors and three components of the question: familiarity with the policy, involvement in 
educational reform, and changes in classroom practice. The fifth section (research question five) examines the relationship between the four school level factors and three components of the question: familiarity with the policy, involvement in educational reform, and changes in classroom practice. The final section summarizes the significant relationships between the reform policy, involvement in educational reform, teacher factors, school level factors, and changes in classroom practice.

\section{Characteristics of the Survey}

\section{$\underline{\text { Respondents }}$}

The Middle School Instructional Staff Survey was conducted at each of the three schools during a faculty meeting in March, 1999. All instructional staff members were asked to complete the survey and return it at the end of the meeting to a teacher leader who recorded the names of all participants. Instructional staff members who were absent or did not turn in a survey were given a survey by the principal and asked to return it within a week. In all cases, the anonymity of participants was safeguarded. Table 3 indicates the demographic characteristics of the survey respondents and the survey return rates for each school. The total number of respondents at all three schools was $157(49,54$, and 54 respectively) or $93 \%$ of the total instructional staff. 
In addition, I conducted in-depth interviews with a total of eight district and building level administrators and nine classroom teachers (three at each middle school). Between February and June, 1999 I also observed each of the nine teachers in their classrooms on five separate occasions and attended numerous professional development workshops, faculty and team meetings with the teachers.

The data were analyzed for each school individually and across all three schools to clarify the connection between standards-based reform policy (HB1209), teachers' learning, and changes in classroom practice.

As indicated by Table 3 below, there were no significant differences among the schools by school size or number of staff by position, academic area, grade level, or gender. However, there was a significant difference $(p=.004)$ among the three schools by previous level of teaching experience. Laurel Middle School had the highest percentage of teachers with high school experience (18\%); Lighthouse Middle School had the highest percentage of teachers with middle school experience ( $31 \%$ ); and Ponderosa Middle School had the highest percentage of teachers with elementary experience (35\%).

The staff at the three schools also varied in the number of years of teaching experience. An ANOVA indicated a significant difference among the three schools for mean years of total teaching experience 
and mean years of teaching at other schools. The staff at Lighthouse Middle School had the highest mean years of teaching experience (15.5) and the highest mean years of teaching experience at other schools (7.3). For Laurel comparable mean years were 10.6 and 4.1 , and for Ponderosa 10.3 and 3.6. All three schools reported teachers with no previous experience at other schools, i.e., their entire career has been at the middle school in the study. Almost half the teachers at Ponderosa Middle School (44\%) and Laurel ( $41 \%)$ have only taught at that school, while only one-fourth of the teachers at Lighthouse Middle School (24\%) have only taught at Lighthouse.

Table 3

Comparison of Survey Return Rates and Demographic Characteristics of Respondents

\begin{tabular}{|l|l|l|l|l|l|l|l|l|l|l|}
\hline & $\begin{array}{l}\text { TOTAL } \\
\text { SURVEY }\end{array}$ & $\begin{array}{l}\text { Laurel } \\
\text { Middle }\end{array}$ & $\begin{array}{l}\text { Lighthouse } \\
\text { Middle }\end{array}$ & $\begin{array}{l}\text { Ponderosa } \\
\text { Middle }\end{array}$ & Sig. \\
\hline Total Instrurtional Staff & 169 & & 49 & & 61 & 59 & & \\
\hline & F & $\%$ & $F$ & $\%$ & $F$ & $\%$ & F & $\%$ & \\
\hline Staff WhoCompleted Survey & $(157)$ & 93 & $(49)$ & 100 & $(54)$ & 89 & $(54)$ & 92 & \\
\hline $\begin{array}{l}\text { Number \& Percent of } \\
\text { Respondents by Position }\end{array}$ & & & & & & & & & NS \\
\hline Teacher & $(108)$ & 69 & $(30)$ & 61 & $(41)$ & 76 & $(37)$ & 69 & \\
\hline Administrators & $(10)$ & 6 & $(3)$ & 6 & $(4)$ & 7 & $(3)$ & 6 & \\
\hline Counselors & $(4)$ & 3 & $(2)$ & 4 & $(2)$ & 4 & 0 & 0 & \\
\hline Specialists & $(12)$ & 8 & $(7)$ & 14 & $(3)$ & 5 & $(2)$ & 4 & \\
\hline Instructional Assts. & $(23)$ & 15 & $(7)$ & 14 & $(4)$ & 7 & $(12)$ & 22 & \\
\hline Number \& Percent of & & & & & & & & & NS \\
Respondents by Academic & & & & & & & & \\
\hline Language Arts & $(39)$ & 25 & $(12)$ & 24 & $(13)$ & 24 & $(14)$ & 26 & \\
\hline Math/Science & $(26)$ & 17 & $(8)$ & 16 & $(6)$ & 11 & $(12)$ & 22 & \\
\hline Multiple Core & $(17)$ & 11 & $(1)$ & 2 & $(10)$ & 18 & $(6)$ & 11 & \\
\hline Elective & $(17)$ & 11 & $(7)$ & 14 & $(7)$ & 13 & $(3)$ & 6 & \\
\hline
\end{tabular}


Table 3

\section{Comparison of Survey Return Rates and Demographic Characteristics of Respondents (continued)}

\begin{tabular}{|c|c|c|c|c|c|c|c|c|}
\hline \multirow{3}{*}{\begin{tabular}{|l|} 
Total Instructional Staff \\
\end{tabular}} & $\begin{array}{l}\text { TOTAL } \\
\text { SURVEY }\end{array}$ & \multicolumn{2}{|c|}{$\begin{array}{l}\text { Laurel } \\
\text { Middle } \\
\end{array}$} & \multicolumn{2}{|c|}{$\begin{array}{l}\text { Lighthouse } \\
\text { Middle }\end{array}$} & \multicolumn{2}{|c|}{$\begin{array}{l}\text { Ponderosa } \\
\text { Middle }\end{array}$} & \multirow[t]{2}{*}{ Sig. } \\
\hline & 169 & 49 & & 61 & & 59 & & \\
\hline & $\%$ & $\mathrm{~F}$ & $\%$ & $F$ & $\%$ & F & $\%$ & \\
\hline $\mathrm{PE} /$ Health & (12) 8 & (4) & 8 & $(5)$ & 9 & (3) & 6 & \\
\hline Learning Support & $(31) \quad 20$ & (12) & 24 & (7) & 13 & (12) & 22 & \\
\hline Other/NA & (15) 9 & (5) & 10 & (6) & 11 & (4) & 7 & \\
\hline $\begin{array}{l}\text { Number \& Percent of } \\
\text { Respondents by Grade }\end{array}$ & & & & & & & & NS \\
\hline Sixth & (34) & (7) & 14 & $(14)$ & 26 & (13) & 24 & \\
\hline Seventh & (26) & (8) & 16 & $(6)$ & 11 & $(12)$ & 22 & \\
\hline Eighth & (33) & $(11)$ & 22 & (7) & 13 & (15) & 28 & \\
\hline Multiple Grades & (52) & (19) & 39 & $(22)$ & 41 & (11) & 20 & \\
\hline Not Applicable & $(12)$ & (4) & 8 & $(5)$ & 9 & (3) & 6 & \\
\hline $\begin{array}{l}\text { Number \& Percent of } \\
\text { Respondents by Gender }\end{array}$ & & & & & & & & NS \\
\hline Male & $(45)$ & $(10)$ & 20 & $(15)$ & 28 & $(20)$ & 37 & \\
\hline Female & $(110) \quad 70$ & (38) & 78 & $(39)$ & 72 & (33) & 61 & \\
\hline $\begin{array}{l}\text { Previous Teaching } \\
\text { Experience by Level }\end{array}$ & & & & & & & & $* *$ \\
\hline $\begin{array}{l}\text { Number \& percent of staff } \\
\text { who taught elementary }\end{array}$ & $(40)$ & $(11)$ & 22 & $(10)$ & 18 & (19) & 35 & \\
\hline $\begin{array}{l}\text { Number \& percent of staff } \\
\text { who taught middle school }\end{array}$ & (25) & (3) & 6 & $(17)$ & 31 & (5) & 9 & \\
\hline $\begin{array}{l}\text { Number \& percent of staff } \\
\text { who taught high school }\end{array}$ & (21) & (9) & 18 & (8) & 15 & (4) & 7 & \\
\hline $\begin{array}{l}\text { Number \& Percent of Staff } \\
\text { who taught K-12 }\end{array}$ & (13) & (5) & 10 & (6) & 11 & (2) & 4 & \\
\hline $\begin{array}{l}\text { NA (no prev. experience } \\
\text { at other schools) }\end{array}$ & (57) 36 & $(20)$ & 41 & (13) & 24 & $(24)$ & 44 & \\
\hline $\begin{array}{l}\text { Mean years of teaching } \\
\text { experience }\end{array}$ & 12.2 & 10.6 & & 15.5 & & 10.3 & & Anova \\
\hline $\begin{array}{l}\text { Mean years of teaching at } \\
\text { this middle school }\end{array}$ & 6.1 & 5.3 & & 6.8 & & 6.1 & & NS \\
\hline $\begin{array}{l}\text { Mean years of teaching at } \\
\text { other schools }\end{array}$ & 5.0 & 4.1 & & 7.3 & & 3.6 & & $\begin{array}{l}\text { Anova } \\
* *\end{array}$ \\
\hline
\end{tabular}

* significance at $<.05$ level ${ }^{* *}$ significance at $<.01$ level NS no significant difference 


\section{Characteristics of the Interviewees}

Seven of the eight administrators whom I interviewed in all three districts were veteran educators whose experience ranged from eighteen to thirty years. One person had a quasi administrative position as the Accelerated Schools Project coach and had four years of teaching experience. All three superintendents were men; three of the five building administrators were women. None of the administrators I interviewed represented ethnic minorities.

Those building level administrators, who had been teachers and or administrators at the elementary level could most clearly articulate their views of teaching and learning. None of the district level administrators interviewed had elementary experience, and they tended to focus on the big picture of educational reform, e.g., Accelerated Schools, Personalized Education, and Expeditionary Learning. In contrast, the building administrators with the most elementary teaching experience were able to explain what teachers should be doing in the classroom to actively engage students and to improve their academic skills.

The nine classroom teachers whom I interviewed ranged in teaching experience from one to 25 years. The three teachers at Lighthouse averaged twenty-two years of teaching experience, while 
those at Laurel and Ponderosa averaged six years and three years respectively. Two of the four sixth grade teachers had extensive elementary experience, while the other two sixth grade teachers and all the seventh grade teachers had mostly taught in middle schools. Six of the teachers were female and three were male. Four of the teachers taught sixth grade while the remaining five teachers taught seventh grade. One teacher was born and reared in Mexico and worked as a migrant farm laborer before earning a college degree; two of the teachers were Asian-American.

The survey did not seek information on participants' educational preparation. However, there were some interesting differences among the three schools in the educational background of the administrators and teachers I interviewed. Both the superintendent and building principal in the Laurel district had doctorates in educational administration and leadership, and their knowledge of educational reform at both the national and state level was more detailed and complex than administrators in the other two districts. All three teachers at Laurel had earned a bachelor's degree in an academic discipline (music, French, German) and then pursued a master's degree in teaching and/or curriculum and instruction. The district administrator and principal in the Lighthouse district had administrative degrees from Oregon State University and Portland State 
University respectively. All three teachers at Lighthouse, which had the most veteran staff, had earned their bachelor of education degrees in the early 1970's and subsequently earned master's degrees in curriculum and instruction and/or educational leadership. Except for the Ponderosa superintendent, who was educated in the Seattle area, both building administrators and all three teachers at Ponderosa had earned their teaching and administrative credentials at the same two central Washington institutions.

\section{Research Question One}

What is the school faculties' understanding of the purpose of HBI209 and their familiarity with the Essential Academic Learning Requirements and the Washington Assessment of Student Learning in language arts and mathematics?

This study began with the assumption that instructional staff members have some understanding of the standards embedded in HB1209 and its intent in order to change classroom practices. The extent of this familiarity with HB 1209 was measured by five questions $(\mathrm{l} a, b, c, d, e)$ on the survey (Appendix B). Because assessment of these standards is an important component of HB1209, the survey also asked 
staff to report their familiarity with the language arts and math standards and test.

As seen in Table 4, a majority of staff reported being somewhat familiar or very familiar (scoring $4-6$ on a scale of $1-6$ ) with the language arts standards ( $71 \%)$ and testing (58\%) and with the math standards (51\%). However, a minority of staff at all three schools $(44 \%)$ reported being somewhat familiar or very familiar with the math testing. Furthermore, the mean familiarity with the language arts standards (4.21) was greater than for the math standards (3.54) among staff at all three middle schools.

\section{Table 4}

Number and Percentage of Staff Reporting Somewhat or Very Familiar* with HBI209

\begin{tabular}{|c|c|c|c|c|c|c|c|c|}
\hline \multirow[t]{2}{*}{$N=155-157$} & \multicolumn{2}{|c|}{ Lang Arts Stand } & \multicolumn{2}{|c|}{ Lang Arts } & \multicolumn{2}{|c|}{$\begin{array}{l}\text { Math } \\
\text { Standards }\end{array}$} & \multicolumn{2}{|c|}{ Math Test } \\
\hline & Freg & Percent & Freg & Percent & Freq. & Percent & Freg. & Percent \\
\hline 1. Not At All & (10) & 6.4 & (11) & 7 & (21) & 13.4 & (19) & 12.1 \\
\hline \multirow{2}{*}{$\begin{array}{l}\text { 2. A Little } \\
3 \text {. }\end{array}$} & $(17)$ & 10.8 & $(21)$ & 13.4 & (27) & 17.2 & (31) & 19.7 \\
\hline & (17) & 10.8 & (32) & 20.4 & $(29)$ & 18.5 & $(38)$ & 24.3 \\
\hline \multirow{2}{*}{$\begin{array}{l}\text { 4. Somewhat } \\
5 \text {. }\end{array}$} & (39) & 24.8 & $(31)$ & 19.7 & $(31)$ & 19.7 & $(26)$ & 16.6 \\
\hline & (3I) & 19.7 & (34) & 21.9 & $(25)$ & 15.9 & $(28)$ & 17.8 \\
\hline 6. A Lot & (41) & 26.1 & $(6)$ & 16.6 & (4) & 15.3 & $(15)$ & 9.6 \\
\hline Mean Score & 4.21 & & 3.87 & & 3.54 & & 3.37 & \\
\hline
\end{tabular}

( ${ }^{*}$ Ranked $4-6$ on a scale of $\left.1-6\right)$

An ANOVA revealed no significant difference by school on familiarity with language arts and math standards (EALRs) or language arts and math tests (WASL). However, examining the mean familiarity 
by school in Table 5 below shows that the Ponderosa staff reported the greatest familiarity with HB1209, followed by the Lighthouse staff, while the Laurel staff reported the lowest familiarity.

Table 5

Comparison of Mean Scores of Familiarity with HB1209 by School*

\begin{tabular}{|l|l|l|l|}
\hline $\mathrm{N}=155-157$ & $\begin{array}{l}\text { LAUREL } \\
\text { MS N=47.49 }\end{array}$ & $\begin{array}{l}\text { LIGHTHOUSE } \\
\text { MS N=54 }\end{array}$ & $\begin{array}{l}\text { PONDEROSA } \\
\text { MS N=54 }\end{array}$ \\
\hline $\begin{array}{l}\text { Lang Arts Standards } \\
\text { (EALRs) }\end{array}$ & 3.9 & 4.2 & 4.5 \\
\hline Lang. Arts Tests (WASL) & 3.7 & 4.0 & 3.9 \\
\hline Math Standards (EALRs) & 3.4 & 3.4 & 3.8 \\
\hline Math Tests (WASL) & 3.3 & 3.4 & 3.4 \\
\hline Total Familiarity & 14.3 & 15.0 & 15.6 \\
\hline
\end{tabular}

*( on a scale of 1 low to 6 high)

A major intent of the interviews for administrators (Appendix A) and teachers (Appendix C) was their interpretation of the purpose of HB1209, in general, and the Essential Academic Learning Requirements (EALRs) and the Washington Assessment of Student Learning (WASL) in particular. Participants at all three schools discussed the state legislators' desire to raise standards and hold schools and districts accountable for student learning. They believed there was a strong push from the business community to better prepare students as future workers and citizens. As a result, interviewees believed that Washington state jumped on the bandwagon of the standards movement as it was sweeping the nation in the early $1990^{\circ} \mathrm{s}$. 
Participants at all three schools explained that the EALRs represent common content standards and benchmarks that the state expects all students to meet. Both the Ponderosa and Lighthouse participants emphasized that their districts had been developing content standards and benchmarks prior to the passage of HB 1209. Thus, the EALRs were not a major change. Ponderosa Middle School administrators commented that the EALRs validated what they had been doing in language arts (use of six trait writing model and scoring rubrics) and empowered them to insist that teachers change their instructional practices. Echoing Stiggins (1994), the Ponderosa principal commented, "The EALRs provide clear targets for student learning" (R: interview, 2/12/99). "The EALRs connect learning to the real world" (R: interview, 1/26/99).

In general Ponderosa participants emphasized the policy's role in requiring teachers to change instructional practices and in encouraging students to assume more responsibility for their own learning. Some noted the creators of HB 1209 intended for students to be better thinkers and problem solvers who could self-assess and reflect on their own learning, thus foreshadowing a constructivist theme. 
Staff in all three districts recognized that the WASL is very challenging, and they did not expect their low achieving seventh grade students to score well on the test given in the spring of 1999. Yet some expressed concern that publication of the WASL scores would have a punitive effect on those schools and districts with a high percentage of low achieving students. Lighthouse staff described the WASL primarily as an accountability tool. However, the Laurel and Ponderosa district staff had a more positive view of the state assessment. They believed the WASL is necessary to ensure that the reforms intended by HB1209 are actually implemented, and some praised the WASL's requirement that students explain their thought processes.

The interview data corroborated the survey results which indicated that Ponderosa Middle School staff reported the greatest familiarity with HB1209. Furthermore, the Ponderosa educators' understanding of the policy seemed more complex and focused on the pedagogical implications of the policy, i.e., requiring teachers to change instructional practices and students to demonstrate higher level thinking. At a focus group I conducted at Ponderosa Middle School in October 1999, teachers explained that the Learning Improvement Team (LIT), i.e., site council, had focused on helping staff understand the implications of HB1209 for changes in classroom practice and student 
learning. Moreover, the LIT helped develop a strategic plan to raise test scores.

While survey data indicated the Laurel Middle School staff had the lowest familiarity with HB1209, interviews with administrators and teachers evidenced a positive view of the policy's potential to improve student learning. For example, the Laurel superintendent remarked at a district staff development workshop, "The future is learning, standards, and Accelerated Schools. We're building knowledge workers" (U:ASP district, 4/23/99). In contrast, the Lighthouse Middle School staff reported the second highest level of familiarity with HB 1209 but had a less positive view of the policy than the other two middle school staffs.

In summary, familiarity with HB1209 varied by school. The faculty at all three schools viewed raising standards and accountability as the primary purposes of HB1209 but were very concerned about the challenges faced by low-achieving students on the seventh grade WASL. Two of the three school districts had developed their own content standards and benchmarks prior to the passage of HB1209, and their staff members were more familiar with the state standards. The staff at Ponderosa Middle School, more so than staff at the other schools, seemed to understand that changes in instructional practice and student learning would be necessary in order to implement HB1209. 


\section{Research Question Two}

What is the school faculties' overall level of involvement in educational reform and in what types of educational reform are they involved?

The data which address this research question are based on survey questions 2 and 3 (Appendix B). Table 6 below compares the mean scores for level of involvement in eleven educational reform activities for all respondents as well as those of individual schools. The mean score for overall level of involvement in educational reform for respondents at all three schools was 3.9 ("somewhat involved"). The three educational reform activities most frequently mentioned were: (2i) participation in a collaborative learning group, $(2 \mathrm{~h})$ use of classroom/state assessment data to make decisions about instructional piactices, and ( $2 f)$ alignment of curriculum to match state standards and assessments. 
Table 6

Comparison of Mean Scores for Level of Involvement
in Educational Reform \#

\begin{tabular}{|c|c|c|c|c|c|}
\hline $\begin{array}{l}\text { Involvement in Educational } \\
\text { Reform }\end{array}$ & $\begin{array}{l}\text { All Schools } \\
N=149-156\end{array}$ & $\begin{array}{l}\text { Laurel } \\
M . S . \\
N=44-48\end{array}$ & $\begin{array}{l}\text { Lighthouse } \\
\text { M.S. } \\
N=49-54\end{array}$ & $\begin{array}{l}\text { Ponderosa } \\
M . S \text {. } \\
N=53-54\end{array}$ & Sig. \\
\hline Collegial Group (2i) & 4.3 & 4.3 & 3.8 & 4.7 & * \\
\hline Use data $(2 h)$ & 4.0 & 3.6 & 4.3 & 4.0 & $*$ \\
\hline Align Curriculum (2f) & 3.9 & 4.0 & 3.9 & 3.7 & NS \\
\hline Develop Standards (2g) & 3.5 & 3.5 & 3.6 & 3.4 & NS \\
\hline Interdisciplinary Team(2c) & 3.3 & 3.7 & 3.3 & 3.0 & NS \\
\hline Standards Workshop (2d) & 3.1 & 3.1 & 3.3 & 2.9 & NS \\
\hline Site Council (2a) & 3.1 & 2.6 & 4.0 & 2.5 & $*$ \\
\hline Testing Workshop (2e) & 3.0 & 2.9 & 3.3 & 2.8 & NS \\
\hline Attend Conference $(2 j)$ & 2.4 & 2.7 & 2.3 & 2.2 & NS \\
\hline Curriculum Comm. (2b) & 2.4 & 2.5 & 2.8 & 1.9 & NS \\
\hline Present at Conference (2k) & 1.6 & 1.7 & 1.4 & 1.7 & NS \\
\hline Overall Involvement (3) & 3.9 & 3.7 & 4.0 & 4.0 & NS \\
\hline
\end{tabular}

Analysis of Involvement in Educational Reform bv school

A chi square analysis revealed no significant differences by school on total involvement in educational reform activities. However, there were variations among schools for involvement in specific educational reform activities. Table 6 above indicates the three educational reform activities in which schools differed significantly: (2i) participation in a collaborative learning group $(p=.038) ;(2 \mathrm{~h})$ use of assessment data to make decisions about instructional practice $(p=.002)$; and $(2 a)$ serving on a school site council $(p<.001)$. Of the three schools, the Ponderosa Middle School staff reported the highest 
level of involvement in a collaborative learning group, while the Lighthouse Middle School staff reported the highest use of data for decision-making and participation on a site council (see Figure 4).

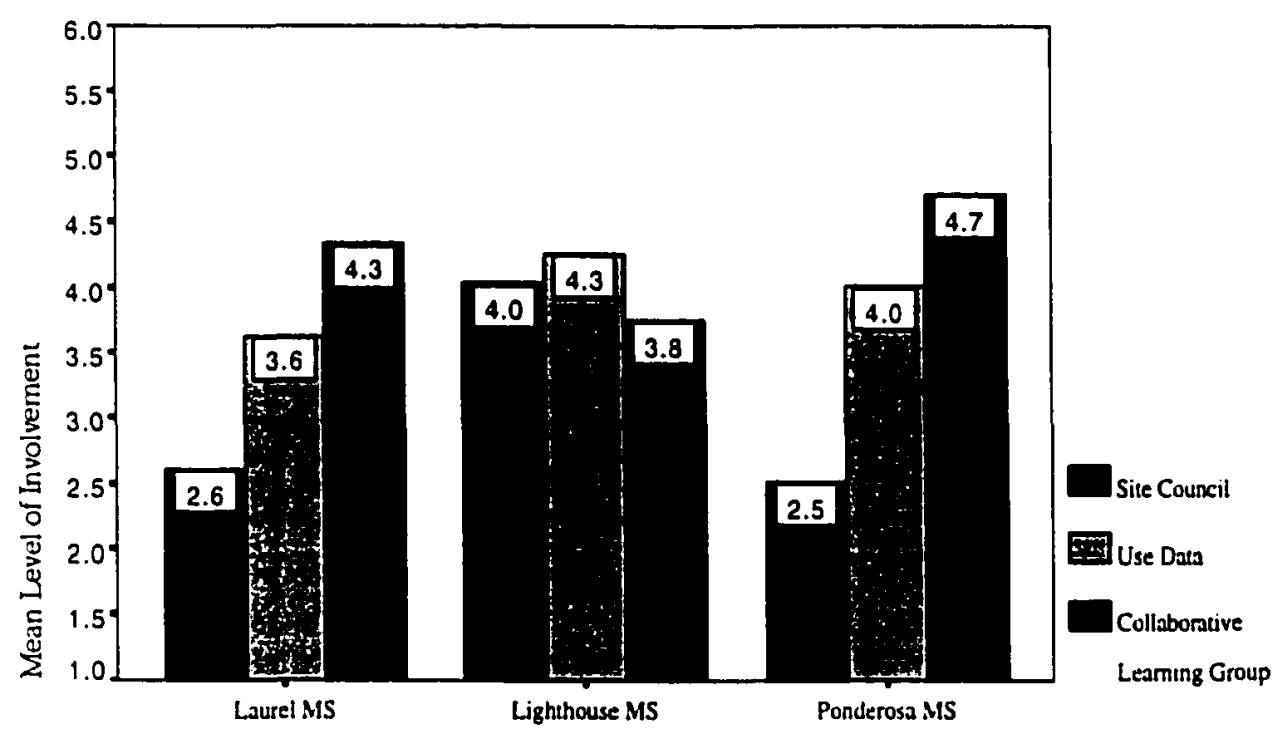

School

Figure 4. Mean level of involvement by school in three educational reform activities with most variation.

All three school districts had implemented site councils seven years ago as part of their application for Student Learning Improvement Grant funds authorized by HB1209. Given the greater teaching experience of the Lighthouse Middle School staff ( 15.5 years), I was not surprised by their significantly higher participation on the site council. Both sixth grade teachers whom I interviewed had served as 
site council chair in the past and continued to participate in the Lighthouse Site Council.

The Lighthouse Middle School ranked highest for its use of classroom and state assessment data to make decisions about classroom practice. Compared to the other two districts, the Lighthouse district emphasized testing at every grade level. Middle school students were given annual district levels tests in reading and math, a writing assessment, a math problem solving assessment and the state mandated ITBS (sixth grade) and the WASL (seventh grade). A new testing requirement for the 1999-2000 school year was the language arts profile which involved recording students' scores on classroom assessments based on the recently adopted literature series. A district administrator explained that the emphasis on Personalized Education required teachers to "screen, diagnose, prescribe, and certify" students. (S: interview, 1/28/99) The Lighthouse Middle School principal's expectation was that her teachers would use data to analyze individual students' needs. In the focus groups teachers corroborated the district's focus on testing but also complained that often the data were not timely enough to use for individual student diagnosis. One of the teachers whose instruction was highly individualized and effective commented, 
I think my awareness of what are good instructional practices and what are things that I can do to enhance and enrich and make my classroom full have been more beneficial to me than any test results, whether it's the state ones or the district ones. (S: interview, 4/16/99)

Her comment and those of the other teachers led me to question whether teachers were using district and state testing data to change their classroom practice or whether teachers were aware of the district's emphasis on data but were still relying on the results of classroom assessments to monitor and adjust their teaching.

Ponderosa Middle School staff indicated the highest participation in a collaborative learning group. Compared to the other two schools, Ponderosa had established elements of a learning community and worked towards that goal. The principal explained several strategic decisions made by the Learning Improvement Team to involve everyone in the Expeditionary Learning Training, including the instructional assistants and tutors. In previous years, when the staff was working with the university consultant on the six trait writing process and literature-based reading, they would read books together, discuss, and plan units. At one of my initial observations, I noticed how teachers entered the conference room and exhibited excitement about a new set of novels that had just arrived. As a group they immediately began to review the books. 
In focus groups I conducted at the school in October 1999, teachers confirmed that in-service activities $s$ were collaborative learning experiences. They used team meeting time to talk about how to use the reading and writing strategies across the curriculum. The building administrators modeled teaching and lesson planning at grade level team meetings and then invited the teachers to critique them.

At each Expeditionary Learning training activity I observed, the Ponderosa principal was an active participant in the grade level team meetings and faculty meetings, learning and sharing his responses with the rest of the staff. The trust level seemed high, and teachers seemed comfortable admitting their own struggles with the strategies. The staff development followed constructivist principles; teachers experienced conflict of ideas, searched for evidence in the text, actively listened to each other, and made connections based on what others had said.

In summary, while there were no significant differences among the three schools on overall involvement in educational reform, there were significant differences on three reform activities: participation on a site council, use of classroom/state assessment data to make decisions about classroom practice, and participation in a collaborative learning group. 


\section{Research Question Three}

To what degree and in what ways do teachers change classroom practice in response to HB1209?

The dala in this section are based on survey questions 6 and 7 (Appendix B). First I will report the degree to which teachers reported change in use of twenty-four classroom practices. Selection of these practices was based on practices implied by implementation of the EALRs and WASL and constructivist pedagogy. Next I will discuss the five instructional practices which instructional staff at all three schools reported they used most frequently. Finally, I will examine those nine instructional practices on which there were significant usage differences by school.

Analysis of Changes in Classroom Practice by Schocl

Survey question 6 asked instructional staff members to rate the degree to which twenty-four classroom practices had occurred more frequently in their teaching since 1990 . The mean scores for all respondents and for those at each school are presented in Table 7 below. The three instructional practices which have occurred most frequently for all the survey respondents were: (6r) teaching writing strategies across the curriculum, (6i) increased expectations of 
students, and (6v) curriculum units, i.e., lesson plans, aligned to the EALRs. The changes in these three instructional practices were directly related to HB1209. This finding was supported by the interviews and observations of classrooms and meetings, in which administrators and teachers reported on the importance of teaching writing across the curriculum, increasing expectations for students, and aligning their curriculum to match the state essential learnings.

As seen in Table 7 below, Ponderosa Middle School reported the highest mean score for every one of the twenty-four changes in classroom practice, while Laurel Middle School and Lighthouse Middle School each reported the lowest mean score for twelve of the changes. There were significant differences by school on changes in nine of the classroom practices: (6t) metacognition by students, $(6 n)$ integration of technology, (6u) active student engagement in learning, (6q) teaching reading strategies across the curriculum, (60) communicating studenı learning through writing, (6a) cooperative learning, $(6 \mathrm{~m})$ intervention with students who do not meet standards, $(6 \mathrm{~g})$ student research and experiments, and (6k) student portfolios. The classroom observations, interviews, and focus groups supported the survey data, indicating significant differences among the three schools. Each of the nine classroom practices, in which schools differed significantly, will be examined in more detail later in the chapter. 
Table 7

\section{Comparison of Mean Scores for Changes in Classroom Practice}

\begin{tabular}{|c|c|c|c|c|c|}
\hline More frequent use of: & \begin{tabular}{|l|} 
Total \\
Survey \\
$N=137.1+9$
\end{tabular} & $\begin{array}{l}\text { Laurel } \\
\text { MS } \\
\mathrm{N}=37.44\end{array}$ & $\begin{array}{l}\text { Lighthouse } \\
M S \\
N=47.54\end{array}$ & $\begin{array}{l}\text { Ponderosa } \\
M S \\
N=48.53\end{array}$ & Sig. \\
\hline $\begin{array}{l}\text { Teach writing strategies } \\
\text { across curriculum (6r) }\end{array}$ & 3.6 & 3.15 & 3.21 & 4.34 & NS \\
\hline $\begin{array}{l}\text { Increased expectations of } \\
\text { students }(6 \mathrm{i})\end{array}$ & 3.52 & 3.38 & 3.17 & 4.02 & NS \\
\hline $\begin{array}{l}\text { Curriculum aligned to } \\
\text { standards }(6 \mathrm{v})\end{array}$ & 3.51 & 3.32 & 3.12 & 4.08 & $\mathrm{NS}$ \\
\hline Use of scoring rubrics (6b) & 3.40 & 2.81 & 3.16 & 4.14 & NS \\
\hline $\begin{array}{l}\text { Metacognition by students } \\
(6 t)\end{array}$ & 3.39 & 2.95 & 3.04 & 4.02 & $* *$ \\
\hline $\begin{array}{l}\text { Integration of technology } \\
(6 n)\end{array}$ & 3.38 & 3.11 & 2.98 & 4.04 & $*$ \\
\hline $\begin{array}{l}\text { Clear standards for student } \\
\text { performance }(6 \mathrm{~h})\end{array}$ & 3.32 & $\beta .12$ & 3.02 & 3.83 & NS \\
\hline Student peer evaluation (6c) & 3.18 & 2.81 & 3.00 & 3.67 & NS \\
\hline Student self evaluation (6d) & 3.11 & 2.82 & 3.02 & 3.45 & NS \\
\hline $\begin{array}{l}\text { Active student engagement in } \\
\text { learning }(6 \mathrm{u})\end{array}$ & 3.09 & 2.63 & 2.69 & 3.81 & * \\
\hline $\begin{array}{l}\text { Teaching reading strategies } \\
\text { across curriculum }(6 q)\end{array}$ & 3.07 & 2.68 & $\overline{7.52}$ & 3.91 & . \\
\hline Performance assessments (6) & 3.01 & 2.77 & 2.92 & 3.29 & NS \\
\hline $\begin{array}{l}\text { Interdisciplinary curriculum } \\
(6 \mathrm{f})\end{array}$ & 2.96 & 3.00 & 2.57 & 3.35 & NS \\
\hline $\begin{array}{l}\text { Use writing to communicate } \\
\text { learning }(60)\end{array}$ & 2.94 & 3.10 & 2.52 & 3.26 & T \\
\hline Cooperative learning (6a) & 2.91 & 2.61 & 2.43 & 3.65 & F \\
\hline $\begin{array}{l}\text { (11tervention with students } \\
(6 \mathrm{~m})\end{array}$ & 2.88 & 2.52 & 2.62 & 3.44 & $=$ \\
\hline Student projects $(6 j)$ & 2.86 & 2.64 & 2.33 & 3.62 & NS \\
\hline $\begin{array}{l}\text { Students talk about } \\
\text { learning }(6 \mathrm{p})\end{array}$ & 2.84 & 2.67 & 2.55 & 3.28 & NS \\
\hline $\begin{array}{l}\text { Ongoing assessment of } \\
\text { students }(6 x)\end{array}$ & 7.70 & 2.45 & 2.54 & 3.04 & NS \\
\hline $\begin{array}{l}\text { Reteach students below } \\
\text { standards }(61)\end{array}$ & 2.69 & 2.58 & 2.28 & 3.20 & NS \\
\hline $\begin{array}{l}\text { Use student data to plan } \\
\text { instruction }(6 \mathrm{w})\end{array}$ & 2.69 & 2.43 & 2.64 & 2.96 & NS \\
\hline Student research $(6 \mathrm{~g})$ & 2.56 & 2.48 & 1.98 & 3.24 & $* *$ \\
\hline Student portfolios $(6 \mathrm{k})$ & 2.55 & 2.02 & 1.39 & 4.18 & $* *$ \\
\hline $\begin{array}{l}\text { Math problem-solving across } \\
\text { curriculum (6s) }\end{array}$ & 2.42 & 1.95 & 2.35 & 2.86 & NS \\
\hline
\end{tabular}




\section{Analysis of Top Five Instructional}

\section{Practices by School}

When the respondents were asked to rank the five instructional practices, which they used most frequently (question 7 ), there were similarities and differences among the three schools as seen in Table 8 below. Instructional staff at all three schools reported cooperative learning (6a), active student engagement in learning tasks (6u), and curriculum aligned to the EALRs (6v) among their top five practices. Only Ponderosa Middle School listed teaching reading strategies (6q) and writing strategies (6r) across the curriculum among the top five practices.

\section{Table 8}

Top Five Instructional Practices Reported by Staff at each School

\begin{tabular}{|l|l|l|l|}
\hline $\begin{array}{l}\text { Practi } \\
\text { ce }\end{array}$ & $\begin{array}{l}\text { Laurel MS } \\
\text { N=44 }\end{array}$ & $\begin{array}{l}\text { Lighthouse MS } \\
\mathrm{N}=50-52\end{array}$ & $\begin{array}{l}\text { Ponderosa MS } \\
\mathrm{N}=52-53\end{array}$ \\
\hline 1 & $\begin{array}{l}\text { Cooperative } \\
\text { learning }\end{array}$ & Cooperative learning & $\begin{array}{l}\text { Curricuium aligned to } \\
\text { standards }\end{array}$ \\
\hline 2 & Student Projects & Student Projects & Cooperative Learning \\
\hline 3 & $\begin{array}{l}\text { Active Student } \\
\text { engagement }\end{array}$ & $\begin{array}{l}\text { Higher Expectations } \\
\text { of Students }\end{array}$ & $\begin{array}{l}\text { Teaching Reading } \\
\text { across the Curriculum }\end{array}$ \\
\hline 4 & $\begin{array}{l}\text { Curriculum aligned } \\
\text { to Standards }\end{array}$ & $\begin{array}{l}\text { Curriculum aligned to } \\
\text { Standards }\end{array}$ & $\begin{array}{l}\text { Active Student } \\
\text { Engagement }\end{array}$ \\
\hline 5 & $\begin{array}{l}\text { Active Student } \\
\text { Engagement }\end{array}$ & $\begin{array}{l}\text { Teaching Writing } \\
\text { across the Curriculum }\end{array}$ \\
\hline
\end{tabular}

\# There was a large gap between the fourth and fifth ranked practices. 
Staff at the three schools reported significantly different usage of cooperative learning and active student engagement in learning tasks. Detailed examination of these practices is examined in the next section.

Metacognition bv students. This is the first instructional practice in which schools differed significantly for change in practice. As indicated in Table 7 , mean scores for more frequent use of reflection or metacognition by students about their own learning indicated that Ponderosa reported the highest increase in use (4.02), followed by Lighthouse (3.04) and Laurel (2.95).

In my classroom observations at Laurel Middle School I never observed students actively reflecting on their own learning, not was it discussed as a strategy by teachers in grade level or department meetings or the ASP inservices that I observed. Students were not asked to think about their own thinking, to reflect on their learning, or set goals for their learning. Perhaps this is because student metacognition is not an explicit aspect of Powerful Learning which focuses on "authentic, interactive, learner-centered, inclusive, and continuous learning" (Accelerated Schools, 1999, p.4). One of the teachers I interviewed responded that metacognition was the latest buzzword and he didn't feel it was critical.

In my observations of the sixth grade classrooms at Lighthouse Middle School, students used metacognitive strategies in the literature 
circle discussions as they reflected on their reading of the stories.

Students in one sixth grade classroom I observed routinely shared what they thought about as they read the story. In the focus groups at Lighthouse one sixth grade teacher was surprised that metacognition had not been ranked higher because metacognitive strategies were used on the district math problem solving assessment and incorporated in the district-adopted literature textbook series. However, another teacher explained, "Student metacognition is not a skill that has been nurtured. Kids want to fill in the blanks and know the right answer" (S: focus group, 2/9/2000).

I was not surprised that Ponderosa Middle School ranked significantly higher (4.02) for metacognition than the other two schools. Metacognitive strategies were modeled by the Expeditionary Learning consultant and by the teachers whose classrooms I observed. For example, I observed a sixth grade ieacher at Ponderosa read a passage aloud from a novel and comment about the mental connections she was making between the text and her own life experiences and other books she had read. Then she asked students (who were working in small groups) to continue to read the novel, pausing about every five minutes to talk about the mental connections they were making as they read the story. The principal and teachers explained that higher level thinking skills were a district focus and the term, "metacognition", had 
been part of the Ponderosa teachers' vocabulary for the previous five to six years. Teachers shared how students used metacognition in language arts, math, and science classes. Moreover, all students were required to reflect orally and in writing on their own learning and set goals as part of their portfolio activities.

Integration of technology. This was the second instructional practice in which the schools differed significantly in their increased use of this practice. Ponderosa Middle School staff reported the greatest change in practice, (4.04) followed by Laurel Middle School (3.11) and Lighthouse Middle School (2.98).

Change in the use of technology was lowest at Lighthouse Middle School due primarily to a lack of technology resources. Teachers could only access the computer lab once a week because it was reserved for teaching keyboarding and remedial reading. While the librarian offered a media worksnop, students had little access to advanced technology such as I-Macs, super drives, or Power Point software. District policy required parent approval for students to access the Internet; thus, independent student research was limited. In general there were only one or two computers in each classroom and no on-site in-service to help teachers learn to integrate new technologies into their instruction. 
The Laurel Middle School staff reported a slightly higher change in the use of technology. In the 1999-2000 school year, the school created a second computer lab which was being heavily used for class projects. While there were only two computers in each classroom, teachers said they could get technical help within their building and from the district.

At Ponderosa Middle School, students were actively engaged in using technology in every classroom I visited. Partially this was due to the high percentage of teachers in the sixth and seventh grades who had participated in the Educational Service District Share 105 and the Gates Foundation programs, attending summer institutes and receiving classroom computers and software. Student access of the Internet, use of Encarta, and creation of Power Point presentations were common. However, according to one teacher, technology was not taught for its own sake. Technology had to have a purpose within the curriculum; it was seen as a tool to help students reach their academic learning goals. Teachers also viewed themselves as technology learners along with their students. Thus, it was not surprising that Ponderosa staff reported the highest increase in use of technology among the three schools.

Active student engagement. This instructional practice was listed by instructional staff at all three schools among their top five instructional practices. However, there was a significant difference 
among the three schools. Ponderosa Middle School staff reported the greatest change in this practice (3.81) followed by Lighthouse Middle School (2.69) and Laurel Middle School (2.63).

While teachers at Laurel Middle School believed in the importance of actively engaging students in learning tasks, they recognized that it was very difficult to do. One teacher commented, "It's easy to teach an engaging lesson. It's harder to have academic standards and teach an engaging lesson" (U: interview, 2/24/99). The Accelerated Schools model of powerful learning focuses on authentic, interactive, and learner-centered instruction, and the focus for ASP inservices during the 1999-2000 school year was on powerful learning strategies. I observed an ASP in-service at Laurel Middle School in October 1999, where teachers worked together to design a lesson using these criteria. Also I noted active student engagement in learning tasks in more than half the classroom observations. Thus, the lower ranking of this practice by Laurel Middle School staff probably reflected the timing of the survey in March of 1999, before student engagement became a focus of professional development the following school year.

Although teachers at Lighthouse Middle School ranked their increased use of active student engagement slightly higher than the teachers at Laurel Middle School, I did not see widespread use of this practice except in the sixth grade classrooms which I observed. Most 
of the instruction in seventh grade language arts classrooms was highly teacher-directed with a high percentage of teacher talk and little student-student interaction.

The Ponderosa Middle School staff reported the greatest increase in this practice among the three schools. This finding was verified in all the classroom observations where there was a balance of teacher talk and student talk and a great deal of student-student interaction. Active student engagement in learning tasks is a major focus of Expeditionary Learning Outward Bound. The program defines learning as,

...an expedition into the unknown. Expeditions [interdisciplinary units] draw together personal experience and intellectual growth to promote self-discovery and construct knowledge. (Cousins, 1998).

Several of the Expeditionary Learning design principles focus on creating learning situations that build on children's curiosity and provide time to experiment and make sense of what they observe. Learning is understood to be both a personal process of discovery and a social activity. While Expeditionary Learning was in its first year of implementation during the 1998-1999 school year, teachers affirmed that active student engagement in learning had been an expectation of the building administrators for many years.

Teaching reading strategies across the curriculum. This was the fourth instructional practice in which schools differed significantly in 
change in practice. Ponderosa Middle School staff reported the greatest change in practice (3.91), followed by Laurel Middle School (2.68) and Lighthouse Middle School (2.52). Also Ponderosa staff members were the only ones to list the teaching of reading strategies across the curriculum among their top five instructional practices.

In all three districts the expectation of the superintendent and the building principal was that every teacher would become a teacher of reading. However, teachers in all three districts were pessimistic about how well their students would perform on the reading portion of the WASL because of the students' difficulty with comprehension and higher level thinking skills.

Lighthouse was the only middle school with a separate reading class for most seventh graders and some eighth graders who were reading below grade level. In the classes I observed at Lighthouse theie was more emphasis on speed and fluency than on critical thinking about the reading. Twice a month a district reading specialist met with teachers who volunteered to attend the discussion group before school. The specialist shared articles about best practices in reading instruction, and teachers shared their experiences with each other.

The most consistent reading instruction I observed at Lighthouse occurred in the sixth grade classrooms where teachers incorporated weekly literature circles. Students read the same book in 
heterogeneous groups, discussed, analyzed, and wrote about their reading. Visualization strategies, paraphrasing, and other metacognitive strategies were used in the classes I observed. Despite the district emphasis on teaching reading, Lighthouse Middle School reported the lowest change in this practice among all three schools.

The Laurel sehool district provided in-service training on a specific reading program, Strategies for Achieving Independent Learners (S.A.I.L.), and these methods were used to some extent by all three teachers I observed. While there was not a school-wide expectation for reading outside of class, many teachers required weekly outside reading with journal entries and parent verification of the reading. One of the seventh grade teachers I observed had developed WASL-type questions to accompany the literature textbook; these questions were used by the whole seventh grade team to prepare their students for the WASL. In spite of the district's emphasıs on teaching reading and the pressure from the state assessment, Laurel Middle School staff reported only a slightly higher frequency of teaching reading than Lighthouse Middle School.

Ponderosa Middle School staff reported the greatest increase in teaching reading strategies across the curriculum among the three schools. This practice was also listed among their top five instructional practices. There are several reasons for this finding. In 
the early 1990's, working with their university consultant, the middle school staff members chose a set of books that included adolescent characters and developed a set of pre-reading, reading, and post-reading activities involving writing and discussion. Staff members read books together and talked about them. This focus on teaching reading lost some of its emphasis when the staff began to focus on social studies unit development and the writing process. However, in the 1998-1999 school year, the teaching of reading again came to the forefront with the school reform plan, Expeditionary Learning.

When I asked why teaching of reading strategies across the curriculum was ranked among the top five instructional practices at Ponderosa, teachers replied, "Reading and writing were emphasized across the curriculum so we couldn't just say we're math and science teachers" ( $R$ : focus group, 10/29/99. The assistanı principal often remarked to students, "Now don't be surprised if it [reading] isn't your favorite type of thing. You're going to create meaning. You're going to reread until meaning comes" ( $R$ : interview, 2/12/99).

There was a school-wide expectation that students would read outside of class every day. The student portfolios were supposed to include three book reports per trimester. Several book clubs/literature 
circles were led by students before and after school with minimal teacher supervision or direction. I observed teachers using a variety of strategies to assist students with reading fiction and non-fiction. At one of the faculty inservices on teaching students how to draw inferences from nonfiction material, one of the teachers asked, "We're trying to help kids pass the test, right? Like how to answer the question on page 3 I" ( $R$ : faculty inservice, $3 / 23 / 99$ )? There was a chorus of No's from the other teachers who responded that this strategy was to help students become better readers in general, not just for the state assessment. Given the degree to which teaching reading was valued by most of the staff I was not surprised that this instructional practice was ranked among the top five for frequency of use and also for increased use.

\section{Communication of student learning through writing. This} question asked participants to report the degree to which students communicated their learning through writing journals, logs, etc. This was the fifth instructional practice in which schools differed significantly in change in practice. Ponderosa Middle School staff reported the greatest increase (3.26) followed by Laurel Middle School 
(3.10) and Lighthouse (2.52). A slightly different but related instructional practice was teaching writing strategies across the curriculum. Ponderosa Middle School staff members were the only ones to list this practice among the top five for frequency of use.

Despite the significant differences reported on the survey, my observations led me to believe that the three schools were more similar than different in how they taught writing. Writing strategies, especially the six trait model and scoring rubric, were emphasized in all three schools. A major influence on the teaching of writing has been the WASL's use of the six trait scoring rubric (ideas and content, organization, voice, word choice, sentence fluency, and conventions/mechanics) and the specific modes such as descriptive, narrative, persuasive, etc. In all three schools in language arts classes, students wrote in journals at least weekly, shared their writing with a peer editor, and had some sort of grammar instruction. Both the district superintendent and building administrators in all three districts stressed that every teacher was to become a teacher of writing and that students would write and assess the quality of their own writing in science, health, math, art, social studies as well as language arts. I turn to an analysis of each school to clarify the difference between the survey data and my observations about teaching writing. 
Because of the Lighthouse district's heavy emphasis on the WASL and the focus on the six trait writing model in many districtsponsored inservices, Lighthouse Middle School language arts teachers refined their teaching of writing to focus on the specific traits and modes of writing on the state test. In the 1999-2000 school year four teachers developed "kid friendly six trait definitions" which were taught to the entire staff for use by students. In addition, science and social studies teachers shared responsibility with the language arts teachers for teaching specific modes of writing (compare/contrast, persuasive) and scoring them with the six trait rubric. These changes in practice were probably not reflected in the survey. which was conducted in March of 1999.

Because of the very poor scores by Laurel Middle School students on the seventh grade writing assessment (WASL) in the spring of 1998 , the new principal developed a plan to focus on teaching writing across all three grade levels. During the 1999-2000 school year the middle school implemented a school-wide writing prompt three days a week in which all students responded to the same prompt and were scored by their classroom teacher on one of the six traits. If the survey would have been conducted in January 2000 , when I conducted the focus groups, rather than March 1999, the reported change in practice in writing might have been higher. 
Among the three schools, Ponderosa teachers reported the greatest change in communicating student learning through writing. A related practice, teaching writing strategies across the curriculum, also was ranked by the staff members among their top five instructional practices. Working with their consultant, the middle school teachers had developed a writing rubric and were teaching various modes of writing several years before the development of the EALRs or the WASL. Thus, the staff had internalized the expectation that everyone was a writing teacher. In the classes I observed, I saw students use writing in their math projects, science and social studies reports, and to evaluate progress in their portfolios. The middle school principal provided a perspective of how the students' use of writing had changed over time.

But I do know that kids' view of writing is different because I know the majority of kids in our building by the time they finish seventh or eighth no longer view writing as something you do in one setting because the teacher told you to do it. They view writing differently and they assume that you would do a draft and they assume that you collect ideas before you try to do a draft and they assume that their ideas are valued and assessed as well as the mechanics. And I don't know if I could pull out data to say that but $I$ know if I sit with kids and I have a conversation with them, they tell me that.

( $R$ : interview, 3/12/99)

Cooperative learning. This was the sixth instructional practice in which schools differed significantly. While teachers at all three schools 
reported that cooperative learning was among the instructional practices they used most frequently, there were significant differences among the three schools. Again Ponderosa staff reported the greatest change in practice (3.65), followed by Laurel (2.61) and Lighthouse $(2.43)$.

All three teachers I interviewed and observed at Laurel Middle School incorporated some form of cooperative learning into their practice. One of the teachers tended to rely on two person student teams because he felt students were more accountable to a partner than to groups of three or four. The other teachers frequently incorporated cooperative learning groups in writing response groups, social studies and science lessons. The sixth grade teacher assigned students to formal roles such as recorder, facilitator, timekeeper and also used jigsaw strategies. Both of the teachers who used cooperative learning groups commented that this practice was modeled for them by the ASP leaders. They also felt this strategy was important for building collaboration among the many diverse cultural groups within the student body.

Even though staff members at Lighthouse Middle School reported cooperative learning among the top five instructional practices, they stated in interviews and focus groups that cooperative learning really wasn $t$ used that extensively at the seventh and eighth grade level. 
Teachers explained that cooperative learning took time to teach at the beginning of the year and was difficult to accomplish in 42 minute periods. Moreover at the seventh and eighth grade level, since students changed classes seven times a day, they didn't get to know one group of peers, unlike the sixth grade where students were together for much of the day. Both sixth grade teachers used some form of cooperative learning when I observed them, ranging from literature circles, to writing response partners, and in science and social studies projects. The sixth grade teachers valued cooperative learning because they believed it helped sixth graders coming from different elementary schools get to know each other and adjust to the middle school and because they felt that students learned more from each other than from the teacher alone. The seventh grade teacher used response partners for peer editing, but that was the limit of her use of cooperative learning.

Increased use of cooperative learning was ranked significantly higher at Ponderosa Middle School than at the other two schools, and teachers explained that this was a major emphasis of both building administrators. I observed some form of cooperative learning in almost every classroom I observed at the sixth and seventh grade levels at Ponderosa. Unlike the concern of some teachers at Lighthouse, Ponderosa schoolteachers did not feel that the interdependence of students in cooperative groups resulted in less academic learning. 
Teachers viewed heterogeneous small groups as an effective way for students to teach each other problem solving and higher level thinking skills. They insisted that every student in the group participate fully and be able to explain the group reasoning. I observed cross age peer tutoring between sixth and eighth grade students and between high school and middle school students.

Interventions with students who do not meet standards. This was the seventh instructional practice in which there was a significant difference by school. Ponderosa Middle School staff reported the greatest change (3.44), followed by Lighthouse (2.62) and Laurel $(2.52)$.

The interventions for low-performing students at Laurel and Lighthouse were typical of most middle schools: phone calls home, parent conferences, referral to the counselors and to special education, ana re-teaching the entire class when students failed to grasp major concepts. At Lighthouse, the sixth grade teachers, whom I observed, paired their students up so that weaker students had a partner who could help during class. However, this did not occur in seventh or eighth grade because students were not part of a cohort (they changed classes every 42 minutes), and the teachers had 150-175 students per day. 
Ponderosa Middle School had instituted a school-wide accountability plan in the 1997-1998 school year. Consequences for missing homework assignments were progressive and included phone calls and letters home and a week of after school tutoring until 4:00 p.m. Students who failed a class the previous trimester attended twenty hours of tutorial after school until 5:30 p.m. or on Saturdays to make up the credit. They also attended summer school. Some students volunteered to stay after school and formed a reading club totally run by the students who sat in the sponsoring teacher's classroom two days a week reading and discussing the book. Another group of boys arrived at school many mornings at 6:30 a.m. and joined the assistant principal's informal book club. Given all of these interventions with students, I was not surprised that Ponderosa staff reported the greatest increase in this practice among the three schools.

Involvement of students in research and experiments. This was the eighth instructional practice which differed significantly among the three schools. Involvement of students in research and experiments varied considerably among the three schools with less use at Lighthouse (1.98) and Laurel (2.48) and the most use at Ponderosa (3.24).

The two sixth grade teachers, whom I observed at Lighthouse, involved their students in frequent research projects in science and 
social studies. However, the seventh grade language arts teacher did not have her students complete any research projects. Part of the challenge in accomplishing this for seventh and eighth grade students was the shortness of the periods, and the lack of access to technology. Despite these challenges, eighth grade students at Lighthouse Middle School did complete a culture fair project, and the sixth grade students completed a science fair project every year. Yet the Lighthouse teachers scored lowest for change in student research and experiments.

All three teachers, whom I interviewed and observed at Laurel, incorporated student research into their practice. The sixth grade teacher emphasized an inquiry approach and the use of multiple sources in student research, although it was highly teacher directed. This teacher believed,

[student research] is the application, the synthesis part that's really missing in education, I feel. And this is where kids are told to be independent, and this is the place where kids really need to search for answers for things themselves. And a lot of times we just want to hand them the answers. And I really would like to see them be more independent learners. (U: interview, 4/23/99)

All eighth grade students participated in a culture fair project in their social studies class, producing a visual display. Seventh grade teachers as a group emphasized student research in science as well as physical education/health. They affirmed that the physical education 
teacher had students in the library/computer lab once a quarter to complete research using the Internet and doing power point presentations.

Ponderosa students' research projects seemed to be displayed everywhere in the school. There was a school-wide expectation that every student would research and present a written and/or oral presentation for the food festival each year. In addition, students conducted research in science and social studies, language arts and math and included some of their work in their student portfolios. I observed students using computers, accessing CD-ROMs and the Internet, and completing power point presentations in every classroom I observed. Thus it was not surprising that Ponderosa staff scored highest for involvement of students in research and experiments of the three schools.

Student portfolios. This was the final instructional practice in which increased use by teachers differed significantly among the three schools. The classroom observations, interviews, and focus groups supported the survey data, indicating significant differences among the three schools. This instructional practice varied considerably among the three schools with less of an increase in use at Lighthouse (1.39) and Laurel (2.02) and the greatest increase at Ponderosa (4.18). 
At Laurel Middle School the portfolio project begun earlier seemed to have diminished in importance by the time of this study. While portfolios of student work were transmitted from the elementary schools to the sixth grade teachers who filed students' writing assessments in the portfolios, the seventh and eighth grade teachers paid little attention to them. Furthermore the middle school teachers believed the high school teachers did not pay attention to the eighth grade portfolios that were sent up to the high school.

A similar situation seemed to have occurred at Lighthouse where middle schooi teachers resisted the use of portfolios. Previous experience with the high school staff, who ignored the middle school writing folders and school-to-work folders, was discouraging. However, during the 191998-1999 school year the Lighthouse district literacy cadre developed a language arts profile for implementation in the 1999-2000 school year. Based on the district language arts adoption, the profile required extensive student testing and record keeping by the language arts teachers. The situation was especially challenging for seventh and eighth grade teachers who had 175 students each.

In the interviews and focus groups Lighthouse teachers acknowledged that the portfolios were being transmitted with greater regularity from the elementary schools to the middle school. While all 
language arts teachers at the middle school were expected to record the language arts profile on each of their students, few of them indicated they had time to look at the folders of incoming students.

Student portfolios were developed at Ponderosa Middle School during the 1997-1998 school year to provide documentation, reflection, and celebration of students' work. Unlike the portfolios in the other two schools, which were district sponsored initiatives, the Ponderosa student portfolio project was designed by the Learning Improvement Team. The goal was to use the portfolios in student-led conferences. The portfolios included evidence of students as "quality workers, academic achievers, life long learners, and citizens" (R: portfolio document) and included grades, attendance, district reading and writing assessments. personal goal statements, and samples of student work: four book reviews, a writing project, an oral presentation, and a math project each trimester. The portfolios also included a parent participation log and students' community service. Specific time was set aside during advisory period each week for students to work on their portfolios. Given the time devoted each week to student work in their portfolio and the involvement of every teacher in the advisory/portfolio period, it was not surprising that Ponderosa staff reported the greatest increase in this practice among the three schools. 
Summary of Changes in Classroom

Practice by School

The instructional staff at Ponderosa Middle School reported significantly different changes in practice than staff at the other two schools. All three schools reported cooperative learning, active student engagement in learning tasks, and curriculum units (lessons) aligned to the EALRs among their top five instructional practices. Only Ponderosa Middle School also reported teaching reading and writing strategies across the curriculum among their top five practices. The three schools differed significantly for changes in nine instructional practices. These nine practices were reflection or metacognition by students, integration of technology, active student engagement in learning tasks. teaching reading strategies across the curriculum. communication of student learning through writing, cooperative learning, intervention with students who do not meet standards, involvement of students in research and experiments, and student portfolios. Ponderosa Middle School staff reported the greatest increase in use for all nine practices. Lighthouse Middle School staff reported the least change in six of these practices.

The next two sections of this chapter (research questions four and five) will examine some of the factors which may be related to these differences in change in practice among the three schools. 


\section{Research Question Four}

How are the following teacher factors related to staff members' familiarity with HB1209, their involvement in educational reform, and changes in classroom practice: (a) present teaching experience (academic area, grade, position); (b) previous teaching experience; (c) pedagogical knowledge; (d) involvement in educational reform; (e) sense of empowerment; and (f) selfefficacy?

In the previous three sections of this chapter I have examined the similarities and differences among the three schools regarding familiarity with HB1209, involvemeni in educational reform, and changes in classroom practice. Ponderosa Middle School staff reported greater familiarit: with HB 1209. Furthermore, the Ponderosa educators' understanding of the policy seemed more complex and focused on the pedagogical implications of the policy, i.e., requiring teachers to change instructional practices and students to demonstrate higher level thinking. While there were no significant differences among the three schools on overall involvement in educational reform activities, Ponderosa instructional staff ranked highest for participation in a collaborative group. Ponderosa Middle School also reported the 
highest mean score for every one of the twenty-four changes in classroom practice.

In order to understand why the staff members at the three schools responded as they did to $\mathrm{HB} 1209$, involvement in educational reform, and changes in practice, it is necessary to examine the teacher factors within the school-based learning community. As discussed earlier in chapter two, these six teacher factors are: (a) present teaching experience (academic area, grade, position); (b) previous teaching experience; (c) pedagogical knowledge; (d) involvement in educational reform; (e) sense of empowerment and ( $f$ ) self-efficacy. Previous research has documented the influence of these teacher factors on changes in classroom practice including: Chrispeels (1997); Cohen and Spillane (1992); Darling-Hammond (1997); Fullan (1993); Gearhart et al. (1994); Hoy and Miskell (1996); Knapp (1997); Lortie (1975); Marks ana Louis (1997); Peterson et al. (1996); Sarason (1996); Senge (1990); Taylor and Bogotch (1994).

First I will examine the relationship of the six teacher factors to familiarity with HB1209. Next, I will examine the relationship of the teacher factors to involvement in educational reform. Finally, I will examine the relationship of the teacher factors to changes in practice. In general, discussion will begin with a focus on all three cases with follow up discussion about any differences among the three schools 
which illuminate the relationship between the specific teacher factor and the question being addressed. In the conclusion to research question four I will examine the critical influence of empowerment on familiarity with HB1209, involvement in reform, and change in classroom practice.

Relation of Teacher Factors and Familiarity with HB1209

The data for this question were derived from the survey, administrator and teacher interviews, focus groups, and my classroom observations. Five of the six teacher factors were included on the survey (Appendix B): present teaching experience, i.e., academic area, grade level, staff position (I. Demographic Information), previous teaching experience (I. Demographic Information), involvement in education reform (2), sense of empowerment $(9 b, d, f, j)$ and selfefficacy $(9 a, c, e, g)$. The qualitative data from the interviews, observations, and focus groups supported the findings from the survey and also provided information about the teacher factor: pedagogical knowledge.

The first teacher factor I examined was present teaching experience, i.e., academic area, grade level, and staff position. I wanted to know if teachers' academic subject was related to their understanding of HB1209. In a study of the relationship between state 
curriculum policy and classroom practice in three states, Grant et al. (1996) confirmed the importance of teachers' prior knowledge and experience. In his review of the research into classroom effects of implementing the California Frameworks, Knapp (1997) found that teachers' understanding of the policy was shaped by their prior experience. He also suggested that teachers of different academic subject areas might view educational reform differently. While EALRs were developed for language arts, math, social studies, science, physical fitness/health, and the arts, the initial state assessments (WASL) focused only on language arts and mathematics. Therefore. I wondered if there would be a difference in the understanding of the EALRs and WASL depending on the staff members' academic teaching area.

Survey questions ( $1 a, b, c, d)$ asked staff members to rank their familiarity with the language arts and math standaras (EALRs) and test (WASL) on a scale of 1 (low) to 6 (high). An ANOVA was conducted and found significant differences by academic area on familiarity with standards (EALRs) and tests (WASL) at the .001 level. As expected, language arts and multiple core teachers reported the greatest familiarity with the language arts standards and test while math/science and multiple core teachers reported the greatest familiarity with the math standards and test (see Table 9). 
Table 9

Mean Level of Familiarity with HB1209 by Academic Area \#

\begin{tabular}{|l|l|l|l|l|l|}
\hline $\begin{array}{l}\text { ACADEMIC } \\
\text { AREA }\end{array}$ & $\begin{array}{l}\text { Lang Arts } \\
\text { Standards } \\
\mathrm{N}=155\end{array}$ & $\begin{array}{l}\text { Lang Arts } \\
\text { Test } \\
\mathrm{N}=155\end{array}$ & $\begin{array}{l}\text { Math } \\
\text { Standards } \\
\mathrm{N}=157\end{array}$ & $\begin{array}{l}\text { Math } \\
\text { Test } \\
\mathrm{N}=157\end{array}$ & $\begin{array}{l}\text { Familiarity } \\
\text { HB1209 } \\
\mathrm{N}=155\end{array}$ \\
\hline Language Arts & 5.3 & 5.2 & 2.9 & 3.0 & 16.4 \\
\hline Multiple Core & 5.1 & 4.1 & 4.2 & 3.0 & 17.3 \\
\hline Math/Science & 3.6 & 3.6 & 5.0 & 4.7 & 17.0 \\
\hline Elective & 3.2 & 2.9 & 2.3 & 2.2 & 10.5 \\
\hline PE Health & 3.3 & 3.0 & 3.1 & 2.8 & 12.3 \\
\hline $\begin{array}{l}\text { Learning } \\
\text { Support }\end{array}$ & 3.4 & 2.9 & 3.1 & 2.7 & 12.1 \\
\hline ANOVA & $*$ & $*$ & & & \\
\hline
\end{tabular}

\# Scale of 1 low to 6 high ** significance at $<.01$ level

A total score for familiarity with HB1209 was created by summing the scores for familiarity with the language arts and math standards and tests. As indicated by Table 9 above, multiple core and math/science teachers reported the greatest familiarity with HB 1209 as a whole, followed closely by language arts teachers. Thus, it would seem that teachers' academic subject area influenced their familiarity with the policy. Those instructional staff members whose subjects are tested by the WASL reported greatest familiarity with the policy.

Given the state requirement that all seventh grade students take the WASL including those with learning disabilities and other special needs, I would have expected the mean familiarity with HB1209 of learning support teachers to be higher than was reported on the survey. The implication of this lower degree of familiarity is that if learning 
support teachers are not familiar with the policy, there is unlikely to be the corresponding changes in practice in response to HB1209.

I also wanted to know whether teachers' grade level was related to their familiarity with HB1209. While essential academic learning requirements were developed for each grade level (K-12), testing occurs only at grades four, seven, and ten. An ANOVA was conducted on mean familiarity with $\mathrm{H} 1209$ by grade level. As indicated by Tablel 0 below, there were significant differences by grade level on familiarity with the language arts standards at the .05 level and with the language arts tests and the math standards and tests at the .001 level. Seventh grade teachers reported the greatest familiarity with the language arts and math standards and tests.

A total score for familiarity with HB1209 was created by summing the scores for familiarity with the language arts and math standards and tests.

Table 10

Mean Level of Familiarity with HB1209 by Grade Level \#

\begin{tabular}{|l|l|l|l|l|l|}
\hline Grade Level & $\begin{array}{l}\text { Lang. Arts } \\
\text { Standards } \\
\mathrm{N}=155\end{array}$ & $\begin{array}{l}\text { Lang. Arts } \\
\text { Tests } \\
\mathrm{N}=155\end{array}$ & $\begin{array}{l}\text { Math } \\
\text { Standards } \\
\mathrm{N}=157\end{array}$ & $\begin{array}{l}\text { Math } \\
\text { Tests } \\
\mathrm{N}=157\end{array}$ & $\begin{array}{l}\text { Familiarity } \\
\text { with HB } 1209 \\
\mathrm{~N}=155\end{array}$ \\
\hline Sixth & 4.5 & 3.6 & 3.6 & 3.2 & 14.9 \\
\hline Seventh & 4.4 & 4.5 & 3.9 & 3.9 & 16.8 \\
\hline Eighth & 4.3 & 4.2 & 3.4 & 3.2 & 15.0 \\
\hline Multi-grade & 3.7 & 3.2 & 3.1 & 2.9 & 12.9 \\
\hline ANOVA & $*$ & $* *$ & $*$ & $*$ & $*$ \\
\hline
\end{tabular}

\# ranked on a scale of 1 low to 6 high $^{* *}$ significance at $<.01$ level 
As indicated by Table 10 above, seventh grade teachers also reported the greatest familiarity with HBI209 as a whole. Since seventh grade is the testing year, it would be expected that seventh grade teachers would report the greatest familiarity. The implication is that if knowledge of the reform policy is a prerequisite for changing practice, seventh grade teachers will be most likely to report changes in practice. It would seem that teachers' grade level also influenced their familiarity with the policy. Those instructional staff members whose students are tested by the WASL reported greatest familiarity with the policy.

I also wanted to know whether staff members' position was related to their familiarity with HB1209. Was there a difference between teachers, administrators, specialists, and instructional assistants regarding their familiarity with the policy? In the initial administrator interviews, I noted that all of the administrators were very familiar with the EALRs and WASL. However, I did not know whether the instructional staff members at each school were similarly well informed.

An ANOVA was conducted and revealed significant differences by staff position on familiarity with standards and tests at the .001 level. As indicated by Table 11, administrators reported the highest 
familiarity with the language arts and math standards and tests, followed by counselors, teachers, specialists, and instructional assistants. However, there were only four counselors compared to 106 teachers, so the stronger reporting by counselors over teachers may not be significant. Thus it seems that staff position also influenced familiarity with HB 1209.

\section{Table 11}

Mean Level of Familiarity with HB1209 by Position \#

\begin{tabular}{|l|l|l|l|l|l|}
\hline Position & $\begin{array}{l}\text { Language Arts } \\
\text { Standards } \\
\mathrm{N}=155\end{array}$ & $\begin{array}{l}\text { Language } \\
\text { Arts Tests } \\
\mathrm{N}=155\end{array}$ & $\begin{array}{l}\text { Math } \\
\text { Standards } \\
\mathrm{N}=157\end{array}$ & $\begin{array}{l}\text { Math } \\
\text { Tests } \\
\mathrm{N}=157\end{array}$ & $\begin{array}{l}\text { Familiarity } \\
\text { with HB } 1209 \\
\mathrm{~N}=155\end{array}$ \\
\hline Teacher & 4.4 & 4.1 & 3.5 & 3.4 & 15.4 \\
\hline Administrator & 5.3 & 5.5 & 5.2 & 5.3 & 21.3 \\
\hline Counselor & 4.3 & 4.3 & 4.3 & 4.3 & 17.2 \\
\hline Specialist & 3.7 & 2.9 & 3.1 & 2.7 & 12.3 \\
\hline $\begin{array}{l}\text { Instructional.As } \\
\text { st }\end{array}$ & 3.1 & 2.7 & 2.9 & 2.6 & 11.2 \\
\hline ANOVA & $* *$ & $* *$ & $* *$ & $* *$ \\
\hline
\end{tabular}

When I examined the data for familiarity with HB1209 by school, I noted significant differences for instructional assistants among the three schools $(p<.01)$. The instructional assistants at Lighthouse Middle School reported a much lower mean score (4.5) for total familiarity with HB1209 than did their counterparts at Laurel (11.1) and Ponderosa (13.4). The greater familiarity with HB1209 reported by instructional assistants at Ponderosa was a function of organization and 
expectations. Each instructional assistant was assigned to a language arts/math science teaching team and was responsible with that team for the academic achievement of a cohort of students. Furthermore, all Ponderosa instructional assistants were expected to attend the inservices and faculty meetings so they could implement the building reform plan along with the teachers. In contrast at Laurel Middle School, many of the instructional assistants did not have direct student contact, nor did they receive training in the EALRs or WASL according to the focus group interviews.

I concluded that the greater familiarity with HB1209 of instructional assistants at Ponderosa Middle School had less to do with their position per se and more to do with school level factors (administrative expectations and organizational features which enhanced time for professional development) defining the position's responsibilities.

The second teacher factor, which I investigated for its relationship to familiarity with HB1209, was previous teaching experience. The demographic section of the survey provided information about the number of years and grade level of participants' previous teaching experience. Years of teaching experience was only slightly related to familiarity with HB1209 and showed a significant difference at the .05 level for familiarity with the language arts 
standards $(r=.182)$ and language arts test $(r=.225)$ only. There was no significant difference between staff members' previous level of teaching experience (elementary, middle school, high school, or K-12) and their reported familiarity with HB1209. Even though the.schools differed in the experience level and years of experience of their staff, there was not a strong relationship between previous experience and familiarity with the policy.

In the interviews, focus groups, and observations of meetings and in-service training, I noted the expectation that all staff members would be familiar with the state reform policy. For most experienced teachers at all three schools knowledge of the policy resulted from inservices and workshops. which will be discussed in the next section on school level factors. An interesting theme of the interviews and focus groups was the positive impact of university teacher preparation programs on teachers' familiarity with HB1209. In the interviews and focus groups teachers, who had been hired at Laurel and Ponderosa since 1995 , indicated the professors in their teacher education courses stressed knowledge and application of the EALRs and WASL.

The third teacher factor which I examined for its relationship to familiarity with HB1209 was the staff members' pedagogical knowledge. Cohen and Spillane (1992) suggest that standards-based reforms require teachers to exchange traditional modes of 
understanding for constructivist visions of knowledge. I wanted to know if there was a difference in how the staff members interpreted HB1209 and if a difference might be related to the staff members' pedagogical knowledge. The data for this question were synthesized from the administrator and teacher interviews and the focus groups.

There was a qualitative difference in the school faculties' understanding of the pedagogical implications of HB1209. The Lighthouse principal explained that the implications of HB1209 had not connected for her teachers, so the "WASL was really pushing them".

(S: administrator interview, 1/7/99). One of the Lighthouse teachers focused on the accountability aspect of HB1209.

[The legislators wanted some] standardization of what they are going to be paying for in the state of Washington with our taxpayers' money, and wanting to have some accountability then and real evidence that the funds they are directing toward Washington students are doing what they should. And so the first step is to define, well what is it that we want them to do. And then the next step was how are we going to go about assessing that. (S: teacher interview, 4/16/99)

Another Lighthouse teacher focused on the professional development funds which HB1209 provided.

It gives us dollars, right? to help us raise our standards, raise common standards, raise our expectations, raise our profession, not just for our students but also for ourselves because it allows in many cases some professional growth. (S: teacher interview, 4/16/99)

This teacher also felt the EALRs provided a direction for instruction. 
Although the EALRS cover a huge area, most of them are very general and broad, but it is kind of a funnel or a sieve. If it's not in there, we should probably take it out. And if it is there, then it's something we better make sure is addressed. (S: teacher interview, 4/16/99)

As noted in the discussion of research question one above,

Ponderosa administrators and teachers focused on the need to change instructional practices, giving more responsibility to students and enabling them to demonstrate higher level thinking

It [HB 1209] was created with the intention of having students be a little more responsible for their learning. And having them be more active in their learning. And to get teachers to modify their teaching practices to make students more responsible and to help them be more of a complete student. (R: teacher interview, 6/9/99)

I really value that the essential learnings in general look at the big picture of what you want the student to learn. I really value the fact that we're talking about the process as well as the product of writing as well as how students perceive it themselves. I really like the fact that there's a part about students assessing their own writing and reflecting on their own writing. And I really 11 ke that in math it's virtually that same thing. How do kids see themselves as mathematicians and do they see math in the real world?. The ELARs talk about does education connect to the real world, and are we using it in a thinking way? ( $\mathrm{R}$ : administrator interview, 1/26/99)

The contrast between the two interpretations of HB1209, as a vehicle for accountability and professional development versus a vehicle to change instructional practices and focus on student learning, illustrates the influence of pedagogical knowledge. As noted in the 
discussion of research question number three, Ponderosa Middle School staff reported the greatest changes in each of the twenty-four classroom practices. Many of these changes reflected a constructivist view of learning, such as student peer and self-evaluation, demonstration of student learning through performance and projects, students talk with each other about their learning and communicate their learning through writing, reflection or metacognition by students about their own learning, and active student engagement in learning tasks. Thus I concluded there was a relationship between staff members' pedagogical knowledge and their interpretation of HB1209.

The fourth teacher factor was involvement in educational reform. Previous research (Chrispeels, 1997) has documented the influence of involvement in educational reform on understanding of policy. Survey questions two and three asked staff members about their overall level of involvement in educational reform and about specific educational reform activities in which they were involved. (Appendix B). An ANOVA on those responses revealed significant differences by total involvement in educational reform and familiarity with standards and tests $(p<.001$ level). Correlational analysis revealed that the higher the level of staff involvement in educational reform activities, the greater the familiarity with the language arts and math standards and testing $(r=.603)$. See Figure 5 below. 


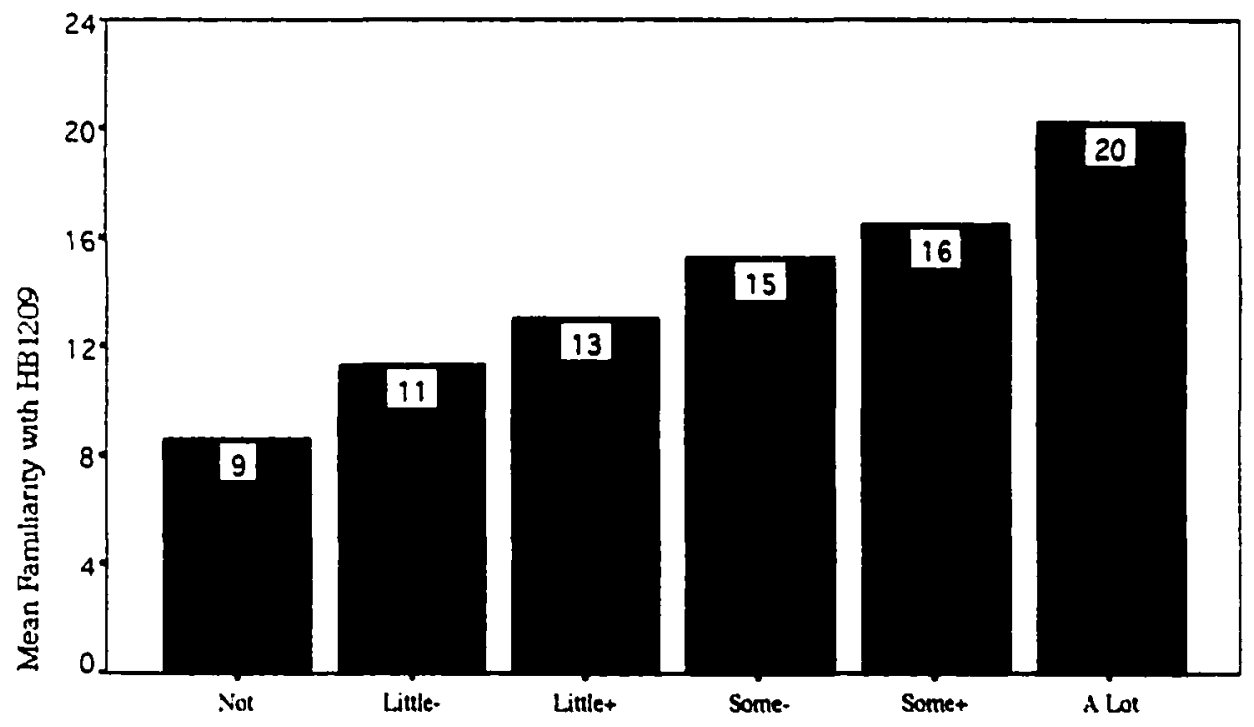

INIOLIED

$(N=152)$

Figure 5. Mean level of familiarity with HB 1209 by level of involvement in educational reform.

When HB 1209 was passed in 1993, the legislature established Student Learning Improvement Grants to pay for professional development opportunities for every teacher, based on school improvement plans that were submitted to the Office of the Superintendent of Public Instruction. Because the policy funded opportunities for involvement in educational reform (i.e., implementation of HB1209, the EALRs and the WASL) it is no surprise that involvement in educational reform and familiarity with HB1209 were highly correlated. Qualitative data from the interviews, focus 
groups, and observation of in-service training at all three schools confirmed this finding.

The fifth teacher factor was sense of empowerment. Empowerment is the degree to which teachers believe they can influence instructional policies and practices. Survey questions $9 b, d$, $\mathrm{f}$, and $\mathrm{h}$ asked staff members about their participation in making important decisions about curriculum, teaching strategies, student discipline and classroom management, and student assessments. An ANOVA revealed significant differences by sense of empowerment and familiarity with the language arts and math standards and tests (ranging from the $<.05$ to the $<.001$ level of significance). In general, the greater the staff members' sense of empowerment, the greater their familiarity with HB1209. A total score variable for sense of empowerment was computed based on survey questions $9 b, d, f, h$, and there was a significant positive correlation between staff members' sense of empowerment and familiarity with HBl209 $(r=.472 ; p<.001)$ as seen in Figure 6 below. 


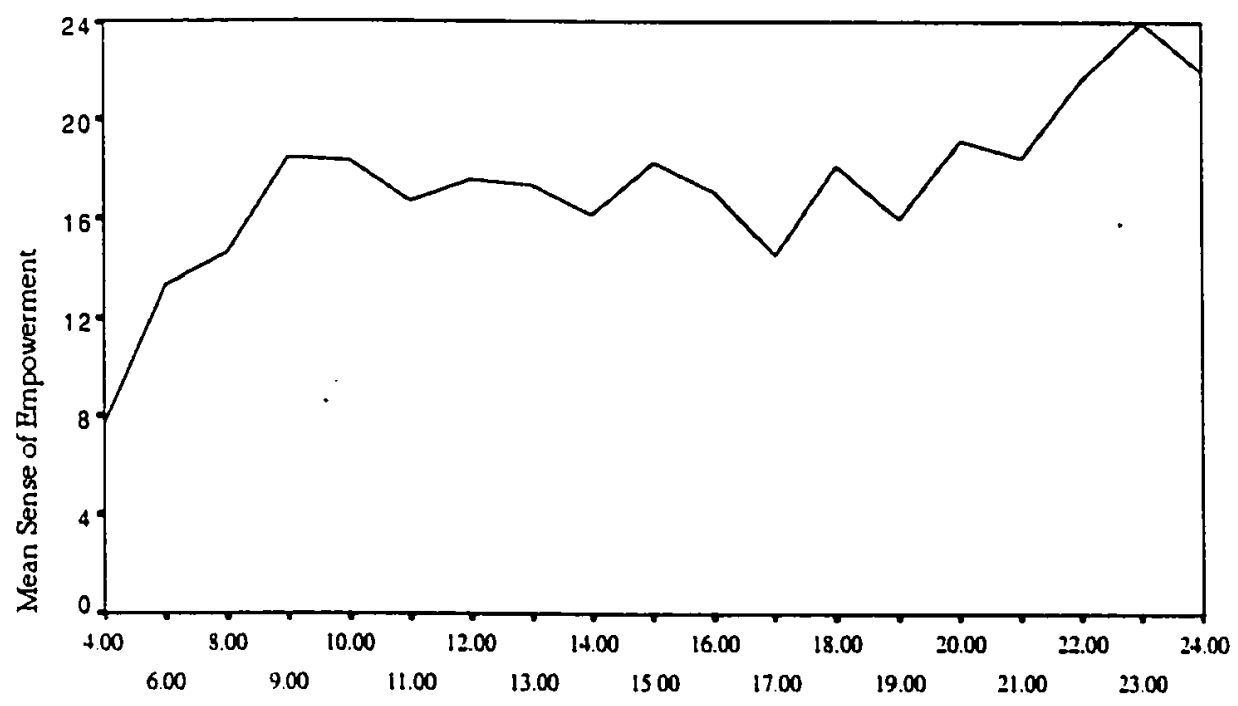

FAMHB 120

$(N=146)$

Figure 6. Mean level of familiarity with HB1209 and total sense of empowerment.

The sixth teacher factor I investigated regarding its relationship to familiarity with HB1209 was staff members' sense of efficacy. Selfefficacy is the teachers' belief they can influence student learning. Sarason (1996) concluded that teachers' sense of efficacy--a belief that the teacher can help even the most difficult or unmotivated students-was related to implementation of innovations. Survey questions $9 a, c, e$, $\mathrm{g}$ asked staff members about their ability to effectively teach difficult or unmotivated students (Appendix B). A total score variable for the 
four variables was computed, and a weak positive correlation $(r=.214$; $\mathrm{p}<.01$ ) was found between total efficacy and familiarity with HB 1209.

Summary of the Relation of Teacher

Factors and Familiarity with HB1209

A number of teacher factors was associated with familiarity with HB 1209. For the total survey, language arts and multiple core teachers reported greatest familiarity with language arts standards and tests while math/science and multiple core teachers reported greatest familiarity with math standards and tests. Seventh grade teachers reported greatest familiarity with $\mathrm{HB} 1209$ as did administrators and counselors. There was a weak positive correlation between total years of teaching experience and familiarity with the language arts standards and tests. University preparation programs for staff hired since 1995 influenced their familiarity with the policy. Staff members' involvement in educational reform and sense of empowerment were highly correlated with familiarity with HB1209. There was also a weak positive correlation between sense of efficacy and familiarity with HB 1209.

A multiple regression analysis was conducted to determine which of the above teacher factors was most predictive of overall familiarity with HB1209. The results are reported in Table 12 below. 
Table 12

\section{Multiple Regression of Teacher Factors and Familiarity with HB 1209}

\begin{tabular}{|l|l|l|l|}
\hline $\begin{array}{l}\text { Teacher factors } \\
\mathrm{N}=144\end{array}$ & $\begin{array}{l}\text { Correlation with } \\
\text { familiarity with HBI209 }\end{array}$ & Beta & R2 \\
\hline $\begin{array}{l}\text { Total involvement in } \\
\text { reform }\end{array}$ & $.603 * *$ & $.492 * *$ & .36 \\
\hline Sense of empowerment & $.472 * *$ & $.205 * *$ & .39 \\
\hline Self-efficacy & $.214 * *$ & NS & \\
\hline
\end{tabular}

** significance at $<.01$ level NS no significant difference

As expected from the correlational statistics, overall involvement in educational reform and sense of empowerment accounted for $39 \%$ of the variance in familiarity with HB 1209.

Relation of Teacher Factors and Involvement in Educational Reform

The second part of research question four was: What is the relationship between the six teacher factors and staff members' involvement in educational reform? Both quantitative and qualitative data were analyzed. Five of the six teacher factors were included on the survey (Appendix B): present teaching experience, i.e., academic area, grade level, staff position (I. Demographic Information); previous teaching experience (I. Demographic Information); involvement in education reform (2); sense of empowerment $(9 b, d, f, j)$; and selfefficacy $(9 a, c, e, g)$. The qualitative data from the interviews, observations, and focus groups supported the findings from the survey 
and also provided information about the sixth teacher factor: pedagogical knowledge.

The first teacher factor I examined was present teaching experience, i.e., academic area, grade level, and staff position. I wanted to investigate a possible relationship between teachers' involvement in reform and their academic area. Survey questions two and three (Appendix B) asked staff to report their involvement in eleven educational reform activities and their overall level of involvement in reform. There were significant differences by academic area on staff involvement in eight educational reform activities and for total involvement in educational reform, at the $<.05$ level of significance on the chi square analysis (see Chart $l$ in Appendix G). The language arts, math/science, and multiple core teachers were consistently ranked in the top three for participation on site councils, curriculum committees, interdisciplinary teams, and in workshops on the EALRs and WASL. These particular reform activities are directly connected with teaching and learning, which is the focus of HB1209. Furthermore, these particular academic areas are also the focus of the statewide assessments. Thus I was not surprised by the relationship of these academic areas and these specific reform activities.

A comparison of the mean scores for overall involvement in educational reform by subject taught was computed, and again there 
was a significant difference by academic area. The results are presented in Figure 7 below. Language arts and multiple core teachers ranked highest for overall level of involvement in reform, followed by math/science, pe/health, electives, and learning support teachers. In Figure 7 , the column NA refers to administrators and counselors.

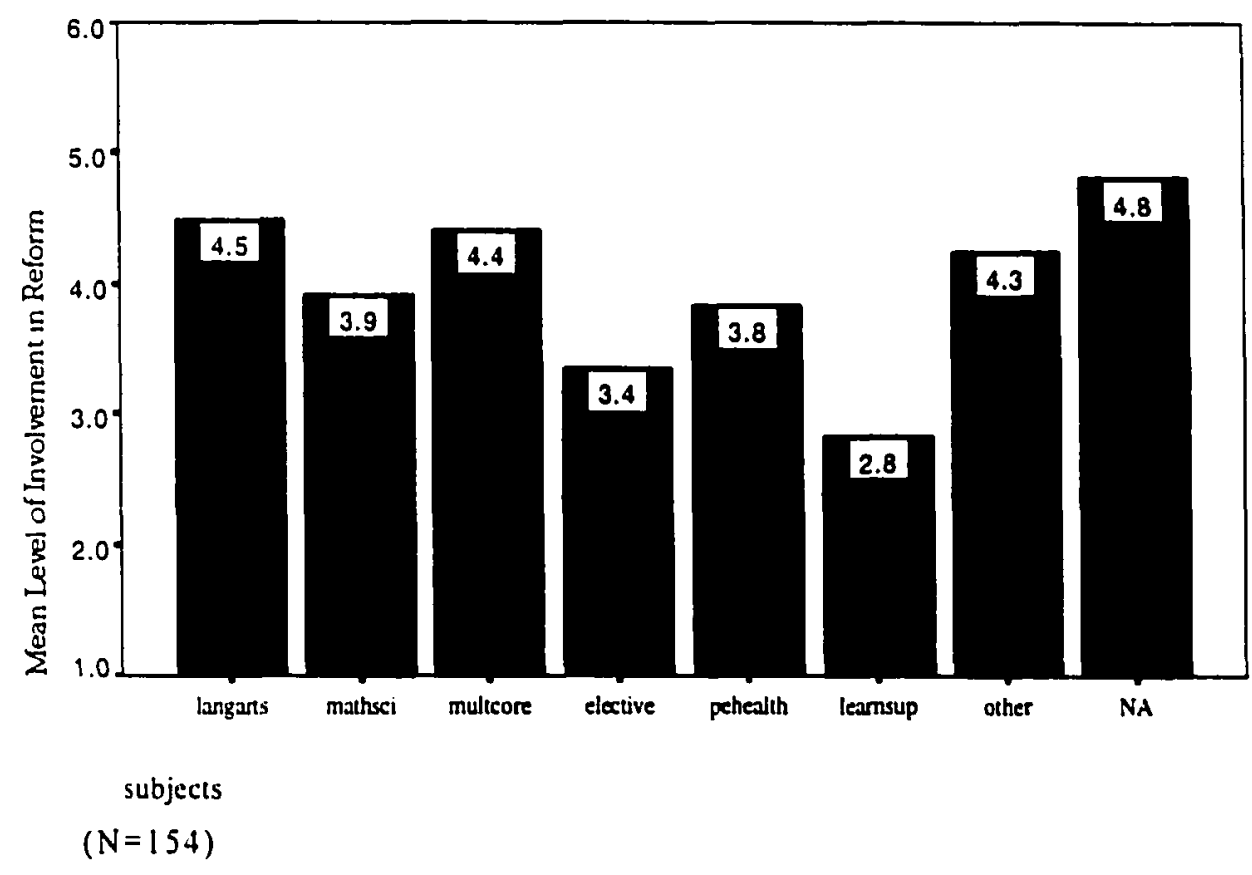

Figure 7. Mean level of staff involvement in educational reform by academic area

Thus it seems that teachers' academic subject area influenced their involvement in educational reform. Those instructional staff members whose subjects are tested by the WASL reported greatest involvement in reform. 
I also wanted to know if there was a relationship between teachers' involvement in educational reform and their grade level teaching assignment. While essential academic learning requirements were developed for each grade level (K-12), testing occurs only at grades four, seven, and ten.

Survey questions two and three (Appendix B) asked staff to report their involvement in specific educational reform activities and to rank their overall involvement in reform. There were significant differences by teachers' grade level on their involvement in five educational reform activities and for overall involvement in educational reform ranging from the $<.05$ to $<.01$ level on the chi square analysis. (see Chart 2 in Appendix G). A comparison of mean scores for involvement in specific educational reform activities was also computed (see Chart 3 in Appendix G). Seventh grade teachers ranked highest for involvement in workshops on the EALRs (3.5) and WASL (3.9). Since seventh grade is the WASL testing year, it would be expected that seventh grade teachers would report higher involvement in those workshops than other grade levels. As indicated by Figure 8 below for overall involvement in educational reform, seventh grade teachers ranked slightly higher followed by sixth and eighth grade teachers. (NA in Figure 8 refers to administrators and counselors.) It seems that teachers' grade level also influenced their involvement in 
educational reform. Those instructional staff members whose students are tested by the WASL, i.e., seventh grade teachers, reported greatest involvement in reform.

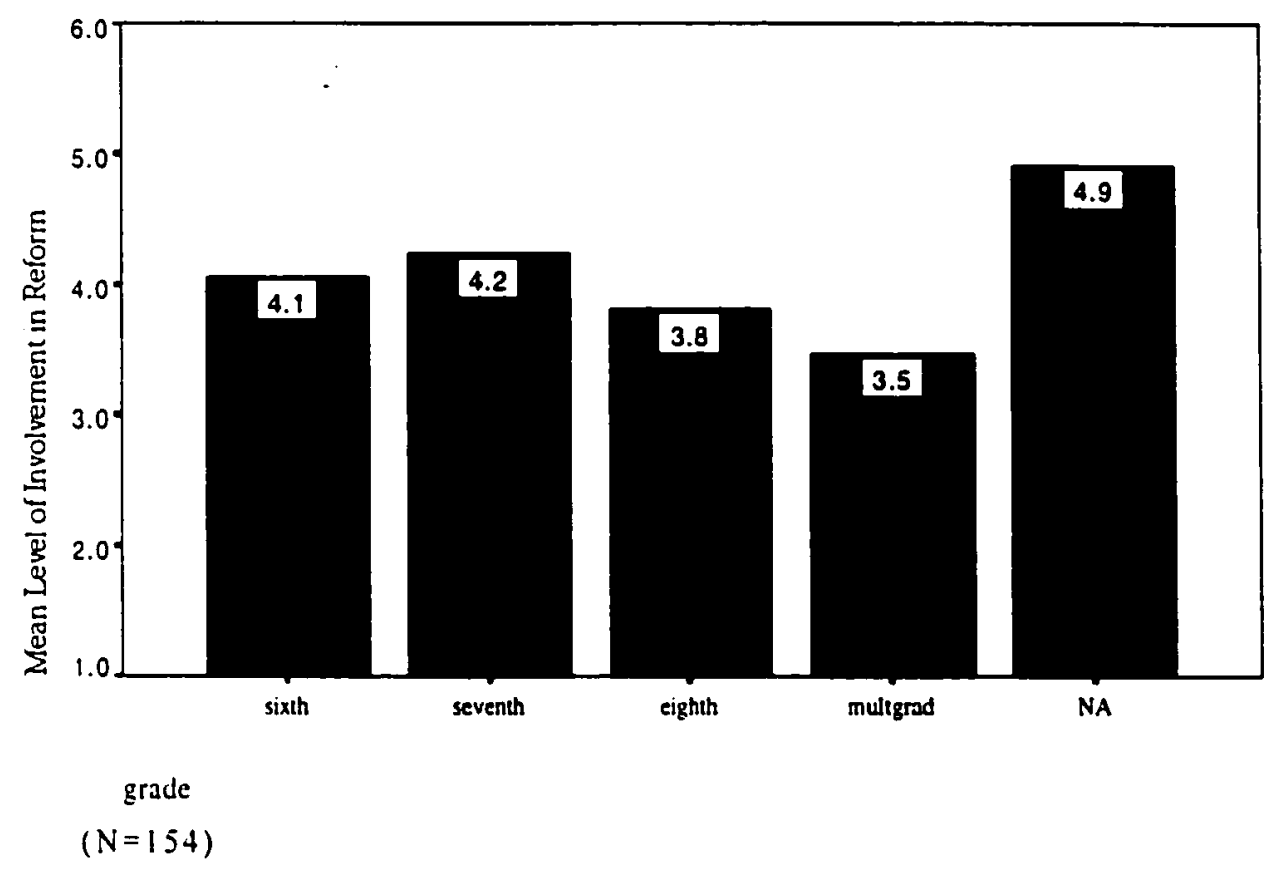

Figure 8. Mean level of overall involvement in educational reform by grade.

I also wanted to know whether staff members' position was related to their involvement. Was there a difference between teachers, administrators, specialists, and instructional assistants regarding their involvement in reform? 
As I expected, there was a relationship between involvement in educational reform (questions two and three on the survey) and staff position. There were significant differences by position on involvement in educational reform activities ranging from the $<.05$ to $<.01$ level on the chi square analysis (see Chart 4 in Appendix G). As indicated by Figure 9 below, administrators reported the highest involvement in educational reform activities, followed by counselors, teachers, specialists, and instructional assistants. However, there were

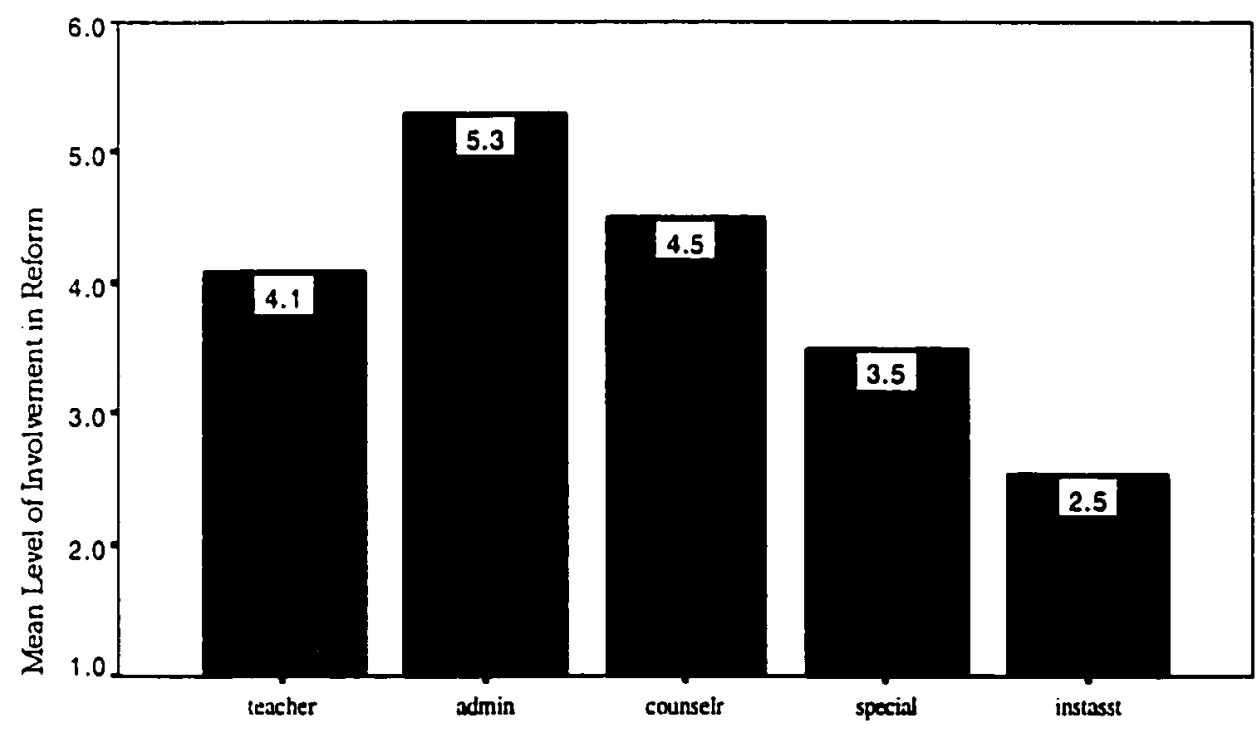
job

$(N=154)$

Figure 9. Mean level of staff involvement in educational reform by position. 
only four counselors compared to 106 teachers, so the stronger reporting by counselors over teachers may not be significant.

The second teacher factor, which I investigated for its relationship to involvement in educational reform, was previous teaching experience (Demographic Information I). There was a weak positive correlation between total years of teaching experience and involvement in educational reform activities $(r=.163 ; p<.05)$. However, there was no significant relationship between level of previous teaching experience (elementary, middle school, high school, $\mathrm{K}-12)$ and involvement in educational reform. Even though the schools differed in the experience level of their staff, there was not a strong relationship between previous years of experience and involvement in educational reform.

The third teacher factor which I examined for its relationship to involvement in reform was pedagogical knowledge (how to align curriculum to the EALRs and WASL and how to actively engage students). The survey provided a wealth of data about the nature of the school faculties' involvement in educational reform, which was summarized in the discussion of research question two above. However, only two questions on the survey allowed me to examine teachers' involvement in reform with their pedagogical knowledge. Questions $4 \mathrm{k}$ and $\mathrm{i}$ (Appendix B) asked teachers to report the degree to 
which lack of understanding of how to align curriculum with the EALRs and WASL and lack of understanding of how to change instruction to engage students in active learning were barriers to changing classroom practice. For the purpose of comparing these two questions to involvement, I recoded the variables ( $4 \mathrm{k}$ and $4 \mathrm{l}$ ) to remove the negative sign (-). A Pearson correlation test found a significant relationship between understanding how to change instruction to engage students in active learning and involvement in educational reform $(r=.315: p<.001)$

Qualitative data also affirmed the impact of some educational reform activities on teachers' pedagogical knowledge, specifically participation in a collaborative learning group, involvement in curriculum committees, aligning the curriculum and developing student performance standards, attending workshops on the EALRs and WASL and teaching on an interdisciplinary team. Teachers in all three schools talked about the connection between their involvement in reform and changes in their pedagogical knowledge.

One of the teachers I interviewed at Laurel had been involved in aligning reading curriculum with the EALRs and had participated in a teacher discussion group focusing on math strategies at her previous school. She commented about the connection between those two reform 
activities and her knowledge of how to teach reading and math to sixth graders.

The two sixth grade teachers I interviewed at Lighthouse had served on the school site council, language arts and math cadres. One of the teachers was originally trained in special education, and she explained that participation in a collaborative learning group at her previous school changed her knowledge and practice of teaching from direct instruction of discrete skills to a more holistic focus on reading and writing and helping students become self-directed learners. Involvement on the language arts cadre in the Lighthouse district led to teachers' pedagogical knowledge about the six trait writing process, student assessment, and portfolio development. Participation on the Lighthouse literacy team was related to knowledge of reading strategies.

Ponderosa Middle School teachers served on the district language arts committee and became trainers in the six trait writing process and scoring rubrics for the rest of the district. According to the principal, Ponderosa's Learning Improvement Team (site council) had made the decision several years ago, in anticipation of HB1209, to focus on curriculum, instruction, assessment, accountability, and parent involvement. Site council members spent several summers educating themselves about these areas, helped develop the district strategic plan, 
and took responsibility for helping plan professional development for Ponderosa teachers and developing the portfolios and student accountability program at the middle school.

Based on the data from the administrator and teacher interviews and focus groups, I concluded that staff members' involvement in educational reform activities was related to their pedagogical knowledge.

The fourth teacher factor which I examined for its relationship to involvement in educational reform was sense of empowerment. Empowerment is the degree to which teachers believe they can influence instructional policies and practices. Survey questions $9 \mathrm{~b}, \mathrm{~d}$, $f$. and $h$ (Appendix B) asked staff members about their participation in making important decisions about curriculum, teaching strategies, student discipline and classroom management, and student assessments. There were significant differences by sense of empowerment (as defined by survey questions $9 \mathrm{~b}, \mathrm{~d}, \mathrm{f}$, and $\mathrm{h}$ ) and involvement in educational reform ranging from.$<05$ to $<.001$ on the chi square analysis (see Chart 5 in Appendix G). A total score variable for sense of empowerment was computed based on survey questions $9 b, 9 d, 9 f$, and $9 \mathrm{~h}$, and a Pearson correlation test indicated a strong positive correlation between staff members' sense of empowerment and involvement in educational reform $(\mathrm{r}=.544 ; \mathrm{p}<.001)$. As indicated in 
Figure 10 below, the greater the staff members' sense of empowerment, the greater their involvement in educational reform.

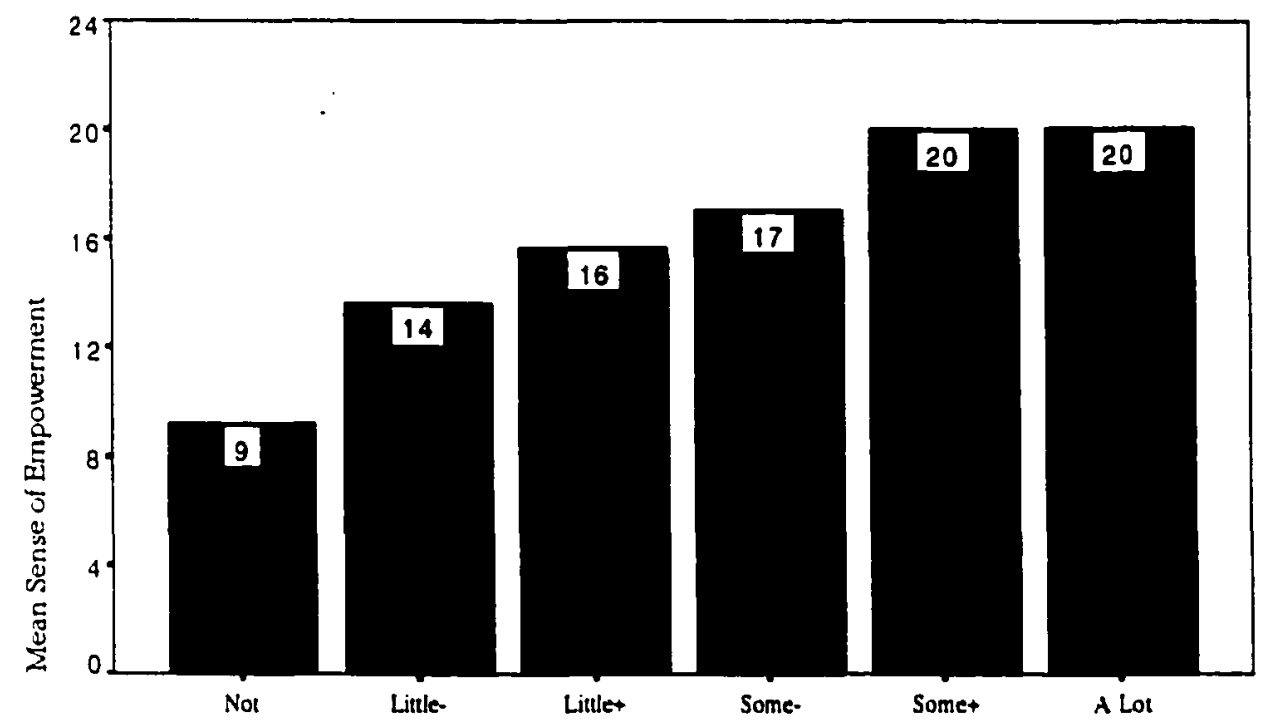

INVOLVED

Figure 10. Comparison of sense of empowerment and involvement in educational reform. $(\mathrm{N}=144)$

The fifth teacher factor which I examined for its relationship to involvement in reform was staff members' sense of efficacy. Selfefficacy is the teachers' belief they can influence student learning. Survey questions $9 a, c, e, g$ asked staff members about their ability to effectively teach difficult or unmotivated students (Appendix B). A chi square analysis found no significant differences by sense of efficacy (as measured by survey questions $9 a, c, e, g$ ) and involvement in 
educational reform. A total score variable for the four variables of efficacy (survey questions $9 a, 9 c, 9 e$, and $9 g$ ) was computed but there was no significant correlation between total efficacy and involvement in educational reform. There did not seem to be a strong relationship between staff members' sense of efficacy and their involvement in educational reform in my study.

Summary of the Relation of Teacher

Factors and Involvement in

Educational Reform

A number of teacher factors was associated with involvement in educational reform. There was a significant relationship between staff members ${ }^{\circ}$ present teaching experience (i.e., academic area, grade level, and position) and their involvement in educational reform. Core academic teachers (language arts, math/science, and multiple core) were consistently ranked highest for participation in site councils, curriculum committees, interdisciplinary teams, and workshops on the standards and tests. For overall level of involvement in educational reform, language arts and multiple core teachers ranked highest while seventh grade teachers ranked highest for involvement in standards and testing workshops and for overall involvement in educational reform. In general, administrators and counselors reported the highest involvement in educational reform activities. 
There was a positive correlation between one aspect of pedagogical knowledge (understanding how to change instruction to engage students in active learning) and involvement in educational reform. Also, the greater the staff members' sense of empowerment, the greater their involvement in educational reform.

A multiple regression analysis was conducted to determine which of the above teacher factors from the survey were most predictive of involvement in educational reform. The results are presented in Table 13 below.

\section{Table 13}

Multiple Regression of Teacher Factors and Involvement in Educational Reform

\begin{tabular}{|l|l|l|l|}
\hline $\begin{array}{l}\text { Teacher factors } \\
(\mathrm{N}=144)\end{array}$ & $\begin{array}{l}\text { Correlation with } \\
\text { involvement in } \\
\text { educational reform }\end{array}$ & Beta & $\mathrm{R} 2$ \\
\hline Sense of empowerment & $.544^{* *}$ & $.494^{* *}$ & .30 \\
\hline $\begin{array}{l}\text { Knowledge of how to change } \\
\text { instruction to engage students }\end{array}$ & $.315^{* *}$ & $.155 *$ & .32 \\
\hline
\end{tabular}

As expected from the correlational statistics, sense of empowerment and knowledge of how to change instruction to engage students accounted for $32 \%$ of the variance in involvement in educational reform. 
Relation of Teacher Factors and

Changes in Classroom Practice

The third part of research question four was: What is the relationship between the six teacher factors and changes in classroom practice? Five of the six teacher factors were included on the survey (Appendix B): present teaching experience, i.e., academic area, grade level, staff position (I. Demographic Information); previous teaching experience (I. Demographic Information); involvement in education reform (2); sense of empowerment $(9 b, d, f, j)$ and self-efficacy $(9 a, c, e, g)$. Survey questions six and seven asked participants to report the degree to which twenty-four classroom practices have occurred more frequently in their teaching and also their overall level of changes in classroom practice. The qualitative data from the interviews, observations, and focus groups supported the findings from the survey and also provided information about the sixth teacher factor, pedagogical knowledge.

Staff members were asked to report their overall level of change in classroom practice (survey question 7). Anova analysis revealed that overall change in practice differed significantly by school (p.021). Comparing mean scores for total change in practice showed Ponderosa Middle School staff reported the greatest changes in practice, followed 
by Laurel Middle School, and Lighthouse Middle School. See Figure 11 below.

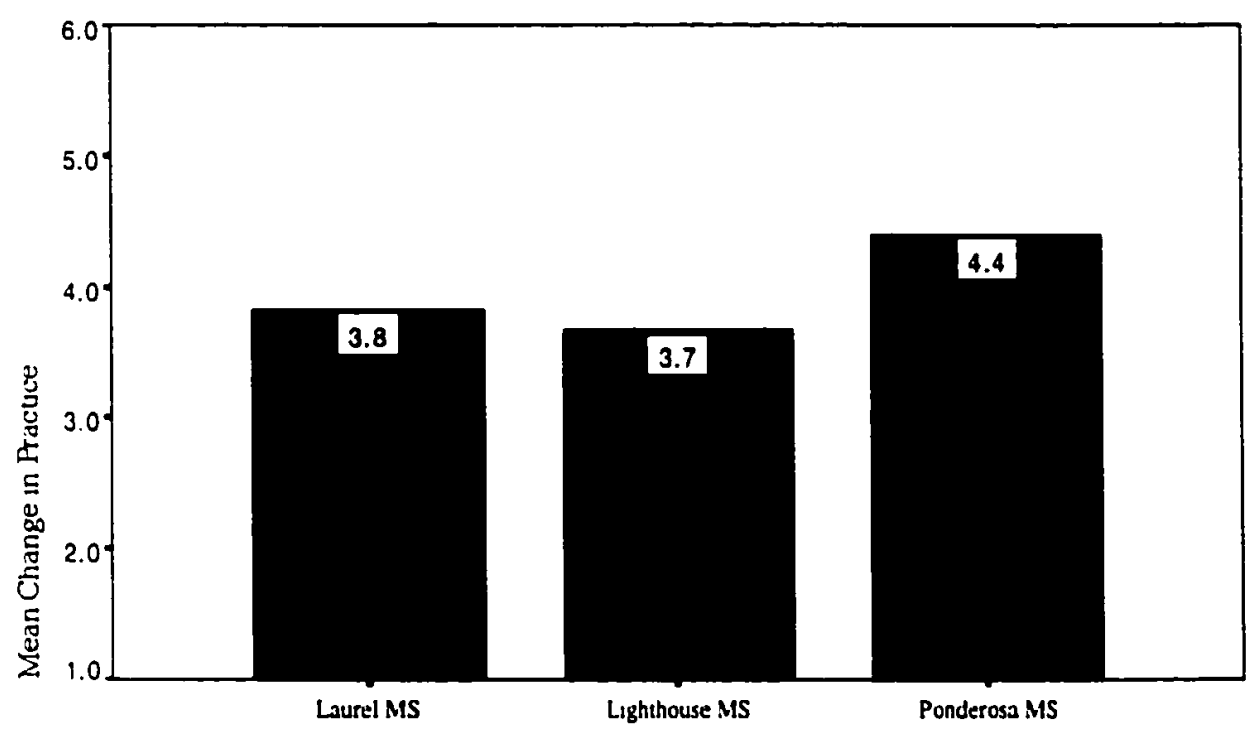

School

Figure 11. Mean change in classroom practice by school. $(N=140)$

The first teacher factor I examined was present teaching experience, i.e., academic area, grade level, and staff position. I wanted to know if teachers' academic subject was related to changes in classroom practice. When analyzing the data for all three schools, there were significant differences by academic area for seven of the twenty-four changes in classroom practice reported on survey question six. Comparing the mean scores indicated language arts teachers ranked highest for five of those seven changes in classroom practice (see Chart 6 in Appendix G). Specifically, language arts teachers 
ranked highest for more frequent use of scoring rubrics, performance assessments, student projects, teaching writing across the curriculum, and active student engagement in learning tasks. As expected, math teachers ranked highest for more frequent teaching of math problem solving. However, there was no significant difference by academic area for overall change in classroom practice. Those instructional staff members whose subjects are tested by the WASL reported the greatest changes in practice. Thus it seems that teachers' academic subject area influenced changes in classroom practice.

I also wanted to know whether teachers' grade level was related to changes in their classroom practice. While essential academic learning requirements were developed for each grade level (K-12), testing occurs only at grades four, seven, and ten.

When analyzing the data for all three schools, there were significant differences by grade level for nine of the twenty-four changes in classroom practice reported on survey question six. Comparing the mean scores indicated that seventh grade teachers ranked highest for eight of those nine changes in classroom practice (see Chart 7 in Appendix G). Specifically, these eight changes in practice were: more frequent use of performance assessment, clear standards for student performance, increased expectations of students, demonstration of student learning through projects, student talk about 
learning, active student engagement in learning tasks, use of student data to plan instruction, and ongoing assessment of students. Classroom observations and teacher interviews confirmed that many seventh grade teachers used these practices in preparing students for the seventh grade WASL

Overall change in practice as reported on survey question seven also differed significantly by grade level $(p<.01)$. Comparing mean scores for total change in practice showed the seventh grade teachers reported the highest degree of change, followed by sixth grade teachers, multiple grade and eighth grade teachers. As seen in Figure 12 below, those instructional staff members whose students are tested by the WASL reported greatest the greatest changes in practice.

I also wanted to know whether staff members' position was related to changes in practice. Was there a difference between teachers, administrators, specialists, and instructional assistants regarding reported changes on twenty-four classroom practices (survey question six) and overall changes in practice (survey question seven)? ANOVA was conducted to determine if there was a relationship between changes in classroom practices and staff position. There was a significant difference by position $(p=.03)$ only for changes in teaching math problem solving. Comparing mean scores indicated that administrators ranked highest (3.6), followed by instructional assistants 


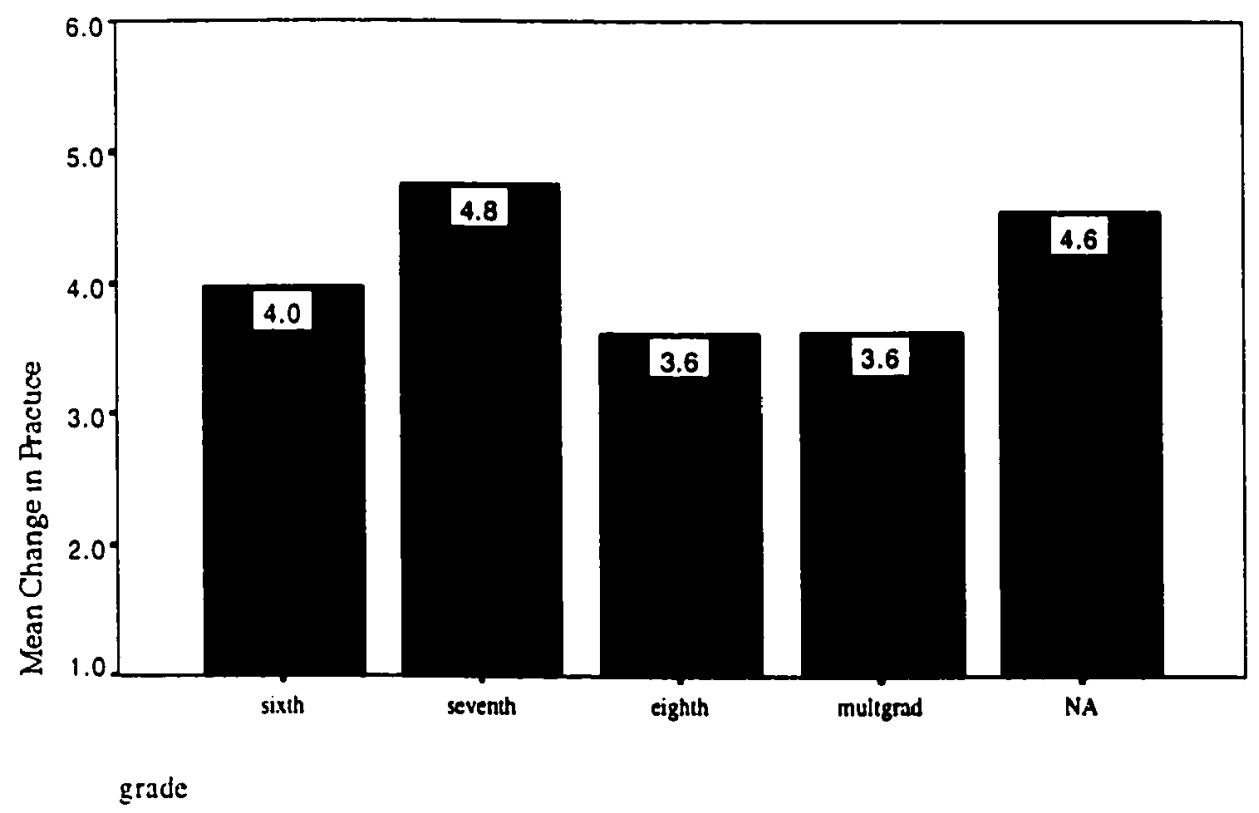

Figure 12. Mean change in classroom practice by grade. $(N=140)$

(3.4), specialists (2.2), and classroom teachers (2.1). It is puzzling that administrators perceived greater frequency of teaching math problem solving strategies than did the teachers. However, overall change in practice did not differ significantly by staff position. Thus I concluded that staff members' position was not strongly related to changes in instructional practice.

The second teacher factor which I examined for its relationship to changes in classroom practice was previous teaching experience. There was a weak positive correlation (ranging from $r=.163$ to $r=.312$ ) between total years of teaching experience and seven of the twenty-four 
changes in classroom practice reported on survey question six.

Teachers with greater years of experience were slightly more likely to report more frequent use of the following: cooperative learning, scoring rubrics, student peer evaluation, performance assessments, integration of technology, curriculum aligned to standards, and use of student data to plan instruction (see Chart 8 in Appendix G).

Overall change in practice, reported on survey question seven, also differed significantly with previous teaching experience. A Pearson correlation test showed that staff with greater years of total teaching experience were slightly more likely to report a higher level of change in classroom practice $(r=.192 ; \mathrm{p}=.02)$. However, previous level of teaching experience (elementary, middle, high school, K-12) was not significantly correlated with overall changes in classroom practice. Even though the schools differed in the experience level of their staff, there was not a strong relationship between previous years of experience and reported changes in classroom practice.

The third teacher factor which I examined for its connection to changes in classroom practice was pedagogical knowledge. The survey provided a wealth of data about the nature of the school faculties' changes in classroom practice, which was summarized in the discussion of research question three above. However, only two questions on the survey allowed me to examine pedagogical knowledge in relation to 
changes in classroom practice. Questions $4 \mathrm{k}$ and 1 (Appendix B) asked teachers to report the degree to which lack of understanding of how to align curriculum with the EALRs and WASL and lack of understanding of how to change instruction to engage students in active learning were barriers to changing classroom practice. For the purpose of comparing these two questions to changes in practice, I recoded the variables $(4 \mathrm{k}$ and 41 ) to remove the negative sign (-). A Pearson correlation test found no significant relationships between understanding how to align curriculum with the EALRs and WASL or understanding how to change instruction to engage students in active learning and changes in classroom practice.

However, the administrator and teacher interviews and classroom observations provided richer data about the relationship between pedagogical knowledge and changes in classroom practice. While the stereotypical view of university teacher preparation courses may not be positive, several teachers commented that some of their masters' level courses had influenced changes in their classroom practice.

A sixth grade teacher at Laurel cited her masters' thesis on using primary source documents to teach history, and subsequently I observed her teaching students to evaluate different sources. Another Laurel teacher commented, 
I particularly remember learning about how people build concepts, how people learn, you know, the different levels of thinking and trying to engage those multiple intelligences ( $U$ : interview, 4/23/99).

He also credited his master's program with teaching him to use cooperative learning strategies and scoring rubrics, both of which I observed in his classroom.

One of the most profound changes was expressed by a sixth grade teacher at the Lighthouse school who credited her master's program with a radical change in educational philosophy. Originally trained as a direct instruction Special Education teacher, she became one of the most skillful facilitators of student self-directed learning I observed.

Well. I kind of divide my professional life into two different periods and one was in the early 70's when I was a SPED teacher and very much into direct instruction and precision teaching, and I came back to the profession in the mid 80's and I immediately started working on my master's program. So everything that came across my path then allowed me to really develop my own and strategies and philosophy about what worked best.

She described a reading class taught by a special education director

It was a whole language class. We learned how to give reading miscue inventories, the whole ball of wax, all of the symbols. This was totally different in my approach to how kids learn. So that gal was again a big influence on changing my whole philosophy and approach to reading instruction. (S: interview, 4/16/99) 
The Ponderosa Middle School principal also talked about influences on his pedagogical knowledge which resulted in changes in his classroom practice.

But also during that time when I was teaching say in the first five years [I attended some amazing summer workshops sponsored by Learning magazine. They sort of did an integrated curriculum model for adults. They brought in researchers ... in wait time, hands on science kits, mathematics. They brought people who were involved in writing process and literature based reading. And these workshops were incredible. You stayed together for a week and you worked with these people 18 hours a day and you talked and thought with them. But I think from those experiences and some of the connections that really changed what I started to want to do in the classroom. (R: interview, $1 / 26 / 99)$

Twenty years later, this pedagogical knowledge was still evident in the classroom practices this principal expected to see at Ponderosa Middle School.

While there was not a significant correlation between the two survey questions regarding pedagogical knowledge and changes in classroom practice, the administrator and teacher interviews and classroom observations indicated rich connections between pedagogical knowledge and changes in practice.

The fourth teacher factor which I examined for its relationship to changes in classroom practice was involvement in educational reform. Previous research has documented the importance of teacher involvement in reform for long-term change in instructional strategies 
(Abdal-Haqq,1995; Almasi et al., 1995; Chrispeels, 1997; Cohen, 1990; Wiley \& Yoon, 1996)

A Pearson test of correlation was conducted to examine the relationship between over involvement in educational reform (survey question three) and twenty-four changes in classroom practice as reported on survey question six. There were significant correlations between total involvement in educational reform and eleven of the twenty-four changes in classroom practice (see Chart 9 in Appendix G). The more staff members indicated they were involved in educational reform, the more likely they were to report more frequent use of these eleven practices: scoring rubrics, student peer and self evaluation, performance assessments, interdisciplinary curriculum, interventions with students who do not meet standards, communication of learning through student writing and talk, metacognition, curriculum aligned to the standards, and use of student data to plan instruction.

Overall change in practice (survey question seven) also differed significantly by overall level of involvement (survey question three). As indicated in Figure 13 below, a Pearson correlation test showed that the higher the level of staff involvement, the more likely staff were to report a higher level of changes in classroom practice $(r=.323 ; p=$ $.001)$. Thus, I concluded that involvement in educational reform was strongly related to changes in classroom practice. 


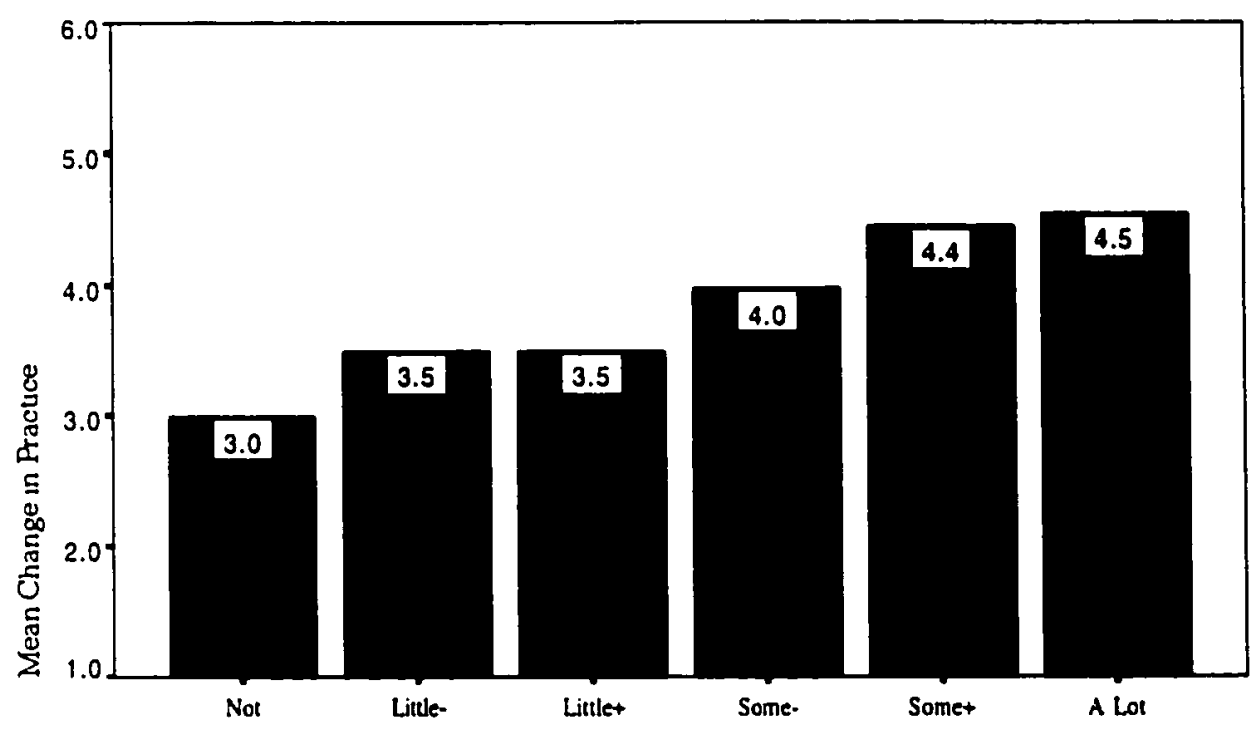

INVOLVED

Figure 13. Mean change in classroom practice by level of involvement in reform. $(\mathrm{N}=139)$

The fifth teacher factor which I examined for its relationship to changes in classroom practice was sense of empowerment. Empowerment is the degree to which teachers believe they can influence instructional policies and practices. Survey questions $9 b, d$, $\mathrm{f}$, and $\mathrm{h}$ (Appendix $\mathrm{B}$ ) asked staff members about their participation in making important decisions about curriculum, teaching strategies, student discipline and classroom management, and student assessments. Results of the Pearson correlation test indicated significant positive 
correlations between sense of empowerment and eight of the twentyfour changes in classroom practice reported on survey question six (see Chart 10 in Appendix G). The more staff felt empowered, the more likely they were to report more frequent use of these eight practices: scoring rubrics, student metacognition, curriculum aligned to the standards, student dialogue about learning, active student engagement. using student data to plan instruction, and student peer and self-evaluation.

Overall change in practice, reported on survey question seven, also differed significantly by sense of empowerment. A Pearson correlation test showed that the higher the sense of empowerment, the more likely staff were to report a higher level of change in classroom practice $(r=.271 ; p=.002)$. I concluded that staff sense of empowerment was moderately related to changes in practice.

Sense of empowerment was highly correlated with familiarity with HB1209 $(r=.472)$ and involvement in educational reform $(r=.544)$. Empowerment was moderately correlated with changes in classroom practice (.271) although it was less predictive of change in practice than was involvement in reform. Data from the interviews and focus groups illuminated the differences in empowerment among the three schools. There were strong individuals at all three schools, and all the building administrators and teachers I interviewed felt empowered to 
make decisions about their school and classroom. However, staff empowerment school-wide was only observed at Ponderosa Middle School. I will now explain why this was the case.

Despite the Laurel superintendent's statement that the Accelerated Schools Project was chosen by $80 \%$ of the staff, faculty perception differed at the middle school. In both interviews and focus groups, I was told that the Accelerated Schools Project was voted down two or three times in the spring of 1998 . One teacher commented, "Choosing ASP was like Safeco Field. The decision was already made" (U: focus group, $1 / 14 / 2000$ ). Consequently the staff did not feel empowered at the beginning of the ASP process, and the new principal had difficulty getting teachers to volunteer to assume leadership roles for the Accelerated Schools Project in the fall of 1999. In both interviews and focus groups I heard staff complain about being overworked. Despite the slow start, by January 2000, when I conducted focus groups at the school, many more teachers were assuming leadership of ASP cadres, researching best practices, aligning curriculum, and developing reading and writing prompts for the schoolwide skill building activities.

The Lighthouse school district had experienced a change from strong site-based leadership teams and empowerment to initiate educational reforms at the individual school level in the early $1990^{\circ} \mathrm{s}$ to 
a more centralized approach in recent years. In the interviews and at the district language arts cadre meetings I noted frustration with frequent changes in district decisions about assessment. For example, at the beginning of the 1998-1999 school year middle school teachers were told to prepare students for the WASL, which would replace district levels testing, writing assessments, and math performance assessments. Then in mid-winter teachers were told their students would not take the WASL, but would take all the other district tests including a writing assessment and math performance assessment. Consequently some teacher leaders felt the district was shooting from the hip, making it difficult for building staff to make plans. One teacher commented. "It doesn't seem like the district knows from day to day what they are doing" (S: interview, 4/27/99).

At the end of the 1998-1999 school year and in the focus groups in January and February 2000 , staff complained of being burdened with endless meetings, increased paperwork with the language arts student portfolios, and required parent contacts for high needs students. There was a feeling of exhaustion.

Ten years ago the Ponderosa district administration allowed the middle school to make some strategic decisions to focus on the writing process and literature-based reading rather than the whole language approach favored by the rest of the district. Over the years the middle 
school staff and administrators assumed leadership on key district committees, shaping the district strategic plan, providing language arts inservices for the rest of the district, presenting their work at national conferences, and gaining a national reputation for innovation and excellence.

Seven years ago the district initiated site-based councils, and at the middle school, the principal insisted that the Learning Improvement Team (LIT) focus on academic issues and make decisions based on knowledge. Consequently the LIT made decisions about implementing the EALRs in the middle school, prioritized expenditure of funds for all curriculum and professional-development projects, and assumed leadership for implementation of educational reforms including, Expeditionary Learning, the student accountability program, parent involvement, and student portfolios.

In grade level team meetings and at faculty meetings and in the interviews, the building principal praised his staff and continued to provide opportunities for them to be involved and make decisions. One teacher commented on what made the Ponderosa school so unique.

There's probably no other school in the state like this. [The principal] believes we can do it, and the kids can do it. Of course they'll do the presentations with quality. The accountability and time on task are unique. We're a staff of doers. None of us are quitters. You can't stay in this school and not work hard. There's not one teacher who has problems with the kids. Our kids need so much, 
and we feel all the extra stuff we do helps them.

( $R$ : informal conversation, 4/2/99)

However, there were some dissenting voices at Ponderosa which I heard about at the beginning of the 1999-2000 school year. One teacher was very frustrated by those who would rather complain about their work load and all the expectations associated with the double planning period. "I would always walk past groups of people that were complaining about how stressed they were during their double planning" (R: interview, 8/19/99).

Thus, empowerment was significantly related to familiarity with HB 1209, involvement in educational reform, and change in classroom practice. Examining the differences in empowerment among the three schools suggests that empowerment school-wide is a very important factor in supporting a learning community.

Sense of efficacy was the sixth teacher factor which I investigated for its relationship to changes in classroom practice. Selfefficacy is the teachers' belief they can influence student learning. Survey questions 9a,c,e, g (Appendix B) asked staff members about their ability to effectively teach difficult or unmotivated students. A Pearson correlation test indicated a significant relationship between staff members' sense of efficacy and three of the twenty-four changes in practice (reported on survey question six): student peer evaluation, 
the development of student portfolios, and student metacognition (see Chart 11 in Appendix G). However, overall change in practice reported on survey question seven did not differ significantly by sense of efficacy.

The administrator and teacher interviews provided a richer picture of the relationship between self-efficacy and changes in classroom practice. Staff at all three schools voiced concerns about lack of parent and community support, which ranked as the fourth highest barrier to changing classroom practice on survey question $4 \mathrm{~h}$ (Appendix B). I wondered if these concerns indicated a lack of confidence that, as educators, they could change their practice given the lack of community and parent support.

In the Laurel district over $22 \%$ of the students are classified English as a Second Language (ESOL), speaking over thirty different languages. Many of the students have recently emigrated from refugee camps around the world, and sixty-four percent of the students are on free/reduced breakfast and lunch programs. One of the Laurel schoolteachers I interviewed felt that parents were well-intentioned but provided no follow-through with expectations of their students. Yet, he felt that while parent support was an important ingredient of student achievement, it did not necessarily affect classroom practice. 
The Lighthouse Middle School had far fewer ESOL, ethnic minority, and low income students than did the Laurel and Ponderosa schools. However, the same concern about lack of parent support was voiced.

And as rigorous as those standards [EALRs] are, most of our parent population isn't able to do the job they need to educate those [high-risk] kids to get them ready for it. It's just not possible. (S: principal interview, 1/7/99)

The principal's answer to the lack of parent community support was to develop parent involvement workshops as she had done as principal of an elementary school in the district; however, lack of funding was an issue because the middle school was not a Title I funded school.

The principal went on to say that many teachers resisted looking at the child as an individual. The teachers were saying,

Here's my standards and these kids just aren't meeting them, and it's the parents' problem and the kids' problem. And they're not looking at it from a holistic approach of who that child is as a learner. (S: interview, 1/7/99)

Her response to these teachers was the district's policy of personalizing education and using student data to plan instruction.

Issues of poverty, race, class, and language were also significant barriers in the Ponderosa district. Over $85 \%$ of the students at the Ponderosa middle school qualified for free and reduced breakfast and lunch programs, and $26 \%$ were ESOL students. The middle school principal acknowledged, 
If a student in [our district] enters kindergarten four years behind in oral language development because of poverty and no books in the home, it makes a different situation when the student arrives in the sixth grade than it would otherwise...I guess I think we're a bit stubborn in saying Yeah but they are smart kids and they can do this.

Anything less is cheating them...I think our staff is really good about believing in the kids. (R: interview, 1/26/99)

While the Ponderosa teachers were frustrated by the lack of parent involvement, they understood the parents' challenges of language barriers, feelings of alienation from public schools, and having to work two jobs. Several years ago the Learning Improvement Team established a series of parent workshops and incorporated parent involvement into the student portfolios.

\section{Summary of the Relation of Teacher}

Factors and Changes in

Classroom Practice

A number of teacher factors were associated with changes in classroom practice. Table 14 below summarizes the changes in practice that were significantly related to the teacher factors across all three sites. There was a significant relationship between staff members' present teaching experience, i.e., academic area and grade level, and changes in classroom practices. Language arts and seventh grade teachers ranked highest for changes in practice. Teachers with more years of experience, greater involvement in educational reform, and 
greater sense of empowerment were also more likely to report changes

in practice.

Table 14

Relation of Teacher Factors and Changes in Classroom Practice

\begin{tabular}{|c|c|c|c|c|c|c|}
\hline Change in Practice & $\begin{array}{l}\text { Present } \\
\text { Experience }\end{array}$ & \begin{tabular}{|l} 
Previous \\
Experience
\end{tabular} & $\begin{array}{l}\text { Pedagogical } \\
\text { Knowledge \# }\end{array}$ & $\begin{array}{l}\text { Involvement in } \\
\text { Reform }\end{array}$ & Empowerment & Efficacy \\
\hline Scoring rubric & LA & $\bar{x}$ & $x$ & $\bar{x}$ & $\bar{x}$ & \\
\hline Perf. Assess. & LA $7^{\text {th }}$ & $\mathrm{X}$ & $x$ & $\mathrm{X}$ & & \\
\hline Stu.Project & LA 7 th & & $\mathrm{X}$ & & & $\bar{x}$ \\
\hline Active Engage. & LA 7 th & & $\bar{x}$ & & $\bar{X}$ & \\
\hline Writing & LA & & $\bar{x}$ & & & \\
\hline Math Problems & Math Admin & & & & & \\
\hline Clear Stand. & 7 th & & & & & \\
\hline Higher Expect. & 7 th & & & & & \\
\hline Student Talk & 7 th & & & $x$ & $\bar{X}$ & \\
\hline Use Student Data & 7 th & $\bar{x}$ & & $x$ & $\bar{X}$ & \\
\hline Ongoing Assess. & $7 \mathrm{th}$ & & & & & \\
\hline Cooperative Lrng & & $\mathbf{X}$ & $\bar{x}$ & & & \\
\hline Stud. Peer Eval & & $\bar{x}$ & $\bar{X}$ & $\mathrm{X}$ & $\mathbf{X}$ & $\bar{x}$ \\
\hline Stud. Self Eval. & & & & $\mathrm{x}$ & $\mathbf{x}$ & \\
\hline Technology & & $x$ & $\mathrm{X}$ & & & \\
\hline Align Curr. & & $x$ & $x$ & $\bar{x}$ & $\bar{X}$ & \\
\hline Reading Strategies & & & $\mathrm{x}$ & & & \\
\hline Metacognition & & & $\bar{x}$ & $\bar{x}$ & $\bar{x}$ & $\bar{x}$ \\
\hline Interdisc.Curr. & & & & $\bar{x}$ & & \\
\hline Stud. Writing & & & & $\bar{x}$ & & \\
\hline
\end{tabular}

\# I observed a direct connection between in-service training or staff members' discussion of their pedagogical knowledge and specific classroom practices.

A multiple regression analysis was conducted to determine which of the above teacher factors was most predictive of overall changes in classroom practice. As indicated by Table 15 below, involvement in 
educational reform accounted for $10 \%$ of the variance in changes in classroom practice.

Table 15

Multiple Regression of Teacher Factors and Changes in Classroom Practice

\begin{tabular}{|l|l|l|l|}
\hline $\begin{array}{l}\text { Teacher factors } \\
(\mathrm{N}=131-1+0)\end{array}$ & $\begin{array}{l}\text { Correlation with } \\
\text { changes in practice }\end{array}$ & Beta & R2 \\
\hline Involvement in Reform & $.323^{* *}$ & $323^{*}$ & .10 \\
\hline Empowerment & $.271^{* *}$ & NS & \\
\hline
\end{tabular}

* significance at $<.01$ level * significance at $<.05$ level

\section{Research Question Five}

How do the following school level factors influence staff members' familiarity with HB1209, their involvement in educational reform, and changes in classroom practice: (a) previous educational policies; (b) participation in a collaborative learning group; (c) building and district administrative expectations and support; and (d) organizational features that enhance time for teachers to learn and collaborate?

In the previous four sections of this chapter I have examined the similarities and differences among the three schools regarding familiarity with HB1209, involvement in educational reform, and changes in classroom practice. I also examined the relationship between six teacher factors and familiarity with the policy, involvement 
in reform, and changes in practice. However, teacher factors are only one part of a school-based learning community. In order to more fully understand the nature of a school-based learning community, it is also necessary to examine the school level factors. These four factors are:

(a) previous educational policies; (b) participation in a collaborative learning group; (c) building and district administrative expectations and support; and (d) organizational features that enhance time for teachers to learn and collaborate.

First, I will examine the relationship of the four school level factors to familiarity with HB1209. Next I will examine the relationship of the school factors to involvement in educational reform. Finally I will examine the relationship of the school factors to changes in classroom practice. In general, discussion will begin with a focus on all three cases with follow-up discussion about any differences among the three schools, which illuminate the relationship between the specific school level factors and the question being addressed.

\section{Relation of School Level Factors and}

\section{Familiarity with HB1209}

The data for this question were derived from the surveys, administrator and teacher interviews, focus groups, and classroom observations. Examining both quantitative and qualitative data helped clarify the relation between school level factors and familiarity with 
the policy. The four school level factors were: (a) previous educational policies; (b) participation in a collaborative learning group; (c) building level and district administrative expectations and support; and (d) organizational features that enhance time for teachers to learn and collaborate.

The first school level factor was_previous educational policies. Research has shown that previous educational policy is an important factor influencing teachers' responses to standards-based reform (Darling-Hammond, 1990; Elmore et al., 1996).

Prior to the passage of HB1209, both the Ponderosa and Lighthouse districts developed content standards and benchmarks, which were similar to the state standards. Both districts also made policy decisions prior to the $1998-1999$ school year to align their curriculum to the EALRs and WASL. Thus it was not surprising that the Ponderosa staff reported the greatest familiarity with HB 1209 , followed by Lighthouse and Laurel staff (see Table 4 on page 132). When I asked the Ponderosa staff in the focus group why they reported such a high level of familiarity with HB 1209 , they acknowledged the impact of previous policy decisions. "We made it a priority. Curriculum was aligned to the EALRs. It was a priority from the superintendent and the school board" (R: focus group, 10/29/99). 
A district administrator and one of the teachers I interviewed believed that the Lighthouse school district did an excellent job of keeping language arts teachers informed of the state essential learnings and prioritizing alignment of the district content standards to the EALRs. Each language arts teacher was given a notebook that included the district and state standards in reading, writing, and communication skills.

Laurel Middle School's new principal recognized that while the district had initiated some work on aligning curriculum to the EALRs and WASL, nothing had been done at the building level. The principal explained the staff attitude at the beginning of the 1998-1999 school year.

I think it [alignment of building curriculum to the EALRs and WASL] was at arm's length. [Veteran teachers felt] somebody else should do it. It's going to happen, but we don't know when. (U: principal interview, 1/14/99)

Consequently. one of the first school-wide workshops conducted by the principal during her first year was curriculum alignment with the EALRs. Every Laurel Middle School teacher participated in a subjectalike group to align the curriculum at each grade level with the essential learnings. This policy decision by the Laurel principal resulted in a school-wide emphasis on the essential learnings which I 
continued to note in focus groups in January of the following school year.

The second school level factor was participation in a collaborative learning group. There is rich research confirming the importance of participation with professional colleagues in helping teachers interpret and respond to educational reforms (Knapp, 1997; O’Day, 1995)

Five questions on the survey (see Appendix B) investigated aspects of a collaborative learning group: ( $5 \mathrm{a})$ collegial teams; ( $5 \mathrm{~b})$ conversations about classroom practice; (5c) inservices and workshops; (51) staff involvement in decision-making; and (5p) modeling of classroom practices. A Pearson correlation test of the relationship between these aspects of a collaborative learning group and familiarity with HB1209 indicated significant differences among the three schools (see Table 16 below). 
Table 16

Correlation of Collaborative Learning Group and

Familiarity with HBI209

\begin{tabular}{|l|l|l|l|l|}
\hline $\begin{array}{l}\text { Collaborative } \\
\text { learning group }\end{array}$ & $\begin{array}{l}\text { Total } \\
\text { Survey }\end{array}$ & $\begin{array}{l}\text { Laurel } \\
\text { Middle }\end{array}$ & $\begin{array}{l}\text { Lighthouse } \\
\text { Middle }\end{array}$ & $\begin{array}{l}\text { Ponderosa } \\
\text { Middle }\end{array}$ \\
\hline $\begin{array}{l}\text { Collegial Teams } \\
\text { Work Together (5a) }\end{array}$ & $.316^{* *}$ & NS & $.433 * *$ & NS \\
\hline $\begin{array}{l}\text { Conversations about } \\
\text { practice (5b) }\end{array}$ & $.239 * *$ & NS & NS & NS \\
\hline $\begin{array}{l}\text { Inservices and } \\
\text { Workshops (5c) }\end{array}$ & $.256 *$ & NS & NS & $.436 *$ \\
\hline $\begin{array}{l}\text { Staff Decision- } \\
\text { making (51) }\end{array}$ & $.197 *$ & NS & NS & $.283 *$ \\
\hline $\begin{array}{l}\text { Modeling of } \\
\text { classroom practices } \\
(5 p)\end{array}$ & $.244^{* *}$ & NS & NS & $.337 *$ \\
\hline $\begin{array}{l}\text { significance at <.05 level * significance at <.01 level } \\
\text { NS no significant difference }\end{array}$
\end{tabular}

There were no significant correlations between aspects of a collaborative learning group and familiarity with HB1209 on the survey results at Laurel Middle School. However, at Lighthouse Middle School there was a significant correlation between familiarity with HB1209 and participation in collegial teams.

Many of the Lighthouse teachers had served on district curriculum committees and were aware of the development of the EALRs and WASL. Furthermore, all middle school teachers were required to attend a day-long workshop on the WASL writing prompts and scoring rubrics and were also required to participate in scoring the district writing assessments. Thus, I would have expected there to be a significant correlation between inservices and workshops $(5 \mathrm{c})$ and 
familiarity with HB1209 for Lighthouse staff. However, in the interviews and focus groups I discovered that the terminology on the survey was unclear and the teachers interpreted survey question " $5 \mathrm{c}$ " as a question about technology. They interpreted question "5 a". (collegial teams working together) as referring to the district language arts and math cadres and the literacy and math committees at the middle school. This may explain the high correlation between collegial teams and familiarity with HB1209 at Lighthouse.

As indicated by Table 16 above, there were significant correlations on the survey results at Ponderosa Middle School between familiarity with HB1209 and three aspects of a collaborative learning group: inservices and workshops, staff decision-making through the site council, and modeling of classroom practices. These relationships existed for several reasons. For the last five years many of the Ponderosa inservices focused on the writing process and on the EALRs. According to the focus group interviews, the staff took the sample WASL several years ago, and the site council talked about the implications of the state test for changes in classroom practice. Both interview and observation data confirmed that the middle school administrators, the university consultant, and the Expeditionary Learning consultant modeled effective reading and writing strategies based on the state EALRs.. 
While all three school staffs had the opportunity to participate in workshops as they learned about HB1209, participation in a collaborative learning group was significantly related to knowledge of the reform policy at Ponderosa and somewhat related to knowledge of the policy at Lighthouse.

The third school level factor was building level and district administrative expectations and support. Researchers (Aschbacher, 1993; Berman \& McLaughlin, 1978; Spillane, 1998) have concluded that district administrative support for reform is a necessary condition for local implementation. Knapp (1997) found that the depth and range of policy impacts on teachers implementing the California math frameworks were dependent on the way the policy influenced and was influenced by district personnel.

Four questions on the survey (see Appendix B) examined aspects of administrative support: (5f) district strategic plan; (5g) school reform plan; ( $5 \mathrm{i})$ building level administrative support; and (5j) district level administrative support. There were no significant correlations on the surveys between administrative expectations and familiarity with HB1 209 at Laurel or Lighthouse Middle Schools. However, the school reform plan, Expeditionary Learning, was significantly correlated with familiarity with HB1209 $(r=.402 ; \mathrm{p}<.01)$ at Ponderosa Middle School. In observations of the Expeditionary Learning (EL) workshops I noted 
how the EL consultant wove the EALRs and WASL requirements into many of her discussions with the entire staff.

Interviews with district and building level administrators revealed a common expectation in all three districts that teachers were to know and apply the EALRs in their classroom practice and prepare students for the WASL. However, only at Ponderosa was there a significant correlation between building level and district administrative expectations, via the school reform plan, and staff members' familiarity with the policy.

The fourth school level factor was organizational features that enhance time for teachers to learn and collaborate. According to Prestine and McGreal (1997), time may be the most important obstacle to changing core technology, i.e., curriculum and instruction.

Three questions on the survey (Appendix B) examined organizational features that enhance time for teachers to learn and collaborate: (5d) time for curriculum planning and professional development; $(5 n)$ financial resources; and (50) flexible staffing resources. A Pearson correlation test indicated a significant positive relationship on the survey between time available for curriculum planning and professional development and familiarity with HB1209 $(\mathrm{r}=.221, \mathrm{p}<.01)$ for participants at all three schools. This correlation was not surprising because all three middle schools used state Student 
Learning Improvement Grant (SLIG) funds to support in-services and curriculum planning focused on the EALRs and WASL.

\section{Summary of the Relation of School Level}

\section{Factors and Familiarity with HB1209}

Interviews and observational data indicated that previous policy decisions to align curriculum with the EALRs had resulted in greater reported familiarity with HB1209 at Lighthouse and Ponderosa than at Laurel, where curriculum alignment work had not begun at the building level until the 1998-1999 school year.

There were no significant correlations between aspects of a collaborative learning group and familiarity with HB1209 on the survey results at Laurel Middle School. However, at Lighthouse Middle School there was a significant correlation between familiarity with HB1209 and participation in collegial teams. There were significant correlations on the survey results at Ponderosa Middle School between familiarity with HBI209 and three aspects of a collaborative learning group: inservices and workshops, staff decision-making through the site council, and modeling of classroom practices.

Interviews with district and building level administrators revealed a common expectation in all three districts that teachers were to know and apply the EALRs in their classroom practice and prepare students for the WASL. However, only at Ponderosa was there a 
significant correlation between building level and district

administrative expectations, via the school reform plan, and staff members' familiarity with the policy.

Finally, there was a significant positive relationship on the survey between time available for curriculum planning and professional development and familiarity with HB1209 for participants at all three schools.

A multiple regression analysis was conducted to determine which of the above school level factors were most predictive of familiarity with HB 1209 for all three schools. The results are presented in Table 17 below.

Table 17

Multiple Regression Analysis of School Factors and Familiarity with HB1209

\begin{tabular}{|l|l|l|l|}
\hline $\begin{array}{l}\text { School Factor: } \\
\text { (N=150-155) }\end{array}$ & $\begin{array}{l}\text { Correlation with } \\
\text { Familiarity } \\
\text { with HB1209 }\end{array}$ & BETA & R2 \\
\hline Collegial teams work together & .316 & $.253 \cdots$ & $10 \%$ \\
\hline School reform plan & .268 & .179 & $13 \%$ \\
\hline Conversations about practice & .239 & NS & \\
\hline Modeling of practices & .244 & NS & \\
\hline Workshops & .256 & NS & \\
\hline Time & .221 & NS & \\
\hline
\end{tabular}

${ }^{* *}$ significance at $<.01$ level * significance at $<.05$ level

As expected from the correlational statistics, collegial teams that work together and comprehensive reform plan at the school level accounted for $13 \%$ of the variance in familiarity with HB1209. 
Relation of School Level Factors and Involvement in Educational Reform

The second part of research question five was: What is the relationship between four school level factors and staff members' involvement in educational reform? The four school level factors were: (a) previous educational policies; (b) participation in a collaborative learning group; (c) building level and district administrative expectations and support; and (d) organizational features that enhance time for teachers to learn and collaborate.

The first school level factor was previous educational policies. Previous research I conducted in a Washington school district (Thieman, 1997) documented the importance of district policies supporting staff involvement in educational reform. Neither this survey data nor the interviews, observations, or focus groups identified a specific relationship between previous policies and teacher involvement in reform.

However, there was a connection between district policy decisions, regarding allocation of state and district resources, and staff involvement in educational reform activities. Specifically, HB1209 included provision of Student Learning Improvement Grant (SLIG) funds from the 1994-1995 school year through the 1998-1999 school year to support professional development and implementation of the 
state EALRs. All three districts used SLIG dollars to fund in-service training and curriculum development related to the EALRs and WASL. Moreover, the Lighthouse and Laurel school districts provided stipends ranging from $\$ 500.00$ to $\$ 800.00$ respectively to fund professional development for individual teachers. The Laurel Middle School principal explained that allocating the professional development funds in this individualized manner "created 34 entrepreneurs" who attended a variety of workshops, whereas her plan was to say, "OK, let's all get on the same page." (U: interview, 1/14/99). The Ponderosa principal was more selective about the workshops he approved for use of SLIG funds, approving only those that fit the school's focus and the district strategic plan.

So if it was a workshop or experience that would lead to a [constructivist approach] I would encourage people to take part and find a way to fund it...If somebody wanted to go to a workshop on how to track kids in math, I probably didn't find a way to find the money. ( $\mathrm{R}$ : interview, 3/12/99)

The second school level factor was participation in a collaborative learning group. Five questions on the survey (Appendix B) investigated aspects of a collaborative learning group: (5a)collegial teams; (5b) conversations about classroom practice; (5c) inservices and workshops; (5l) staff involvement in decision-making; and (5p) modeling of classroom practices. A Pearson correlation test of the 
relationship between these aspects of a collaborative learning group and involvement in educational reform indicated significant differences on the survey among the three schools (see Table 18).

There were no significant correlations on the survey between aspects of a collaborative learning group and involvement in educational reform at Laurel Middle School. The primary vehicle for participation in collaborative learning at Laurel Middle School was the Accelerated Schools Project, and the major focus the first year of the

\section{Table 18}

Correlation of Collaborative Learning Group and Involvement in Educational Reform

\begin{tabular}{|l|l|l|l|l|}
\hline $\begin{array}{l}\text { Collaborative learning } \\
\text { group }\end{array}$ & $\begin{array}{l}\text { Total Survey } \\
\text { N=149-154 }\end{array}$ & $\begin{array}{l}\text { Laurel } \\
\text { Middle } \\
\text { N=45.48 }\end{array}$ & $\begin{array}{l}\text { Lighthouse } \\
\text { Middle } \\
\text { N=51-53 }\end{array}$ & $\begin{array}{l}\text { Ponderosa } \\
\text { Middle } \\
\text { N=50-53 }\end{array}$ \\
\hline $\begin{array}{l}\text { Collegial Teams Work } \\
\text { Together (5a) }\end{array}$ & $.285^{*}$ & NS & $.510^{* *}$ & .286 \\
\hline $\begin{array}{l}\text { Conversations about } \\
\text { practice (5b) }\end{array}$ & $.172 *$ & NS & $.297 *$ & NS \\
\hline $\begin{array}{l}\text { Inservices and } \\
\text { Workshops (5c) }\end{array}$ & $.227 *$ & NS & $.284^{*}$ & $.368 * *$ \\
\hline $\begin{array}{l}\text { Staff Decision-making } \\
\text { (51) }\end{array}$ & NS & NS & NS & .315 \\
\hline $\begin{array}{l}\text { Modeling of classroom } \\
\text { practices (5p) }\end{array}$ & $.254^{* *}$ & NS & NS & $.434^{* *}$ \\
\hline
\end{tabular}

* significance at $<.05$ level ${ }^{* *}$ significance at $<.01$ level

NS no significant difference

project (1998-1999 school year) was the process of developing a governance structure, data gathering, and building a common vision. The focus on educational reform didn't occur until the second year of ASP in the fall of 1999. If the survey would have been conducted in 
the spring of 2000 , the correlation between a collaborative group and involvement in reform might have been higher.

As stated previously, the Lighthouse staff explained in the focus group interviews their interpretation of question " $5 \mathrm{a}$ " as referring to the district language arts and math cadres and the literacy and math committees at the middle school. Thus I was not surprised by the high correlation between Lighthouse staff members who reported involvement in these reform activities and who also reported that collegial teams working together support changes in practice. According to the interviews and focus groups, conversations about practice tended to occur in the academic subject area meetings, e.g., district language arts and math cadres and literacy and math committees at the middle school. Involvement in these reform activities was voluntary, and thus I would have expected a positive correlation between involvement, conversations about practice, and workshops.

As indicated by Table 18, Ponderosa Middle School staff reported significant correlations between their involvement in educational reform and four of the five aspects of a collaborative learning group. My observations of the grade level team meetings confirmed a high level of collaboration and conversation about practice. Both the principal and the Expeditionary Learning consultant facilitated discussions in which the teachers talked about books they 
were reading and the instructional strategies they used with those books in their classes. Teachers confirmed in the focus groups that

Inservices were collaborative learning experiences. In team time we thought about how to use these strategies-reading and writing-- in language arts, science department meetings and in grade level team meetings. We were a collaborative group, and we were learning. We talked about instruction and practices. (R: focus group, 10/29/99)

Several teachers also reported to me that the two building administrators would model a teaching practice at grade level team meetings and whole staff meetings and then the staff would critique the model lesson.

The third school level factor was building level and district administrative expectations and support. Leithwood et al (1998) identified aspects of supportive districts and features of transformational leadership practices that facilitated organizational learning. While there was a common expectation in all three districts that teachers were to be familiar with and apply HB1209, only Ponderosa Middle School reflected significant evidence on the survey of administrative support for staff involvement in reform.

Four questions on the survey (Appendix B) examined aspects of administrative support: (5f) district strategic plan; $(5 \mathrm{~g})$ school reform plan; (5i) building level administrative support; and (5j) district level administrative support. A Pearson correlation test indicated a 
significant relationship between the school reform plan, Expeditionary Learning, and involvement in educational reform $(\mathrm{r}=.454 ; \mathrm{p}<.01)$ and between building administrative support and involvement in reform $(\mathrm{r}=.310 ; \mathrm{p}<.05)$ at Ponderosa Middle School. There was no significant correlation on the surveys between these aspects of administrative support and involvement at the other two schools.

In the years prior to my research, according to the interviews with district administrators and the new principal, the focus at Laurel Middle School had been on remodeling the facility. When the new principal came on board, one of her first tasks was to seek teacher involvement in the Accelerated Schools Project. In an interview at the beginning of my research I asked her to estimate staff involvement in educational reform. "I think it's very low... maybe 1/4 of them" (U: interview $1 / 14 / 99)$.

One of the key principles of Accelerated Schools Project is teacher involvement in reform. During the first year of ASP at Laurel (when I conducted my research) the focus was on involving teachers in data gathering and visioning. In the focus group interviews in January 2000 , there seemed to be more teacher involvement than was indicated by the survey the previous year. This may be due to the principal's change in the master schedule to provide time for collaboration in 
department and cadre meetings and the ASP emphasis during the second year of the project on teacher involvement in cadres.

The emphasis on teacher involvement in reform played out differently at Lighthouse Middle School. Both the district strategic plan and the school reform plan, Personalized Education, emphasized teachers using classroom and district assessment data to individualize instruction for students. Despite district financial support for teacher participation in workshops and the building principal's encouragement of teacher collaboration, teacher involvement in educational reform did not seem to be a priority for the staff. This lack of involvement will be explored in more detail in the next section on organizational features.

Staff involvement in educational reform had been an expectation of the Ponderosa principal for many years. He made a strategic decision approximately ten years earlier to use curriculum development funds to support training for the entire staff in literature-based reading and the writing process. The school reform plan, Expeditionary Learning, also prioritized staff involvement. According to the school's application for the state CSRD grant to fund Expeditionary Learning, staff development and technical assistance release time would be provided for 48 staff members (including classified instructional staff as well as certified teachers). Ponderosa was the only school to involve all instructional assistants in workshops about the school reform plan 
as well as certified teachers). Ponderosa was the only school to involve all instructional assistants in workshops about the school reform plan as well as the state EALRs and WASL. Again this involved a strategic decision by the principal to allocate funds and time so that instructional assistants would be involved in professional development along with the certified staff. Thus I was not surprised that involvement in educational reform was significantly correlated with building level administrative support and the school reform plan.

The fourth school level factor was organizational features that enhance time for teachers to learn and collaborate. Studies of the restructuring movement and shared decision-making in the early $90^{\circ} \mathrm{s}$ attest to the importance of time for collaboration and professional development (Donahoe, 1993; Waters \& Castle, 1993).

Three questions on the survey (Appendix B) examined the organizational features that enhance time for teachers to learn and collaborate: (5d) time for planning and professional development; ( $5 n)$ financial resources; and (50) staffing resources. While the Laurel district allocated up to $\$ 800.00$ per certified teacher for professional development, a Pearson correlation test did not indicate a significant relationship on the surveys between these organizational features at Laurel Middle School and staff involvement in reform. The Laurel principal's criticism of the lack of a consistent focus in the past for 
allocating resources for professional development may explain this lack of connection. Furthermore, the principal's changes to the master schedule to allow time for departments and cadres to collaborate and plan did not take place until the 1999-2000 school year.

There was a significant correlation on the surveys between time for curriculum planning and professional development and involvement in reform in the Lighthouse district $(r=.410 ; p<.01)$. However, interviews and focus group discussions clarified that Lighthouse teachers interpreted question " 5 d" (time) to mean it would be a support for changing classroom practice if they had time for planning and professional development, not that it was a support.

Lack of time is more of an issue. What used to be SLIG days [for planning and collaboration] are now used by the building and district [ due to change in legislative policy for the 1999-2000 school year]. Conference days are gone. (S: focus group, 2/9/00)

Lighthouse's daily schedule allowed only one 42 minute period per day for individual and grade level team planning. If teachers wanted to plan by department with other grade levels, they had to do so before or after school which conflicted with faculty meetings, IEP conferences, and teacher supervision of extracurricular activities.

A Pearson correlation test indicated a significant relationship on the surveys between financial resources and staff involvement in educational reform at Ponderosa Middle School $(r=.335 ; p<.05)$. Due 
to the high numbers of low income students, the school received federal and state funds as a school-wide chapter I program. In addition the district received a state CSRD grant to implement Expeditionary Learning. Over the years the principal had allocated district and state (SLIG) funds to provide up to twenty days of professional development opportunities at the building level for all the instructional staff. Thus there was a direct connection between financial resources and teacher involvement in educational reform activities which were funded by those financial resources.

Summary of the Relation of School Level Factors and Involvement in Educational Reform

While the data did not indicate a specific relationship between previous policies and teacher involvement in reform, there was a direct connection between district decisions regarding allocation of resources and staff involvement in educational reform. All three districts used state SLIG dollars to fund in-service training and curriculum development related to the EALRs and WASL. This relationship was further clarified in the examination of the survey data and correlations between organizational features (that enhance time for teachers to learn and collaborate) and involvement in educational reform. Ponderosa 
staff responses indicated a significant correlation on the surveys between financial resources and staff involvement in reform.

As indicated by Table 18, the surveys showed significant correlations between four aspects of participation in a collaborative learning group (collegial teams work together, conversations about practice, inservices and workshops, and modeling of classroom practice) and involvement in educational reform. Closer examination of the survey data revealed that these correlations were driven by the results for Lighthouse and Ponderosa rather than indicating a significant relationship at all three schools.

There were no significant correlations on the survey between building level and district administrative expectations and support and involvement in reform for Laurel or Lighthouse. However, there were significant correlations between the school reform plan and involvement in educational reform and between building level administrative support and involvement in educational reform at Ponderosa Middle School.

Table 19 presents the results of multiple regression analysis of the school level factors which were most predictive of involvement in educational reform for all three schools. 
Table 19 Multiple Regression Analysis of School Factors
and Involvement in Reform

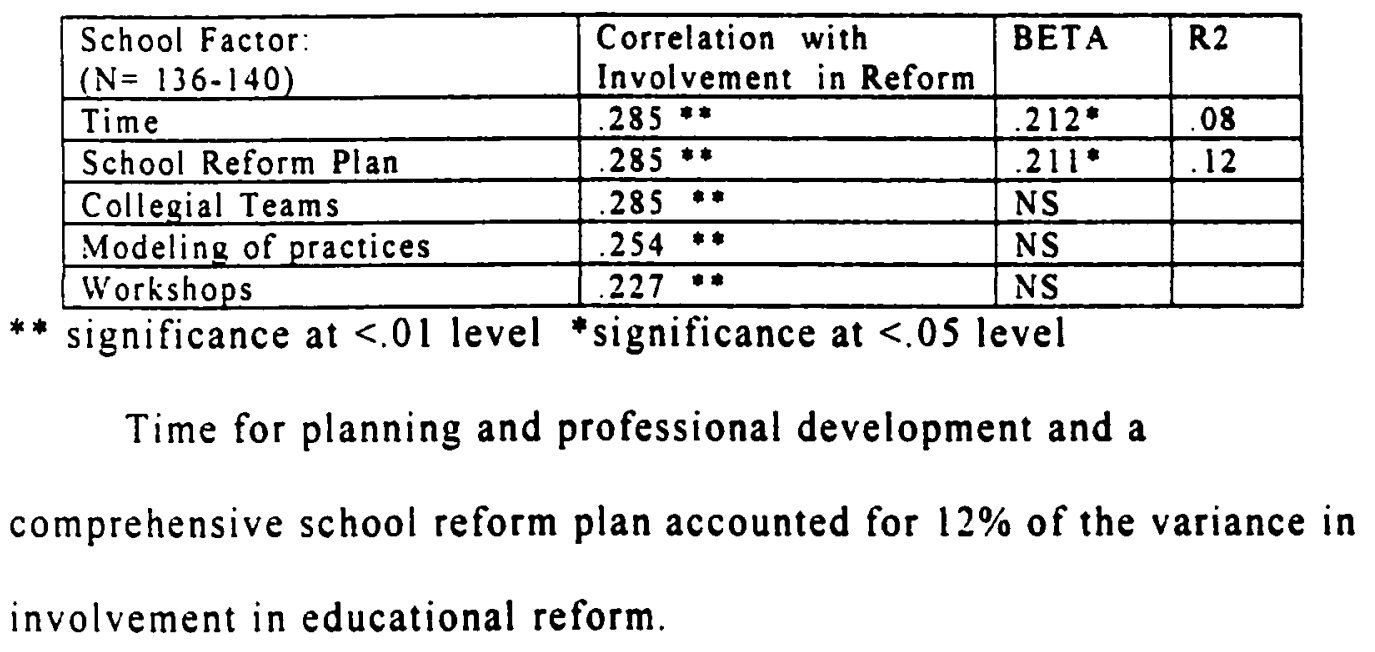

\section{Relation of School Level Factors and} Changes in Classroom Practice

The third part of research question five was: What is the relationship between four school level factors and changes in classroom practice? The four school level factors were: (a) previous educational policies; (b) participation in a collaborative learning group; (c) building level and district administrative expectations and support; and organizational features that enhance time for teachers to learn and collaborate.

On survey question five (Appendix B), respondents reported the degree to which they perceived sixteen school level factors as supports for changing classroom practice in their school. Chart 12 in Appendix 
G presents the mean scores and associated school level factors for support, reported for all three schools and for each individual school. Respondents were also asked to rank the top supports overall for changing classroom practice (see Chart 13 in Appendix G).

The first school level factor was previous educational policies. Earlier research (Aschbacher, 1993; Cohen \& Ball, 1990a, 1990b; Darling-Hammond, 1990; Elmore et al., 1996) suggests that previous educational policy influences teachers' responses to standards-based reform. This study confirmed the impact of previous district and state policies on changes in teachers' classroom practice. I will discuss each of these in the section below.

Survey question $4 \mathrm{n}$ (Appendix B) asked teachers to indicate the degree to which contradictions between district curriculum and the state assessment (WASL) acted as a barrier to changing classroom practice. Contradiction between the district curriculum and the state assessment was ranked ninth out of fifteen barriers to changing classroom practice (see Chart 14 in Appendix G). Moreover, there was a significant difference $(p<.05)$ among the three schools with Laurel staff reporting the highest mean score for this barrier (3.4) followed by Lighthouse (3.1) and Ponderosa (2.2). As indicated previously, Laurel Middle School staff members were in the beginning stages of aligning 
curriculum to the EALRs and WASL, while the other two schools had been involved in curriculum alignment for a longer period of time.

In all three school districts, teachers perceived some district policies as problematic for changing practice. From the beginning of the Accelerated Schools Project at Laurel Middle School, there was an acknowledgement by the principal and teachers I interviewed of the tension between district needs to control and align the curriculum K-12 and middle school needs to investigate best practices and experiment with curriculum and instruction. In the district level ASP meetings I observed, there was prolonged discussion of how to integrate the previously existing district, subject-area, K-12 curriculum teams with the ASP steering council at the middle school. After a year of discussion this was resolved. However, in the focus groups teachers continued to criticize the district's lack of a clear vision of what teaching and learning should be like. Several teachers complained that the district staff members made philosophical statements about the need to change instructional practice but had no clear cut strategies.

They [district] say, use "best practice, use manipulatives, use open ended activities. Just do it. But nobody knows what we're doing. Nobody tells us how to get there. There's a gap between administrative abstract thought and concrete reality. (U: focus groups, 1/14/00)

One teacher I interviewed noted that ASP has been the strongest attempt to move towards systemic reform, and while the school board 
and superintendent want systemic reform, they don't see it requires change at every level in every area including the district office.

According to a Lighthouse school district administrator, the superintendent opposed the state approach to the WASL because the test results don't take into account the individual child's continuous growth, nor does the WASL scoring allow for personalization. Thus there was a contradiction between the district's assessment policy of individualized levels testing and the WASL. In response to state standards the district had developed a writing assessment and a math problem solving assessment. However, I noted a contradiction between the state's holistic scoring model and the district's analytical model of scoring the writing samples, which was presented to all middle school teachers in February 1999 . Furthermore, the district substituted its own assessments of student learning for the seventh grade WASL in the spring of 1999.

On the surface it seemed as though district policies fully supported the changes in practice at Ponderosa Middle School. The district superintendent was vocally supportive of the school reform plan, Expeditionary Learning. However, in late April 1999, the superintendent announced plans to administratively restructure the district, resulting in the transfer of another building administrator to the middle school as principal. I attended the school board meeting 
where seventeen teachers and some community leaders questioned the superintendent's and board's decision. They spoke about the success of the middle school's program, the principal's strong leadership, and their fear that a new building administrator would not be as committed to the middle school team or to Expeditionary Learning. The superintendent responded that he and the board wanted to achieve some different goals. "I understand there is a middle school team, but we want a school district team where everybody is on the team" (R: board meeting, 4/29/99). These words echoed the superintendent's statement earlier in the spring that he wanted his administrators "in the fold" and that meant, "total complete loyalty to the organization and the superintendent and open communication and trust." (R: interview, $3 / 12 / 99)$

Previous policies at the state level also impacted change in classroom practice. Survey question 4 o (Appendix B) asked teachers to indicate the degree to which contradictions between other state assessments and the WASL acted as a barrier to changing classroom practice. Contradiction between other state assessments and the WASL was ranked thirteenth out of fifteen barriers to changing classroom practice (see Chart 14 in Appendix G) and thus did not seem very significant. However, staff in all three districts acknowledged that the state-mandated Iowa Test of Basic Skills (ITBS) for eighth grade was 
not aligned to the EALRs or the district content standards and benchmarks. While the seventh grade WASL is criterion referenced and emphasizes problem solving and application of skills, the ITBS is norm referenced and focuses on speed and computational skills. One teacher complained, "The contradiction between the ITBS and the WASL gave kids whiplash!" (R: focus group, 10/29/99)

The second school level factor examined in relation to changes in practice was participation in a collaborative learning group. In addition to the survey questions, many of the interviews and observations focused on the relationship between participation in a collaborative group and changes in classroom practice. Thus this section of the chapter is particularly detailed with examination of all five aspects of a collaborative learning group at each school.

Five questions on the survey (Appendix B) investigated aspects of a collaborative learning group: (5a) collegial teams; (5b) conversations about practice; (5c) inservices and workshops; (51) staff involvement in decision-making; and (5p) modeling of classroom practices. A Pearson correlation test indicated a weak positive relationship between all five features of a collaborative learning group and overall changes in classroom practice (survey question 7) as indicated by Table 20. Even this weak correlation was probably driven 
by the strong relationships reported by Ponderosa Middle since there were no significant correlations for Laurel or Lighthouse.

Table 20

Correlation of Collaborative Learning Group and Changes in Classroom Practice

\begin{tabular}{|l|l|l|l|l|}
\hline $\begin{array}{l}\text { Collaborative } \\
\text { learning group }\end{array}$ & $\begin{array}{l}\text { Total Survey } \\
\text { N=140-156 }\end{array}$ & $\begin{array}{l}\text { Laurel } \\
\text { Middle } \\
\text { N=39-49 }\end{array}$ & $\begin{array}{l}\text { Lighthouse } \\
\text { Middle } \\
\text { N=51-54 }\end{array}$ & $\begin{array}{l}\text { Ponderosa } \\
\text { Middle } \\
\text { N=50-54 }\end{array}$ \\
\hline $\begin{array}{l}\text { Collegial Teams } \\
\text { Work Together (5a) }\end{array}$ & $.210 *$ & NS & NS & .317 \\
\hline $\begin{array}{l}\text { Conversations about } \\
\text { practice (5b) }\end{array}$ & $.251 *$ & NS & NS & .345 \\
$\begin{array}{l}\text { Inservices and } \\
\text { Workshops (5c) }\end{array}$ & $.272 *$ & NS & NS & .439 \\
\hline $\begin{array}{l}\text { Staff Decision- } \\
\text { making (51) }\end{array}$ & $.193 *$ & NS & & .336 \\
\hline $\begin{array}{l}\text { Modeling of } \\
\text { classroom practices } \\
\text { (5p) }\end{array}$ & $185 *$ & NS & NS & .319 \\
\hline
\end{tabular}

*significance at $<.05$ level **significance at $<.01$ level NS no significant difference

Collegial teams working together and frequent conversations about classroom practice were ranked the top two supports for changing classroom practice on the surveys by the Ponderosa Middle School staff. At Laurel and Lighthouse they were ranked somewhat lower but still in the top five supports for changing practice (see Chart 13 in Appendix $G$ ). However, as indicated in Table 16 above, there was not a significant correlation between features of a collaborative learning group and changes in classroom practice at Laurel and Lighthouse 
Middle Schools. Closer examination of the interview and focus group data helps explain this seeming contradiction.

The most common reference to a collaborative learning group at Laurel Middle School was the Accelerated Schools Project. About half the teachers I talked with identified ASP as a learning experience. However, other teachers said the ASP groups were more focused on getting things done, not exploring or learning.

Most conversations about classroom practice at Laurel Middle School seemed to occur in daily grade level team meetings. The seventh grade team was noted for free wheeling discussions, working through disagreements, and collaborative decision-making. The eighth grade team members had strong personalities which seemed to prevent open dialogue or consensus. At the focus groups in January 2000 , I continued to hear about lack of trust on some teams. Inertia was still an obstacle to change, but the ASP process seemed to be helping, and more people were talking about their classroom practice in a reflective manner.

During the 1998-1999 school year, Laurel Middle School teachers participated in nine early release half-day workshops on the Accelerated Schools Project. There was an emphasis on governance and procedure rather than instructional practice, although I observed one workshop on powerful learning principles and these ideas had also 
been introduced in the fall. The district decision to allocate all of the early release days to ASP was viewed positively at the middle school.

And I think this is one of the first years that the feedback that I have received has been that the professional development is continuous and growing and not just a three hour. slam stuck in. So I think one of the things that is nice about always doing ASP on the half days is that's what the staff expects. They learn from it and they grow from one month to the next. (U: interview, 2/24/99)

On the whole ASP workshops seemed to have started teachers talking about practice and attempting some constructivist, learner-centered strategies based on powerful learning principles.

During the second year of ASP at Laurel, starting in the fall of 1999, cadres began researching instructional strategies in literacy, science, mathematics, and the humanities. Several middle school teachers attended the summer ASP institute on powerful learning principles and were available to model these practices and help colleagues develop strategies for effective instruction. However, several teachers commented in the focus groups on the challenges of implementing this professional development model.

[The ASP coach] will cover classes. Who are you to watch? What am I supposed to see? What are we supposed to be looking for? Where do I go to see manipulatives and hands-on in this building? There's a big difference between summer school where there were four teachers and eighteen kids. I said, Wow I'm going to totally do that in the fall. Then I got 33 kids and just $m e$, and I can't do it. They don't understand that 
manipulatives take more time. Performance-based assessment is more demanding. (U: focus group;1/24/00)

Sustained professional development focusing on change in practice was just beginning at Laurel Middle School. While collegial teams working together and conversations about practice were viewed as supports for changing classroom practice, they had not yet resulted in significant changes in practice at Laurel.

A similar contradiction in the survey data was evident at Lighthouse Middle School. There were no significant correlations on the surveys between a collaborative learning group and changes in practice, yet staff ranked collegial teams working together and conversations about practice among the top supports for changing practice. Again, closer examination of the interviews and focus groups provides a possible explanation.

There were several learning groups in which Lighthouse staff members participated. Twice a month the district reading specialist met with approximately 12 teachers at the middle school to discuss reading strategies. There was also a building level math team that met twice a month. Eight teachers were representatives to the district language arts or math cadres that met monthly to learn new strategies and to make decisions about curriculum, materials adoption, and 
district assessments. However, unlike Laurel and Ponderosa, these learning groups did not involve the faculty as a whole.

Although the Lighthouse staff ranked collegial teams very highly, in the interviews and focus groups teachers clarified that such collaboration was more of a desire than a reality. Most of them agreed that if collegial teaming existed, it would support changes in classroom practice. However, the reality was many teachers still thought of themselves as subject matter specialists. "We have strong minded individuals who will share materials but aren't willing to change their practice" (S: focus group. 2/9/00).

Some teachers felt that the house structure that separates sixth grade from seventh and eighth is divisive and inhibits collaboration across grade levels. In the interviews and focus groups, teachers also commented that the sixth grade functions on an elementary model with more interdisciplinary teaching and teaming, while the seventh and eighth grades function on a junior high model emphasizing separate academic disciplines. Lighthouse teachers agreed that most of the conversation about practice occurred between teaching partners and more of this occurred at the sixth grade level and within subject areas, e.g., the language arts teachers. Thus collaboration and conversations about practice were not school-wide practices and did not seem to result in changes in classroom practice. 
There were a plethora of workshops for Lighthouse Middle School teachers. Several district-sponsored workshops focused on maximizing students' performance on the WASL, and all middle school teachers were required to attend the workshops on the six trait writing assessment and scoring rubric. While the district had been providing workshops on writing and reading strategies since the early 1990's, these had been targeted at language arts teachers. The expectation that all staff would become teachers of reading and writing was not verbalized until the 1998-1999 school year and was continuing to be emphasized by the middle school principal in the 1999-2000 school year.

Classroom observations of the two sixth grade teachers confirmed the workshops on reading and writing strategies had resulted in changes in their classroom practice to a more constructivist, learner-centered approach. The seventh grade teacher's practice focused on the six trait writing model to the virtual exclusion of reading strategies, partly due to the school policy of providing a separate reading class to most seventh graders and also due to the pressure the teacher felt to improve the students' scores on the district and state writing assessments.

During the 1999-2000 school year the middle school principal set aside time at faculty meetings for teachers to model best practices, e.g., six trait writing process, literature circles, parent conferences, and 
student behavior management. The principal also facilitated discussion of writing strategies that would be used school-wide in science and social studies classes as well as language arts and at each grade level.

The lack of significant correlation on the surveys between features of a collaborative learning group and changes in practice at Lighthouse Middle School may have been caused by the reluctance to change of the seventh and eighth grade teachers who considered themselves to be subject matter specialists. The expectation that all teachers would change their practice and become teachers of reading and writing had just been expressed in the 1998-1999 school year, and modeling of these practices in school-wide faculty meetings did not occur until the 1999-2000 school year.

All five aspects of a collaborative learning group were significantly correlated to changes in practice for Ponderosa staff (see Table 20 above). Also, collegial teams working together and frequent conversations about classroom practice were ranked the top two supports on the survey for changing classroom practice by Ponderosa Middle School staff (see Chart 13 in Appendix G).

A major support for collegial teaming at Ponderosa Middle School was the double block ( 94 minutes each day) for team and individual planning while the instructional assistants provided remedial instruction for students. The principal structured the week so that 
different groups planned each day: grade level teams, subject area teams, teaching partners, and partners with their instructional assistant.

Not all of the teams were as collaborative as the seventh grade group. A sixth grade teacher commented that her colleagues tended to have organizational meetings for fact finding rather than collaboration whereas the seventh grade team was more of a think tank ( $R$ : focus group, 10/29/99). An eighth grade teacher admitted that her group was not as collegial or inclusive as the seventh grade team.

As stated previously, the Ponderosa school staff members had participated in sustained professional development in reading and writing strategies for a number of years. In the mid 1990's the middle school instituted a writing sample and at the workshops that year the teachers created the scoring rubrics with the university consultant and used those rubrics to score all the students' papers. In 1997 all instructional staff attended a five-day workshop, revisiting the six trait writing model and also developing student portfolios. Classroom observations confirmed that teachers were using this rubric to teach writing and were using the portfolios. All instructional staff members participated in an orientation to Expeditionary Learning in August of 1998 and continued to attend all the grade level team meetings and early-release days with the consultant. Classroom observations and discussion at grade level team meetings confirmed that teachers were 
changing their classroom practice to reflect this professional development.

Teachers at all three schools discussed the influence of professional development on their teaching, and I was able to confirm some changes in practice in my classroom observations. The four major themes for professional development at Laurel Middle School were the six trait writing model and scoring rubric, cooperative learning (modeled by the Accelerated Schools Project training), reading strategies (S.A.I.L.) and classroom assessment strategies. Lighthouse Middle School teachers credited workshops on reading strategies (literature circles), WASL writing prompts, scoring rubrics, and classroom assessment strategies with influencing their classroom practice.

The most detailed list of workshops was provided by the teachers and building administrators at Ponderosa Middle School. At the top of the list was the work over the years with the university consultant on the six trait writing model, scoring rubrics and literature-based reading. Last year during my study, teachers were also focusing on reading strategies with their Expeditionary Learning consultant. Classroom assessment strategies and incorporating technology (Gates Foundation and Share 105 technology workshops) were also a major emphasis for the Ponderosa teachers. 
There were two major differences in the influence of professional development on classroom practice at Laurel and Lighthouse versus Ponderosa. First, Ponderosa Middle School was the only one to have sustained professional development provided by the same consultant for an extended period of time, which was provided to the staff as a whole. At Laurel and Lighthouse, much of the professional development occurred at the individual teacher level, rather than school-wide. Second, the principal at Ponderosa Middle School had participated in those workshops with his teachers for ten years and expected to see those workshop-related classroom practices when he observed teachers. Having a sustained focus for school-wide professional development and the principal's expectation that workshops would result in changes in practice may explain why there was a significant correlation between a collaborative learning group and changes in classroom practice at Ponderosa Middle School.

The third school level factor was building level and district administrative expectations and support. Previous research has documented the importance of administrative support, both at the district and building levels, for sustained changes in practice (Leithwood et al., 1998; Sarason, 1996).

Four questions on the survey (Appendix B) examined aspects of administrative support: (5f) district strategic plan; $(5 g)$ school reform 
plan; ( $5 \mathrm{i}$ ) building level administrative support; and ( $5 \mathrm{j}$ ) district level administrative support. At Ponderosa Middle School there were significant correlations between the school reform plan, Expeditionary Learning, and changes in classroom practice $(r=.350 ; p<.05)$ and also between building level administrative support and changes in classroom practice $(r=.331 ; p<.05)$. However, there were no significant correlations for Laurel or Lighthouse.

Contrary to my expectation, the existence of a district strategic plan did not correlate with changes in classroom practice at any of the middle schools. Furthermore, the district strategic plan (5f) ranked as the lowest support for changing classroom practice (see Chart 12 in Appendix $G$ ) for the survey respondents as a whole and for the Laurel and Lighthouse respondents. However, it was rated more highly as a support for changing classroom practice at Ponderosa Middle School than at the other two schools. The difference may be related to the process used to develop the district strategic plan.

Despite the enthusiastic support of the district strategic plan by the Laurel superintendent, I never heard the plan mentioned in my interviews or observations of meetings at Laurel Middle School. While the Lighthouse district strategic plan (personalized education) was discussed by the building principal and middle school teachers were aware of the focus on using data to individualize instruction, it was 
still ranked last on the survey as a support for changing practice. In contrast, the Ponderosa Middle School staff had been active participants in creating the district strategic plan, and it was discussed by the principal in grade level team and faculty meetings. However, the district strategic plan still did not correlate with changes in practice at Ponderosa.

Nor did district level administrative support $(5 \mathrm{j})$ correlate with changes in practice at any of the middle schools. However, it may be more informative to compare administrators' stated expectations about teaching with the instructional practices that were identified as being used most frequently on question six of the survey (Appendix B).

At Laurel Middle School, teachers reported the greatest change in two practices: increased expectations of students (6i) and curriculum aligned to the standards $(6 v)$ as indicated in Table 7 on page 145 . The instructional practices which were used most frequently by the Laurel Staff (see Table 8 on page 146) were cooperative learning (6a), student projects $(6 j)$, active student engagement $(6 u)$, and curriculum aligned to the standards (6v). Not coincidentally, the superintendent in that district stated, 
Teachers need clear understandings of the EALRs and must align their curriculum and instruction to the standards... I would like to see many more cooperative learning groups, many more projects that students are engaged in. I'd like to see students using research methods to develop some culminating activities. (U: interview, 1/15/99)

At Lighthouse Middle School, teachers reported the greatest change in three classroom practices (see Table 7): teaching writing across the curriculum (6r), using scoring rubrics (6b), and increased expectations of students (6i). The major staff development focus for the district has been teaching the six trait writing process and using scoring guides to evaluate students' writing. In February 1999, I observed a district-wide training for all Lighthouse Middle School teachers in the WASL writing prompts and scoring criteria. The clear message was that teaching writing and using the six trait scoring rubrics were expectations of all middle school teachers, not just those in language arts or in seventh grade. In May 1999, all middle school and high school teachers were required to participate in scoring the district writing samples.

At Ponderosa Middle School, teachers reported the greatest changes in three practices (see Table 7): teaching writing across the curriculum (6r), using scoring rubrics (6b), and student portfolios (6k). The instructional practices which were used most frequently as indicated in Table 8 were: curriculum aligned to the state standards 
$(6 v)$, cooperative learning (6a), teaching reading (6q) and writing (6r) across the curriculum, and active student engagement (6u). Each of these instructional practices was prioritized by the superintendent, building administrators, and the teachers I interviewed. According to the superintendent, reading, writing, and language acquisition must be prioritized with instruction focusing beyond knowledge and comprehension to higher levels of thinking. The building principal emphasized teachers facilitating students to be engaged in the learning process.

I believe that kids really need to read and be motivated To read interesting, exciting things, and they need to be challenged... I see kids doing incredibly different things in writing because they write as opposed to filling in the blanks. (R: interview, 1/26/99)

While there was not a significant correlation on the surveys between district administrative expectations and changes in practice, interviews, focus groups, and observations suggested a strong connection.

The support of building level administrators (5i) was ranked the third highest support for changing classroom practice by the total survey respondents (see Chart 12 in Appendix G). It ranked first for Laurel and Lighthouse Middle Schools and seventh for Ponderosa Middle School. Interviews and observational data shed important light on the role of building level administrators in supporting change and 
revealed some inconsistencies between the survey rankings and feelings of teachers in the interviews and focus groups.

It seemed as though the high ranking of administrative support for changing classroom practice support by Laurel survey respondents was more of a wish than reality. In the focus groups the Laurel school staff expressed confusion about their new principal's leadership style. One staff member commented, "[The principal] isn't clear about the decision making model she's going to use... When she gets stressed out, she reverts to an autocratic style" (U; focus group, 1/14/00).

Several staff members were concerned that the principal allowed staff to make derogatory remarks about fellow teachers and sometimes did so herself.

While understanding the high expectations of building administrators by the superintendent, many Laurel teachers commented that their building administrators weren't in the classroom enough and couldn't provide concrete suggestions about curriculum and instruction. One teacher said, "I want administrators in the classrooms daily. No one knows what I'm doing, [because] there are no complaints. If no one dies on your watch, you win!" (U: focus group, 1/14/2000) Given this and similar perspectives, it was not surprising that that there was no correlation on the surveys between building level administrative support and changes in classroom practice at Laurel. 
The Lighthouse Middle School staff also ranked building administrator support ( $5 \mathrm{i}$ ) as the most important support for changing practice on the survey. My initial impression of the school (subsequently confirmed in interviews, classroom and meeting observations, and focus groups) was of a traditional staff which was being pushed by an energetic principal. This principal provided resources and encouraged the staff to attend a variety of district inservices and workshops. She attended building and district curriculum meetings at least twice a month. At times the principal provided her staff so much information from the district office that they felt overwhelmed. There were so many opportunities for teachers and so many different strategies to learn, that there didn ${ }^{\circ}$ seem to be a unifying theme for the professional development opportunities at the school. This may explain why there was no correlation on the surveys between administrative support and changes in classroom practice at Lighthouse.

The Ponderosa Middle School staff ranked building administrative support ( $5 i)$ the seventh most important support for changing classroom practice which surprised me given the positive feeling in the building. However, several teachers commented that the building principal's strong support was accompanied by very high expectations, which were stressful for some staff. 
[The principal] has a vision of what education should be and it's up here and the rest of us are down here. Over the years there have been some difficulties with him pushing so hard. He expects a lot of us. The administration here [in the building] is so supportive. ( $R$ : interview,4/2/99)

The principal agreed that his high expectations exhausted some staff but felt it was his job to provide consistency and direction and push hard for change. His priorities for educational reform were reflected in his professional development and hiring decisions.

You cultivate what you want to harvest... We've gotten pretty blunt about saying. This is what this school is about. If this doesn't match for you, please don't accept the job... You will be miserable if you accept the job in this building and you believe something so different from where we are going. (R: interview, 1/26/99)

The principal's instructional leadership was especially strong at Ponderosa Middle School. He attended weekly grade level team meetings and led the discussions about classroom practice and attended all the Expeditionary Learning workshops. He read the books and modeled the practices he wanted staff to implement.

When I asked the Ponderosa staff to explain why they had chosen the top five instructional practices on the survey (aligning curriculum to the EALRs, cooperative learning, actively engaging students in learning, teaching reading and writing strategies across the curriculum), they said it was because these were the practices that had been 
consistently emphasized by the building principal and all the workshops they attended.

However, teachers continued to be concerned about the number of innovations they were expected to implement each year and the lack of consistent follow through in some areas. For example, student portfolios were instituted in 1997 , but during the spring of 1999 other activities seemed to take precedence over student work on their portfolios. The student accountability system was continuing; however, specific implementation methods changed every year. Technological changes had also stressed some teachers who were not comfortable learning how to record attendance, missing assignments, and grades on their classroom computer. It seemed that the increasing expectations of staff to change their practice was challenging for some teachers, even though they reported the highest percentage of changes in practice on the surveys of all three schools. Finally, the integrated curriculum features of Expeditionary Learning were perceived as challenging since many teachers had not experienced such curriculum and were unsure of their ability to develop and implement these new ideas. Despite these challenges there was a significant correlation on the survey between building level administrative support and changes in classroom practice $(r=.331 ; p<.05)$ at Ponderosa Middle School. 
The fourth school level factor was organizational features that enhance time for curriculum planning and professional development. Three questions on the survey (Appendix B) examined organizational features that enhance time for teachers to learn and collaborate: (5d) time for curriculum planning and professional development; $(5 n)$ financial resources; and (50) staffing resources. There were no significant correlations between organizational features and changes in practice for Laurel and Lighthouse. However, at Ponderosa, time for planning and professional development correlated significantly with changes in practice $(r=.476 ; p<.01)$. Financial resources also correlated significantly with changes in practice $(r=.289 ; p<.05)$. As with other correlations, examining interview and observational data sheds additional light on the relationship between these organizational features and changes in practice.

Despite the generous paid time for curriculum planning and professional development in the Laurel school district, teachers reported in the interviews in the spring of 1999 , they did not have sufficient planning time with other teachers in their department or across grade levels. During the 1998-1999 school year core academic departments met for thirty minutes once a week and grade level teams had a daily common planning period. However, the amount of planning and collaboration that occurred during grade level team time varied 
substantially among the three grade levels. The new principal instituted a change at the beginning of the 1999-2000 school year to increase weekly department planning time and support weekly cadre meetings. Grade level teams continue to have daily common planning, and the principal meets with each grade level team weekly.

In the focus groups teachers agreed that "We have some of the best planning time of any district" (U: focus group, 1/14/00). The district provides a monthly half-day early release for professional development, and 1998/1999 was the first year there was a common theme for all the meetings, i.e., ASP. In addition teachers receive seven paid staff development days outside of the 180-day calendar for curriculum development.

Because Laurel Middle School was just beginning the ASP process last year, it is difficult to assess any specific changes in classroom practice that have directly resulted from the planning and professional development time. In the focus group several teachers commented that new strategies such as use of math manipulatives and performance assessments take much more time to develop and implement and consequently they don't use them as often as they would like. Other teachers commented that the cadre planning time focuses on research of best practices and continued curriculum alignment rather than planning and discussing actual changes in classroom practice. 
Lack of time was mentioned as a barrier to changing classroom practice in every interview and focus group I conducted at Lighthouse Middle School. In part this was due to the junior high schedule of seven 42 minute periods, allowing teachers just 42 minutes a day for individual and house (team) planning. The intent was for each house to meet twice a month before school for 45 minutes. But during the 1999 . 2000 school year, house meeting time was being usurped by faculty meetings to address information from the district office and other building wide concerns.

Each of the seventh/eighth grade houses had a common lunch; however, the common lunch for the sixth grade houses had been eliminated to accommodate logistical student scheduling needs. In addition veteran teachers were frustrated that the monthly early release half days had been eliminated, further reducing the opportunities to meet together to plan.

You're lucky if you have time to meet with your assigned teaching partner. There are so many other meetings; either large staff meetings or house meetings or dealing with bigger issues than just your classroom practice. There is very little time and it seems like when we try to set aside time it will often get usurped. So I definitely see how people would feel that is a real barrier. How can I do things differently if I don't know what other things are going on in other classrooms because I don't get to hear their ideas shared? (S: interview, 4/16/99) 
Teachers also wanted time to meet by department across grade levels within the school and also district-wide.

The concern about lack of time for planning and collaboration was supported by the Lighthouse Middle School principal, who quoted a state department of education official:

We need to give teachers time to meet across curriculum areas and figure out how this applies to instruction.

It is not just the job of the language arts or math teacher. It takes the entire staff. We need the same vocabulary and tools to find connections across the curriculum. (S: faculty meeting, 2/10/99)

In the focus groups teachers clarified that time for planning and professional development would be a support for changing classroom practice if they had it. Thus the high ranking of time as a support on the Lighthouse school surveys was a wish rather than a reality. However, they also acknowledged that each teacher was allocated $\$ 500.00$ for professional development which could be supplemented if not all district funds were expended. In addition, there had been statefunded Student Learning Improvement Grant days (SLIG) for professional development. However, the SLIG days were eliminated by the state legislature for the 1999-2000 school year.

In the interviews and focus groups Ponderosa Middle School teachers praised the double planning period that enabled them to devote blocks of time each week to planning and collaboration. Use of this 
time had resulted in changes in practice which I observed in classrooms. For example, at the weekly department meetings earlier in the year, the seventh grade team had agreed upon the writing curriculum for the year and had chosen strategies to help their students prepare for the writing assessment on the WASL.

A unique feature at Ponderosa was the intentional involvement of every classified instructional staff member in the professional development and faculty meetings. Time was provided for them to meet with the Expeditionary Learning consultant each month, and they met weekly to plan instruction with their teaching team. Thus, the instructional assistants' knowledge of HB1209, the EALRs and WASL, and reading and writing strategies was significantly higher than the knowledge of classified instructional staff at the other two schools.

Despite the double planning period, monthly early release halfdays, and paid professional development days, Ponderosa Middle School teachers still reported lack of time (4a on the survey) as a barrier to changing classroom practice. The timing of the survey may have been problematic since it was done right before the Cultural Unity Fair (CUF) activities. In the spring of 1999 , this event involved a major fund-raiser and demonstration of student learning with projects and activities on display from every classroom. Unlike school science fairs or cultural history fairs that only involve a department or grade 
level, CUF involved every teacher and student in the school. The fundraiser in March, 1999, was a precursor to the CUF performances in April, which again involved every teacher and approximately 450 students. Teachers spent many before and after school hours preparing with their students for the performances to a state-wide audience.

While teachers were very pleased by the double planning time, they recognized that it was accompanied by administrative expectations that teachers would meet together and plan, rather than using the time for individual lesson planning. Four of the five double planning periods were scheduled for grade level team meetings with the principal, department meetings, team partner meetings, and team partner/ instructional assistant meetings.

The fourth school level factor, organizational features that enhance time for teaches to learn and collaborate, also included financial and staffing resources. There were distinct differences among the three schools in terms of financial and staffing resources to support change. Due to Laurel's and Ponderosa's school-wide Chapter I status, these schools were able to access supplementary federal and state funds that were not available to Lighthouse Middle School.

Because of its location, the Laurel district enjoyed a favorable property tax base and was able to pass bonds and levies with apparent ease. Levy monies were used to award each teacher approximately 
\$800. towards professional development. However, there had been no common focus at the building or district level; each teacher was an entrepreneur. Student Learning Improvement Grant (SLIG) funds were used to support district professional development opportunities, such as literacy training. In addition, the district received two $\$ 50,000$. CSRD grants, one for the middle school, to implement the Accelerated Schools Project (ASP). Federal Chapter I, state SLIG and CSRD funds, and district levy monies were combined to support implementation of ASP. Despite these financial resources, there was not a correlation on the survey between financial resources and changes in classroom practice.

Although the Lighthouse Middle School staff perceived a growing number of high needs students who were academically challenged, the school did not have a high enough percentage of low income students to qualify for school-wide Chapter I programs. The district provided each teacher a minimum of $\$ 500$ per year for individual professional development. In addition, the district provided up to 8 hours of district directed in-service for all staff and an additional 40 hours of professional development time, some of which could be accessed for building directed professional development and reform activities. The district also accessed SLIG funds. Despite the generous amount of professional development funds for individuals, both the building principal and the teachers were concerned about the 
lack of funds to support collaboration and planning at the building level and to provide additional student support (such as extended days, summer school, parent training workshops). As with Laurel Middle School, there was no correlation between financial resources and changes in classroom practice.

As previously stated, Ponderosa Middle School received federal and state funds as a school-wide chapter I program due to high numbers of low income students. In addition, the district received a $\$ 68,000$ state CSRD grant to implement the school's reform plan, Expeditionary Learning. Over the years the school had accessed district and state (SLIG) funds to provide up to twenty days of professional development opportunities at the building level.

Another important source of funds was Share 105 (an ESD funded program for computer literacy) and Gates fellowships which provided extensive training, computers, and software for eight teachers in the building. As was seen in the discussion of classroom practices, this support enabled teachers to integrate technology into their classrooms to a degree not possible in the other two schools. Given these resources it was not surprising to find a significant correlation between financial resources and changes in practice at Ponderosa Middle School $(r=.289 ; p<.05)$. 
Summary of the Relation of School

Level Factors and Changes in Practice

Staff at all three schools reported that some district policies were problematic for changing classroom practice. Also teachers at all three schools perceived a contradiction between the two mandated state assessments: the norm referenced ITBS test and the criterion-referenced WASL, which impacted classroom practice.

Extensive interview and observational data revealed the complexity and challenge of developing a collaborative learning group at each school. Significant correlations between all five aspects of a collaborative learning group (collegial teams work together, conversations about practice, inservices and workshops, staff decisionmaking, and modeling of classroom practices) and overall changes in classroom practice were found at Ponderosa Middle School. Although the staff at the other two schools reported some aspects of a collaborative learning group, there were no correlations on the surveys with actual changes in classroom practice.

There were no significant correlations between a district strategic plan or district level administrative support and changes in practice at any of the schools. However, interview and observational data indicated a strong connection between district and building level administrative expectations and changes in classroom practice at all 
three schools. There were significant correlations on the surveys at Ponderosa Middle School between the school reform plan, Expeditionary Learning and changes in classroom practice and also between building level administrative support and changes in classroom practice

Finally, there were significant correlations on the surveys between time for planning and changes in practice and between financial resources and changes in practice at Ponderosa Middle School, but not at the other two schools.

A multiple regression analysis was conducted to determine which school level factors were most predictive of changes in classroom practice for all three schools. Table 21 presents the results of multiple regression analysis. Workshops and conversations about classroom practice accounted for $10 \%$ of the variance in changes in classroom practice.

\section{Table 21}

\section{Multiple Regression Analysis of School Factors and Changes in Practice}

\begin{tabular}{|l|l|l|l|}
\hline $\begin{array}{l}\text { School Factor: } \\
(\mathrm{N}=139-140)\end{array}$ & $\begin{array}{l}\text { Correlation with } \\
\text { Changes in Practice }\end{array}$ & Beta & R2 \\
\hline Workshops & $.272 *$ & .211 & $7 \%$ \\
\hline Conversations about practice & $.251 *$ & $.179 *$ & $10 \%$ \\
\hline Time & .251 & NS & \\
\hline Collegial Teams & .210 & NS & \\
\hline
\end{tabular}




\section{Relationship of Familiarity with the Reform Policy, Involvement in Educational Reform, and Changes in Practice}

In the previous five sections of this chapter I have examined the similarities and differences among the three schools regarding familiarity with HB1209, involvement in educational reform, and changes in classroom practice. I examined the relationship between the six teacher factors and familiarity with the policy, involvement in reform, and changes in practice. I also examined the relationship between the four school level factors and familiarity with the policy, involvement in reform, and changes in practice.

Contrary to my original hypothesis, familiarity with the reform policy itself was related to involvement in educational reform and with changes in classroom practice. The strong correlation between familiarity with HB1209 and staff involvement in educational reform $(\mathrm{r}=.603 ; \mathrm{p}<.01)$ was examined in Table 12 on page 186 . In this final section of chapter IV, I will examine the relationship of familiarity with HB1209 and changes in practice for all three schools and for each individual school. I will also discuss the findings of multiple regression analyses of the impact of familiarity with HB1209 on involvement in reform and changes in practice. 
Table 22 below indicates the correlation between familiarity with HB1209 and changes in practice for all three schools and for each individual school.

Table 22

Correlation of Familiarity with HB1209 and Changes in Classroom Practice

\begin{tabular}{|l|l|l|l|l|}
\hline & $\begin{array}{l}\text { Total } \\
\text { Survey } \\
\mathrm{N}=155\end{array}$ & $\begin{array}{l}\text { Laurel } \\
\text { MS } \\
\mathrm{N}=47\end{array}$ & $\begin{array}{l}\text { Lighthouse } \\
\mathrm{MS} \\
\mathrm{N}=54\end{array}$ & $\begin{array}{l}\text { Ponderosa } \\
\mathrm{MS} \\
\mathrm{N}=54\end{array}$ \\
\hline $\begin{array}{l}\text { Correlation of HB1209 } \\
\text { \& Changes in Practice }\end{array}$ & $.339^{* *}$ & $.367^{*}$ & $.322^{*}$ & $.286^{*}$ \\
\hline
\end{tabular}

${ }^{* *}$ significance at $<.01$ level * significance at $<.05$ level

There were significant correlations between familiarity with HB 1209 and overall changes in classroom practice for all three schools and for each individual school. The interviews and observational data, which I will report next, provide a more detailed picture of the relationship between knowledge of the policy and changes in practice at each school.

In the Laurel district, there had been some work on district curriculum committees regarding the EALRs, but there had been no building work until the fall of 1999 when the new principal was hired. As a result of the principal's insistence that teachers align their curriculum to the EALRs and the emphasis by the Accelerated Schools Project trainers on incorporating best practices and the state standards 
for each subject area, progress was made towards incorporating the EALRs into classroom practice.

In January 2000 , I conducted focus groups at Laurel Middle School, and teachers reported that every department had revised its curriculum based on the state standards. Besides language arts, science, math, and even physical education instruction were integrated with the EALRs. Within the language arts department, implementation varied from one teacher to another as illustrated by these comments: "We did our planning with the EALRs. Every lesson we did, if we couldn't justify it by tying it back to the EALRs, we didn't do it" (U: interview, 4/23/99). A nother teacher explained, "It's [the EALRs] a good guiding piece. I'll be honest, I haven't used it all probably as much as I should" (U: interview, 4/23/99). There were a few dissenting voices, who questioned whether the aligned curriculum was really affecting practice.

By the time you develop the curriculum and meet with the department and try to integrate and align the EALRs the year is over. If you do align the curriculum, the work goes in a box. It's not affecting practice. (U: focus group, $1 / 14 / 2000)$

The WASL was an even bigger influence on practice according to the teachers and building principal at the Laurel school. The first major school-wide change was a complete restructuring of the master schedule from seven 42 minute periods to four blocks of 84 minutes 
which doubled the amount of instruction in language arts/social studies, math, and science. Many electives were eliminated, and a three times/week reading and writing prompt was instituted school-wide. In the focus groups in January 2000 , teachers reported the following changes in their practice: (a) teaching reading from an elementary perspective; (b) writing research reports in physical education; (c) emphasizing the math test with lots more problem solving and self evaluation; (d) creating WASL type interpretation questions to accompany the literature text; (e) using the anchor papers the state provided for the writing prompts; and (f) students evaluating their own writing using the scoring rubrics. The most poignant comment was made by a seventh grade teacher who said, "This year, we WASL'd our kids to death. I mean I feel like I put WASL on a mallet and beat them over the head with it" (U: interview, 4/23/99).

Many of the seventh grade teachers were very concerned with the pressure they felt from the district office. The superintendent acknowledged the impact of the WASL scores the previous year.

I think it was seeing the results of the test scores in 97 of the fourth grade WASL, seeing the scores in 98 of the fourth and seventh grade WASL and realizing how poorly our students did on these state standards. It was very sobering. It was like an eight on a Richter scale.

(U: interview, 1/15/99) 
As the Lighthouse school district was developing content standards and benchmarks in the early 1990's, the district committees were aware of the state essential learnings and worked to ensure the district standards were in line with the state standards. When the Lighthouse school staff investigated remediation programs for their LAP students, they chose the HOSTS program because it integrated the state EALRs as well as district standards for language arts and math. All three teachers I interviewed could relate their choice of instructional units to the EALRs. The seventh grade language arts teacher was especially selective about her lessons.

I look at something and say, "Is this addressed in our EALRs?" If it's not addressed... we should probably take it out. And if it is there, then it's something we better make sure is addressed. ( $S$ : interview, 4/16/99)

There were many references to the influence of the WASL on classroom practice. According to the Lighthouse school principal, the focus school-wide during the 1999-2000 school year is to prepare for the WASL. She admitted that the state EALRs hadn't connected for the teachers, but the WASL was really pushing them. One of the sixth grade teachers I interviewed explained that the WASL was pushing her to make sure that all of her students could apply all six traits and write to all of the modes without assuming they had learned this in elementary school. 
During the spring of 1999 , the Lighthouse faculty met to develop a school-wide protocol for teaching writing across the curriculum, using the state's six trait writing model and scoring rubrics. This protocol was implemented in the fall of 1999.

The seventh grade language arts teacher I observed frequently commented on the pressure she felt to change her practice.

When we got our scores back this fall, it really blew me away that we didn't do better. I liked the way I was teaching but maybe that emphasis isn't there for what the WASL is looking at... It definitely affected what I cover in my classroom. (S: interview, 4/16/99)

The strongest connection between HB1209 and changes in classroom practice was observed at Ponderosa Middle School where the principal and staff knew about the EALRs and WASL and made decisions early on to change practice. While curriculum alignment work had been done at the district level in all three cases, only the Ponderosa school staff internalized it at a building level.

The policy empowered the Ponderosa school principal and staff who wanted to teach writing using the six trait model and forced others to change. When the language arts EALRs were published, the Ponderosa school administrators said, "Now we have the law on our side!" (R: interview, 1/26/99) The EALRs also improved articulation of reading and writing skills between the elementary and middle school. The sixth grade teacher noted that in the last year, particularly, her 
students were entering sixth grade knowing about the six trait writing model, so that she was able to build upon that foundation in her language arts instruction.

As in the other two schools, the WASL had the most profound changes on practice. One of the seventh grade teachers explained,

It [WASL] has been the driver behind the practices, the way I ask students to process problems in math and science, the reading. It asks students to be more active, do more reasoning, a lot more discussion in class.

( $R$ : interview, 4/29/99)

Preparation for the WASL was the focus for two school-wide workshops in the winter of 1999 with an emphasis on reading and writing strategies across the curriculum. The Expeditionary Learning consultant wove the WASL into many of her discussions with staff about reading strategies. In the final interviews with the seventh grade teachers last summer, both of them commented they felt their students were much better prepared for the WASL because of the changes in practice they had made throughout the year.

Both the survey data and the interviews and observational data support the strong connection between knowledge of HB1209 and changes in practice. (The relationship between familiarity with HB1209 and staff involvement in educational reform was examined earlier in this chapter.) A multiple regression analysis was conducted to determine whether familiarity with $\mathrm{HB} 1209$, teacher factors or 
school level factors were most predictive of involvement in educational reform for all three schools (see Table 23).

Table 23

Multiple Regression Analysis of Familiarity with HB1209,

Teacher Factors, School Level Factors and Involvement in Educational Reform

\begin{tabular}{|l|l|l|l|}
\hline$(\mathrm{N}=144-153)$ & $\begin{array}{l}\text { Correlation with } \\
\text { Involvement in } \\
\text { Educational Reform }\end{array}$ & Beta & R2 \\
\hline Familiarity with HBl209 & $.603^{*}$ & $.439 *$ & .36 \\
\hline Teacher Factors & & & \\
\hline Sense of empowerment & $.544^{* *}$ & $.292 *$ & .45 \\
\hline Pedagogical Knowledge & $.315^{* *}$ & $.138 *$ & .47 \\
\hline School Factors & & & \\
\hline School Reform Plan & $.285^{* *}$ & NS & \\
\hline Time & $.285^{* *}$ & NS & \\
\hline Collegial Teams & $.285^{* *}$ & NS & \\
\hline Modeling of practices & $.254 * *$ & NS & \\
\hline Workshops & $.227^{* *}$ & NS & \\
\hline
\end{tabular}

* significance at $<.01$ level ** significance at $<.05$ level

As expected from the correlational statistics, familiarity with HB1209, sense of empowerment, and knowledge of how to change instruction to engage students accounted for $47 \%$ of the variance in staff involvement in educational reform for all three schools.

Next a multiple regression analysis was conducted to determine whether familiarity with HB1209, teacher factors or school level factors was most predictive of changes in classroom practice for all 
three schools (see Table 24). The multiple regression analysis found that familiarity with HB1209 and the presence of professional development workshops predicted $15 \%$ of the changes in practice for all three schools.

\section{Table 24}

Multiple Regression Analysis of Familiarity with HB1209, Involvement in Educational Reform, Teacher Factors,

School Level Factors, and Changes in Practice

\begin{tabular}{|l|l|l|l|}
\hline$(\mathrm{N}=131-140)$ & $\begin{array}{l}\text { Correlation with } \\
\text { Changes in Practice }\end{array}$ & BETA & R2 \\
\hline Familiarity HBl209 & $.339^{* *}$ & $.289 *$ & .12 \\
\hline Teacher Factors: & & & \\
\hline Empowerment & $.271^{* *}$ & NS & \\
\hline Involvement in Reform & $.323^{* *}$ & NS & \\
\hline School Factors: & & & \\
\hline Workshops & $.272 * *$ & $.198 *$ & .15 \\
\hline $\begin{array}{c}\text { Conversations about } \\
\text { practice }\end{array}$ & $.251^{* *}$ & NS & \\
\hline Time & $.251^{*}$ & & \\
\hline Collegial Teams & $.210^{* *}$ & NS & \\
\hline
\end{tabular}

** significance at $<.01$ level * significance at $<.05$ level

Summary of the Relation of Familiarity with HB 1209. Teacher Factors, School Level Factors, and Changes in Practice

Reviewing the original conceptual model and the multiple regression analyses reveals which teacher and school level factors are more highly related to understanding HB1209, involvement in 
educational reform, and changes in classroom practice. Contrary to my original hypothesis, knowledge of HB1209 itself was highly related to involvement in educational reform and changes in practice. However, while knowledge of the policy was necessary, it was not a sufficient predictor of change. In general, teacher factors such as empowerment, and pedagogical knowledge (knowing how to change instruction to engage students) predicted more of the involvement in reform than did school level factors (time for planning and curriculum development, school reform plan). Both teacher factors (involvement in reform) and school level factors (workshops, conversations about practice) predicted the same amount of variance in changes in classroom practice.

To test whether a similar pattern occurred at the individual case study level, multiple regression analysis was conducted for each school. Table 25 below summarizes multiple regression analysis of familiarity with HB1209, involvement in reform, and changes in practice for each individual school (see Charts $15-17$ in Appendix G for full details of the multiple regression, correlational, and Beta statistics). 
Table 25

Multiple Regression Analysis of Familiarity with HB1209, Involvement in Reform, Teacher and School Level Factors, and Changes in Practice for each Individual School

\begin{tabular}{|c|c|c|c|}
\hline Correlation & $\begin{array}{l}\text { Laurel MS } \\
\text { R2 }\end{array}$ & $\begin{array}{l}\text { Lighthouse MS } \\
\text { R2 }\end{array}$ & $\begin{array}{l}\text { Ponderasa MS } \\
\text { R2 }\end{array}$ \\
\hline $\begin{array}{l}\text { Familiarity with HBl209 } \\
\text { and }\end{array}$ & $(N=41)$ & $(N=47)$ & $(N=50)$ \\
\hline Involvement in reform & .42 & .52 & .28 \\
\hline Empowerment & .35 & NS & NS \\
\hline Workshops & NS & NS & .35 \\
\hline Involvement in Reform and & $(N=41)$ & $(\mathrm{N}=50)$ & $(\mathrm{N}=50)$ \\
\hline $\begin{array}{l}\text { Familiarity with } \\
\text { IIB } 1209\end{array}$ & NS &. .52 & .42 \\
\hline Sense of Empowerment & .31 & NS & .29 \\
\hline Pedagogical Knowledge & 41 & .60 & NS \\
\hline Changes in Practice and & $(N=35)$ & $(\mathrm{N}=50)$ & $(\mathrm{N}=47)$ \\
\hline Sense of Empowerment & 23 & NS & NS \\
\hline $\begin{array}{l}\text { Years of Teaching } \\
\text { Experience }\end{array}$ & 32 & NS & NS \\
\hline $\begin{array}{l}\text { Familiarity with } \\
\text { HB1209 }\end{array}$ & NS & .10 & NS \\
\hline $\begin{array}{l}\text { Time for planning \& } \\
\text { develop. }\end{array}$ & NS & NS & .23 \\
\hline
\end{tabular}

As indicated by Table 25 , multiple regression analysis revealed that involvement in educational reform was a significant predictor of familiarity with HB1209 at all three schools. At Laurel Middle School staff sense of empowerment was also a significant predictor of familiarity with the policy, and at Ponderosa Middle School 
participation in workshops was also a significant predictor of familiarity with $\mathrm{HB} 1209$.

There was some variation among the schools of those factors which most highly predicted involvement in educational reform. Familiarity with the policy was a significant predictor of involvement in educational reform at Lighthouse and Ponderosa. Sense of empowerment was a significant predictor of involvement at Laurel and Ponderosa. Pedagogical knowledge was a significant predictor of involvement at Laurel and Lighthouse.

Multiple regression analysis indicated that the factors, which most highly predicted changes in classroom practice, differed at each school. At Laurel staff sense of empowerment and teaching experience were most highly predictive of changes in practice. At Lighthouse familiarity with HB1209 was the greatest predictor of changes in practice. At Ponderosa time for planning and professional development most highly predicted changes in practice.

Multiple regression analysis at the individual school level supported the overall research study finding that familiarity with HB1209 and involvement in educational reform were highly correlated and predictive of each other. Furthermore, analysis at the individual school level supported the overall research study finding that empowerment and pedagogical knowledge were significant predictors of 
involvement in reform. However, analysis at the individual school level did not support the overall research study finding of the importance of familiarity with the policy and workshops for predicting changes in practice. The greatest predictors for changes in practice differed at each school as indicated by Table 25 above. 


\section{CHAPTER FIVE}

\section{CONCLUSIONS}

The first section of this chapter reviews the purpose of the research, the theoretical framework, and research design. The second section summarizes the major findings of the research questions. The third section analyzes the research model presented at the end of chapter two in light of the study findings. The fourth section discusses implications and recommendations of the study for practitioners. The final section suggests directions for further research.

\section{Review of the Study}

This study was designed to examine the assumption underlying the Washington Education Reform Act (HB 1209): If the state raises standards and requires standards-based assessments, teachers will change classroom practice, and students will demonstrate improved academic achievement. The research examined the initial legislative model and tested other factors which, in combination with standards and assessments, led to changes in classroom practice in three middle schools which are currently implementing HB1209. 
Purpose of the Study

Passed in 1993, HB 1209 mandated an increased focus on the improvement of teaching and learning through systemic changes rather than the piecemeal initiatives of earlier eras. HB1209 established a set of content and performance standards known as Essential Academic Learning Requirements (EALRs); mandated state assessments (WASL) for all fourth, seventh, and tenth grade students; and funded professional development to support the expected changes in classroom practice and student learning.

Despite the assumptions of HB1209, the premise of a causal link between (a) reform policy, (b) changing classroom practice, and (c) improving student learning has not been well documented. On the contrary, research extending from the RAND study of federally funded educational programs of the 1960's to the analysis of implementation of the California Curriculum frameworks in the 1990's reveals that changing classroom practice and improving student learning are complex, multidimensional phenomena. My research was designed to examine some of the dynamic relationships in the assumptive framework of the Washington Education Reform Act. Because implementation of HB1209 is still in its early stages, the research focused on factors, which influence teachers to change their classroom practice in response to standards-based reform. 
Research indicates that systemic standards-based reform (such as HBI 209 envisions) requires complex changes in epistemology, curriculum, and pedagogy. Such reform calls into question traditional ideas of how learning takes place, what content should be taught, and how students should be taught and assessed. These changes will not occur simply because of legislative policy. The literature indicates that teachers must be active participants in a community of learners in order to change their understanding of teaching (Fullan, 1993). According to Knapp (1997), organizational learning, which focuses on the learning of teachers at both the individual and organizational level, is needed to change classroom practice and implement standards-based reforms. My study of three middle schools focused on the connection between standards-based reform policy, teachers' learning, and changes in classroom practice to improve student learning.

\section{Theoretical Framework of the Study}

The theoretical framework for this study drew from three areas of research. These three areas are systemic reform, organizational learning theory, and constructivism.

The concept of systemic reform policy has developed over the last twenty-five years. Systemic reform goes beyond restructuring of the individual components of the school organization and considers the dynamic complexity of schools and the change process. Sarason (1996) 
and Hoy and Miskel (1996) view the school as an open, dynamic system with internal and external feedback loops which provide information about the system and potentially allow it to self-correct and change. Both Sarason and Hoy and Miskel emphasize the importance of the system's external environment (e.g. state legislatures, community attitudes, socio-economic factors). Senge (1990) and Fullan (1993) stress the importance of the system's internal environment (e.g., the culture, relationships, and communication within the organization). Thus, systemic (educational) reform involves changing classroom practice within the opportunities and constraints of a dynamic, complex, open system.

In the last decade standards have been incorporated into systemic reform. Standards-based systemic reform refers to the alignment of standards, curriculum, texts, instructional practices, assessment, and teacher preparation. Smith and O'Day (1991), Darling-Hammond (1997), and Knapp (1997) apply the concept of "systemic reform" to those educational policies which combine state curriculum frameworks with site-based reforms. This model of systemic reform underlies the premises of HB 1209.

I believe Knapp's (1997) articulation of systemic reform through professional and organizational learning is the clearest picture of the factors which influence teachers to change classroom practice in 
response to standards-based reform. Knapp uses the term "professional and organizational learning" to explain learning by individual professional teachers and by the school organization as a whole. Both the learning of individual teachers as professionals and the learning that takes place at the organizational level are necessary for change in practice to occur.

The concept of learning organizations was popularized by Senge (1990). His five disciplines provide a starting point for understanding how the capacity or will to change develops in an educational organization. Personal mastery, mental models, shared vision, team learning, and systems thinking are interrelated, essential elements of all learning organizations. Senge argues that the goal of the learning organization is "metanoia" or the shift of mind that enables people to discover how they create their reality and how they can change it.

Fullan (1993, pp. 15-17) applies Senge's ideas at the individual level and describes four capacities which are necessary for teachers to change. The four capacities are mastery, personal vision building, inquiry, and collaboration. He contends that individual and organizational change occur simultaneously. According to Fullan, both individual (professional) and organizational change are more likely to occur when individuals work in collaboration with others in a "community of learners." 
This study focused on the factors which influence middle school teachers to change classroom practice in response to standards-based reform. Specifically, my research considers the factors which affect the professional learning of individual teachers and the organizational learning of the school as a whole. Based on the work of Senge (1990), Fullan (1993), and Knapp (1997) cited above, a school-based learning community is one in which learning of an intentional nature is taking place, simultaneously and interactively, at both the individual professional and organizational level.

Organizational learning theory provides a framework for understanding the research into the conditions which influence teachers to change classroom practice in response to standards-based reform. Over forty studies, conducted since the 1980's, provide insight into the barriers and supports for the organizational learning needed to implement state educational reforms similar to HB1209. Many of the studies focus on those factors which influence teachers to change their classroom practices. A simple framework which I developed for organizing these factors is to view them as teacher (professional) and school level (organizational) influences on classroom practice. Within a school-based learning community both sets of factors interact and influence teachers' will and capacity to change practice. 
Teacher (professional) factors are those influences which are internal to the teacher as a learner. They include: (a) present teaching experience (academic area, grade, position); (b) previous teaching experience; (c) pedagogical knowledge needed to implement the reform; (d) involvement in educational reform; (e) sense of empowerment; and (f) self-efficacy. Teachers' previous learning, beliefs, and attitudes are an essential ingredient in the process of change (Darling-Hammond, 1990; Gearhart et al., 1994). These ideas develop through teachers' experiences as students themselves and as teachers (Lortie, 1975). Also, researchers argue that standards-based reforms require teachers to shed established modes of understanding and adopt constructivist visions of knowledge (Cohen \& Spillane, 1992; Knapp. 1997). This requires changes in teachers' pedagogical knowledge, e.g., instructional and assessment strategies. Furthermore, the standards also require changes in teachers' content knowledge. Many research studies have documented the critical importance of a third factor, active teacher involvement in educational reform (Chrispeels, 1997; Cohen, 1990). And finally teacher empowerment and self-efficacy have been documented as important factors influencing teachers' capacity and will to change (Marks \& Louis, 1997; Sarason, 1996). 
$\underline{\text { School level factors }}$ are those influences which are external to the teacher but affect the school's culture as a learning organization. They include: (a) previous educational policies; (b) participation in a collaborative learning group; (c) building level and district administrative expectations and support; and (d) organizational features which enhance time for teachers to learn and collaborate. Previous educational policy is an important factor influencing teachers' response to standards-based reform (Cohen \& Ball, 1990b; Darling-Hammond, 1990). In addition, the important influence of a teacher's colleagues and professional community has been well documented (Louis et al.,1996; Peterson et al.,1996). Third, researchers (Aschbacher, 1993; Berman \& McLaughlin, 1978; Sarason, 1996; Spillane, 1998) have concluded that administrative leadership and support for reform is a necessary condition for local implementation. And finally, an obvious, but often underestimated influence on teachers' ability to change classroom practice is time for learning, planning, practicing, and revising as well as collaborating with colleagues (Prestine \& McGreal, 1997).

While the primary focus of this research was the factors which influence teachers to change their classroom practice in response to standards-based reform, a secondary issue was the types of changes which result. Based on my understanding of the standards movement in 
general and HB1209 in particular, I contend that constructivist ideas of teaching and learning are embedded in the Washington educational reform plan.

Fosnot (1996) defines constructivism as a theory about knowledge and learning which describes what knowing is and how one comes to know. While constructivism is not a theory of teaching, it does suggest ways of teaching. Major elements of constructivist epistemology (Caine \& Caine, 1991, 1997; Chaille \& Britain, 1997; Lambert et al., 1995) are: (a) Knowledge exists within the learner. (b) The learner constructs meaning from personal values, beliefs, and experiences. (c) Learning is a social activity enhanced by shared inquiry. (d) Reflection and metacognition are essential aspects of constructing knowledge and meaning. (e) Learners play a central role in assessing their own learning.

The connection between constructivist pedagogy and standardsbased reform is articulated by Wolf et al. (1991, pp. 47-48) as they define the "epistemology of mind" that underlines standards-based teaching and assessment. By this phrase they mean all learners construct rather than merely absorb knowledge, through inference, observation, rule generation, and theory building. Learning is understanding how to apply what one knows, not just the amount of information one can absorb. 
Zemelman et al. (1998) summarize the constructivist practices which underly the recommendations for practice of national curriculum standards reports, including: experiential learning, active student engagement, emphasis on higher order thinking, student meta- . cognition, performance-based assessments, scoring guides/rubrics, reading of whole books and primary sources, student self evaluation, student portfolios, and cooperative learning.

Constructivist pedagogy is not specifically referenced in the legislation or documentation of the Washington Education Reform Act. However, several elements of constructivist pedagogy, active student learning and performance assessment, are key features. Furthermore, $\underline{A}$ Framework for Excellence (OSPI, 1996) refers to metacognition, an important aspect of constructivist pedagogy, in the description of performance assessments. The Washington Assessment of Student Learning (WASL) is designed to elicit students' understanding of core processes and concepts and give them the opportunity to demonstrate their reasoning in problem solving. In addition to an emphasis on reflection and metacognition, the Washington state assessments also reflect the principle that learners construct meaning from personal values, beliefs, and experiences. 
Just as constructivist theory helps inform the changes in teaching and learning for students, it also sheds light on adult learning within schools. Lambert et al. (1995) call for constructivist leadership which involves developing an interactive professional culture. In such a learning community, teachers can converse with each other about practice and experience the supported encounters with discrepant information about teaching and learning that are essential for significant change.

\section{Research Design}

Five questions framed the research for this study:

1. What is the school faculties' understanding of the purpose of HB1209 and their familiarity with the Essential Academic Learning Requirements and the Washington Assessment of Student Learning in language arts and mathematics?

2. What is the school faculties' overall level of involvement in educational reform and in what types of educational reform are they involved?

3. To what degree and in what ways do teachers change classroom practice in response to $\mathrm{HB} 1209$ ?

4. How are the following teacher factors related to staff members' familiarity with HB1209, their involvement in educational reform, and changes in classroom practice: (a) present teaching experience 
(academic area, grade, position); (b) previous teaching experience;

(c) pedagogical knowledge; (d) involvement in educational reform;

(e) sense of empowerment and (f) self-efficacy?

5. How are the following school level factors related to staff members' familiarity with HB1209, their involvement in educational reform, and changes in classroom practice: (a) previous educational policies; (b) participation in a collaborative learning group; (c) building level and district administrative expectations and support; and (d) organizational features that enhance time for teachers to learn and collaborate?

This research involved case studies of three middle schools, which are responding to the requirements of $\mathrm{HB} 1209$, and included the following research activities:

- interviews with district and building administrators

- surveys completed by instructional staff at each middle school

- interviews with three language arts teachers at each middle school who volunteered to participate in interviews/classroom observations

- five classroom observations of each interviewed teacher

- review of district/ building documentation regarding response to HB 1209

- observation of faculty meetings, site council and team meetings at each school. 
- focus group interviews with each grade level team at each middle school

Multiple sources of evidence for the areas of inquiry were designed to facilitate triangulation of data. Both the administrative interview data and the documentary evidence helped refine the surveys. The selection of classroom practices for the survey and subsequent observations was based on practices implied by implementation of the EALRs and WASL and constructivist pedagogy. The teacher interviews were designed to clarify and amplify the data from the staff surveys. In turn the initial teacher interviews helped focus the classroom observations. Finally, the post-observation interviews with the teachers provided reflection on the changes in classroom practice in response to HB1209. The focus group interviews with grade level teams provided an opportunity to corroborate the findings of the survey and note any significant changes during the following school year.

Both quantitative and qualitative analytical tools were used to analyze the data from the administrator and teacher interviews, surveys, and classroom observations. The data were analyzed for each school individually and across all three schools to clarify the connection between standards-based reform policy (HB1209), teachers' learning, and changes in classroom practice. 
The following analytical tools, using SPSS, were employed: (a) frequency statistics (demographic data, familiarity with HB1209, involvement in educational reform, staff sense of empowerment and self-efficacy, school level factors which act as barriers and supports to changing classroom practice, and changes in classroom practice); (b) chi square and ANOVA tests to determine significant differences among participants by various teacher factors and school level factors; (c) correlational analysis to test for relationships between teacher and school level factors and familiarity with HB1209, involvement in educational reform, and changes in practice; (d) multiple regression analysis to determine which of the above teacher and school level factors were most predictive of familiarity with HB1209, involvement in educational reform, and changes in practice.

The transcribed interviews, observations, and focus groups were analyzed, using a qualitative software program, N.U.D.I.S.T. (Nonnumerical, Unstructured Data Indexing, Searching, and Theory Building). The following steps were taken: (a) development and refinement of a coding scheme for the data (see Appendix F); (b) data searches to analyze the findings by individual schools and across cases; (c) development of propositions or explanations for each case; (d) creation and presentation of an interim site report synthesizing the 
quantitative and qualitative data; and (e) final synthesis and reporting of the data.

\section{Major Findings}

This section summarizes findings from the five research questions.

\section{Research Question One}

The first research question focused on the school faculties' understanding of the purpose of HBI209 and their familiarity with the policy. Previous research (Knapp, 1997) has indicated the influence of staff members' interpretation of policy on its implementation at the school level. The faculty at all three schools viewed raising standards and accountability as the primary purposes of HB 1209 but were concerned about the challenges faced by low-achieving students on the seventh grade WASL. Two of the three school districts had developed their own content standards and benchmarks prior to the passage of HB 1209 , and their staff members were more familiar with the state standards. The interview data corroborated the survey results, which indicated that Ponderosa Middle School staff reported the greatest familiarity with HB1209. Furthermore, the Ponderosa educators' understanding of the policy seemed more complex and focused on the 
pedagogical implications of the policy, i.e., requiring teachers to change instructional practices and students to demonstrate higher level thinking.

\section{Research Question Two}

The second research question considered the school faculties' involvement in educational reform. While there were no significant differences among the three schools on overall involvement in educational reform, there were significant differences on three reform activities: participation on a site council, use of classroom/state assessment data to make decisions about classroom practice; and participation in a collaborative learning group. Ponderosa Middle School staff indicated the highest participation in a collaborative learning group. Compared to the other two schools, Ponderosa had emphasized elements of a learning community and worked towards that goal. Ponderosa teachers confirmed that in-service activities were collaborative learning experiences which seemed to follow constructivist principles: teachers experienced conflict of ideas, searched for evidence in the texts, actively listened to each other, and made connections based on what others had said. Moreover, the Ponderosa principal's role behavior was that of an instructional leader, modeling expectations, learning, and sharing with the rest of the staff at in-service training and weekly grade level team meetings. 


\section{Research Question Three}

The third research question analyzed the changes in classroom practice which have occurred in response to HB1209. The survey asked staff to report the degree to which they have changed their use of twenty-four classroom practices and to report their top five practices. Ponderosa Middle school staff reported the highest mean score for every one of the twenty-four changes in practice, while Laurel Middle School and Lighthouse Middle School each reported the lowest mean score for twelve of the changes in practice.

The three schools differed significantly for changes in nine of the twenty-four instructional practices. These nine practices were reflection or metacognition by students, active student engagement in learning tasks, communication of student learning through writing, cooperative learning, involvement of students in research and experiments, student portfolios, integration of technology, teaching reading strategies across the curriculum, and intervention with students who do not meet standards. Ponderosa Middle School staff reported the greatest increase in use for all nine practices. Six of these nine practices are constructivist in nature.

The schools also differed in the classroom practices which they reported using most frequently. While all three schools reported 
cooperative learning, active student engagement in learning tasks, and curriculum units (lessons) aligned to the EALRs among their top five instructional practices, only Ponderosa Middle School also reported teaching reading and writing strategies across the curriculum among their top five practices.

\section{Research Question Four}

The fourth research question examined the relationship between six teacher factors and familiarity with the policy, involvement in reform, and changes in practice. A number of teacher factors were associated with familiarity with HB1209. As expected, seventh grade teachers and language arts, math/science, and multiple core teachers reported the greatest familiarity with the policy. University preparation programs for staff hired since 1995 influenced their familiarity with the policy. Staff members' involvement in educational reform and sense of empowerment were highly correlated with familiarity with HB1209. A multiple regression analysis was conducted to determine which teacher factors were most predictive of overall familiarity with HB1209. Overall involvement in educational reform and sense of empowerment accounted for $39 \%$ of the variance in familiarity with HB1209.

Certain teacher factors were also associated with involvement in educational reform. There was a significant relationship between staff 
members' present teaching experience, i.e., academic area, grade level, and position, and their involvement in educational reform. Those instructional staff members whose subjects (language arts and math/science) and grade level (seventh) are tested by the WASL reported greatest involvement in reform activities. There was a positive correlation between one aspect of pedagogical knowledge (understanding how to change instruction to engage students in active learning) and involvement in educational reform. Also, the greater the staff members' sense of empowerment. the greater their involvement in educational reform. A multiple regression analysis was conducted to determine which of the teacher factors were most predictive of overall involvement in educational reform. Sense of empowerment and pedagogical knowledge accounted for $32 \%$ of the variance in involvement in educational reform.

Teacher factors were also examined for their relationship to changes in classroom practices. There was a significant relationship between staff members' present teaching experience and changes in their classroom practice. Those instructional staff members whose subjects (language arts and math/science) and grade level (seventh) are tested by the WASL reported the greatest changes in practice. While there was not a significant correlation between the two survey questions regarding pedagogical knowledge and changes in classroom 
practice, the interviews and classroom observations indicated rich connections between pedagogical knowledge and changes in practice. Teachers with more years of experience, greater involvement in educational reform, and greater sense of empowerment were also more likely to report changes in classroom practice. A multiple regression analysis was conducted to determine which of the above teacher factors were most predictive of overall changes in classroom practice. Involvement in educational reform accounted for $10 \%$ of the variance in changes in classroom practice.

\section{Research Question Five}

The fifth research question examined the relationship between four school level factors and familiarity with the policy, involvement in reform. and changes in practice. A number of school level factors was associated with familiarity with HB1209. Interviews and observational data indicated that previous policy decisions to align curriculum with the EALRs had resulted in greater familiarity with $\mathrm{HB} 1209$ at Lighthouse and Ponderosa than at Laurel. The relationship between participation in a collaborative learning group and familiarity with HB1209 differed at the three schools. There were significant correlations at Ponderosa Middle School between familiarity with the policy and aspects of a collaborative learning group. This may be due to the strategic decisions made by the building principal and site 
council to involve all instructional staff (including instructional assistants) in training related to HB1209 and the school reform plan.

There was a common expectation in all three districts that teachers were to know and apply the EALRs in their classroom practice and prepare students for the WASL. However, only at Ponderosa was there a significant correlation between building level and district administrative expectations, via the school reform plan, and staff members' familiarity with the policy. Finally there was a significant positive relationship between time available for curriculum planning and professional development and familiarity with HB1209 for participants at all three schools. Multiple regression analysis was conducted to determine which of the above school level factors were most predictive of familiarity with HB1209 for all three schools.

Collegial teams that work together and a comprehensive reform plan at the school level accounted for $13 \%$ of the variance in familiarity with HB 1209.

School level factors were also related to involvement in educational reform. There was a direct connection between district decisions regarding allocation of resources and staff involvement in educational reform at all three schools. The surveys also showed significant correlations between four aspects of participation in a collaborative learning group (collegial teams work together, 
conversations about practice, inservices and workshops, and modeling of classroom practice) and involvement in educational reform at Lighthouse and Ponderosa. Only Ponderosa showed significant correlations between building level and district administrative expectations, via the school reform plan, and involvement in educational reform. Ponderosa staff responses also indicated a significant correlation between organizational features that enhance time for teachers to learn and collaborate and staff involvement in reform. Multiple regression analysis was conducted to determine which of the above school level factors were most predictive of involvement in educational reform for all three schools. Time for curriculum planning and professional development and a school reform plan accounted for $12 \%$ of the variance in involvement in educational reform.

School level factors were also related to changes in classroom practice. This study confirmed the impact of previous district and state policies on changes in teachers' classroom practice. Staff at all three schools reported that some district policies were problematic for changing classroom practice. Also teachers perceived a contradiction between the two mandated state assessments, the norm-referenced ITBS test and the criterion-referenced WASL, which impacted changes in practice. Extensive interview and observational data revealed the 
complexity and challenge of developing a collaborative learning group at each school. Significant correlations between all five aspects of a collaborative learning group (collegial teams work together, conversations about practice, inservices and workshops, staff decisionmaking, and modeling of classroom practices) and overall changes in classroom practice were found at Ponderosa Middle School. Although the staff at the other two schools reported aspects of a collaborative learning group, there were no correlations on the surveys with actual changes in classroom practice. Interview and observational data indicated a strong connection between building level and district administrative expectations and changes in classroom practice at all three schools. Finally, there were significant correlations on the surveys between time for planning and changes in practice and between financial resources and changes in practice at Ponderosa Middle School, but not at the other two schools. Multiple regression analysis was conducted to determine which of the above school level factors were most predictive of changes in classroom practice for all three schools. Workshops and conversations about classroom practice accounted for ten percent of the variance in changes in practice. 


\section{Research Model}

This research study was designed to examine the fundamental assumption underlying the Washington Education Reform Act: If the state raises standards and requires standards-based assessments, teachers will change classroom practice, and students will demonstrate academic achievement. The legislative model assumes that both raising standards and requiring assessments are necessary for teachers to change classroom practice. A major premise of HB1209 is that standards are needed to provide a common understanding of what students should know and being able to do; assessments are necessary to provide accountability for teachers and students.

However, the research cited in this literature review indicates that changes in classroom practice and student learning will not occur simply because of legislative policy. The literature indicates that professional and organizational learning is needed to change classroom practice. The research model, which I developed in Figure 14 below, shows the connection between standards-based reform policy, a schoolbased learning community and changes in classroom practice. 

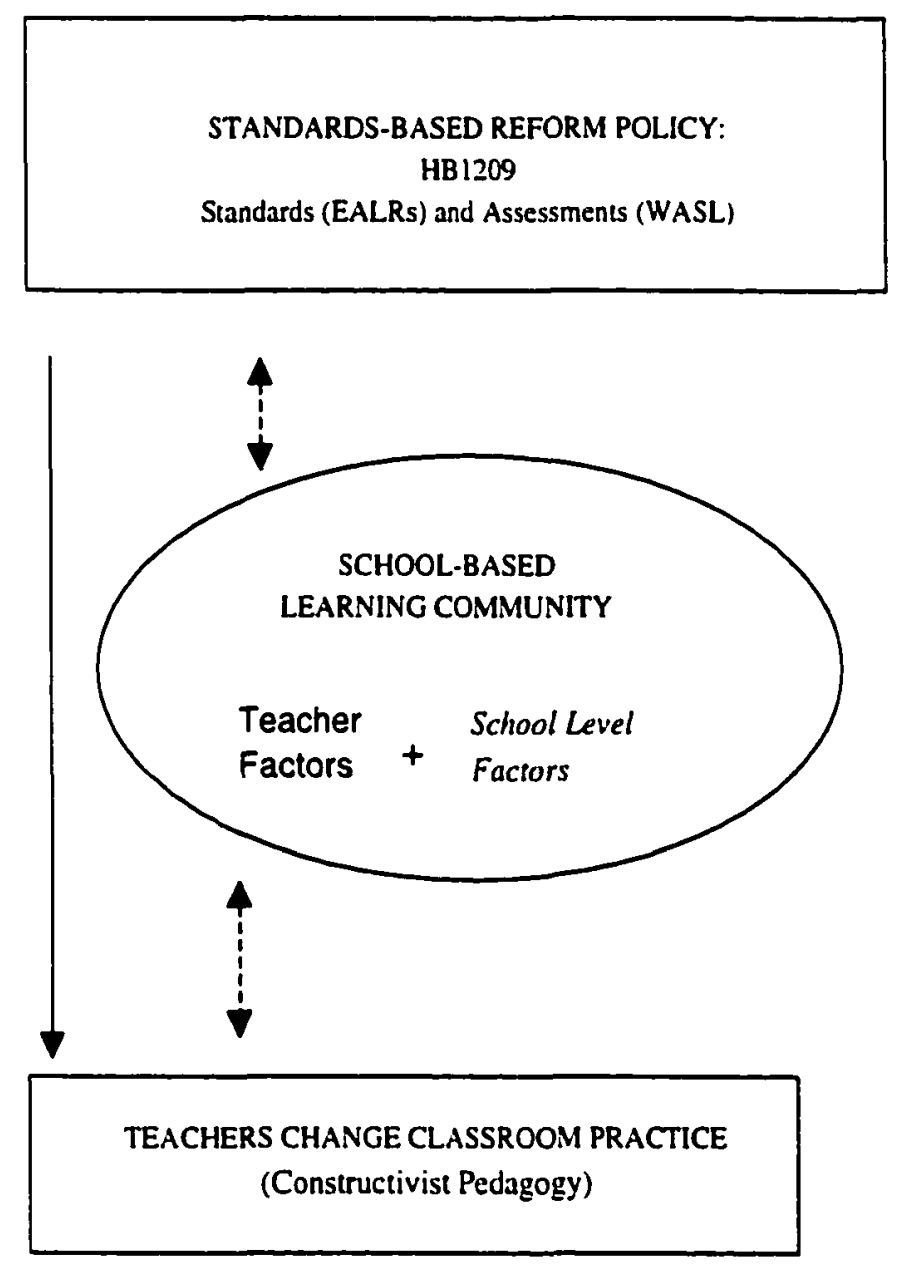

Figure 14. Research model of the connection between standards-based reform policy, school-based learning community, and changes in classroom practice.

In the conceptual framework above, the initial legislative model is indicated by rectangular boxes and solid arrows. It is assumed that the legislative policy (HB1209) will result in changes in classroom practice. However, research shows that a school-based learning community is needed to mediate between policy and practice. The 
school-based learning community is indicated by an oval and dotted arrows. Within the school-based learning community are both teacher factors and school level factors. The research model also indicates that changes in classroom practice may include a constructivist approach to learning. The dotted two-way arrows indicate the interaction between the standards-based reform policy, a school-based learning community, and changes in classroom practice. In Figure 14 and all subsequent replications of the model, teacher factors will be printed in Geneva type, and school level factors will be printed in Times ltalic.

The research in this study clarified the relationship between a school-based learning community (teacher factors and school level factors) and (a) familiarity with the reform policy, (b) involvement in educational reform, and (c) changes in classroom practice. Each of these relationships will be examined in the models below. In Figure 15 multiple regression analysis indicates which teacher factors and school level factors account for the variance in survey participants' familiarity with HBI 209. 


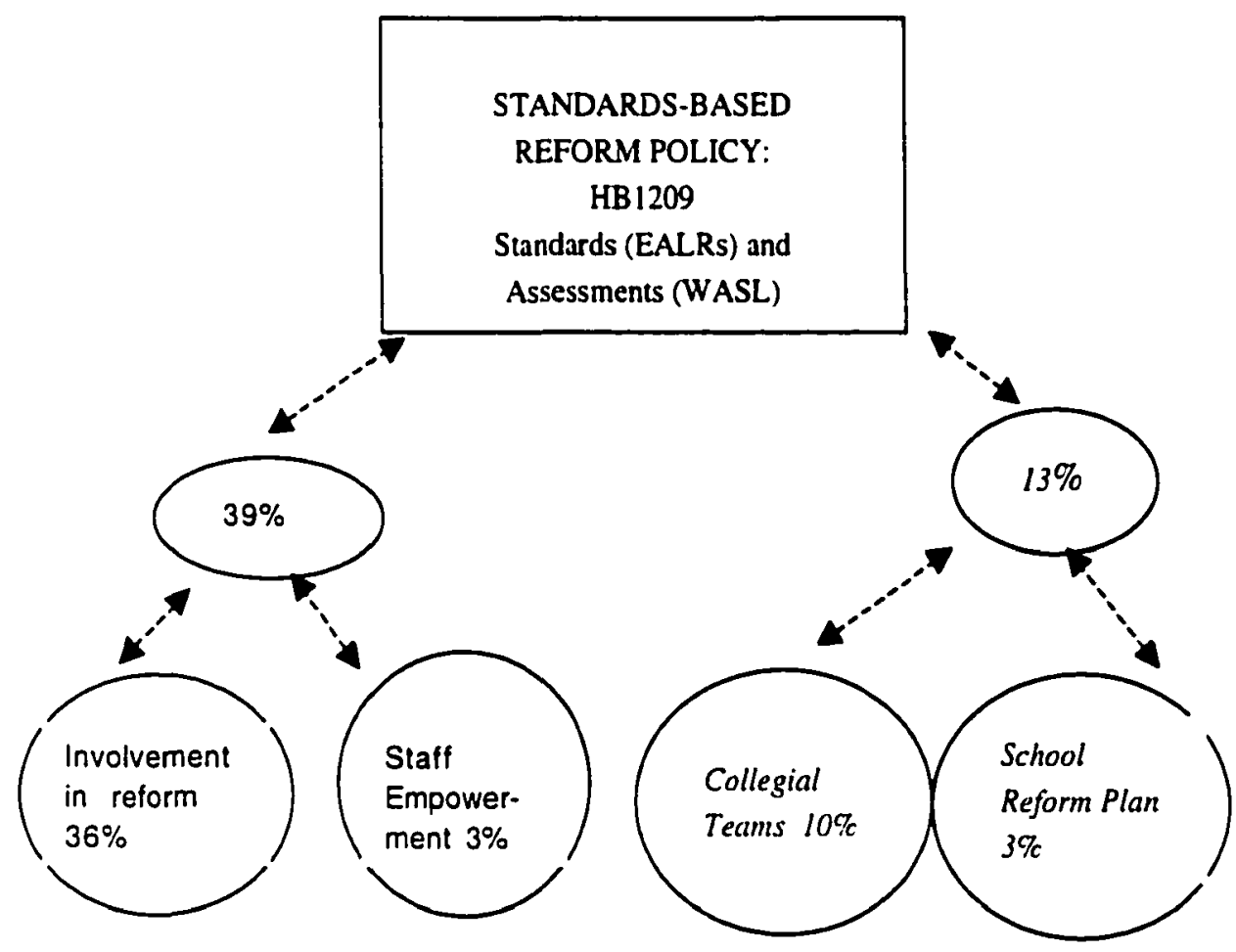

Figure 15. Multiple regression of teacher and school level factors with familiarity with HB1209.

The research model in Figure 15 above shows that both teacher factors and school level factors are related to familiarity with the policy. Staff involvement in educational reform and empowerment account for $39 \%$ of the variance in familiarity with the policy. Collegial teams and a school reform plan account for $13 \%$ of the variance in familiarity with the policy.

In Figure 16 below multiple regression analysis indicates which teacher factors and school level factors account for the variance in staff involvement in reform. 


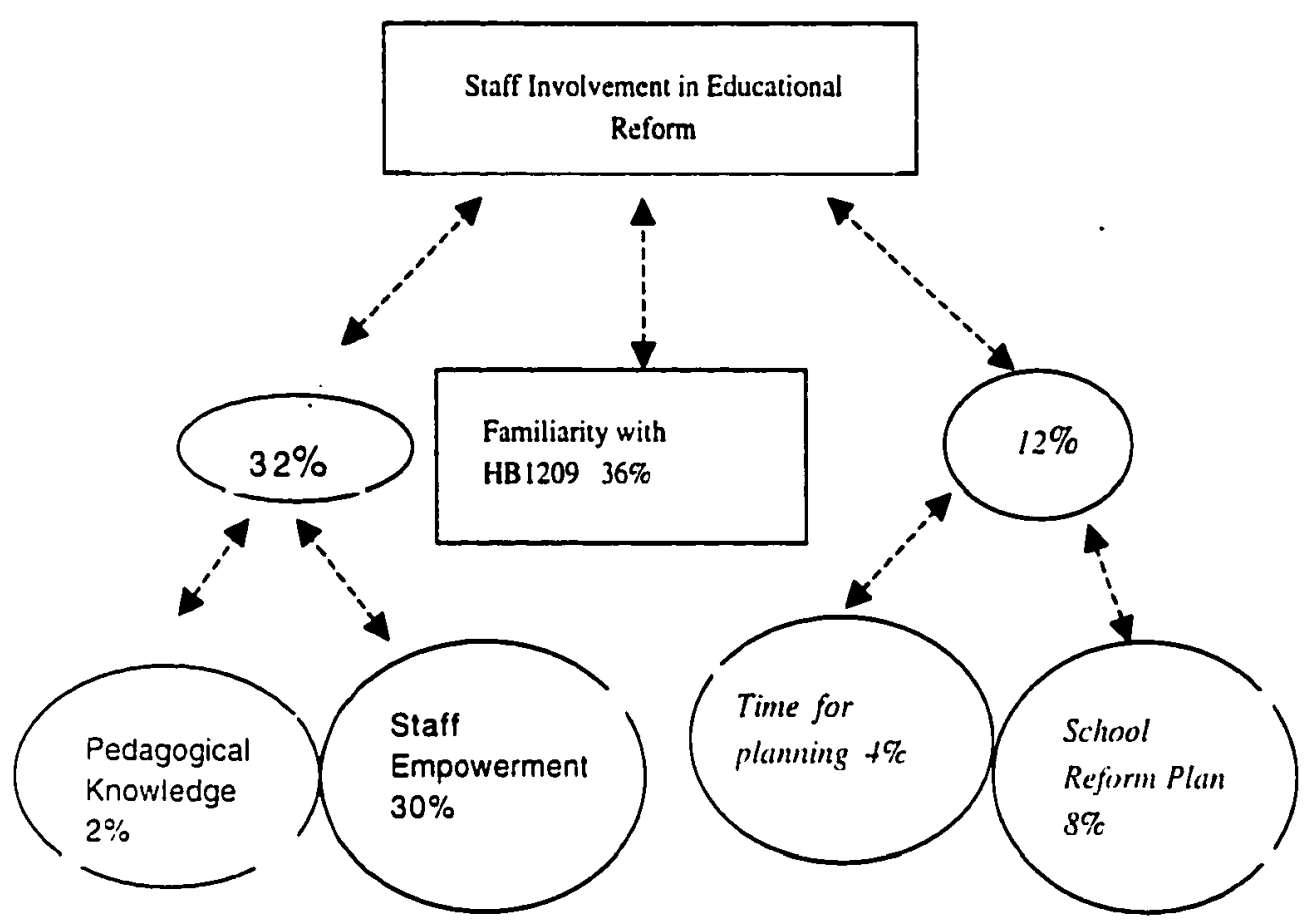

Figure 16. Multiple regression of teacher and school level factors and familiarity with HB1209 with involvement in educational reform

The research model in Figure 16 above shows that both teacher factors and school level factors are related to involvement in educational reform as well as familiarity with the policy. Staff empowerment and pedagogical knowledge account for $32 \%$ of the variance in involvement in reform. Time for planning and professional development and a school reform plan account for $12 \%$ of the variance in involvement in reform. Contrary to my original hypothesis 
familiarity with the reform policy itself accounts for $36 \%$ of the variance in involvement in educational reform.

In Figure 17 below multiple regression analysis indicates which teacher factors and school level factors account for the variance in changes in classroom practice.

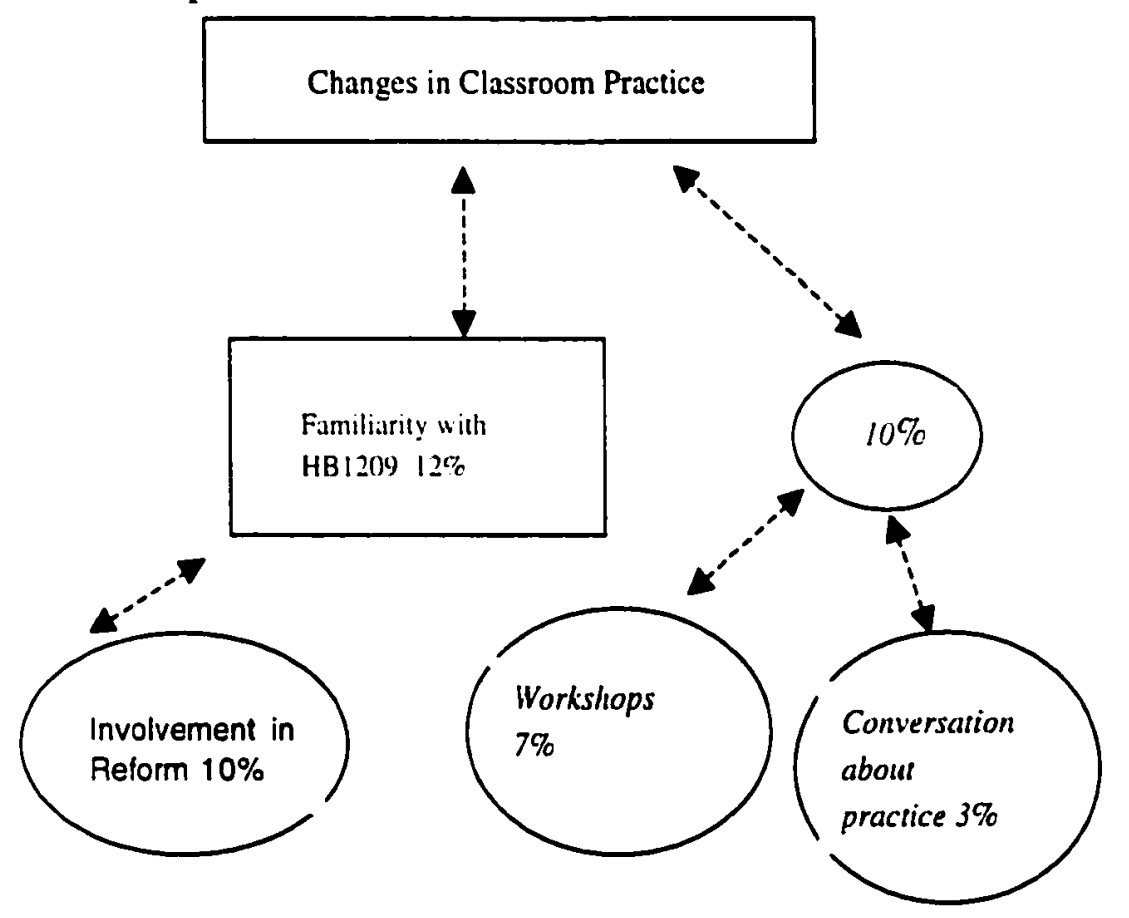

Figure 17. Multiple regression of teacher and school level factors and familiarity with HB1209 with changes in classroom practice.

The research model in Figure 17 above shows that both teacher factors and school level factors are related to changes in classroom practice as well as familiarity with the policy. Involvement in educational reform accounted for $10 \%$ of the variance in changes in 
practice. Workshops and conversations about practice accounted for $10 \%$ of the variance in changes in practice. Contrary to my original hypothesis familiarity with the reform policy itself accounted for $12 \%$ of the variance in classroom practice.

Multiple regression analysis was also conducted to determine whether familiarity with HB1209, teacher or school level factors were most predictive of involvement in educational reform and changes in practice for all three schools. Figure 18 below indicates that familiarity with the reform policy itself was the largest single predictor of involvement in reform and of changes in classroom practice.

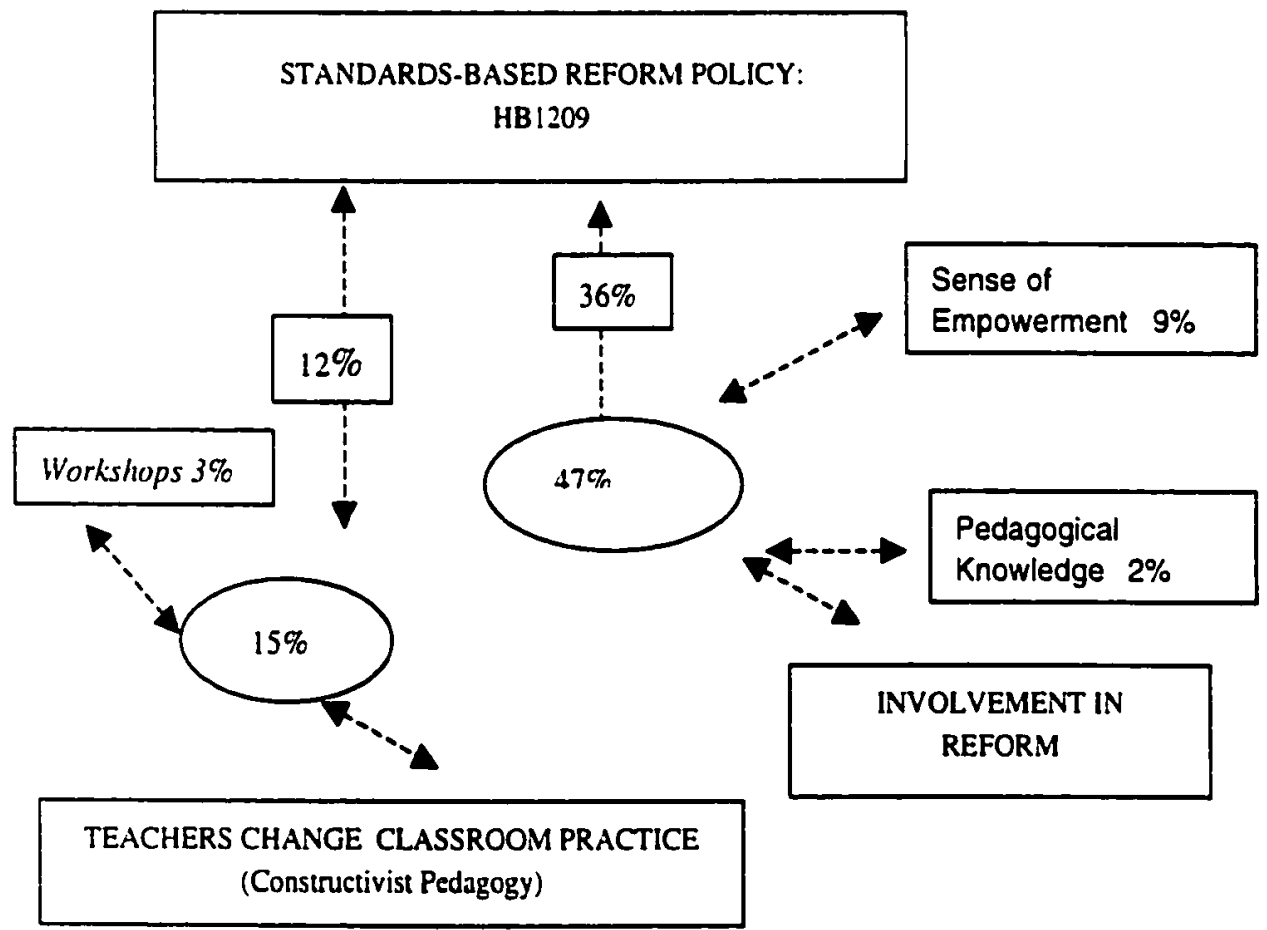

Eigure 18. Multiple regression of reform policy, teacher and school level factors with involvement in educational reform and changes in classroom practice. 
Figure 18 above indicates that knowledge of HB1209 itself, was the largest single predictor of involvement in educational reform and of changes in classroom practice. However, while knowledge of the policy was necessary it was not a sufficient predictor of involvement in reform or change. As indicated by Figure 16, teacher factors such as staff empowerment and pedagogical knowledge predicted more of the involvement in reform (32\%) than did school level factors, such as time for planning and curriculum development and school reform plan $(12 \%)$. As indicated by Figure 17, teacher factors (involvement in reform) and school level factors (workshops and conversations about practice) were equally predictive of changes in classroom practice $(10 \%)$.

Implications and Recommendations of the Study

In the following section I will present implications of the study findings for legislators and policy-makers, school district administrators, building level administrators, instructional staff, and university educational preparation programs. I will also present recommendations based on the study findings. 


\section{Implications for Legislators and}

Policy-makers

In a word, policy matters. Contrary to my original hypothesis, familiarity with HBl209 was the single largest predictor of involvement in reform and of changes in classroom practice across all three schools. The school that reported the highest mean familiarity with HB1209 (Ponderosa) also reported the greatest change in practice for each of the twenty-four classroom practices on the survey.

The interpretation of the policy also matters. The constructivist aspects of HB1209 were most clearly articulated by the principal and staff at one of the schools (Ponderosa). They believed the creators of HB1209 intended for students to be better thinkers and problem solvers and for teachers to change instructional practices. Not surprisingly, that staff also reported the greatest increase in use of constructivist classroom practices (student metacognition, active student engagement, cooperative learning, student research and experiments, student portfolios, and communication of student learning through writing). In contrast the staff at the two schools which focused on the accountability aspect of HB1209 demonstrated the least changes in practice in general and the least use of constructivist practices in particular.

While it was to be expected that instructional staff members, whose subjects (language arts and math/science) and grade level 
(seventh) are tested by the WASL, reported the greatest changes in practice, this finding is a cause of concern. If long-term, school-wide changes in classroom practice and improvements in student learning are to occur, then teachers of all subjects and grade levels ought to be equally familiar with the policy. When the science and social studies assessments are implemented in 2001 and 2006 respectively, teachers of those subjects will of necessity become more knowledgeable of the policy. However, teachers of elective subjects may still not see a connection between HB1209 and their subject areas.

Previous research about the importance of time for teachers to learn and collaborate in order to change practice was confirmed by this study. There was a significant correlation between time for curriculum planning and professional development and familiarity with HB1209 $(\mathrm{r}=.221, \mathrm{p}<.01)$. This is because HB1209 included provision of Student Learning Improvement Grant (SLIG) funds for five years (1994-1999). Consequently, all three middle schools used state SLIG funds to support in-services and curriculum planning focused on the EALRs and WASL. Furthermore, two of the three schools received state and federally funded Comprehensive School Reform Design (CSRD) grants to support their school reform plan and professional development. One of the schools (Ponderosa) reported a significant correlation between financial resources and changes in practice $(r=.289 ; p<.05)$. 
Legislators should recognize that systemic reform takes time and sustained support. Recent research suggests that "without stable policy environments and resources outside the school, the chances of enduring change are limited" (Louis, Toole, \& Hargreaves, 1999, p. 269). Elimination of SLIG funding by the legislature in 1999 was viewed as a significant barrier to continued professional development and change by the Lighthouse principal and teachers. Their school did not have a CSRD grant or school-wide chapter I programs which could provide the resources needed for school-wide professional development and collaboration.

As the Office of the Superintendent of Public Instruction continues to monitor implementation of the EALRs and WASL with new assessments in science and social studies it will be essential to continue funding for professional development and school reform. Sustained funding at the level required to promote systemic reform among the highly diverse schools and districts across the state needs to be a shared lobbying priority of districts, teachers' and administrators' professional organizations, and the business community.

Furthermore, instructional staff at all three schools acknowledged the contradiction between the state-mandated ITBS and WASL. The norm-referenced ITBS for eighth grade was not aligned to the EALRs and focused on speed and computational skills while the criterion- 
referenced WASL emphasized higher level thinking skills, text interpretation, writing, and problem solving. Since this study began the state has moved the ITBS to sixth grade, a decision which still does not address the contradictions in the state's assessment policy. If the legislature intends to raise academic standards and student achievement, a consistent performance-based assessment system will be essential.

\section{Implications for District}

Level Administrators

District policies and district administrators' expectations and support are important. Previous policy decisions in two of the districts to align curriculum with the EALRs resulted in greater familiarity with HB1209 in those districts.

District interpretation of the policy is also important. There was a common expectation in all three districts that teachers were to know and apply the EALRs in their classroom practice and prepare students for the WASL. However, there were different emphases in each district. The Laurel district superintendent emphasized "building knowledge workers", while the Lighthouse superintendent focused on "personalized education" using assessment data to individualize instruction for students. The Ponderosa superintendent prioritized the development of literacy and higher order thinking skills. Only one 
school (Ponderosa) showed significant correlations between administrative expectations, via the school reform plan, and familiarity with HBl209, involvement in reform, and changes in practice.

The implication is that if district administrators wish to influence staff members' involvement in educational reform and changes in practice, they will need to communicate their expectations very clearly at the building level, and the school reform plan will need to address those district expectations. Studies of school implementation of educational reform over time demonstrate that "pressure and support from the district office are critical to maintaining the scope of the effort" (Marks \& Louis, 1999).

District support in providing financial resources is important. All three districts authorized use of state SLIG funds for implementation of HB1209. In two of the districts the superintendent directed the building principal and staff to choose a comprehensive school reform model and to seek state funding through CSRD grants. In one district the superintendent had supported the middle school's decision to use its funds to sustain a ten-year professional development focus on literacy and the writing process.

Time for planning and professional development is crucial. Two of the districts had an early release half day each month for collaborative planning and professional development. During my study 
the early release time in both of those districts was consistently used to support implementation of the schools' reform plan. Staff at the school which no longer had an early release half day criticized the district's decision to eliminate that planning time, arguing that it significantly reduced their opportunities to collaborate and plan together.

The Ponderosa principal creatively allocated staffing resources to allow a double planning period each day and then directed the staff to use that time to work together in grade level, subject area, and teaching teams. Rather than praising this principal's proactive and assertive advocacy for his staff. the superintendent criticized the principal, citing the tensions it caused within the district because other building administrators were not able to create the same opportunities for their schools.

A consistent focus over the years of district and building sponsored professional development was a critical influence on change in practice. Sustained professional development focusing on agreed upon changes in practice was well established at one school (Ponderosa) and just beginning at a second school (Laurel). However, the third school (Lighthouse) which had the greatest variety of staff development programs over the years also demonstrated the least consensus on changes in practice. 
Finally the district's support of the principal as an instructional leader is vital. The Laurel superintendent praised the middle school principal as an instructional leader but then made it difficult for the principal to carry out that role due to all the other district office expectations which interfered with the principal's ability to get into classrooms on a consistent basis. The Lighthouse district expected building principals to be instructional leaders and provided opportunities for them to participate in district committees. However, district communications and directives also usurped much of the building principal's faculty meeting time so that there was little time left for collaboration or instructional leadership.

The Ponderosa superintendent was vocally supportive of the school reform plan. However at the end of the1998-1999 school year, the superintendent replaced the middle school principal with another district administrator. In addition the assistant principal, who had been a leader in the school's focus on literacy and the writing process, retired. In observations and focus group interviews the following school year, I noted the new administrators' diminished level of instructional leadership and the difficulty staff was experiencing in maintaining a collaborative learning group. The leadership vacuum resulting from the loss of both administrators was most keenly felt by 
the staff who had been most committed to the reform plan and its associated changes in practice.

\section{Implications for Building Administrators}

In "Rethinking School Improvement" Louis, Toole, and Hargreaves (1999) cite Leithwood's definition of "transformational leadership that focuses on the role of the principal as setting vision, organizing resources, and creating positive pressures for change" ( $p$. 267. The importance of the principal's instructional leadership role was confirmed by this study. All three principals communicated to staff their expectations about student learning and specific changes in classroom practice. However, the principals differed in the years they had served as principal of their schools (ranging from one to ten years). The school whose principal had been there for ten years (Ponderosa) reported the greatest familiarity with HB1209, the highest degree of participation in a collaborative learning group, and the most changes in classroom practice. That person had spent ten years deliberately building a collaborative learning community, and I observed collegial teams working together, frequent conversations about practice, modeling of practices by the principal and others, staff involvement in decision-making, and active involvement of the principal in all the inservices. 
The principal's role in managing organizational resources to enhance time for teachers to learn and collaborate is also essential. All three principals changed the master schedule to provide opportunities for staff collaboration and to focus on core academic skills. The Ponderosa principal was able to allocate financial and staffing resources to secure.double planning time for the staff. That principal also directed the staff to use the time for weekly meetings by grade level, subject area, and teaching teams. In addition he involved all instructional staff. including instructional assistants. in planning and training. This requirement resulted in much more collaboration and changes in practice than I observed at the other two schools.

The principal's role in facilitating the development and implementation of a school reform plan is also key to changing classroom practice. All three principals supported their school's reform plan by involving staff in decision-making, facilitating staff involvement in relevant workshops, using available funds for staff planning, and initiating discussions about the reform plan. Across all three schools, staff involvement in reform, participation in workshops, and conversations about practice were significantly correlated with changes in classroom practice. 
Implications for Instructional Staff

Teachers are the chief agents for changing educational practices and implementing policies (Cohen, 1990). If the constructivist implications of HB1209 are to be implemented "teachers will not only be creating a new culture of learning for their students. They will also be creating a culture of teaching for themselves... discarding the assumptions and practices of their own teaching past" (Miller, 1998, p. $530)$.

The importance of factors, which are internal to the teacher as a learner, was confirmed by my research. In this study teacher factors (such as involvement in educational reform and staff empowerment) were more predictive of familiarity with the reform policy than school level factors. Similarly teacher factors (such as staff empowerment and pedagogical knowledge) were more predictive of staff involvement in reform than school level factors. Teacher factors (involvement in reform) were equally as important as school level factors (workshops and conversations about practice) in predicting changes in classroom practice.

This study confirmed the findings of previous research that teacher involvement in educational reform is necessary for changes in practice. The new standards and assessment policies seek great changes in knowledge, learning, and teaching which will not occur 
unless teachers take an active role. Instructional staff involvement in workshops provided opportunities to learn about the EALRs and WASL as well as the implied changes in practice.

Another essential condition for teachers' learning and change is empowerment, the ability to influence policies and practices pertaining to their work as educators. Previous research has confirmed the role of empowerment of teachers as a condition for building a school culture focused on teaching and learning. Empowerment was highly correlated with familiarity with the policy and involvement in reform at each of the three schools. Empowerment was also correlated with changes in practice at one of the schools.

The importance of teachers' pedagogical knowledge was also confirmed by this study. Standards-based reforms required teachers to exchange traditional modes of understanding for constructivist views of knowledge acquisition. There were rich connections between staff members' pedagogical knowledge and the changes in classroom practice which they reported and I observed.

Instructional staff members, whose subjects (language arts and math/science) and grade level (seventh) are tested by the WASL, reported the greatest familiarity with $\mathrm{HB} 1209$, the most involvement in educational reform, and the most changes in practice. However, if long-term, school-wide changes in classroom practice and 
improvements in student learning are to occur, then teachers of all subjects and grade levels will need to share responsibility.

\section{Implications for University Educational}

Preparation Programs

University teacher preparation programs are also important in training pre-service teachers and providing in-service workshops. Teachers who had been hired since 1995 indicated their professors stressed knowledge and application of the EALRs and WASL. Thus, university teacher preparation programs should provide pre-service teachers the opportunity to learn and reflect on the implications of standards-based reform.

For most experienced teachers at all three schools, knowledge of the policy resulted from inservices and workshops. However, recent research has documented the importance of outside professional networks such as a regional school/university partnership for supporting teacher change in practice (Miller, 1998). One of the schools (Ponderosa) had established a long term relationship (over ten years) with a university professor who served as a consultant/trainer for the staff in literature based reading and the writing process. This school also reported the greatest changes in classroom practice. Thus, universities should also prioritize the development of partnerships between public schools and teacher education programs. 
While none of the administrators credited their university administrative preparation program with teaching them to be instructional leaders who could facilitate a school-based learning community, the implication is clear. As the demand for building level and district administrators grows due to demographic changes and as the pressure for teacher and principal accountability increases and the assessment stakes get higher, university preparation programs will need to respond appropriately.

In my experience as a secondary school administrator and as an instructor in educational administration, I have seen very few secondary principals who were trained to be instructional leaders. Moreover, despite the research, cited in this study on the importance of learning communities, very few secondary schools actually support organizational learning. Universities should teach and model the importance of instructional leadership and collaborative learning communities. Administrative preparation programs should also provide opportunities for interns to participate in collaborative learning communities (via a cohort model) and to internalize the importance of staff empowerment and involvement in educational reform.

\section{Recommendations of the Study}

The following recommendations are based on the implications of the study findings for legislators and policy-makers, district level 
administrators, building administrators, instructional staff, and university educational preparation programs.

The Commission on Student Learning has developed fifteen regional centers to provide professional development for continued implementation of HB1209. These workshops should emphasize the constructivist implications of implementing HB1209 and associated changes in classroom practice which need to occur. In addition the Superintendent of Public Instruction should recommend to the legislature the elimination of norm-referenced testing (ITBS) which contradicts the basic principles of criterion-referenced, performancebased assessment (WASL). Finally, the Superintendent of Public Instruction should recommend continued state funding for professional development (SLIG) and school reform (CSRD).

Starting with the superintendent, district level administrators should clearly and consistently communicate district expectations regarding implementation of HB1209. District supervisors should prioritize and facilitate the principals' instructional leadership and eliminate unnecessary constraints on the principals' time and attention. Given the statewide paucity of substitute teachers, districts should provide early release half-days at least monthly to facilitate schoolwide professional development and planning. Districts should also support flexible use of financial and staffing resources to provide time 
for weekly planning and collaboration. Finally districts should expect building principals to develop school-wide comprehensive reform plans and provide support in seeking additional funding to support implementation of those plans.

Principals should involve their entire instructional staff, including instructional assistants, in developing a school-wide comprehensive reform plan to provide a consistent focus for professional development and reform. Principals should expect every staff member, regardless of subject area or grade level, to be involved in educational reform and to be making appropriate changes in classroom practice. Principals should aggressively seek financial and staffing resources to facilitate weekly collaboration and planning and then insist that staff use the time for planning and professional development. Finally principals should recognize that systemic standards-based reform requires complex changes and that teachers must be active participants in a community of learners in order to change their understanding of teaching and their classroom practices. Teachers need to feel empowered, have the opportunity to learn new pedagogy, and be involved in educational reform. Teachers also have the responsibility of actively promoting a school-based learning community, becoming involved in educational reform, and seeking 
ways to change their classroom practices in response to standards-based reform.

University educational preparation programs should provide preservice teachers the opportunity to learn and reflect on the implications of standards-based reform. Universities should also teach and model for administrative interns the importance of instructional leadership and collaborative learning communities.

\section{Directions for Further Research}

My study included multiple sources of evidence (administrator and teacher interviews, surveys, classroom observations, focus groups, and documentary evidence) which allowed me to triangulate the data and develop converging lines of inquiry and conclusions. The data were analyzed for each school individually and across all three schools to clarify the connection between standards-based reform policy, teachers' learning, and changes in classroom practice. The data collection spanned parts of two school years from January 1999 to February 2000. I was able to engage nine teachers in rich conversations about their practices and observe their classrooms over a four-month period of time. The focus groups enabled me to share the preliminary findings from the surveys, interviews, and observations and seek clarification from all of the instructional staff members at each 
school. However, the study was only a series of snapshots that could not reveal the full complexity of a learning community. Furthermore, the study was limited to three schools.

Further research is needed at other school sites to develop richer insights into the connection between standards-based reform policy, organizational learning, and changes in classroom practice at the secondary level. Many middle schools in Washington are organized into grade level teams which may potentially facilitate collaboration and planning. However, as this study indicates even among middle schools there are great differences in the time and resources allocated for curriculum planning, professional development, and collaboration.

Many Washington high schools are organized by departments which may result in balkanization within the school and fragmented communication (Kruse \& Louis as cited in Marks \& Louis, 1999). In their study of 24 restructuring schools, Marks and Louis (1999) reported that high schools typically lack a strong capacity for organizational learning and teacher empowerment. More research is needed at the high school level to clarify the features of organizational learning, teacher empowerment and involvement in reform, and related changes in practice.

A second area of research is the development of school-wide reform across an entire district. Ponderosa Middle School was noted 
for its leadership of educational reform in language arts across the district. However, this leadership caused tensions among the district administrators and may have led to the superintendent's decision to remove the Ponderosa principal. Previous research has documented the resentment of staff at neighboring schools who feel their own work is being ignored by the attention focused on the reforming school (Miller, 1998). When one school within a district gets too far ahead of the others, how do the resulting isolation, tensions, and jealousies undermine that school's ability to sustain its educational reforms?

The Lighthouse district's reform plan, Personalized Education, is being implemented district-wide. It would be interesting to explore the different implementation patterns at other middle schools in the district as well as at the elementary and high school levels. As an observer at Lighthouse district professional development and governance meetings, I noted contrasting interpretations and implementations of the district's reform policy among the schools. Is there an optimum district size, above which implementation of district-wide reform is problematic?

All five schools in the Laurel district chose one of two comprehensive school-wide reform plans. Research focusing on implementation of district-wide reform is currently underway in the Laurel district. (Chenoweth \& Petti, 2000) An interesting topic to study would be the synergistic effects of similar reform plans being 
implemented simultaneously across the district. What changes occur in district office expectations and support for each school's reform efforts?

A third area of research is the principal's instructional leadership which this study showed was instrumental in setting expectations, securing and managing organizational resources to enhance time for teachers to learn and collaborate. Miller (1998) reported that the principals of all four schools in a case study of school improvement and reculturing had been leading their schools for seven to fourteen years. Is there an optimum range of years in which principals are most effective as instructional leaders? What supports do principals need to enhance their effectiveness as instructional leaders?

A fourth area of research is the impact of organizational learning on student learning. A basic premise of the research on organizational learning is that student achievement depends on the "intellectual, dispositional, and ethical capacities of teachers... and on the extent to which schools support the ongoing development of teachers' knowledge and skills" (Smylie \& Hart, 1999, p. 421). This study deliberately focused on the impact of a school-based learning community on changes in practice and did not investigate changes in student learning as evidenced by improved scores on the state assessments (WASL). A longitudinal study of the relationship between changes in practice and 
changes in student learning on the WASL is a logical next step.

However, that opens up the whole question of student assessment and the contradictions between norm-referenced (e.g., ITBS) and criterionreferenced, performance-based assessments (e.g., WASL).

Finally, further research is needed to understand the fragility of school-based learning communities. This study suggests that while no one factor can create a learning community, removal of one or two factors, such as loss of district level support or the building principal, can destroy it. Further research in the Ponderosa district might reveal whether teacher factors, such as involvement in reform and empowerment, can compensate for the lack of school level factors, such as district level and building administrative support and instructional leadership. 


\section{REFERENCES}

Abdal-Haqq, I. (1995). Professional standards development: Teacher involvement. Washingt on, DC: ERIC Clearinghouse on Teaching and Teacher Education. (ERIC Document Reproduction Service No. ED 383693 )

Accelerated Schools Project, (1999). Accelerated Schools, 8 (2).

Almasi, J. F., Afflerbach, P. P., Guthrie J. T. \& Schafer, W. D. (1995). Effects of a statewide performance assessment program on classroom instructional practice in literacv. (Reading Research Report No. 32). National Reading Research Center: Universities of Georgia and Maryland. (ERIC Document Reproduction Service No. ED379 635)

Aschbacher, P. (1993). Issues in innovative assessment for classroom practice: Barriers and facilitators. (Technical Report 359). Los Angeles: University of California, CRESST. (ERIC Document Reproduction Service No. ED355 280)

Baker, E. L., \& Linn, R. (1994). Effects of performance assessments on teachers and students. The CRESST Line. Los Angeles: University of California, CRESST.

Baker, E. L. \& O'Neil, H. F. (1995). Performance assessment and equity: A view from the USA. The CRESST Line. University of California Los Angeles.

Ball, D. L. (1990). Reflections and deflections of policy: The case of Carol Turner. Educational Evaluation and Policy Analysis, 12 (3), 247-259.

Bandura, A. (1986). Social foundations of thought and action.

Englewood Cliffs, NJ: Prentice-Hall. 
Baron, J. B. (1991). Strategies for the development of effective performance exercises. Applied Measurement in Education 4 (4), 305-318.

Barth, R. (1990). Improving schools from within. San F rancisco: Jossey -Bass.

Berman, P., \& McLaughlin, M.W. (1978). Eederal programs supporting educational change Vol VUL_Implementing and sustaining innovations. Santa Monica, CA: RAND Corporation.

Borko, H., Flory, M., \& Cumbo, K. (1993). Teachers'ideas and practices about assessment and instruction: A case study of the effects of alternative assessment. (Technical Report 366). Los Angeles: University of California, CRESST.

Bransford, J.D., \& Vye, N. J. (1989). A perspective on cognitive research and its implication for research. In L. Resnick \& $L$. Klop fer (Eds.), Ioward the thinking curriculum: Current cognitive research. Alexandra, VA: ASCD.

Bridges, W. (1991). Managine transitions: Making the most of change. Reading, MA: Addison-Wesley.

Brooks, J. G., \& Brooks, M. G. (1993). In search of understanding: The case for constructivist classrooms. Alexandria, VA: ASCD.

Burger, D. (1995). Designing a sustainable standards-based assessment sy stem. In What's notew orthy on learners learning schooling Aurora, CO: Mid Continent Regional Educational Lab. (ERIC Document Reproduction Service No. ED 398 641)

Caine, R. N. \& Caine, G. (1991). Making connections: Teaching_and the human brain. Alexandria, VA: ASCD.

Caine, R. N., \& Caine, G. (1997). Education on the edge of possibility Alexandria, VA: ASCD.

Chaille, C., \& Britain, L. (1997). The young child as scientist. New York: Longman. 
Chenoweth, T.G., \& Petti, A.D. (2000). Implementing district-wide comprehensive school reform. Paper presented at the annual meeting of the American Educational Research Association, New Orleans, LA.

Chrispeels, J. H. (1997). Educational policy implementation in a shifting political climate: The California experience. American Educational Research Journal, 34 (3), 453-481.

Cohen, D. K. (1990). A revolution in one classroom: The case of Mrs. Oublier. Educational Evaluation and Policy Analysis. 12 (3), 311 . 329.

Cohen, D. K., \& Ball, D. L. (1990a). Policy and practice: An overview. Educational Evaluation and Policy Analy sis, 12 (3), 233-246.

Cohen, D. K., \& Ball, D. L. (1990b). Relations between policy and practice: A commentary. Educational Evaluation and Policy Analysis, 12 (3), 331-338.

Cohen, D. K., \& Spillane, J. P. (1992). Policy and practice: The relations between governance and instruction. Review of Research in Education, 18, 3-49.

Cookson, P. W., Jr. (1995). Goals 2000: Framework for the new educational federalism. Teachers College Record, 96 (3), 405-417.

Cousins, E. (1998). Reflections on design principles. Dubuque, IA: Kendall/Hunt.

CRESST. (1995). Five years of research. National Center for Research on Evaluation, Standards, and Student Testing, UCLA.

Darling-Hammond, L. (1990). Instructional policy into practice: The power of the bottom over the top. Educational Evaluation and Policy Analy sis, 12 (3), 339-347. 
Darling-Hammond, L. (1994a). National standards and assessments: Will they improve education? American Journal of Education, 102, 478-510.

Darling-Hammond, L. (1994b). Setting standards for students: The case for authentic assessment. The Educational Forum, 59, 14-27.

Darling-Hammond, L. (1997). The right to learn. San Francisco: Jossey Bass.

Donahoe, T. (1993). Finding the way: Structure, time, and culture in school improvement. Phi Delta Kappan, 75 (4), 298-305.

Ellis, A. K. \& Jeffrey, T. (1997). Research on educational innovations. Larchmont, NY: Eye on Education.

Elmore, R. F., Peterson, P. L. \& McCarthey, S. J. (1996).

Restructuring in the classroom: Teaching, learning, \& school organization. San Francisco: Jossey-Bass.

Everson, S. T. (1995). Developing organizational learning in schools. In What's noteworthy on learners, learning, schooling. Aurora, CO: $M$ id Continent Regional Educational Lab. (ERIC Document Reproduction Service No. ED 398 641)

Fennema, E., Franke, M. L, Carpenter, T. P., \& Carey, D. A. (1993). Using childrens' mathematical knowledge in instruction. American Educational Research Journal, 30 (3),585-610.

Firestone, W. A., Fuhrman, S. H., \& Kirst, M. W. (1991). State educational reform since 1983: Appraisal and the future. Educational Policy.5 (3), 233-250.

Flexer, R. J., Cumbo, K., Borko, H., May field, V., \& Marion, S. F. (1995). How messing about with performance assessment in mathematics affects what happens in classrooms. (Technical Report 396). Los Angeles: University of California, CRESST. 
Flexer, R. J., \& Gerstner, E. A. (1995). Dilemmas and issues for teachers developing performance assessments in mathematics. (Technical Report 364). Los Angeles: University of California, CRESST.

Fosnot, C. T. (1996). Constructivism theory, perspectives, and practice. New York: Teachers College Press.

Fuhrman, S. H., \& Elmore, R. F. (1990). Understanding local control in the wake of state educational reform. Educational Evaluation and Policy Analysis, 12 (1), 82-96.

Fullan, M. (1993). Change forces: Probing the depths of educational reform. London: The Falmer Group.

Fullan, M., \& Stiegelbauer, S. (1991). The new meaning of educational change. New York: Teachers' College Press.

Gardner, H. (1987). The mind's new science: A history of the cognitive revolution. New York: Basic Books.

Gearhart, M., Wolf, S. A., Burkey, B., \& Whit taker, A. K. (1994). Engaging teachers in assessment of their students' narrative writing: Impact on teachers' knowledge and oractice. (Technical Report 377). Los Angeles: University of California, CRESST.

Goals 2000: Educate America Act. H.R. 1804, $103^{\text {rd }}$ Cong., $2^{\text {nd }}$ Session (1994)

Goertz, M.E., Floden, R.E., \& O'Day, J. (1995). Studies of education reform: Systemic reform: Vol. I. findings and conclusions. Newark: Rutgers, the State University of New Jersey, Center for Policy Research in Education.

Goodlad, J. (1984). A place called school. New York: McGraw-Hill.

Governor's Council on Education Reform and Funding. (1992). Putting children first: Improved student performance in Washington state. Olympia, WA: Office of the Governor. 
Grant, S.G., Peterson, P.L., \& Shojgreen-Downer, A. (1996). Learning to teach mathematics in the context of systemic reform. American Educational Research Journal. 33 (3), 509-541.

Guskey, T. R., \& Passaro, P. D. (1994). Teacher efficacy: A study of construct dimensions. American Educational Research Journal, 31 (3), 627-643.

Hasseler, S., \& Collins, A. M. (1993). Using collaborative reflection to support changes in classroom practice. Paper presented at the annual meeting of the American Educational Research Association, Atlanta, GA. (ERIC Document Reproduction Service No. ED 361330 )

Hoy, W. K., \& Miskel, C. G. (1996). Educational administration: Theorv, research, and practice. New York: McGraw-Hill, Inc.

Kelley, C., \& Protsik, J. (1997). Risk and reward: Perspectives on the implementation of Kentucky's school-based performance award program. Educational Administration Quarterly, 33 (4), 474-505.

Knapp, M.S. (1997). Between systemic reforms and the mathematics and science classroom: The dy namics of innovation, implementation, and professional learning. Review of Educational Research, 67 (2), 227-266.

Lambert, L., Walker, D., Zimmerman, D. P., Cooper, J. E., Lambert, M . D., Gardner, M. E., \& Ford Slack, P.J. (1995). The constructivist leader. New York: Teachers College.

Leithwood, K., Leonard, L., \& Sharrott, L. (1998). Conditions fostering organizational learning in Schools. Educational Administration Quarterly, 34 (2), 243-276.

Lewis, A. C. (1995). An overview of the standards movement. Phi Delt a Kappan, 76 (10), 744-750.

Linn, R. L., \& Baker E. L. (1995). What do international assessments imply for world class standards? Educational Evaluation and Policy Analysis. 17 (4), 405-418. 
Lipton, L., \& Melamede, R. (1997). Organizational learning: The essential journey. In A. Costa \& R. Liebmann (Eds.), The process-centered school: Sustaining a renaissance community. (pp. 30-53). Thousand Oaks, CA: Corwin Press.

Little, J. W. (1990). The persistence of privacy: Autonomy and initiative in teachers' professional relations. Teachers College Record. 91 (4), 509-536.

Lortie. D. C. (1975). Schoolteacher: A sociological study. Chicago: University of Chicago Press.

Louis, K. S., \& Marks, H. M. (1998). Does professional community Aaffect the classroom? Teachers' work and student experiences in restructuring schools. American Journal of Education, 106, $532-575$.

Louis. K. S., Marks, H. M., \& Kruse, S. (1996). Teachers' professional community in restructuring schools. American Educational Research Journal, 33 (4), 757-798.

Louis, K.S., Toole, J., \& Hargreaves, A. (1999). Rethinking school improvement. In J. Murphy \& K. S. Louis (Eds.), Handbook of research on educational administration, 2nd ed. San Francisco: Jossey-Bass.

Marks, H. M., \& Louis, K. S. (1997). Does teacher empowerment affect the classroom? The implications of teacher empowerment for instructional practice and student academic performance.

Educational Evaluation and Policy Analysis, 19 (3), 245-275.

Marks, H. M., \& Louis, K. S. (1999). Teacher empowerment and the capacity for organizational learning. Educational Administration Quarterly, 35 (Supplemental), 707-750.

McLaughlin, M.W. (1987). Lessons from experience: Lessons from policy implementation. Educational Evaluation and Policy Analysis, 9, 171-178. 
McLaughlin, M.W., \& Shepard, L.A. (1995).Improving education through standards-based reform: A report by the National Academy of Education Panel on Standards-Based Education Reform. Washington, DC: National Academy of Education.

Miles, M. B., \& Huberman, M. A. (1984). Qualitative data analysis: A sourcebook of new methods. Newbury Park, CA: SAGE.

Miller, L. (1998) Redefining teachers, reculturing schools: Connections, commitments and challenges. In $A$. Hargreaves, $A$. Lieberman, $M$. Fullan, \& D. Hopkins (Eds.), International handbook of educational change, part one (pp. 529-543). London: Kluwer Academic.

National Association of Secondary School Principals. (1992). A leader's guide to school restructuring. Reston, VA: NASSP.

National Commission on Educational Excellence. (1983). A nation at risk: The imperative for educational reform. Washington, DC: Government Printing Office.

Newmann, F. M., Secada, W. G., \& Wehlage, G. G. (1995). A guide to authentic instruction and assessment: Vision, standards, and scoring. Madison: Wisconsin Center for Education Research.

O'Day, J. (1995). Sy stemic reform in California. In M.E. Goertz, R.E. Floden, \& J. O'Day (Eds.), Studies of education reform: Systemic reform-.Vol. II: Case studies (pp. 1-38). Newark: Rutgers, the State University of New Jersey, Center for Policy Research in Education.

Odden, A.R. (1991). The evolution of education policy implementation. In A.R. Odden (Ed.), Educational Policy Implementation (pp. 1112). Albany: State University of New York Press.

Odden A.R. (1995). Educational leadership for America's schools. New York: McGraw-Hill. 
O'Sullivan, F. (1997). Rethinking schools as learning organizations. Paper presented at the annual meetingof the American Educational Research Association, Chicago, IL. (ERIC Document Reproduction Service No. ED 407 704)

Peterson, K., \& Deal, T. (1998). How leaders influence the culture of schools. Educational Leadership, 56 (1), 28-30.

Peterson, P. L. (1990.) Doing more in the same amount of time: Cathy Swift. Educational Evaluation and Policy Analysis, 12 (3), 261280.

Peterson, P. L., McCarthey, S. H., \& Elmore, R. F. (1996). Learning from school restructuring. American Educational Research Journal, 33 (1), 119-153.

Peterson, P.L., Prawatt, R.S., \& Grant, S.G. (1994). Rising expectations and declining resources: Learning to make reform in the best and worst of times. Paper presented at the annual meeting of the American Educational Research Association, New Orleans, LA.

Porter, A. C. (1994). National standards and school improvement in the 1990's: Issues and promise. American Journal of Education, 102, $421-449$.

Prestine, N. A., \& McGreal, T. L. (1997). Fragile changes, sturdy lives: Implementing authentic assessment in schools. Educational Administration Quarterly, 33 (3), 371-400.

Project 2061. (1989). Project 2061: Report on Literacy Goals in Science, Mathematics, and Technology. Washington, D.C.: A merican Association for the Advancement of Science.

QSR NUD*IST . (1997). Non-numerical unstructured data: Indexing, searching, and theory building [Computer software]. Thousand Oaks, CA: SCOLARI, Sage Publ. Software.

Reitzug. U. C. (1994). A case study of empowering principal behavior. A merican Educational Research Journal, 31 (2), 283-307. 
Resnick, L. B. \& Klop fer, L. E. (1989). Toward the thinking curriculum: Current cognitive research. Alexandra, VA: ASCD.

Riley, R. W. (1995). Reflections on Goals 2000. Teachers College Record 96 (3), 380-388.

Sagor, R. (1997). Collaborative action research for educational change. In A. Hargreaves (Ed.), Rethinking educational change with heart and mind. Alexandra, VA: ASCD.

Sarason, S. B. (1996). Revisiting "The culture of school and the problem of change". New York: Teachers College Press.

Senge, P. M. (1990). The fifth discipline The art and practice of the learning organization. New York: Doubleday/Currency.

Shepard, L. A. (1995). Effects of introducing classroom performance assessments on student learning. (Technical Report 394). Los Angeles: University of California, CRESST.

Smith, M., \& O'Day, J. (1991). Systematic school reform. In S.H. Fuhrman and B. Malen (Eds.), The politics of curriculum and testing. Bristol, PA: The Falmer Press.

Smy lie, M. A. (1992). Teacher participation in school decision-making: Assessing willingness to participate. Educational Evaluation and Policy Analysis, 14 (1), 53-67.

Smy lie, M. A. (1996). From bureaucratic control to building human capital: The importance of teacher learning in education reform. Educational Researcher, 25 (9), 9-11.

Smylie, M. A. \& Hart, A. W. (1999) School leadership for teacher learning and change: A human and social capital development perspective. In J. Murphy \& K. S. Louis (Eds.), Handbook of research on educational administration, 2nd ed. San Francisco: Jossey-Bass. 
Smylie, M. A., Lazarus, V., \& Brownlee-Cony ers, J. (1996).

Instructional outcomes of school-based participative decisionmaking. Educational Evaluation and Policy Analysis. 18 (3), 181 . 198.

Spillane, J. P. (1998). State policy and the non-monolithic nature of the local school district: Organizational and professional considerations. American Educational Research Journal 35 (1), $33-63$.

SPSS. (1994). Statistical package for the social sciences: Version 6.4 for Macintosh [Computer software]. Chicago: SPSS, Inc.

Stecher, B. M., \& Mitchell, K. J. (1995). Portfolio driven reform: Vermont teachers' understanding of mathematical problem solving and related changes in classroom practice. (Technical Report 400). Los Angles: University of California, CRESST.

Stiggins, R. J. (1991). Facing the challenges of a new era of educational assessment. Applied Measurement in Education 4 (4), 263.273.

Stiggins, R.J. (1994). Student-centered classroom assessment. Columbus, $\mathrm{OH}$ : Prentice Hall.

Sylwester, Robert. (1995). A celebration of neurons. An educator's guide to the human brain. Alexandria, VA: ASCD.

Taylor, C. (1994). Assessment for measurement or standards: The peril and promise of large scale assessment reform. American EducationaL Research Journal. 31 (2), 231-262.

Taylor, D. L., \& Bogotch, I. E. (1994). School level effects of teachers' participation in decision-making. Educational Evaluation and Policy Analysis.16 (3), 302-319.

Thieman, G. Y. (1997). Analysis of Camas school district survey: How exit requirements and demonstration tasks are changing classroom practice and student learning in the Camas school district. Unpublished manuscript. 
Thompson, J. P. (1993). Systemic education reform. Eugene, OR: Oregon School Study Council.

U.S. Department of Education. (1990). National goals for education, Washington, D. C.: Author.

Vinovskis, M. A. (1996). An analy sis of the concept and uses of systemic educational reform. American Educational Research Journal, 33 (1), 53-85.

Vitali, G. (1994). Factors influencing teachers' practices in an assessment driven reform. (ERIC Document Reproduction Service No. ED 373053 )

Wang, M. C., Haertel, G. D., \& Walberg, H. J. (1993). Toward a knowledge base for school learning. Review of Educational Research.63 (3), 249-294.

Washingt on Education Reform Act. HB1209. (1993).

Washingt on Office of the Superintendent for Public Instruction. (1996) A framework for excellence: The Washingt on state comprehensive plan for the improvement of student learning. Oly mpia, WA: Author.

Washingt on State Commission on Student Learning. (undated). WASL Example Test Grade 7. Oly mpia, WA: Author.

Washingt on State Commission on Student Learning. (1997). EALR Technical Manual. Olympia, WA: Author.

Washingt on State Legislature. (1993). HB1209.

Waters, G. D., \& Castle, S. (1993). The time dilemma in school restructuring. Phi Delta Kappan, 75 (4), 306-310.

Weick, K.E. (1979). Cognitive process in organization. Research in Organizational Behavior, I, 41-74. 
Wiemers, N. J. (1990). Transformation and accommodation: A case study of Joe Scott. Educational Evaluation and Policy Analysis. 12 (3), $281-292$.

Wiley, D. E., \& Yoon, B. (1996). Teacher reports on opportunity to learn: Analy ses of the 1993 California learning assessment system. Educational Evaluation and Policy Analysis, 17 (3), 355 370 .

Wilson, S. M. (1990). A conflict of interests: The case of Mark Black. Educational Evaluation and Policy Analysis, 12 (3), 292-310.

Wilson, S. M., Peterson, P.L., Ball, D.L., \& Cohen, D.K. (1996). Learning by all. Phi Delta Kappan, 77(7), 468-477.

Wolf, D., Bixby, J., Glenn, J., III, \& Gardner, H. (1991). To use their minds well: New forms of student assessment. Review of Research in Education. 17 $31-74$.

Yin, R. K. (1994). Case study research design and methods (2nd ed.): Vol 5. Applied social research methods series. Thous and Oaks, CA: SAGE.

Zemelman, S., Daniels, H. \& Hyde, A. (1998). Best practice: New standards for teaching and learning in America's schools (2nd ed.) Portsmouth, NH: Heinemann. 
APPENDIX A

ADMINISTRATIVE INTERVIEW PROTOCOL 
ADMINISTRATIVE INTERVIEW PROTOCOL

DATE:

SITE:

POSITION:

I. OPENING REMARKS

a. Introduction

b. Brief summary of research study

c. Ask administrator to sign informed consent form

d. Ask permission to tape record interview.

II. EDUCATIONAL BACKGROUND (Please review for me your:)

a. Educational preparation

b. Teaching experience

c. Administrative experience

d. Other experiences that shape your beliefs about teaching and learning

III. INTERPRETATION OF POLICY (What is your understanding of the intent of:)

a. HB1209 in general

b. EALRs for middle school

c. WASL for middle school

IV. CHANGES NEEDED TO IMPLEMENT HB 1209 (What kinds of changes may be needed in your district in order to implement HB 1209?)
a. Changes needed in curriculum
b. Changes needed in epistemology
c. Changes in classroom practice
d. Changes in student assessment 
V. PSYCHOLOGICAL/INTERNAL FACTORS SUPPORTING CHANGE

a. Administrator's sense of empowerment (Do you believe you are empowered to make the changes that are necessary to implement HB1209? Are there any obstacles preventing you from making those changes?)

b. Staff sense of empowerment (Do you believe your staff is empowered to make the changes that are necessary to implement HB1209? Are there any obstacles preventing them from making those changes?

c. Administrator's sense of personal efficacy (Do you believe that you can accomplish the changes you want to make and improve student learning? Are there limitations over which you have no control?

d. Staff sense of efficacy (Do you believe your staff believe they can accomplish the changes they want to make and improve student learning? Are there limitations over which they have no control?)

VI. DISTRICT OR BUILDING INVOLVEMENT IN THE FOLLOWING:

a. Creating a vision of expected classroom practices and student learning

b. Creating time for teachers to learn and collaborate

c. Creating professional development

d. Creating collaborative learning groups 
e. Involving instructional staff in site-based decisionmaking connected to teaching/learning

f. Aligning curriculum to match state EALRs and assessment (WASL)

g. Developing/articulating student performance standards

h. Using classroom and state assessments to inform instructional practice

i. Changing classroom practice to a more constructivist approach

j. Involvement in educational reform activities

$k$. Other forms of district/building leadership and support

VII IMPACT OF PREVIOUS EDUCATIONAL POLICIES or PRACTICES

a. State policies or practices that impact implementation of HB 1209

b. District policies or practices that impact implementation of $\mathrm{HB} 1209$

VIII PERCEPTION OF CHANGES IN CLASSROOM PRACTICE THAT ARE OCCURRING IN RESPONSE TO HB 1209 
APPENDIX B

MIDDLE SCHOOL INSTRUCTIONAL STAFF SURVEY 
MIDDLE SCHOOL INSTRUCTIONAL STAFF SURVEY

Thank you for completing the following questionnaire. My primary purpose is to understand the supporting conditions which influence changes in classroom practice in response to standards-based reform (i.e., HB1209 which established the Essential Academic Learning Requirements or EALRs and the state assessment, known as the WASL).

Your school was recommended because of its involvement in educational reform. I have conducted interviews with the administration to understand the changes that are occurring. Now I would like to survey the entire instructional staff.

I hope you will help by laking the time to sign the consent form and complete this survey. It is very important to receive the reedback from all the staft to accurately reflect opinion at your school. To ensure your anonymity, please do net put your name on this questionnaire. If you have any questions or concerns about this survey please call me at Portland State University (503-725-5263), or you may call my dissertation advisor, Dr. Robert Everhart (503-725-4747). Thank you, Gayle Y. Thieman

I. DEMOGRAPHIC INFORMATION

1. What is your primary job? (Elease select only one response.)

J Classroom Teacher a Counselor

$J$ Instructional AssistanUPara-Educator J Specialist

JAdministrator/Admin. Intern a Other

2. In what subject areas do you teach_primarily? (at least 4 out of 5-7 classes)

$\checkmark$ Core Academic (English/Reading and/or Social Studies)

$J$ Core Academic (Math and/or Science) a Physical Education and/or Health

J Multiple Core Academic Subjects a Academic Learning Sup./Special Ed.

J Electives (Arts, Technology. Foreign Language, etc.) Q Other:

] Not Applicable

3. At what grade level do you teach primarily? (Elease select only one response)

J sixth Jseventh $\square$ eighth a multiple grade levels a Not Applicable

4. How long have you worked in the field of education (certified and/or classified)? Years

5. How long have you worked at this Middle School?___Years

6. Gender: QMale QFemale

7. Previous teaching experience at another school (s):

$\begin{array}{lll}\text { Grade Level(s)___ Subjects___ } & \text { Years } \\ \text { Grade Level }(s) \_ \text {Subjects_______ Years }\end{array}$

Please Turn Over. 
II.PLEASE ANSWER THE FOLLOWING QUESTIONS BASED ON YOUR EXPERIENCE IN THIS DISTRICT.

1. How familiar are you with the following aspects of HB1209?

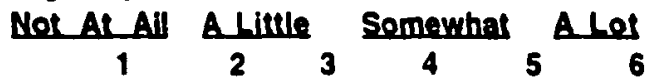

a. Essential Academic Learning Requirements for language arts?

b. Essential Academic Learning Requirements for math?

c. State (WASL) language arts assessments for seventh grade?

d. State (WASL) math assessments for seventh grade?

e. What do you see as the purpose of the Essential Academic Learning Requirements and the state assessment (WASL) of HB1209?

2. To what degree are you currently or have you been involved in the following activities? Not At All a little Somewhat

a. Serve(d) on school site council (L.I.T.)

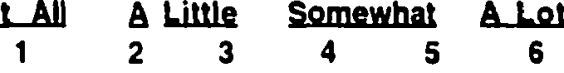

b. Serve(d) on district or state curriculum or assessment committee

c. Teach (taught) on an interdisciplinary team

d. Participate(d) in workshops on state EALRs

e. Participate(d) in workshops on seventh grade state assessment (WASL)

f. Align(ed) curriculum to match state EALRs/ assessment

g. Develop(ed) student performance standards (rubrics)

h. Use(d) classroom/state assessment data 10 make decisions about instructional practice

i. Participate(d) in collaborative learning group (Writing Process, Expeditionary Learning)

j. Participate(d) in state or national conference

k. Present(ed) at a local, state, or national workshopa

I. Other

3. How would you describe your eyerall level of involvement in implementing educational reform?

$\begin{array}{cccccc}\text { Net At All } & \text { A Little } & \text { Somewhas } & \text { ALos } \\ 1 & 2 & 3 & 4 & 5 & 6 \\ 0 & 0 & 0 & 0 & 0 & 0\end{array}$


4. Please indicate how much each of the following acts as a barrier to changing classroom practice in this school?

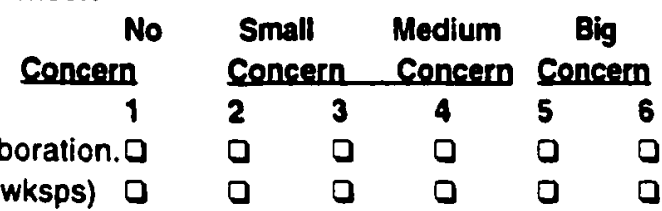

b. Lack of technical assistance (inservices, wksps)

c. Staff members who don't want to change instructional practice

d. Staff members who don't want to collaborate.

e. Trying to make changes when school is in session.

f. Lack of building level administrative support.

g. Lack of district level administrative support

h. Lack of parent/ communily support.

i. Student resistance to change

j. Not enough information about seventh grade state assessment (WASL)

k. Lack of understanding of how to align curriculum with EALRs and seventh grade assessment (WASL)

I. Lack of understanding of how to change instruction to engage students in active learning.

m. Difficulty implementing curriculum and instructional practices that are fundamentally different than those I experienced as a student or a teacher.a

n. Contradiction between district curriculum and seventh grade assessment (WASL)

o. Contradiction between other state and/or district assessments \& 7 th grade assessment (WASL)

p. Other

Using a-p from question four above, please rank the six most important barriers

to changing classroom practice:

BIGGEST CONCERN 1._ 2._ 3.__ 4._ 5._ 6._ SMALLER CONCERN

Please Turn Over. 
5. Please indicate how much each of the following acts as a suppont to changing classroom practice in this school?

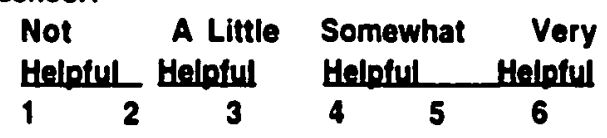

a. Collegial teams working together.

b. Frequent conversations about classroom practice

a

a

a

a $\square$

C. Technical assistance (inservices,wksps)

d. Time for curriculum planning \& professional development for staff

e. Opportunity to visit other programs.

f. District strategic plan

g. Comprehensive school reform plan at the building level (e.g. Expeditionary Learning)

h. Strong teacher support of changing classroom practice

i. Building level administration support

j. District level administration support

k. Community support of changing classroom practice

I. Clear process for staft involvement in decision-making

$\mathrm{m}$. Critical mass of staff desire change

n. Availability of resources (e.g. grant money ISLiG funds)

o. Availability of flexible stafting resources,

(e.g. instruction. Aides)
p. Consultants or colleagues who teach/model new

$\begin{array}{llllll}0 & 0 & 0 & 0 & 0 & 0\end{array}$ classroom practices with staff (e.g. Writing Process, Expeditionary Learning)

q. Other

Using a-q from question five above, please rank the six most_important supports for changing classroom practice.

MOST HELPFUL 1 2. 3.

4. 5. 6.__ LESS HELPAUL 
6. Thinking back no further than 1990, and considering your work at this school, to what extent have the following instructional practices occurred more frequently in your* teaching?

(" If your current job does nel primarily involve teaching, please respond to questions 6 and 7 based on your observation of teaching at this school)

a. Cooperalive learning among students

b. Use of scoring rubrics.

c. Use of student peer evaluation/critique.

d. Use of student sell evaluation.

e. Performance based assessments

t. Interdisciplinary or thematic curriculum

g. Invoivement of students in research $\&$ experiments

h. Clarilied standards/criteria for student performance

1. Increased expectations of students

1. Demonstration of student learning through performances or projects

k. Use of student portfolios

l. Reteaching of students who initially do not meet standards

m. Intervention with students who initially do not meet standards

n. Integration of technology into the curriculum

o. Communication of student learning through writing (journals, logs, elc.)

p. Students talk with each other about their learning

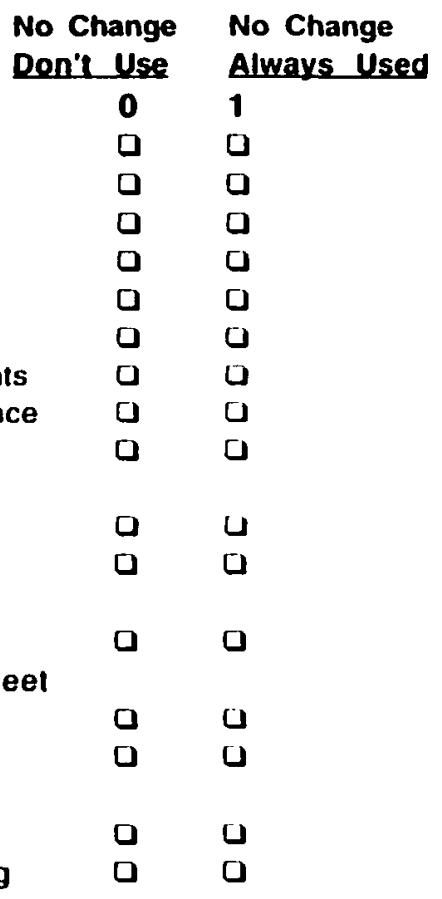

\begin{tabular}{lllll} 
Changed & \multicolumn{2}{l}{ Changed } & Changed \\
Allitle & \multicolumn{2}{c}{ Somewhat } & ALot \\
2 & 3 & 4 & 5 & 6 \\
0 & 0 & 0 & 0 & 0 \\
0 & 0 & 0 & 0 & 0 \\
0 & 0 & 0 & 0 & 0 \\
0 & 0 & 0 & 0 & 0 \\
0 & 0 & 0 & 0 & 0 \\
0 & 0 & 0 & 0 & 0 \\
0 & 0 & 0 & 0 & 0 \\
0 & 0 & 0 & 0 & 0 \\
0 & 0 & 0 & 0 & 0 \\
0 & 0 & 0 & 0 & 0 \\
0 & 0 & 0 & 0 & 0 \\
0 & 0 & 0 & 0 & 0 \\
0 & 0 & 0 & 0 & 0 \\
0 & 0 & 0 & 0 & 0 \\
0 & 0 & 0 & 0 & 0 \\
0 & 0 & 0 & 0 & 0
\end{tabular}

Please Continue This Question. Turn over 
6 cont. Thinking back no further than 1990, and considering your work at this school, to what extent have the following instructional practices occurred more frequently in your teaching?

(" If your current job does not primarily involve leaching, please respond based on your observation

of teaching at this school)

$$
\begin{array}{ll}
\text { No Change No Change } \\
\text { Den't Use Always Used }
\end{array}
$$

Changed

Changed

A Litule

Somewhat

Changed

q. Teaching of reading strategies across the curriculum

r. Teaching of writing strategies across the curriculum

01

s. Teaching of math problem solving strategies

口

0

t. Reflection or metacognition by students about their own learning

u. Active student engagement in learning tasks

v. Curriculum units (lesson plans)aligned to EALRs

23

4

๘

$0 \quad 0$

口 0 0

$0 \quad 0$

00

0 00

w.Use a variety of student data resources (e.g. assessment information) to plan instruction

$x$.Ongoing assessment of students (throughout lesson or unit of instruction).

$\begin{array}{ll}0 & 0 \\ 0 & 0 \\ 0 & 0\end{array}$

a 0

y. Other

둔

Using a-y above, please rank the six instructional practices which are used most frequently by you* (*or in teaching you have observed at this school).

MOST FRECUENT 2 2 3 4. 5 6

\section{LESS FREQUENT}

7. Based on your response to question six, how would you describe the overall level of changes

in your* classroom practice? (" or in teaching you have observed at this school)

$\begin{array}{llllll}\text { Ne Change } & \text { A Lille } & \text { Somewhal } & \text { A Lot } \\ 1 & 2 & 3 & 4 & 5 & 6 \\ 0 & 0 & \square & 0 & 0 & 0\end{array}$


8. Please describe the changes in classroom practice that you feel have had the most impact on student learning at this school. (If helpful, refer to question six)

9. Please indicate your agreement or disagreement with the following statements.

\section{Strongly \\ Disagree}

1

a. If I try really hard, I can get through to even the most difficult or unmotivated students.

b. At my school, I participate in making important decisions about the curriculum.

c. I am very limited in what I can achieve because a student's home environment is a large influence on his or her achievement.

d. At my school, I make important decisions about teaching strategies.

e. When it comes right down to it, a leacher really can't do much because most of a student's motivation and performance depends on the home environment.

f. At my school, I make important decisions about student discipline and classroom management. g. When the grades or test scores of students improve, it is usually because their teachers found more effective teaching approaches.

h. At my school, I participate in making important decisions about student assessments.

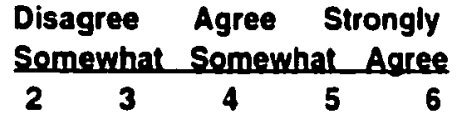

9

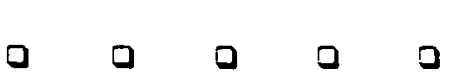

a $0 \quad 0 \quad 0$

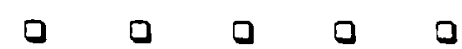


10. For each area below, please describe what kinds of changes are needed if $\mathrm{HB1209}$ is to be implemented in your school?

a. Changes in thinking about how students learn:

b. Changes in curriculum:

c. Changes in classroom practice:

d. Changes in student assessment:

e. Other changes:

THANK YOU FOR YOUR TIME AND SUPPORT. PLEASE PLACE YOUA QUESTIONNAIRE IN THE SEALED ENVELOPE AND TUAN IT IN TO 


\section{APPENDIX C}

TEACHER INTERVIEW PROTOCOL 
TEACHER INTERVIEW PROTOCOL

DATE:__ SITE:___ POSITION:

I. OPENING REMARKS

Introduction

Brief summary of research study

Acknowledge that teacher signed informed consent form

Ask permission to tape record interview.

II. EDUCATIONAL BACKGROUND

Educational preparation

Teaching experience

Other experiences that shape teacher's beliefs about teaching and

learning e.g., workshops, conferences, influence of colleagues

III. TEACHER'S INVOLVEMENT IN EDUCATIONAL REFORM:

(What kinds of professional development or educational reform activities have you been involved in since 1990 or since you began teaching at this middle school?)

Creating a vision of expected classroom practices and student learning.

Participating in professional development

Participating in collaborative learning groups.

Participating in site-based decision-making connected to teaching/learning.

Aligning curriculum to match state EALRs and assessment (WASL).

Developing/articulating student performance standards.

Using classroom and state assessments to inform instructional practice.

Changing classroom practice to a more constructivist approach.

Other educational reform activities

IV. TEACHER'S INTERPRETATION OF INTENT/GOALS OF HBI209.

(Probe for deeper understanding of what middle school teachers said in response to question le on the survey)

HB1209 in general

EALR's for middle school

WASL for middle school 
V. TEACHER'S UNDERSTANDING OF CHANGES NEEDED TO IMPLEMENT HB1209

(Probe for deeper understanding of what middle school teachers said in response to question 10 on the survey)

Changes needed in curriculum

Changes needed in epistemology (thinking about how students learn)

Changes in classroom practice

Changes in student assessment

VI. IMPACT OF PREVIOUS/CURRENT EDUCATIONAL POLICIES OR PRACTICES

(Are there other state or district policies that are impacting implementation?)

VII. PSYCHOLOGICAL/INTERNAL FACTORS SUPPORTING CHANGE

Teacher's sense of empowerment. (Do you feel empowered to make the changes that are necessary to implement HB1209? Why or why not? Are there any obstacles preventing you from making these changes?)

Teacher's sense of personal efficacy? (Do you believe you can accomplish the changes you want to make and improve student learning? Why or why not? Are there limitations over which you have no control?)

VIII. REFLECTIONS ON CHANGES IN TEACHER'S OWN LEARNING AND CHANGES IN CLASSROOM PRACTICE

Discussion of classroom observation protocol and classroom practices I observed. (Probe for rationale for instructional decisions and changes in practice.)

IX. DISCUSSION OF BUILDING LEVEL SURVEY RESULTS

(Probe for deeper understanding of why staff responded as they did to survey questions 4,5 , and 6 .) 


\section{APPENDIX D}

CLASSROOM OBSERVATION PROTOCOL 
CLASSROOM OBSERVATION PROTOCOL

TEACHER

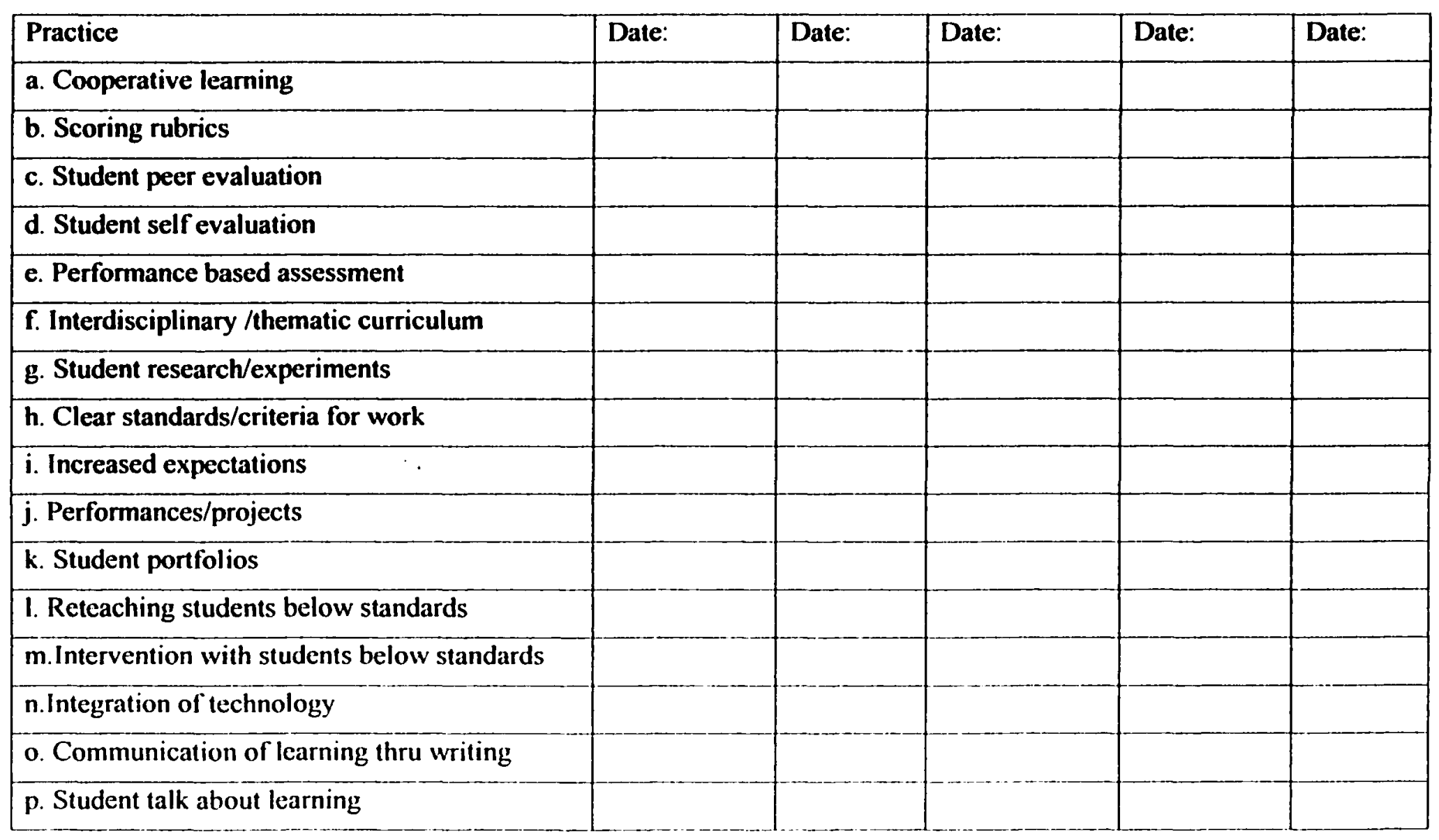




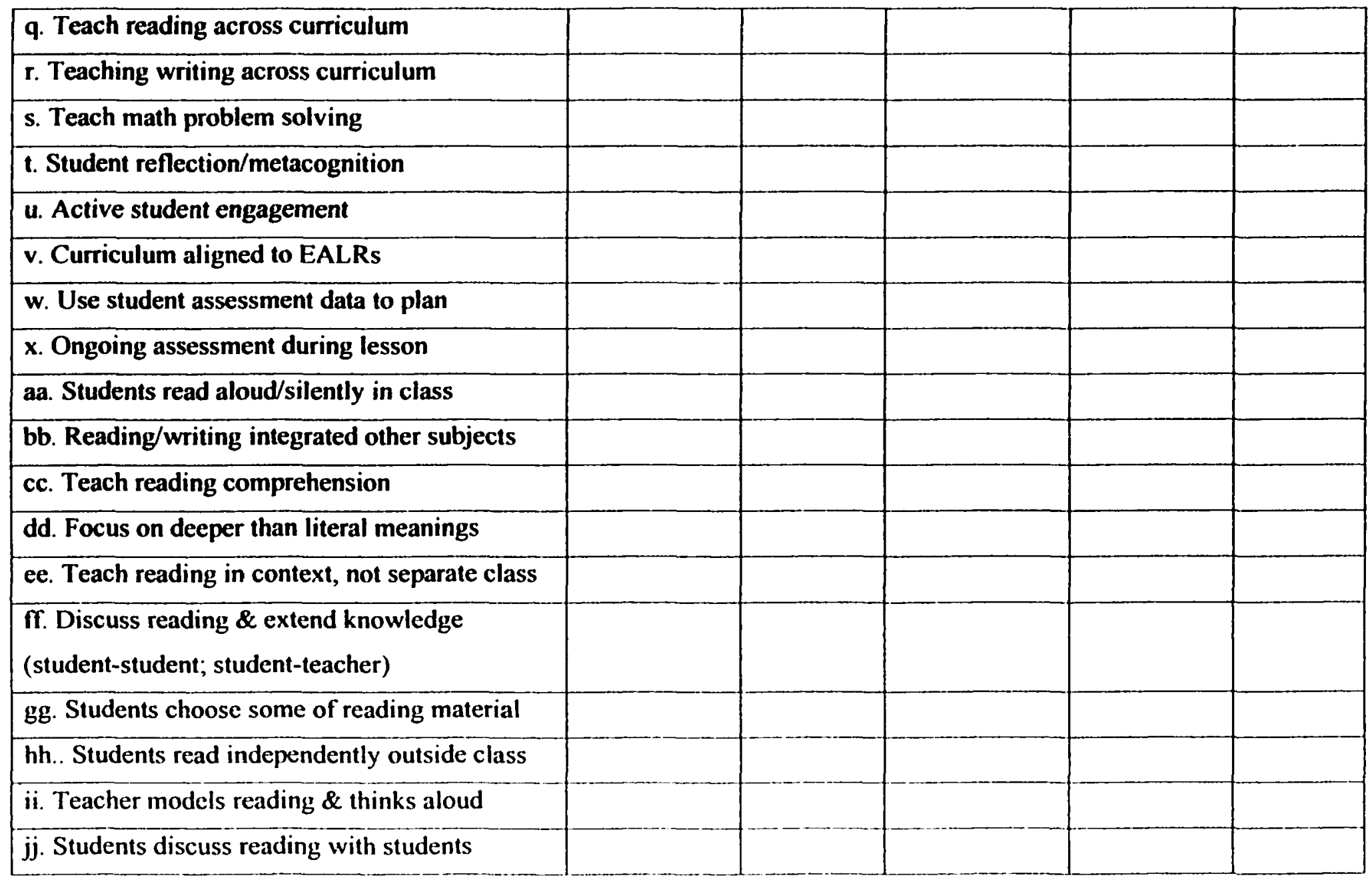


족

\begin{tabular}{|l|l|l|l|l|l|}
\hline kk. Students write extended responses & & & & & \\
\hline II. Students write short answers (notes, wkshts) & & & & & \\
\hline mm. Teach grammar in context of writing & & & & & \\
\hline nn.Teach conventions thru DOL/drills & & & & & \\
\hline oo.Students use writing process & & & & & \\
\hline pp.Writing is connected to student knowledge & & & & & \\
\hline qq.Students write for audience beyond class & & & & & \\
\hline rr. Students discuss writing with each other & & & & & \\
\hline ss. Students choose own topics for writing & & & & & \\
\hline tt. Students set goals for reading/writing & & & & & \\
\hline uu.Students critique each other's writing & & & & & \\
\hline
\end{tabular}




\section{APPENDIX E}

INTERIM REPORTS AND FOCUS GROUP PROTOCOL 


\section{INTERIM REPORT AND FOCUS GROUP PROTOCOL}

\section{FACTORS INFLUENCING MIDDLE SCHOOL TEACHERS TO CHANGE CLASSROOM PRACTICE IN RESPONSE TO STANDARDS-BASED REFORM}

Portland State University

Graduate School of Education

Gayle Y. Thieman, Researcher

October 27, 1999

The purpose of my study is to examine the connection between standardsbased reform policy, teachers' learning, and changes in classroom practice to improve student learning. An intended outcome is to provide useful information to teachers and administrators who are implementing HB1209. The overarching question my study seeks to answer is: How might teachers' involvement in a school-based learning community (i.e. "organizational learning") enhance their ability to change classroom practice in response to HB1209? Four additional questions frame the research for the study.

1. What is the school faculties' understanding of the purpose of $\mathrm{HB} 1209$ and their familiarity with the Essential Academic Learning Requirements and the Washington Assessment of Student Learning in language arts and mathematics?

2. How might the following teacher factors influence teachers' capacity and will to change: a) present teaching experience (school, academic area, grade, position); b) previous teaching experience; c) pedagogical knowledge; d) involvement in educational reform; e) sense of empowerment and $f$ ) self-efficacy?

3. How might the following school level factors influence teachers' capacity and will to change: a) previous educational policies; b) participation in a collaborative learning group; c) building level and district administrative support; d) organizational features that enhance time for teachers to learn and collaborate?

4. To what degree and in what ways might teachers change classroom practice in response to $\mathrm{HB} 1209$ ?

General Demographic Findings

- Summarize data from survey

Familiarity with HB1209 Findings

- Summarize data from survey, administrator and teacher interviews and probe for clarification.

Involvement in Educational Reform Findings

- Summarize data from survey, administrator and teacher interviews and probe for clarification. 
- Barriers to Changing Classroom Practice Findings

Summarize data from survey, administrator and teacher interviews and probe for clarification.

Supports for Changing Classroom Practice Findings

- Summarize data from survey, administrator and teacher interviews and probe for clarification.

Changes in Classroom Practice Findings

- Summarize data from survey, administrator and teacher interviews and probe for clarification.

Total Change in Practice Findings

- Summarize data from survey, administrator and teacher interviews and probe for clarification. 
APPENDIX F

QUALITATIVE DATA CODING SCHEME 
N.U.D.I.S.T. CODING SCHEME

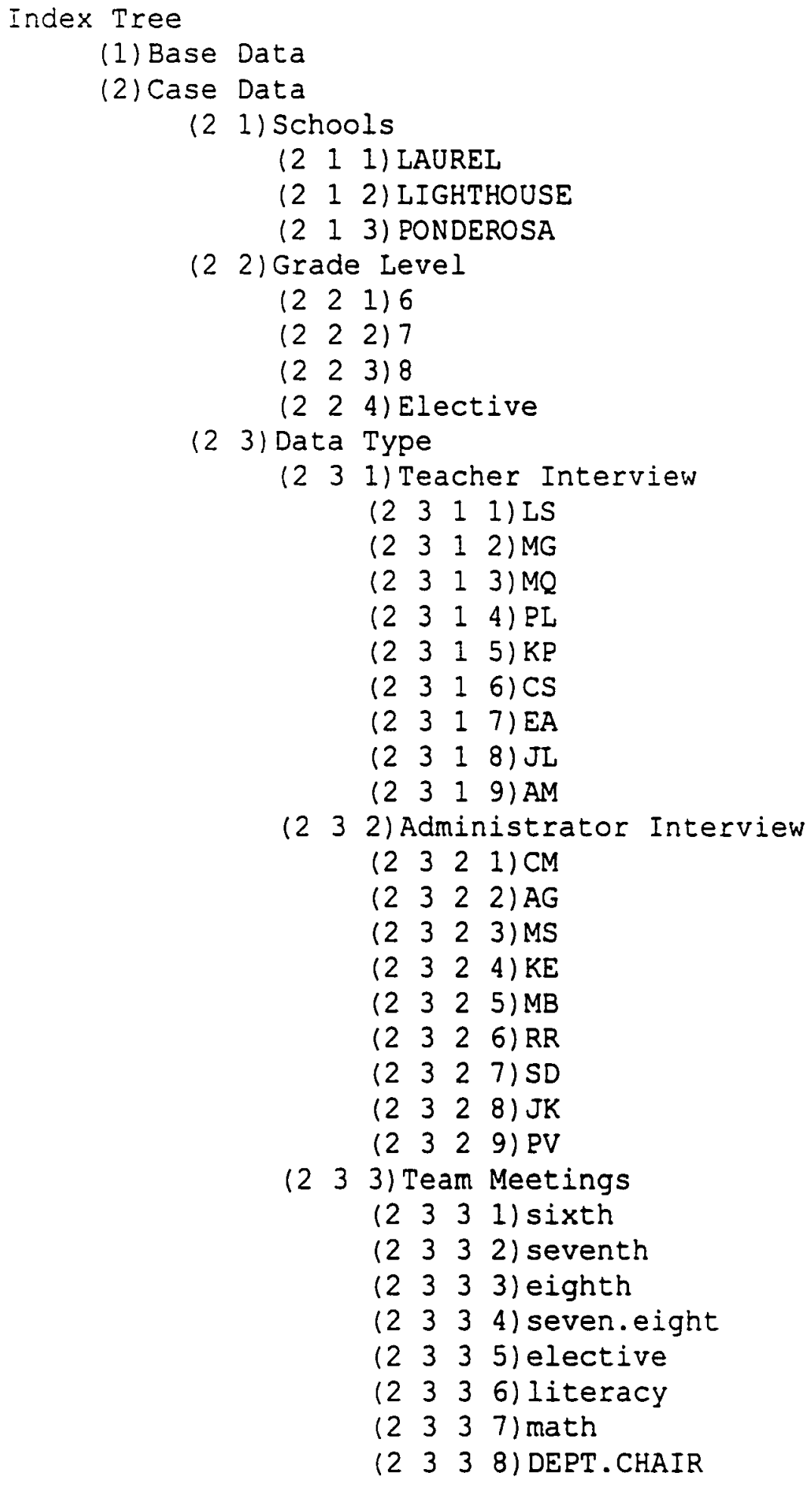

(2) 3 2) Administrator Interview

(12 $\left.3 \begin{array}{lll}2 & 2 & 1\end{array}\right) \mathrm{CM}$

(12 $\left.\begin{array}{llll}2 & 3 & 2 & 2\end{array}\right) A G$

(12 $\left.\begin{array}{llll}2 & 3 & 2 & 3\end{array}\right)$ MS

(12 $\left.3 \begin{array}{lll}2 & 3 & 4\end{array}\right) \mathrm{KE}$

(12 $\left.\begin{array}{llll}2 & 3 & 2 & 5\end{array}\right) \mathrm{MB}$

(12 $\left.3 \begin{array}{lll}2 & 3 & 6\end{array}\right)$ RR

$\left(\begin{array}{llll}2 & 3 & 2 & 7\end{array}\right)$ SD

(12 $\left.\begin{array}{llll}2 & 2 & 8\end{array}\right)$ JK

(12 $\left.\begin{array}{llll}2 & 2 & 9\end{array}\right)$ PV

(2) 33 3) Team Meetings

(12 $\left.\begin{array}{llll}2 & 3 & 1\end{array}\right)$ sixth

(l $\left.\begin{array}{llll}2 & 3 & 3 & 2\end{array}\right)$ seventh

(12 $\left.3 \begin{array}{lll}2 & 3 & 3\end{array}\right)$ eighth

(2 $\left.\begin{array}{llll}2 & 3 & 3 & 4\end{array}\right)$ seven. eight

(12 $\left.3 \begin{array}{lll}2 & 3 & 5\end{array}\right)$ elective

$\left(\begin{array}{llll}2 & 3 & 3 & 6\end{array}\right)$ literacy

(12 $\left.\begin{array}{llll}2 & 3 & 3 & 7\end{array}\right)$ math

(2 $\left.\begin{array}{llll}2 & 3 & 3 & 8\end{array}\right)$ DEPT. CHAIR 
(2 3 4) Eaculty Meetings

(2 3 5) Professional Development

(2 $\left.3 \begin{array}{lll}2 & 5 & 1\end{array}\right)$ Bldg.ASP

(2 $\left.\begin{array}{llll}2 & 3 & 5 & 2\end{array}\right)$ Dist.ASP

(2 $\left.\begin{array}{llll}2 & 3 & 5 & 3\end{array}\right)$ Bldg. Literacy

(2 $\left.\begin{array}{llll}2 & 3 & 5 & 4\end{array}\right)$ Dist. Literacy

(2 $\left.\begin{array}{llll}2 & 3 & 5 & 5\end{array}\right)$ Dist. Math

(2 355 6) Bldg. Exped. Lrng

(2 3 6) Eocus Groups

(2 366 1) sixth

(2 $\left.\begin{array}{llll}2 & 3 & 6 & 2\end{array}\right)$ seventh

(2 366 ) eighth

(2 $\left.\begin{array}{llll}2 & 3 & 6 & 4\end{array}\right)$ seven. eight

(2 $\left.3 \begin{array}{lll}2 & 6 & 5\end{array}\right)$ elective

(3) Policy

(3) HB1209

(3) 1 1) HB1209 Legislation

(3 $\left.\begin{array}{llll}3 & 1 & 1 & 1\end{array}\right)$ EALRS

$\left(\begin{array}{llll}3 & 1 & 1 & 2\end{array}\right)$ WASL

(3 $\left.\begin{array}{llll}3 & 1 & 3 & 1\end{array}\right)$ EALR. Influence Involvement

$\left(\begin{array}{llll}3 & 1 & 3 & 2\end{array}\right)$ WASL. Influence Involvement

$\left(\begin{array}{llll}3 & 1 & 4 & 1\end{array}\right)$ EALR. Influence Change

$\left(\begin{array}{llll}3 & 1 & 4 & 2\end{array}\right)$ WASL. Influence Change

(4) Teacher Eactors

(4 2 1) Previous. Exper.

(4) 3 1) Pedagogical Beliefs

(4 $\left.\begin{array}{llll}4 & 3 & 1 & 1\end{array}\right)$ University

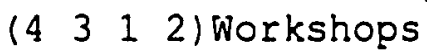

(4 3 2) Ped. Fam

(4 $\left.\begin{array}{llll}4 & 3 & 2 & 1\end{array}\right)$ University \& Eamiliarity

(4 $\left.\begin{array}{llll}4 & 3 & 2 & 2\end{array}\right)$ Workshops \& Eamiliarity

$\left(\begin{array}{llll}4 & 3 & 4 & 1\end{array}\right)$ University Influences Change

(4 $\left.\begin{array}{llll}4 & 3 & 4 & 2\end{array}\right)$ Workshops Influence Change

(4 4) Involvement in Reform

(4 $\left.4 \begin{array}{ll}4 & 1\end{array}\right)$ Type of Involvement

$\left(\begin{array}{llll}4 & 4 & 1 & 1\end{array}\right)$ Decision-making

(4 $\left.\begin{array}{llll}4 & 4 & 1 & 2\end{array}\right)$ Curriculum \& Instruction

(4 4 2) Involvement Influences Eamiliarity

$\left(\begin{array}{llll}4 & 4 & 2 & 1\end{array}\right)$ Decision-making \& Fam.

$\left(\begin{array}{llll}4 & 4 & 2 & 2\end{array}\right)$ Curriculum/Inst. \& Fam.

(4 5) Empowerment

(4 5 1) Empowerment

(4) 6) Efficacy

(4) 6 1) I am effective

(5) School Eactors 
(5 1) District Policies

(5) 1 1) Level of Policy

(5 $\left.\begin{array}{lll}5 & 1 & 1\end{array}\right)$ District Strategic Plan

(5 1 1 12 ) Building Level Reform Plan

$\left(\begin{array}{lll}5 & 1 & 2\end{array}\right)$ Policy \&amiliarity

$\left(\begin{array}{llll}5 & 1 & 2 & 1\end{array}\right)$ District Plan \& Eamiliarity

(5 I 2 2) Building Plan \& Eamiliarity

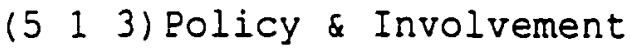

$\left(\begin{array}{llll}5 & 1 & 3 & 1\end{array}\right)$ District Plan \& Involvement

$\left(\begin{array}{llll}5 & 1 & 3 & 2\end{array}\right)$ Building Plan \& Involvement

(5 1 4) Policy \&Change

$\left(\begin{array}{llll}5 & 1 & 4 & 1\end{array}\right)$ District Plan \& Change

( $\left.\begin{array}{llll}5 & 1 & 4 & 2\end{array}\right)$ Building Plan \& Change

(5) 1 5) Policy. Conflicts. HB1209

(5 I 5 1) District Plan Conflicts

(5 15 2) Building Plan Conflicts

( $\left.\begin{array}{lll}5 & 1 & 5\end{array}\right)$ State policy Conflicts

(5 2) Supports

(5 2 1) Type of Support

(15 211 1) Parent/Student

(5 21 2) Building Administrators

$\left(\begin{array}{llll}5 & 2 & 1 & 3\end{array}\right)$ District Administrators

(5 23 3) District Admin. \& Involvement

(5 2 4) Support \&Change

$\left(\begin{array}{llll}5 & 2 & 4 & 1\end{array}\right)$ Parent Student \&Change

(5 244 2) Building Admin. \&Change

(5 24 3) District Admin. \&Change

(5 3) Collegiality

(5 3 1) Type of Collegiality

$\left(\begin{array}{llll}5 & 3 & 1 & 1\end{array}\right)$ Learning Group

$\left(\begin{array}{llll}5 & 3 & 1 & 2\end{array}\right)$ Team

$\left(\begin{array}{llll}5 & 3 & 1 & 3\end{array}\right)$ Staff Collaboration

(5 3 2) Collegiality \& Fam

(5 322 1) Learning Group \& Eam.

(15 32 2 2) Team \& Eam.

(5 3 4) Collegiality YChange

(5 $\left.3 \begin{array}{lll}5 & 4 & 1\end{array}\right)$ Learning Group \& Change

(5 344 2) Team \& Change

(5 34 3) Staff Collaboration \& Change

(5 4) Organizational Features

(5 4 1) Types of Organizational Eeatures

$\left(\begin{array}{llll}5 & 4 & 1 & 1\end{array}\right)$ Time

$\left(\begin{array}{llll}5 & 4 & 1 & 2\end{array}\right)$ Workshops

(l $\left.\begin{array}{llll}5 & 4 & 1 & 3\end{array}\right)$ Resources

$\left(\begin{array}{llll}5 & 4 & 1 & 4\end{array}\right)$ Changes during year 
(5 4 2)Organizational Eeatures \& Fam.

$\left(\begin{array}{llll}5 & 4 & 2 & 1\end{array}\right)$ Time Influences Eam.

$\left(\begin{array}{llll}5 & 4 & 2 & 2\end{array}\right)$ Workshops Influence Eam.

(5 4 3) Organizational Eeatures

\& Involvement

( $\left.\begin{array}{llll}5 & 4 & 3 & 1\end{array}\right)$ Time Influences Involvement

(5 4 4)Organizational Features \& Change

( $\left.\begin{array}{llll}5 & 4 & 4 & 1\end{array}\right)$ Time Influences Change

$\left(\begin{array}{llll}5 & 4 & 4 & 2\end{array}\right)$ Workshops Influence Change

$\left(\begin{array}{llll}5 & 4 & 4 & 3\end{array}\right)$ Resources Influence Change

$\left(\begin{array}{llll}5 & 4 & 4 & 4\end{array}\right)$ Changes during year

(6) Changes in Practice

(6 1) Reading Strategies

(6 2 ) Writing Strategies

(6 2 1) Journals \&logs

$\left(\begin{array}{lll}6 & 2 & 2\end{array}\right)$ Six trait writing process

(6 3) Technology

$\left(\begin{array}{lll}6 & 3 & 1\end{array}\right)$ Internet

$\left(\begin{array}{lll}6 & 3 & 2\end{array}\right)$ Power Point

(6 4) Math Strategies

(6 5) Student Interaction \& Engagement

(6 5 1) Student Peer Evaluation

(6 5 2 2 ) Student Self Evaluation

(6 5 3) Cooperative Learning

(6 5 4) Students Talk about learning

(6 55 5) Student Metacognition

(6 5 6 6) Student Research

(6 5 7 7) Active Engagement

$(6$ 6) Interventions

(6 7) Assessment Practices

(6 7 1 1) Performance Based

$\left.\begin{array}{lll}6 & 7 & 2\end{array}\right)$ Projects

$\left(\begin{array}{lll}6 & 7 & 3\end{array}\right)$ Portfolios

$1674)$ Scoring rubric

(6 7 5) Use Data to plan instruction

(6 8) Interdisciplinary Curriculum

(6 9) Standards

(6 6 9 1) Clarify Standards

$\left(\begin{array}{lll}6 & 9 & 2\end{array}\right)$ Increased Expectations

(6 9 3) Align curriculum to EALRs 
APPENDIX G

SUPPLEMENTAL CHARTS 
Chart 1

Number and Percent of Staff Reporting Somewhat or Very Involved \# in Educational Reform by Academic Area. $(\mathrm{N}=149-155)$

\begin{tabular}{|c|c|c|c|c|c|c|c|}
\hline Ed Reform & $\mathrm{x}$ & Lang. Ants & MathSci & Multicor & Elective & Pehealth & LeamSu \\
\hline Activity & Sig. & Freq. Perc. & Freq.Per & Freq.Per & Freq.Per & Freg.Per & Freq.Per \\
\hline Site Council & ** & (21) 55.3 & (14) 56 & (8) 47.1 & (7) 41.2 & (5) 41.7 & (1) 3.3 \\
\hline Curr Comm. & $*$ & (13) 33.3 & (11) 45.8 & (7) 41.2 & (2) 11.8 & (4) 33.3 & (1) 3.4 \\
\hline InterdisTeam & $*$ & (29) 74.3 & (15) 57.7 & (13) 76.5 & (3) 17.6 & (5) 41.7 & $(6) 20$ \\
\hline Stand. Wksp & $* *$ & $(26) 66.7$ & (14) 53.8 & $(10) 58.8$ & (6) 35.3 & (5) 41.7 & (2) 6.8 \\
\hline Test. Wksp & $\neq *$ & (22) 59.5 & (11) 44 & $(10) 66.7$ & (4) 23.5 & (2) 16.6 & (5) 16.6 \\
\hline Align Curr. & $\neq$ & (32) 82 & (18) 75 & (11) 78.6 & (13) 76.5 & (6) 50 & (7) 24.1 \\
\hline Dev. Stand & $\neq *$ & (29) 74.3 & (12) 46.2 & (13) 76.4 & (11) 64.7 & (7) 58.3 & (5) 17.2 \\
\hline Use Data & $\neq$ & $(28) 71.8$ & (19) 79.2 & (16) 94.1 & (7) 41.1 & (11) 91.7 & (11) 36.7 \\
\hline $\begin{array}{l}\text { Overall } \\
\text { Involve }\end{array}$ & $* *$ & (32) 84.2 & $(16) 64$ & $(14) 82.3$ & (9) 52.9 & (8) 66.7 & (10) 33.3 \\
\hline
\end{tabular}

Char 2

Number and Percent of Staff Reporting Somewhat or Very Involved \# in Educational Reform by Grade Level $(\mathrm{N}=150-155)$

\begin{tabular}{|c|c|c|c|c|c|}
\hline Reform Activity & $x$ & Sixth & Seventh & Eighth & Multigrade \\
\hline & Sig. & Freg. Percent & Freq. Percent & Freg. Percent & Freg. Percent \\
\hline Site Council & * & (14) 41.2 & (9) 34.6 & (14) 46.7 & (21) 40.3 \\
\hline Curriculum. Comm. & 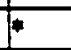 & (10) 30.3 & (8) 30.8 & (II) 34.4 & (10) 20 \\
\hline Standard workshop & $*$ & (18) 52.9 & $(16) 61.5$ & (11) 34.4 & (19) 37.2 \\
\hline Testing workshop & 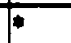 & (15) 48.4 & (16) 61.5 & (10) 33.3 & (13) 25 \\
\hline Attend Conference & * & (11) 32.3 & (2) 7.7 & (7) 21.9 & (13) 25 \\
\hline Overall Involvement & * & (23) 67.6 & (20) 76.9 & (20) 64.5 & (29) 56.8 \\
\hline
\end{tabular}

significance at $<.05$ level \# ranked 4.6 on a scale of 1.6

Chan 3

Mean Level of Involvement in Reform Activities by Grade Level $(\mathrm{N}=150-155)$

\begin{tabular}{|l|l|l|l|l|l|}
\hline Reform Activity & Sig. & Sixth & Seventh & Eighth & Multigrade \\
\hline Site Council & & 2.9 & 2.7 & 3.1 & 2.9 \\
\hline Curriculum Comm & & 2.4 & 2.4 & 2.5 & 2.0 \\
\hline Interdisciplinary Team & & 3.8 & 3.9 & 3.5 & 2.6 \\
\hline Testing workshop & & 3.2 & 3.9 & 2.6 & 2.2 \\
\hline Attend conference & & 2.5 & 1.6 & 2.3 & 2.4 \\
\hline Standards workshop & & 3.4 & 3.5 & 2.8 & 2.6 \\
\hline Overall Involvement & & 4.1 & 4.2 & 3.8 & 3.5 \\
\hline
\end{tabular}




\section{Chart 4}

Number and Percent of Staff Reporting Somewhat or Very Involved \# in Educational Reform by Position ( $\mathrm{N}=149.155)$

\begin{tabular}{|c|c|c|c|c|c|c|}
\hline Reform Activity & Chi Sq. & Teacher & Administra. & Counselor & Specialist & Inst. Asst. \\
\hline & Sig & Freg. Perc. & Freq. Perc & Freg. Perc & Freq. Perc & Freq. Perc \\
\hline Site Council & $* *$ & (53) 50 & (10) 100 & (3) 100 & (2) 16.7 & (1) 4.5 \\
\hline Curr. Comm. & $*$ & (35) 33.1 & (7) & (3) & (1) 9.1 & (1) 4.5 \\
\hline Interdisc.Team & $\neq *$ & (63) 58.4 & (6) 60 & b & (3) 33.3 & (3) 13.5 \\
\hline Standards Wksp & $* *$ & (59) 54.6 & (9) & (2) 50 & (2) 18.2 & (1) 4.5 \\
\hline Testing Wksp & $* *$ & (48) 46.6 & (7) 70 & (3) 100 & (1) & (3) 13.6 \\
\hline Align Curr. & $* *$ & (78) 75.7 & (6) 60 & (2) & (3) 30 & (4) 18.1 \\
\hline Develop Stand & $* *$ & (69) 64.5 & (7) 70 & 0 & (5) 41.6 & (1) 4.5 \\
\hline Use Data & $* *$ & (79) 74.5 & (9) 90 & (1) 25 & (7) 58.3 & (6) 27.3 \\
\hline Collegial .Group & NS & 80 & (9) 90 & (2) 50 & (7) 58.4 & (10) 45.4 \\
\hline Attend Conf. & $\cdots$ & (28) 25.9 & (8) 88.9 & (2) 50 & (2) 16.7 & $(2)$ \\
\hline Overall Involve. & $*$ & (77) 72.6 & (9) 90 & (3) 75 & $\begin{array}{ll}(8) & 67.7\end{array}$ & (5) 22.7 \\
\hline
\end{tabular}

* significance at $<.05$ level ** significance at $<.01$ level

NS no significant difference \#ranked $4-6$ on a scale of $1-6$

Chart 5

Significant Differences between Sense of Empowerment and Level of Involvement in Educational Reform $(\mathrm{N}=144)$

\begin{tabular}{|l|l|}
\hline "Empowerment Variable & Level of Involvement in Reform \\
\hline 9b Curriculum Decisions & $*$ \\
\hline 9d Teaching Decisions & $*$ \\
\hline 9f Class. Mgnt. Decisions & $*$ \\
\hline 9h Assessment Decisions & $*$ \\
\hline Total Empowerment & $r=.544$ \\
\hline
\end{tabular}

"significance at $<.05$ level "significance at $<.01$ level 
Chart 6

Comparison of Mean Scores for Changes in Classroom Practice by Academic Area $(\mathrm{N}=141-146)$

\begin{tabular}{|l|l|l|}
\hline More Frequent Use of & Anova Sig. & Academic Area \\
\hline Scoring rubrics & $*$ & $\begin{array}{l}\text { Lang Arts 4.2 } \\
\text { Mathsci 2.5 }\end{array}$ \\
\hline Perform assessment & $*$ & $\begin{array}{l}\text { Lang Arts 3.6 } \\
\text { Elective } 1.5\end{array}$ \\
\hline Student projects & $*$ & Lang Arts 3.5 \\
& & Elective 1.6 \\
\hline Math problems & $*$ & Mathsci 3.4 \\
& & Lang Arts 1.1 \\
\hline Active student engagement & $*$ & Lang Arts 3.5 \\
& & Elective 1.7 \\
\hline Ongoing student assessment & $*$ & $\begin{array}{l}\text { Pehealth } 3.0 \\
\text { Elective } 1.6\end{array}$ \\
\hline Teach writing across curr & $*$ & Lang Arts 4.2 \\
& & Multicore 2.6 \\
\hline
\end{tabular}

" significance at $<.05$ level * significance at $<.01$ level

Chart 7

Comparison of Means Scores for Changes in Classroom Practice and Grade Level $(\mathrm{N}=141-154)$.

\begin{tabular}{|l|l|l|}
\hline More Frequent Use of & ANOVA Sig & Grade Level \\
\hline Performance Assessment & $*$ & $\begin{array}{l}\text { Seventh 3.9 } \\
\text { Multgrad2.6 }\end{array}$ \\
\hline Clear Standards & $* *$ & $\begin{array}{l}\text { Seventh 4.4 } \\
\text { Eighth 2.7 }\end{array}$ \\
\hline High expectations & $* *$ & $\begin{array}{l}\text { Seventh 4.6 } \\
\text { Eighth 2.9 }\end{array}$ \\
\hline Student Projects & $* *$ & $\begin{array}{l}\text { Seventh 3.9 } \\
\text { Eighth 2.5 }\end{array}$ \\
\hline Stud. talk about learning & $* *$ & $\begin{array}{l}\text { Seventh 3.9 } \\
\text { Eighth 2.5 }\end{array}$ \\
\hline Math problem solving & $* *$ & $\begin{array}{l}\text { Sixth 2.8 } \\
\text { Eighth 1.7 }\end{array}$ \\
\hline Active student engagement & $*$ & $\begin{array}{l}\text { Seventh 3.9 } \\
\text { Eighth 2.5 }\end{array}$ \\
\hline Use of student data & $*$ & $\begin{array}{l}\text { Seventh 3.2 } \\
\text { Eighth 2.1 }\end{array}$ \\
\hline Ongoing assessment & $* *$ & $\begin{array}{l}\text { Seventh 3.6 } \\
\text { Eighth 2.2 }\end{array}$ \\
\hline
\end{tabular}

* significance at $<.05$ level ** significance at $<.01$ level 
Chart 8

Correlation of Years of Experience and Changes in Classroom Practice $(\mathrm{N}=137-154)$

\begin{tabular}{|l|l|l|}
\hline Change in Practice & Corr with Years of Experience & Sig. \\
\hline Cooperative learning & .267 & \\
\hline Scorinb rubrics & .217 & \\
\hline Student peer evaluation & .200 & \\
\hline Performance assessments & .200 & \\
\hline Integration of technology & .177 & \\
\hline Curriculum aligned to EALRs & .312 & \\
\hline Use assessment data to plan instruction & .163 & \\
\hline
\end{tabular}

** significance at $<.01$ level * significance at $<.05$ level

Chart 9

Correlation between Overall Involvement in Educational Reform and Changes in Classroom Practice. $(N=136-152)$

\begin{tabular}{|l|l|l|}
\hline More frequent use of & $\begin{array}{l}\text { Corr. with overall } \\
\text { Involvement }\end{array}$ & Sig. \\
\hline Scoring rubrics & $r=.357$ & $*$ \\
\hline Student peer evaluation & $r=.275$ & $* *$ \\
\hline Student self evaluation & $r=.274$ & $*$ \\
\hline Performance assessment & $r=.256$ & $*$ \\
\hline Interdisciplinary curriculum & $r=.194$ & $*$ \\
\hline Intervention with students & $r=.194$ & $*$ \\
\hline Use writing to communicate learning & $r=.191$ & $*$ \\
\hline Students talk about learning & $r=.242$ & $*$ \\
\hline Metacognition & $r=.245$ & \\
\hline Curriculum aligned to students & $r=.264$ & \\
\hline Use student data to plan instruction & $r=.557$ & \\
\hline
\end{tabular}

" significance at $<.05$ level * significance at $<.01$ level 
Chart 10

Correlation between Sense of Empowerment and Changes

in Classroom Practice. $(\mathrm{N}=128-138)$

\begin{tabular}{|l|l|l|}
\hline More frequent use of: & $\begin{array}{l}\text { Corr. With } \\
\text { Empowerment }\end{array}$ & Sig. \\
\hline Scoring rubrics & $r=.215$ & \\
\hline Metacognition & $r=.238$ & \\
\hline Curriculum aligned to standards & $r=.306$ & \\
\hline Communicate learming thru student talk & $r=.237$ & $*$ \\
\hline Active student engagement & $r=.189$ & $*$ \\
\hline Use student data to plan instruction & $r=.194$ & $*$ \\
\hline Student peer evaluation & $r=.183$ & $*$ \\
\hline Student self evaluation & $r=.172$ & $*$ \\
\hline
\end{tabular}

* significance at $<.05$ level " significance at $<.01$ level

\section{Chart 11}

Correlation between sense of efficacy and changes in classroom practice $(\mathrm{N}=133-139)$.

\begin{tabular}{|l|l|l|}
\hline More frequent use of & Corr. With self-efficacy & Sig. \\
\hline Student peer evaluation & $r=.167$ & $*$ \\
\hline Student portfolios & $r=.178$ & $*$ \\
\hline Metacognition & $r=.199$ & $*$ \\
\hline
\end{tabular}

" significance at $<.05$ level "* significance at $<.01$ level 
Chart 12

Comparison of Mean Scores for Perception of Supports for Changing Classroom Practice

\begin{tabular}{|c|c|c|c|c|c|}
\hline School Level Support & $\begin{array}{l}\text { Total Survey } \\
N=151-157\end{array}$ & \begin{tabular}{|l|} 
Laurel \\
Middle \\
$\mathrm{N}=47-49$ \\
\end{tabular} & $\begin{array}{l}\text { Lighthouse } \\
\text { Middle } \\
\mathrm{N}=51-54 \\
\end{array}$ & \begin{tabular}{|l} 
Ponderosa \\
Middle \\
$\mathrm{N}=50-54$ \\
\end{tabular} & $\begin{array}{l}\text { Chi Sq. } \\
\text { Sig. }\end{array}$ \\
\hline $\begin{array}{l}\text { Collegial teams work } \\
\text { together (5a) }\end{array}$ & 5.07 & 4.92 & 5.06 & 5.22 & NS \\
\hline $\begin{array}{l}\text { Conversations about practice } \\
\text { (5b) }\end{array}$ & 5.03 & 5.06 & 5.09 & 4.93 & NS \\
\hline $\begin{array}{l}\text { Bldg. level admin. support } \\
\text { (5i) }\end{array}$ & 4.98 & 5.06 & 5.15 & 4.72 & NS \\
\hline $\begin{array}{l}\text { Time for curriculum } \\
\text { plan/prof. dev. (5d) }\end{array}$ & 4.94 & 4.94 & 5.11 & 4.76 & NS \\
\hline $\begin{array}{l}\text { Availability of financial } \\
\text { resources }(5 n)\end{array}$ & 4.91 & 4.86 & 5.14 & 4.76 & NS \\
\hline $\begin{array}{l}\text { Teacher support of changing } \\
\text { practice (5h) }\end{array}$ & 4.87 & 4.90 & 4.98 & 4.72 & NS \\
\hline $\begin{array}{l}\text { Availability of staffing } \\
\text { resources }(50)\end{array}$ & 4.74 & 4.79 & 4.57 & 4.88 & NS \\
\hline $\begin{array}{l}\text { Modeling of classroom } \\
\text { practices (5p) }\end{array}$ & 4.65 & 4.29 & 4.89 & 4.77 & - \\
\hline $\begin{array}{l}\text { Critical mass for change } \\
(5 \mathrm{~m})\end{array}$ & 4.60 & 4.54 & 4.87 & 4.37 & NS \\
\hline $\begin{array}{l}\text { Process for site decisions } \\
\text { 5i) }\end{array}$ & 4.56 & 4.58 & 4.81 & 4.27 & NS \\
\hline $\begin{array}{l}\text { District level admin. support } \\
\text { (5j) }\end{array}$ & 4.50 & 4.55 & 4.58 & 4.39 & NS \\
\hline $\begin{array}{l}\text { Inservices and workshops } \\
(5 \mathrm{c})\end{array}$ & 4.42 & 4.35 & 4.55 & 4.35 & NS \\
\hline $\begin{array}{l}\text { School reform plan at bldg. } \\
\text { level }(5 \mathrm{~g})\end{array}$ & 4.17 & 4.10 & 4.28 & 4.13 & NS \\
\hline $\begin{array}{l}\text { Opportunity. to visit other } \\
\text { program (5e) }\end{array}$ & 4.08 & 4.02 & 4.33 & 3.86 & NS \\
\hline $\begin{array}{l}\text { Community support of } \\
\text { changing practice ( } 5 \mathrm{k})\end{array}$ & 3.98 & 3.89 & 4.23 & 3.81 & NS \\
\hline District strategic plan (5f) & 3.77 & 3.71 & 3.71 & 3.88 & - \\
\hline
\end{tabular}

\# (based on a scale of 1 low to 6 high) "significance at $<.05$ level 


\section{Chart 13}

Top ranked supports for changing practice reported by school.

\begin{tabular}{|l|l|l|l|}
\hline Support & Laurel Middle & Lighthouse Middle & Ponderosa Middle \\
\hline 1 & $\begin{array}{l}\text { Collegial teams working } \\
\text { together }\end{array}$ & $\begin{array}{l}\text { Collegial teams working } \\
\text { together }\end{array}$ & $\begin{array}{l}\text { Collegial teams working } \\
\text { oogether }\end{array}$ \\
\hline 2 & Building level admin support & $\begin{array}{l}\text { Frequent conversations about } \\
\text { classroom practice }\end{array}$ & $\begin{array}{l}\text { Frequent conversations about } \\
\text { classroom practice }\end{array}$ \\
\hline 3 & $\begin{array}{l}\text { Frequent conversations about } \\
\text { classroom practice }\end{array}$ & $\begin{array}{l}\text { Time for curr. planning \& } \\
\text { professional development }\end{array}$ & $\begin{array}{l}\text { Time for curr. planning \& } \\
\text { professional development }\end{array}$ \\
\hline & $\begin{array}{l}\text { Time for curr. planning \& } \\
\text { professional development }\end{array}$ & & \\
\hline
\end{tabular}

\section{Chart 14}

Comparison of Mean Scores for School Level Factors that act as Barriers to Changing Classroom Practice

\begin{tabular}{|c|c|c|c|c|c|}
\hline Bartier & $\begin{array}{l}\text { Total Survey } \\
N=149-157\end{array}$ & $\begin{array}{l}\text { Laurel } \\
N=45.59\end{array}$ & $\begin{array}{l}\text { Lighthouse } \\
\mathrm{N}=50-54\end{array}$ & $\begin{array}{l}\text { Ponderosa } \\
\mathrm{N}=52-54\end{array}$ & $\begin{array}{l}\text { Chi Sq. } \\
\text { Sig. }\end{array}$ \\
\hline Changing during school vear & 4.0 & 4.2 & 4.2 & 3.7 & NS \\
\hline Lack of time together to plan & 4.0 & 4.0 & 4.8 & 3.2 & $* *$ \\
\hline Staff who won't change practice & 3.6 & 4.4 & 3.7 & 2.7 & 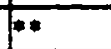 \\
\hline Lack of inservice or workshops & 3.4 & 3.4 & 3.8 & 3.1 & 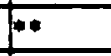 \\
\hline Lack of parent comm. support & 3.4 & 3.7 & $\overline{3.0}$ & 3.6 & NS \\
\hline Staff who won't collaborate & 3.3 & 4.0 & 3.4 & 2.6 & $=$ \\
\hline Don't know how to change pract. & 3.1 & 3.1 & 2.9 & 3.2 & 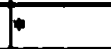 \\
\hline Students resist changed practice & 2.9 & 2.6 & 3.0 & 3.1 & NS \\
\hline Curr. \& WASL contradict & 2.9 & 3.4 & 3.1 & 2.2 & 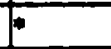 \\
\hline Don't know how to align curric & 2.8 & 2.8 & 2.8 & 2.8 & NS \\
\hline Previous teacher experience & 2.8 & 3.0 & 2.8 & 2.7 & NS \\
\hline Not enough info re: test & 2.7 & 2.7 & 2.8 & 2.8 & NS \\
\hline Dist. and WASL contradict & 2.7 & 2.9 & 3.0 & 2.3 & NS \\
\hline Lack of district admin. support & 2.6 & 2.8 & 2.7 & 2.4 & NS \\
\hline Lack of bldg level admin & 2.1 & 2.4 & 1.6 & 2.3 & NS \\
\hline
\end{tabular}

\# (based on scale of I low to 6 high)

* significance at $<.05$ level * *significance at $<.0$ l level NS no sigificant difference 
Chart 15

Multiple Regression of Familiarity with HB 1209, Involvement in Reform, and Changes in Practice at Laurel Middle School

\begin{tabular}{|l|l|l|l|}
\hline $\mathrm{N}=41$ & $\begin{array}{l}\text { Correlation with } \\
\text { Familiarity with HB1209 }\end{array}$ & BETA & R2 \\
\hline Sense of Empowerment & $.592^{* *}$ & $.418^{* *}$ & .35 \\
\hline Involvement in Reform & $.546^{* *}$ & $.314^{*}$ & .42 \\
\hline $\mathrm{N}=41$ & $\begin{array}{l}\text { Correlation with } \\
\text { Involvement in Reform }\end{array}$ & & \\
\hline Sense of Empowerment & $.556^{* *}$ & $.472^{* *}$ & .31 \\
\hline Familiarity with HB1209 & $.546^{* *}$ & NS & \\
\hline Pedagogical Knowledge $\#$ & $.453^{* *} \#$ & $.333^{*}$ & .41 \\
\hline N=35 & $\begin{array}{l}\text { Correlation with Changes } \\
\text { in Classroom Practice }\end{array}$ & & \\
\hline Sense of Empowerment & $.476^{* *}$ & $.422^{* *}$ & .23 \\
\hline Involvement in Reform & $.455^{* *}$ & NS & \\
\hline Pedagogical Knowledge \#\# & $.433^{* *} \# \#$ & NS & \\
\hline Years of Teaching Exper. & $.378^{* *}$ & $.303 *$ & .32 \\
\hline Familiarity with HBl209 & $.367^{*}$ & NS & \\
\hline
\end{tabular}

** significance at $<.01$ level * significance at $<.05$ level

\# No information on WASL (-) negative correlation reversed for clarity

\#\# Lack of information on how to align curriculum (-) negative correlation reversed for clarity

\section{Chart 16}

Multiple Regression of Familiarity with HB1209, Involvement in Reform, and Changes in Practice at Lighthouse Middle School

\begin{tabular}{|l|l|l|l|}
\hline $\mathrm{N}=47$ & $\begin{array}{l}\text { Correlation with } \\
\text { Familiarity with HB I209 }\end{array}$ & BETA & R2 \\
\hline Involvement in Reform & $.718^{* *}$ & $.718^{* *}$ & .52 \\
\hline Empowerment & $.470^{* *}$ & $\mathrm{NS}$ & \\
\hline $\mathrm{N}=50$ & $\begin{array}{l}\text { Correlation with } \\
\text { Involvement in Reform }\end{array}$ & $.652^{* *}$ & .52 \\
\hline Familiarity with HBI209 & $.718^{* *}$ & $\mathrm{NS}$ & \\
\hline Empowerment & $.550^{* *}$ & $\mathrm{NS}$ & \\
\hline Collegial Teams & $.510^{* *}$ & $.292^{* *}$ & .60 \\
\hline Pedagogical Knowledge $\#$ & $.441 * * \#$ & \\
\hline N=50 & $\begin{array}{l}\text { Correlation with Changes } \\
\text { in Practice }\end{array}$ & & \\
\hline Familiarity with HB1209 & $.322 *$ & $.322 *$ & .10 \\
\hline Involvement in Reform & $.291 *$ & NS & \\
\hline
\end{tabular}

** significance at $<.01$ level significance at $<.05$ level

$\$$ No information on how to actively engage students (-) negative correlation reversed for clarity 
Chan 17

Multiple Regression of Familiarity with HB1209, Involvement in Reform, and Changes in Practice at Ponderosa Middle School

\begin{tabular}{|c|c|c|c|}
\hline$N=50$ & $\begin{array}{l}\text { Correlation with } \\
\text { Familiarity with HB!209 }\end{array}$ & BETA & $\mathbf{R 2}$ \\
\hline Involvement in Reform & $.533 * 0$ & $.431 *$ & .28 \\
\hline Workshops & $.436 *$ & $.277 *$ & .35 \\
\hline School Reform Plan (E.L.) & $.402 *$ & NS & \\
\hline Support of Critical Mass & $.376 *$ & NS & \\
\hline Empowerment & $.354 * *$ & NS & \\
\hline Modeling of Practices & $.337 *$ & NS & \\
\hline$N=50$ & $\begin{array}{l}\text { Correlation with } \\
\text { Involvement in Reform }\end{array}$ & & \\
\hline Empowerment & $.536 * *$ & $.398 * *$ & .29 \\
\hline Familiarity with HB1209 & $.533 * *$ & $.392 *$ & .42 \\
\hline School Reform Plan (E.L.) & $.454 * *$ & NS & \\
\hline Modeling of Practices & $.434 *$ & NS & \\
\hline Workshops & $.368 * *$ & NS & \\
\hline Efficacy & $.351 *$ & NS & \\
\hline Resources & $.335 *$ & NS & \\
\hline$N=47$ & $\begin{array}{l}\text { Correlation with } \\
\text { Changes in Practice }\end{array}$ & & \\
\hline Time for planning & $.476 * *$ & $.476^{* *}$ & .23 \\
\hline Workshops & $.439 * *$ & NS & \\
\hline School Reform Plan (E.L.) & $.350 * *$ & NS & \\
\hline Conversations about practice & $.345 *$ & NS & \\
\hline Site Council Decisions & $.336^{*}$ & NS & \\
\hline Building Admin. Support & $.330^{*}$ & NS & \\
\hline Collegial Teams & $.317^{*}$ & NS & \\
\hline Modeling of Practices & $.318^{\circ}$ & NS & \\
\hline Support of Critical Mass & $.312^{*}$ & NS & \\
\hline Familiarity with HB1209 & $.286^{*}$ & NS & \\
\hline
\end{tabular}

** significance at $<.01$ level * significance at $<.05$ level

(E.L) Expeditionary Learning 
APPENDIX $\mathrm{H}$

DOCUMENT CHECKLIST 
SITE:

1. District and school demographics

- student enrollment by grade level (6-8)

- student ethnic composition

- students eligible for subsidized lunch

- students in Challenge (gifted) program

- students in limited English (ESL)

- students in learning support (SPED)

- students in structured learning (SPED)

- students in title I/LAP

2. Use of State Block Grant (SLIG, etc.) funds

3. Achievement tests results for school and district

- district tests

- state tests (including WASL)

4. School organization (teams, houses, etc.)

5. School calendar for winter/spring semester

6. Site council or decision-making team minutes

7. Summaries of professional development workshops

8. Faculty meeting minutes or agendas

9. School Performance Report Card (requirement of HB1209)

10. School Improvement Plan

11. Building and/or district newsletters

12. Relevant school board and/or administrative team minutes 